\title{
Hydraulic modelling approaches to decrease uncertainty in flood frequency relations UNIVERSITY OF TWENTE.
}

Anouk Bomers 


\section{Graduation committee:}

prof. dr. ir. G.P.M.R. Dewulf prof. dr. S.J.M.H. Hulscher dr. R.M.J. Schielen prof. dr. J.C.J. Kwadijk dr. ir. D.C.M. Augustijn prof. dr. H. Middelkoop prof. dr. ir. M. Kok prof. dr. J. Herget
University of Twente, chairman and secretary University of Twente, supervisor University of Twente, Rijkswaterstaat, co-supervisor University of Twente University of Twente Utrecht University Delft University of Technology University of Bonn

The presented research in this thesis is carried out at the Water Engineering and Management (WEM) department, Civil Engineering, University of Twente, The Netherlands.

This work is part of the research programme Floods of the Past-Design for the future with project number 14506, which is (partly) financed by the Netherlands Organisation for Scientific Research (NWO).

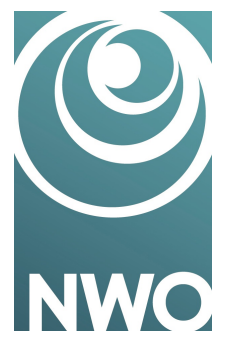

ISBN: $978-90-365-4928-8$

DOI: $10.3990 / 1.9789036549288$

Cover: Edited Satellite image by Anouk Bomers

Printed by: Ipskamp printing (ipskampprinting.nl)

Copyright (C) 2019 Anouk Bomers

All rights reserved. No parts of this thesis may be reproduced, stored in a retrieval system or transmitted in any form or by any means without permission of the author. 


\title{
HYDRAULIC MODELLING APPROACHES TO DECREASE UNCERTAINTY IN FLOOD FREQUENCY RELATIONS
}

\section{DISSERTATION}

\author{
to obtain \\ the degree of doctor at the University of Twente, \\ on the authority of the Rector Magnificus \\ Prof.dr. T.T.M. Palstra, \\ on account of the decision of the graduation committee, \\ to be publicly defended \\ on Friday January 17, 2020 at 14:45
}

by

Anouk Bomers

born on January 21, 1992

in Enschede, The Netherlands 
This dissertation has been approved by:

prof. dr. S.J.M.H. Hulscher University of Twente, supervisor

dr. R.M.J. Schielen

University of Twente, Rijkswaterstaat, co-supervisor 
'When models turn on, Brains turn off'

Til Schulman 


\section{Contents}

$\begin{array}{ll}\text { Preface } & 9\end{array}$

$\begin{array}{ll}\text { Summary } & 11\end{array}$

$\begin{array}{lr}\text { Samenvatting } & \mathbf{1 5}\end{array}$

$\begin{array}{llr}1 & \text { Introduction } & \mathbf{1 9}\end{array}$

2 The influence of grid shape and grid size on hydraulic $\begin{array}{ll}\text { modelling performance } & \mathbf{3 7}\end{array}$

3 Application of a lower-fidelity surrogate hydraulic model $\begin{array}{ll}\text { for historic flood reconstruction } & 65\end{array}$

4 Historic flood reconstruction with the use of an Arti$\begin{array}{lr}\text { ficial Neural Network } & 97\end{array}$

5 Consequences of dike breaches and dike overflow in a bifurcating river system

6 Decreasing uncertainty in flood frequency analyses by including historic flood events in an efficient bootstrap approach

$\begin{array}{lll}7 & \text { Discussion } & 181\end{array}$

8 Conclusions and recommendations $\quad 199$

$\begin{array}{ll}\text { List of References } & 209\end{array}$

List of publications $\quad \mathbf{2 2 5}$

$\begin{array}{ll}\text { About the author } & \mathbf{2 2 9}\end{array}$ 


\section{Preface}

Na vier jaar is het dan zover. Mijn proefschrift ligt klaar! Dit had ik natuurlijk nooit kunnen bereiken zonder de hulp van velen.

Allereerst wil ik graag mijn begeleider Ralph Schielen en promotor Suzanne Hulscher bedanken. Ralph, bedankt voor de vele discussiemomenten. Jij wist altijd kritische vragen te stellen en onze discussies hebben bijgedragen aan de kwaliteit van mijn werk. Suzanne, jij wist mijn papers altijd naar een hoger niveau te tillen. Bedankt voor je vertrouwen in mij als onderzoeker. Ook wil ik graag Anke, Monique, Dorrette en Joke bedanken voor alle hulp in de afgelopen jaren.

Daarnaast wil ik graag Rita Lammersen van Rijkswaterstaat en Anke Becker van Deltares bedanken voor de vele contactmomenten. Ik kon altijd met mijn vragen bij jullie terecht en ik heb veel gehad aan jullie input betreffende de GRADE modellen en het Nederlandse en Duitse watersysteem. Ook wil ik graag Frans Hoefsloot en Walter van Doornik bedanken voor hun hulp met Baseline. Daarnaast gaat mijn dank uit naar de overige gebruikers van het project, naar Mark Hegnauer van Deltares, naar Jules Beersma van het KNMI en naar Willem Toonen van KU Leuven.

Mijn onderzoek maakte onderdeel uit van het project Floods of the past - Design for the future. Ik ben erg blij dat ik binnen dit project samen met Bas van der Meulen een paper heb kunnen schrijven en een tweede is in de maak. Bas, ik wil je dan ook graag bedanken voor de samenwerking de afgelopen tijd, de gezellige meetings en natuurlijk de leuke tripjes naar Padua en Bonn. Kim Cohen en Hans Middelkoop ook jullie bedank ik graag voor de samenwerking en discussies de afgelopen jaren. 
Juergen Herget, thank you for your tour in Bonn and Cologne. It helped me a lot to get understanding of the river system in the upstream part of my study area. Furthermore, it was a lot of fun to see all the "hidden" water marks on the buildings, churches and city walls.

In addition, many thanks to Juan Pablo. You introduced me into the world of academia. Without you, I would have never considered doing a $\mathrm{PhD}$ and look at me now. Five years later, and still enjoying (most part of) it. Many thanks for that!

Geert, jij heel erg bedankt voor het beschikbaar stellen van je template. Zonder jou was dit boekje nooit zo mooi geworden als het nu is.

Furthermore, I would like to thank all my colleagues of the Water Engineering and Management group of the University of Twente. Thank you for the daghappen, pub quizzes, soccer matches, bike rides and of course the parties "tot de vroege uurtjes". You made my work much more enjoyable. Specifically, I would like to thank my office mates Geert, Pepijn, Paran, Hero, Eros, Alejandro, La and Alma for the chats about the weekends, the culture differences, or something that was bothering us at that moment.

Ook wil ik graag mijn lieve familie bedanken. Pap, mam, jullie zijn de besten! Ik kan mij geen lievere ouders voorstellen. Nienke en Jeen, wat ben ik blij dat ik jullie als grote zus en broer heb. Wat hebben wij toch een leuke familie!

Ruben, jou vergeet ik natuurlijk niet. Wat ben ik blij met jou! Bedankt voor je steun en luisterend oor. Ik hoop dat ik nog heel lang tegen je aan mag zeuren en ik kijk uit naar alle spannende momenten die ik met jou mag meemaken in de toekomst! 


\section{Summary}

River floods are a major global hazard causing extensive damage and loss of lives. To protect the hinterland from severe inundations, flood defences are commonly designed according to appropriate safety levels that are determined based on a statistical return period. To estimate discharges associated with different return periods, flood frequency analyses are used that fit a distribution to the data set of annual maximum discharges.

The data sets of measured annual maximum discharges are generally in the order of 100 years. Consequently, the predicted design discharges with a return period of e.g. 100,000 years are based on extrapolation and therefore highly uncertain. To decrease the uncertainty of flood frequency relations, historical flood information can be added to the data set of measured discharges.

We aimed to study the effect of extending the data set of measured discharges on the reduction of the $95 \%$ uncertainty interval of flood frequency relations. The data set was extended with reconstructed historic flood events using hydraulic modelling approaches. The Rhine delta was used as a case study, but the proposed methodologies can also be applied to other river basins and coastal areas provided that sufficient data is available.

A drawback of reconstructing historic flood events with the use of hydraulic models is the high computational cost. Because historical information is limited and uncertain, many model runs have to be performed to include these uncertainties in the analysis. Therefore, the hydraulic model must be efficient in terms of model accuracy and computational time. We first developed a fully two dimensional (2D) hydraulic model, after which we simplified this model to achieve a data driven model, referred to as a response surface surrogate model. By simplifying the model, computational times are reduced. However, it is important that the simplified models are still capable of reproducing the desired output. 
The outline of this thesis is as follows.

In Chapter 2, we show which 2D grid is most efficient in terms of model performance. We compared structured rectangular, unstructured triangular and hybrid (consisting of both structured and unstructured grid cells) grids with a high and low resolution. The performance of both the non-calibrated and calibrated models were compared based on simulated water levels. Furthermore, flow velocities in a meander bend were evaluated to assess the correctness of the physical processes. We show that there are three important grid generated features that influence model results, namely: (1) bathymetry accuracy and (2) numerical friction, both as a result of grid resolution, and (3) numerical viscosity as a result of grid shape. Numerical friction and numerical viscosity have the same effect on model results as physical bed friction has, namely attenuating the discharge wave and in increasing the simulated water levels.

In Chapter 3 we developed a 1D-2D coupled model, also referred to as a lowerfidelity physically based surrogate model, to study whether this model can replace a fully $2 \mathrm{D}$ model to reduce computational time. In this simplified model, the main channel and floodplains are schematized by 1D profiles and the embanked areas are discretized on a $2 \mathrm{D}$ grid. We used this model to perform a sensitivity analysis to analyse which parameter has the highest impact on maximum discharges during a flood event. In 1926 the largest measured flood event has occurred. This flood event was used as a case study. We conclude that the model output is most sensitive to the roughness class with the largest share in surface area. Furthermore, we show that the 1D-2D coupled model is capable of producing model results with the same accuracy as a fully $2 \mathrm{D}$ model. Therefore, the $1 \mathrm{D}-2 \mathrm{D}$ coupled model was used as a high-fidelity model in the next Chapter.

In Chapter 4, we developed a surface response surrogate model with training data created with the $1 \mathrm{D}-2 \mathrm{D}$ coupled model. This data driven surrogate model has no physical interpretation, but reproduces the input-output relations of the high-fidelity model based on simple mathematical functions. As a result, many model runs can be performed within a couple of seconds. We reconstructed the maximum discharge at Lobith (German-Dutch border) during the 1809 flood event based on measured water levels of surrounding locations. Chapter 4 shows that the confidence intervals of the 1809 maximum discharge are reduced compared to the results of existing methods that did not use hydraulic models to perform the reconstruction.

Before historic flood events can be added to the data set of annual maximum discharges, they must be normalized for natural and anthropogenic changes in the river system. To do so, the upstream discharges of the historic flood events were routed over the present geometry using the 1D-2D coupled modelling approach (Chapter 3). In Chapter 5, we show the present system behaviour of the Rhine delta as a result of various upstream discharges. Dike breaches are included in 
the model domain as random input parameter resulting in various overland flow patterns. We conclude that dike breaches and resulting overland flow patterns may significantly change the discharge partitioning of and flood risk along the Dutch Rhine river branches.

Finally, in Chapter 6, we created a continuous data set of annual maximum discharges of approximately 700 years. The data from the period 1772-2018, comprising of discharge and water level measurements, was extended with 12 historic flood events. The 12 historic flood events were normalized using the modelling approach developed in Chapter 5. We used a bootstrap approach to sample discharges for the missing years in the historical time period, resulting in a continuous series. Next, a flood frequency analysis was performed with the extended data set. The results of this analysis were compared with the flood frequency relation created by solely using measured discharges. We show that uncertainty in flood frequency relations decreases if the length of the considered data set of annual maximum discharges is extended. Therefore, we recommend to include as many historic flood events as possible in the considered data set such that the uncertainty intervals of flood frequency relations are reduced. This even applies if the magnitude of the historic flood event itself is highly uncertain. In this manner, future design discharges can be predicted with less uncertainty. 


\section{Samenvatting}

Rivieroverstromingen zorgen elk jaar wereldwijd voor veel schade en hoge sterftecijfers. Om het achterland van overstromingen te beschermen, worden waterkeringen ontworpen volgens een geschikte veiligheidsnormering gebaseerd op een statistische herhalingstijd. Afvoeren behorende bij verschillende herhalingstijden worden bepaald door middel van afvoerfrequentie-analyses. In zulke analyses wordt een kansverdeling opgesteld aan de hand van een dataset van jaarlijkse maximale afvoerwaarnemingen.

De datasets van gemeten jaarlijkse maximale afvoeren hebben vaak een lengte van $\sim 100$ jaar. Een ontwerpafvoer met een herhalingstijd van bijvoorbeeld 100.000 jaar wordt dus bepaald door extrapolatie en is daarom erg onzeker. De onzekerheid in afvoerfrequentiekrommen kunnen verkleind worden door informatie over historische overstromingen toe te voegen aan de dataset van gemeten afvoeren.

Het doel van dit onderzoek was om de effecten van het uitbreiden van de dataset van gemeten afvoeren op de afname van de $95 \%$ betrouwbaarheidsinterval van afvoerfrequentiekrommen te bepalen. De dataset is uitgebreid met gereconstrueerde historische overstromingen gebruikmakende van verschillende hydraulische modelleringsaanpakken. De Rijndelta is gebruikt als casus, maar de gepresenteerde methodes kunnen ook toegepast worden op andere stroomgebieden en kustgebieden mits er voldoende data beschikbaar is.

Een nadeel van het reconstrueren van historische overstromingen met hydraulische modellen is de lange rekentijd. Aangezien historische informatie beperkt en onzeker is, moet een groot aantal modelsimulaties uitgevoerd worden om deze onzekerheden mee te nemen in de analyse. Daarom moet het hydraulische model efficiënt zijn wat betreft nauwkeurigheid en rekentijd. Allereerst hebben we een 
volledig twee dimensionaal (2D) model opgezet, waarna deze versimpeld is naar een data-gedreven surrogaat model. Door het versimpelen van het model wordt de rekentijd teruggebracht. Het is echter wel van belang dat het versimpelde model instaat is om de gewenste output te genereren. De structuur van dit proefschrift is als volgt.

In hoofdstuk 2 laten we zien welk 2D grid het efficiëntst is wat betreft modelprestaties. We vergeleken gestructureerde rechthoekige, ongestructureerde driehoekige en hybride (bestaande uit zowel gestructureerde als ongestructureerde gridcellen) grids met een hoge en lage resolutie. Gesimuleerde waterstanden van zowel gekalibreerde en niet-gekalibreerde modellen zijn met elkaar vergeleken. Daarnaast zijn stroomsnelheden in een meander berekend om de juistheid van de fysische processen te beoordelen. We laten zien dat drie belangrijke gridgegenereerde aspecten de modelresultaten beïnvloeden, namelijk: (1) nauwkeurigheid van de bathymetrie en (2) numerieke frictie, beide als gevolg van gridresolutie, en (3) numerieke viscositeit als een gevolg van gridvorm. Numerieke frictie en numerieke viscositeit hebben hetzelfde effect op de modelresultaten als fysische bodemruwheid, namelijk vertraging van de afvoergolf en toename van de waterstanden.

In hoofdstuk 3 hebben we een 1D-2D gekoppeld model ontwikkeld om te kijken of dit type model een volledig $2 \mathrm{D}$ model kan vervangen om rekentijden te verkorten. In dit gesimplificeerde model zijn het zomer- en winterbed geschematiseerd door $1 \mathrm{D}$ profielen en is het achterland gediscretiseerd met behulp van een $2 \mathrm{D}$ grid. We hebben dit model gebruikt om een gevoeligheidsanalyse uit te voeren om te analyseren welke input parameter de hoogste impact heeft op de maximale afvoeren tijdens een hoogwater. In 1926 heeft een grote overstroming opgetreden. Deze overstroming is gebruikt als casus. We concluderen dat de modeluitkomsten het meest gevoelig zijn voor de ruwheidsklasse met de grootste oppervlakte. Ook laten we zien dat het $1 \mathrm{D}-2 \mathrm{D}$ gekoppelde model instaat is om modelresultaten met eenzelfde nauwkeurigheid als een volledig 2D model te produceren.

In hoofdstuk 4 hebben we een data-gedreven surrogaat model opgezet met trainingsdata gecreëerd met de 1D-2D gekoppelde modelleringsaanpak. Dit type surrogaat model heeft geen fysische interpretatie, maar reproduceert enkel de inputoutput relaties van het $1 \mathrm{D}-2 \mathrm{D}$ gekoppelde model gebaseerd op enkele simpele wiskundige functies. Als gevolg kunnen veel modelsimulaties uitgevoerd worden in slechts enkele secondes. We hebben de maximale afvoer bij Lobith (DuitsNederlandse grens) tijdens het 1809 hoogwater gereconstrueerd op basis van gemeten waterstanden van omliggende meetstations. Hoofdstuk 4 laat zien dat de betrouwbaarheidsintervallen van de gereconstrueerde 1809 maximale afvoer kleiner zijn in vergelijking met resultaten van bestaande methodes die geen gebruik maken van hydraulische modellen om de reconstructie uit te voeren. 
Voordat de historische overstromingen toegevoegd kunnen worden aan de dataset van gemeten jaarlijkse maximale afvoeren moeten deze genormaliseerd worden voor menselijke en natuurlijke veranderingen in het rivierensysteem. Om dit te doen, worden de bovenstroomse afvoeren van de historische hoogwaters losgelaten over de huidige geometrie gebruikmakende van de 1D-2D gekoppelde modelleringsbenadering (hoofdstuk 3 ). In hoofdstuk 5 laten we het huidige systeemgedrag van de Rijndelta zien ten gevolge van verschillende bovenstroomse afvoeren. Dijkdoorbraken zijn in het model meegenomen als willekeurige input parameter resulterende in verschillende overstromingspatronen. We concluderen dat dijkdoorbraken en bijbehorende overstromingspatronen tot een significante verandering van de afvoerverdeling van en overstromingsrisico langs de Nederlandse Rijntakken kan leiden.

Allerlaatst hebben we in hoofdstuk 6 een continue dataset van jaarlijkse maximale afvoeren van ongeveer 700 jaar geconstrueerd. De data van de periode 1772-2018, bestaande uit afvoer- en waterstandsmetingen, zijn uitgebreid met 12 historische hoogwaters. De 12 historische hoogwaters zijn genormaliseerd gebruikmakende van de modelleringstechnieken ontwikkeld in hoofdstuk 5. We hebben gebruik gemaakt van een bootstrap-benadering om afvoeren over de missende jaren in de historische tijdsperiode te samplen, resulterende in een continue reeks. Daarna is een afvoerfrequentie-analyse uitgevoerd met de uitgebreide dataset. We hebben de resultaten van deze analyse vergeleken met de afvoerfrequentiekromme gecreëerd op basis van enkel gemeten afvoeren. We laten zien dat de onzekerheid in afvoerfrequentiekrommen afneemt als de lengte van de gebruikte dataset van jaarlijkse maximale afvoeren toeneemt. Wij bevelen daarom aan om zoveel mogelijk historische overstromingen mee te nemen in de gebruikte dataset om zo de onzekerheidsbanden van afvoerfrequentiekrommen zo klein mogelijk te houden. Dit geldt zelfs als de maximale afvoer van een hoogwater erg onzeker is. Op deze manier kunnen toekomstige ontwerpafvoeren met een kleinere onzekerheid geschat worden. 


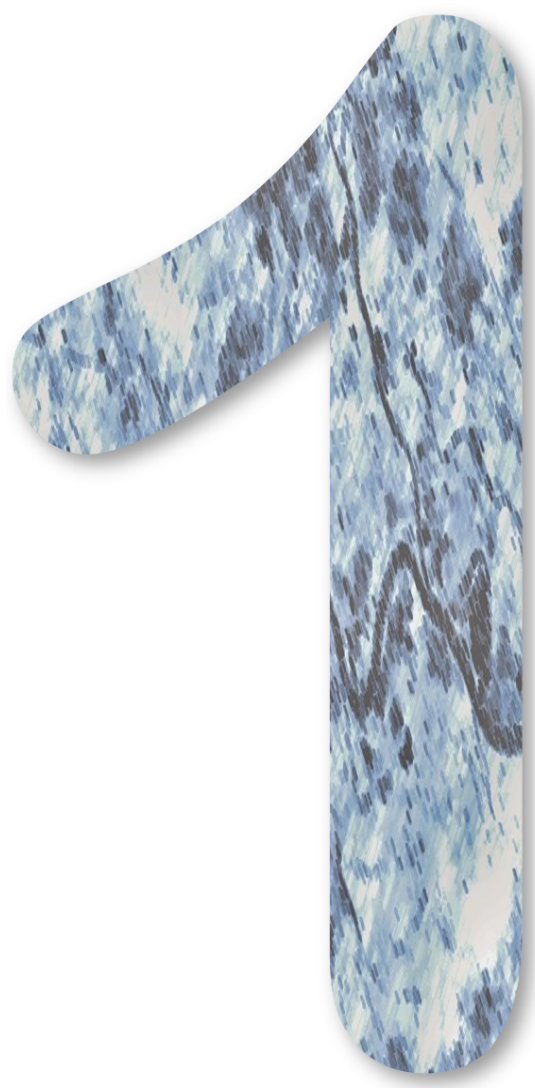

Introduction 


\subsection{Flood frequency analyses}

Floods are considered as one of the main hazards causing extensive damage and life-loss worldwide. Over recent years, flooding occurred with immense social impact (Benito et al, 2004). Recent floods in Uganda's Eastern Region, the province of Chaco in Argentina and the province of Alicante in Spain have led to enormous damage in 2019. These floods show the importance of accurate design of flood defences according to an appropriate safety level. Moreover, floods become a growing problem as societies become wealthier causing more material damage (Brázdil et al, 2006). It is expected that annual flood losses in Europe increase fivefold by 2050 (EEA, 2016).

To protect the hinterland from severe inundations, flood defences are commonly designed according to an appropriate safety level that are most often determined based on a statistical return period. Throughout Europe, flood frequency analyses (FFA) are used to estimate discharges associated with different return periods (Benito et al, 2004). Also in other countries such as the USA, Australia and several South American countries, the use of frequency analyses is common practice (Machado et al, 2015). These analyses are straightforward to apply. They consist of a technique of fitting a probability distribution to a series of observations for defining the probabilities of future occurrences of some events of interest (Khaliq et al, 2006). For this study, we are mainly interested in annual maximum discharges of a river (Fig. 1.1). In general, an FFA consists of three steps: (1) selecting a probability distribution, (2) choosing a parameter estimation method, and (3) providing an estimate of uncertainty associated with the parameters of interest (Khaliq et al, 2006). Probability distribution functions that are commonly used in literature are Generalized Extreme Value distributions, normal distributions, Gumbel distributions and Log-Pearson distributions. The choice of the probability distribution that best fits the sample data is often based on a goodness-of-fit criterion (Khaliq et al, 2006). Next, the parameters of the distribution are estimated with the use of a parameter estimation method such as the method of moments, the method of maximum likelihood or the method of L-moments. With this fitted distribution, discharges corresponding to any return period can be derived (Van den Boogaard et al, 2014). However, these discharges are commonly uncertain since it is unrealistic to expect that the fitted probability distribution is able to summarize all information about a future occurrence in a single number (Khaliq et al, 2006). To capture this uncertainty, uncertainty intervals of the fitted flood frequency relation are generally also computed.

Two widely used methods exist to sample the data used to fit the probability distribution function, namely: selecting the annual maximum discharges of the observational record or selecting the peak values that exceed a certain threshold. Normally, at-site FFAs are performed which only use observations of a single measurement station. However, if this data set covers a too short time period 
to successfully fit the distribution function, a regional FFA can be applied. In a regional analysis, observations of surrounding measurement stations are used to improve the accuracy of the fitted distribution. The method involves pooling of flood data from different stations in a hydrologically homogeneous region to obtain regional flood information (Hailegeorgis and Alfredsen, 2017).

Although FFAs are straightforward to apply, they do have some limitations and drawbacks. Firstly, the assumptions of independence and stationarity are necessary conditions to proceed with the analysis (Khaliq et al, 2006; Sankarasubramanian and Lall, 2003). Independence means that two observation points do not belong to the same flood event, which is excluded using the method of annual maximum discharges considering hydrological years (e.g. in the Netherlands the $1^{\text {th }}$ of October to the $30^{\text {th }}$ of September). Stationary means that the underlying processes are constant in time, and that hence the annual maximum flood corresponds to an independent identically distributed process (Sankarasubramanian and Lall, 2003). In other words, the parameters of the fitted distribution function do not change over time. However, it is widely acknowledged that both climate change and land use changes modify flood frequency relations (Section 1.6.4).

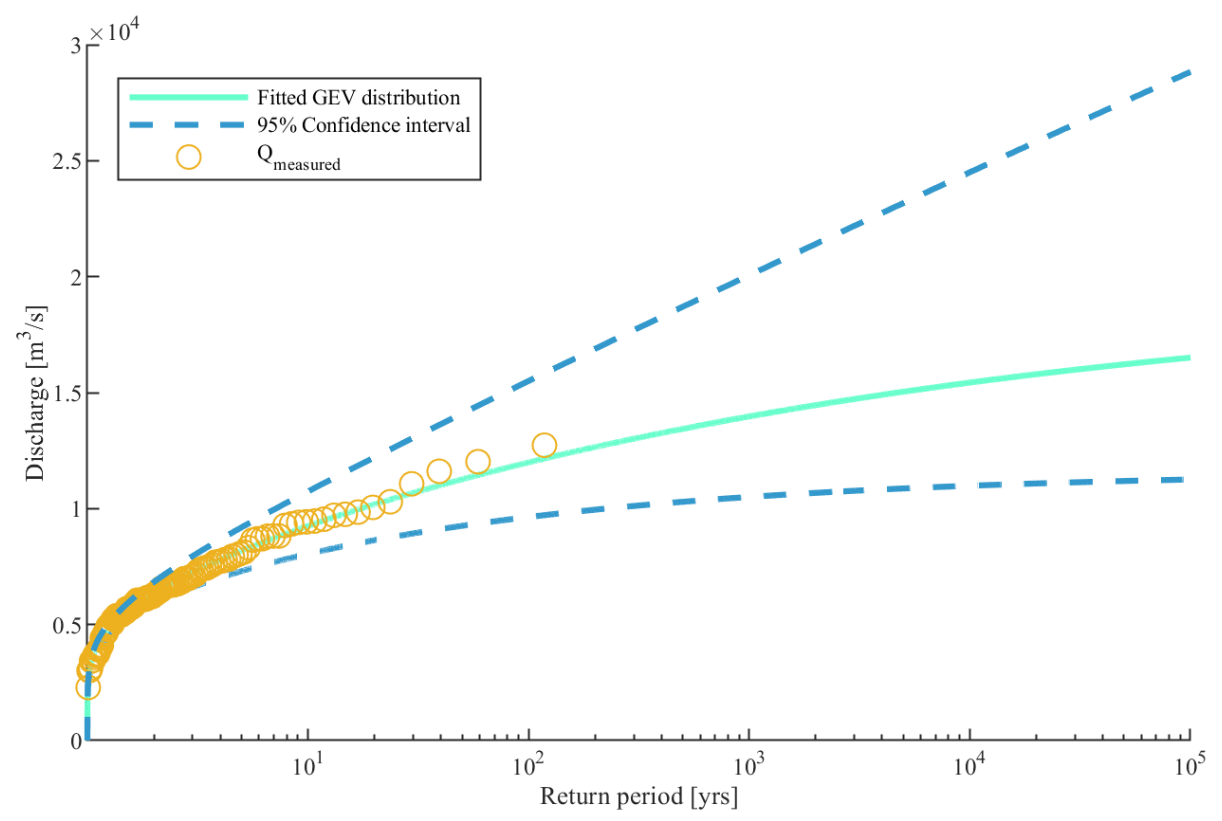

\section{Figure 1.1}

Fitted GEV distribution of the data set of measured annual maximum discharges ( $Q$ ) of the Rhine river at Lobith. Data provided by the Dutch Ministry of Infrastructure and Water Management. 
Furthermore, the fitted distribution functions become more accurate if a long series of observations is available. However, the length of these observational time series is often insufficient to accurately estimate the parameters of the distribution resulting in large uncertainty intervals. In Europe, each country manages its own measurement station network and discharge data is usually available for the last 40-50 years (Benito et al, 2004). Discharge measurements of the Rhine river have been performed relatively long and the data set has a length of approximately 120 years at the German-Dutch border (Lobith). Water level measurements even go back to 1772 at the nearby gauging stations Emmerich, Pannerden and Nijmegen. However, using this relatively long data set to fit a distribution function and to compute subsequent design discharges corresponding to a return period of e.g. 100,000 years still results in large uncertainties (Fig. 1.1). Furthermore, the short data set of observations may be unrepresentative. This is particularly the case if the data set comprises a period of relatively high or low discharges (Bayliss and Reed, 2001).

\subsection{Dealing with uncertainty in flood frequency anal- yses}

An FFA is subject to two types of uncertainties: sampling uncertainty and model uncertainty (Bobée et al, 1993), which are both highly affected by the amount of data available. The model error represents the error caused by the fitted distribution function. This error is relatively more important in the extrapolation region of the flood frequency relation, whereas for small return periods the global uncertainty is mainly due to sampling (Bobée et al, 1993). Decision makers see uncertainty as the lack of exact knowledge, regardless of the cause of this deficiency (Refsgaard et al, 2007). This is why, decision makers are interested in the global uncertainty, which is a combination of the two sources of uncertainty (sampling and model). The global uncertainty is especially pronounced for the estimation of design discharges corresponding to rare events (Fig. 1.1).

Traditionally, decision makers treat uncertainty implicitly through conservative design equations or through rules of thumb (Hall and Solomatine, 2008; Warmink et al, 2017). For example, to cope with the uncertainties related to design water levels, crest levels of the flood defences are computed and increased with a specific height to ensure that the flood defences are high enough to cope with the uncertainties. Even up till now, there is little evidence in literature on explicit uncertainty quantification for flood model predictions (Berends et al, 2019). Lack of explicit uncertainty quantification leaves room for free interpretation of model uncertainty by decision makers (Pinter, 2003). 
However, the last decade decision makers are increasingly demanding information about the extent of the uncertainties in the evidence upon which they are basing their decisions (Hall and Solomatine, 2008). Probabilistic modelling, i.e. modelling approaches (such as a Monte Carlo analysis) that incorporate uncertainty into the model calculations at all stages of the modelling, are increasing in popularity (Uusitalo et al, 2015). With probabilistic modelling, it is possible to compute the uncertainty intervals of a flood. Generally, decision makers are interested in the $95 \%$ uncertainty intervals to exclude uncertainties caused by scenarios with an extremely low probability of occurrence. These intervals are of high importance since flood protection measures are based on an appropriate safety level and corresponding design discharges. These design discharges are computed with the use of flood frequency relations.

\subsection{Historic flood reconstructions}

The global uncertainty of flood frequency relations can be reduced by extending the data set of measured discharges. Over the recent years, many studies have succeeded in the reconstruction of historic flood events. In general, these reconstructions can be divided into two groups, namely: reconstruction based on paleoflood hydrology and reconstruction from historical sources (Benito et al, 2004).

\subsubsection{Reconstructions based on paleoflood hydrology}

Sources of paleoflood data are geological indicators such as flood deposits, silt lines or erosion lines found in floodplains, terraces and along a river's channel (Benito et al, 2004). Paleoflood data most often represent minimum flood indicators representing flood stages that at least have been exceeded during the event. Techniques to estimate peak discharges based on paleostage indicators have been successfully employed worldwide. For example, Wolfe et al (2006) was able to construct flood history spanning the past 180 and 300 years for two oxbow lakes located near the Peace River, Canada. Laminated sediment depositions in combination with physical and geochemical analyses were used. It was found that flood frequency has been highly variable over the past 300 years. This indicates that changes in hydrology are a natural feature of the studied ecosystem independent of human influence or intervention (Wolfe et al, 2006).

In China, sediments of the Yangtze river were collected for grain size measurements with the aim to reconstruct the flood events over the past 150 years (Zhan et al, 2010). The sediments were taken from a sandbar where sediments were deposited during high water levels. Major grain size parameters such as mean grain size and probability cumulative curve clearly indicate the flood event depositions. Several 
large floods between 1850 to 1954 that agree well with historical documents were identified (Zhan et al, 2010).

O'Connell et al (2002) reconstructed so-called paleohydrologic bounds for both the Santa Ynez river, California, and the Big Lost river, Idaho. Paleohydrologic bound data represents high discharge stages that have not been exceeded since the geomorphic surface stabilized. These bounds are not actual floods, but limits on flood stages over a measured time interval. It was found that paleohydrologic bounds narrow the uncertainty intervals of peak discharges when estimating flood events with low probability of occurrence.

Other countries where paleoflood reconstructions successfully have been applied are, among others, India, South Africa, Peru, Australia and many countries in Europe (Benito et al, 2004).

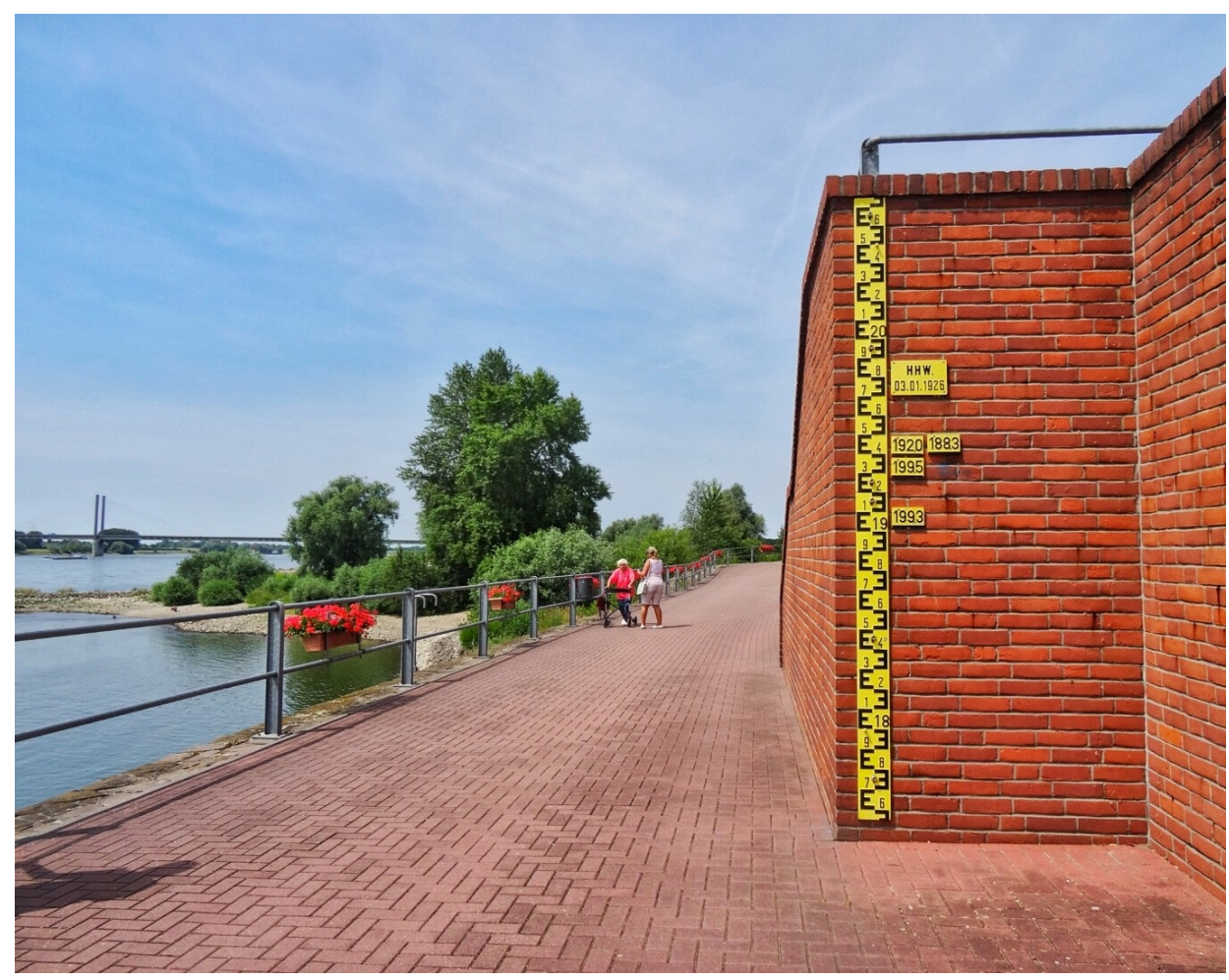

Figure 1.2

Flood marks of the Rhine river near Rees, Germany. Photo by A. Bomers. 


\subsubsection{Reconstructions based on historical sources}

Historical sources are commonly used to derive flood levels of specific flood events. These flood levels can be translated into discharges such that they can be incorporated in an FFA. There is a large volume and variety of sources which may provide information about a specific event (e.g. paintings, flood marks (Fig. 1.2), diaries, newspapers). According to studies performed so far, information that may be obtained from historical archives is among others the precise dating of the past flood event, the damage incurred, some reference to peak flood levels and certain information about the prevailing weather conditions (Benito et al, 2004).

Flood reconstruction based on historical sources have been widely applied. Herget and Meurs (2010) used documentary data to estimate peak discharges of historic flood levels near the city of Cologne, Germany. The reconstructions made use of all available data, including estimations of channel incisions and anthropogenic modifications of the river and its floodplains. A simple approach was applied to estimate peak discharges of several historic flood events with the use of the Manning's equation to take into account roughness and channel geometry. Herget and Meurs (2010) found that the Rhine river floods in 1993 and 1995 were exceeded at least four times in the pre-instrumental period.

For several Mediterranean catchment areas flood discharges were reconstructed with the use of recent and historical rating curves to account for geomorphological changes (Neppel et al, 2010). They recommend to carefully evaluate the various sources of uncertainty in order to assess the impact of using historical data to extend the data set of measured discharges. However, Neppel et al (2010) also found that the single most important factor influencing the uncertainty of flood frequency estimation is the length of the record. This clearly shows the benefits of extending the data set of measured discharges with historic events.

Sheffer et al (2003) constructed a long-term record of the extreme flood events of the Ardèche river, France, by extending the data set of measured discharges with both historic and paleo floods. Information about historical cross sections, topographic maps and field surveys were used to determine the historical maximum discharges with the use of a one dimensional hydraulic model. Only the main channel and its floodplains were included in the model domain and the model was not calibrated. Instead, two Manning's coefficient values were used. This led to a range of the potential maximum discharge of the various historic floods evaluated. They found that the floods in the Ardèche river are not randomly distributed in time but are clustered as there were long gaps in flood occurrences present in the constructed long-term record. Furthermore, Sheffer et al (2003) found that the nineteenth century floods of the Ardèche river at the end of the Little Ice Age from $\sim 1820$ to 1890 were the largest at the millennial time scale. 


\subsubsection{Hydraulic modelling tools for flood reconstructions}

The previous studies showed that historic flood events can be reconstructed based on paleo and historical information. However, up till now no highly detailed two dimensional (2D) hydraulic models are used to perform the reconstructions, while these models are typically suited to simulate extreme flood events. Since 2D hydraulic models are capable of simulating in high detail flow patterns and inundation extent during a flood event, they are generally used to get an understanding of present river system behaviour (e.g. Alkema and Middelkoop (2005); Leandro et al (2014); Moya Quiroga et al (2016)).

A major disadvantage of hydraulic computations on a $2 \mathrm{D}$ grid is the computational time. Therefore, many studies try to reduce this time by setting up so-called surrogate models which represent a simplified version of a highly detailed 2D model. In general, two types of surrogate models exist: (1) lower-fidelity physically based models and (2) response surface surrogate models. A lower-fidelity physically based surrogate model is a simplified representation of the high detailed model which is still based on the physical conditions of the system. It is set up with the original input data of the high detailed model. Contrarily, a response surface surrogate model represents a statistical or empirical data-driven model emulating the original system. It has no physical interpretation and solely consists of relatively simple mathematical functions. Both methods are already often applied to predict flood wave propagation on present-day geometries. Among others, Dibike and Solomatine (2001) and Campolo et al (1999) used a response surface surrogate model for river flow forecasting problems.

\subsection{Knowledge gap}

Many studies were able to reconstruct maximum flood stages at a specific location. These stages, although generally quite uncertain, are commonly translated into discharges such that they can be included into a flood frequency analysis. However, generally simple relations are used to perform this translation. None of the studies conducted so far used hydraulic models of any kind to reconstruct historic flood events along a long river stretch with multiple bifurcations including its flood-prone hinterland, while these models have shown their applicability of flood modelling for present situations. The use of sophisticated hydraulic models for historic flood reconstructions can have several advantages compared to previous methods (Section 1.3). Firstly, the uncertainty intervals of the reconstructed maximum discharges can be reduced since hydraulic models are capable of simulating the physical processes during a flood event in high detail. Secondly, the use of hydraulic models provide knowledge on the system behaviour of the river of interest for the specific time period considered. System behaviour represents the 
characteristics (e.g. timing of overflow and dike breaches, inundation patterns) of flood events of the considered river. As a result, not only the maximum discharge during the events can be determined, but also the discharge stages along the entire river stretch and the most dominant flow patterns through the embanked areas are predicted. The embanked areas represent the areas that are protected by flood defences and are hence not part of the river system. Finally, hydraulic models provide insights in the inundated areas during high flood stages. This is valuable information for the design of flood defences and evacuation plans.

A disadvantage of reconstructing historic flood events with the use of (highly detailed) hydraulic models is the computational cost. Using hydraulic models in an efficient way requires a reconstruction of the historical geometry as input data as well as proper boundary conditions to determine the flood wave propagation along the model domain. However, historical information (e.g. historical topography, occurred water levels, inundated areas) is limited and uncertain. This uncertainty influences the maximum discharge of the historic flood events at the location of interest. For this reason, input uncertainty must be included in the analysis. This can be done with the use of a probabilistic modelling approach in which the uncertain input parameters are considered as random input in a Monte Carlo framework. To perform such a Monte Carlo analysis, many model runs are required to reach convergence in the model output. Therefore, the model (hydraulic or any other kind of model) used for historic flood reconstructions must be efficient in terms of model accuracy and computational time. Up till now, we do now know to what extent the use of sophisticated hydraulic models to reconstruct historic flood events can result in a reduction of the $95 \%$ uncertainty intervals of flood frequency relations.

\subsection{Research aim and questions}

The aim of this research is:

to study the effect of extending the data set of measured discharges with reconstructed historic flood events, using hydraulic modelling tools, on the reduction of the $95 \%$ uncertainty interval of flood frequency relations.

Discharge records generally have a length up to approximately 100 years. Performing an FFA with this short data set results in large uncertainties. This uncertainty is specifically large for design discharges corresponding with low probability of occurrence. The uncertainty interval of flood frequency relations can be reduced by extending the data set with historic flood events using efficient hydraulic modelling tools. However, before the reconstructed historic flood events can be added to the data set of annual maximum discharges, they must be normalized for 


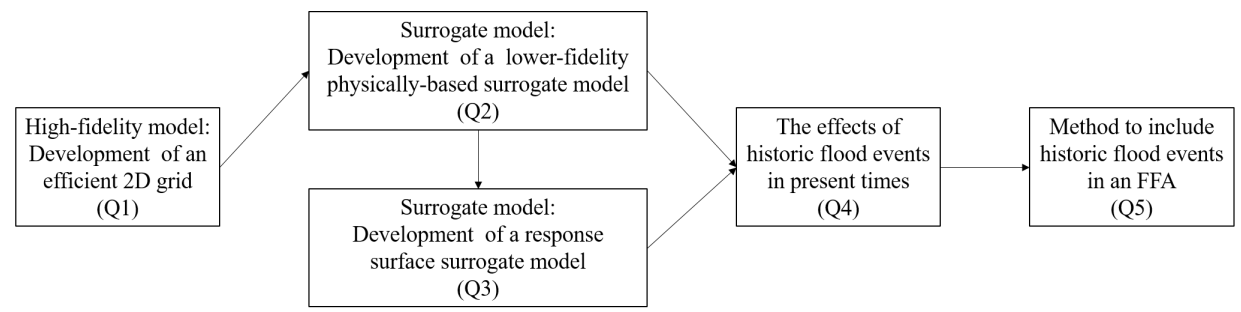

\section{Figure 1.3}

Methodology for setting up hydraulic models for historic flood reconstruction purposes. These reconstructed events can then be normalized and hence be included in a flood frequency analysis.

anthropogenic and natural changes in the river system (Section 1.6.4). Then, a continuous data set must be created since only some extreme events are known in the historical time period. With this long continuous data set an FFA can finally be performed. Based on the research aim, five research questions are formulated:

Q1 Which computational 2D grid structure is most efficient in terms of model accuracy and computational time for hydraulic modelling of large river systems?

Q2 Which lower-fidelity physically based surrogate model can be used to reconstruct a historic flood event of which the upstream discharge wave is known?

Q3 To what extend can a response surface surrogate model be used to reconstruct a historic flood event of which the upstream discharge wave is unknown?

Q4 What are the most important elements in normalizing reconstructed historic flood events?

Q5 How can maximum discharges of historic flood events be included into a flood frequency analysis to reduce the uncertainty interval of the flood frequency relation?

These research questions are answered using the Rhine river delta as a case study. Before we explain the methodology, details of the studied area are provided in the next Section. 


\subsection{Case: the Rhine river}

The proposed methodology (Section 1.7) is applied to the Rhine river (Fig. 1.4). The data set of measured annual maximum discharges at the German-Dutch border, Lobith, is extended. With this extended data set, we will evaluate if the uncertainty of the flood frequency relation can be reduced. The proposed method can be applied to any river system of which historical information about flood events is available.

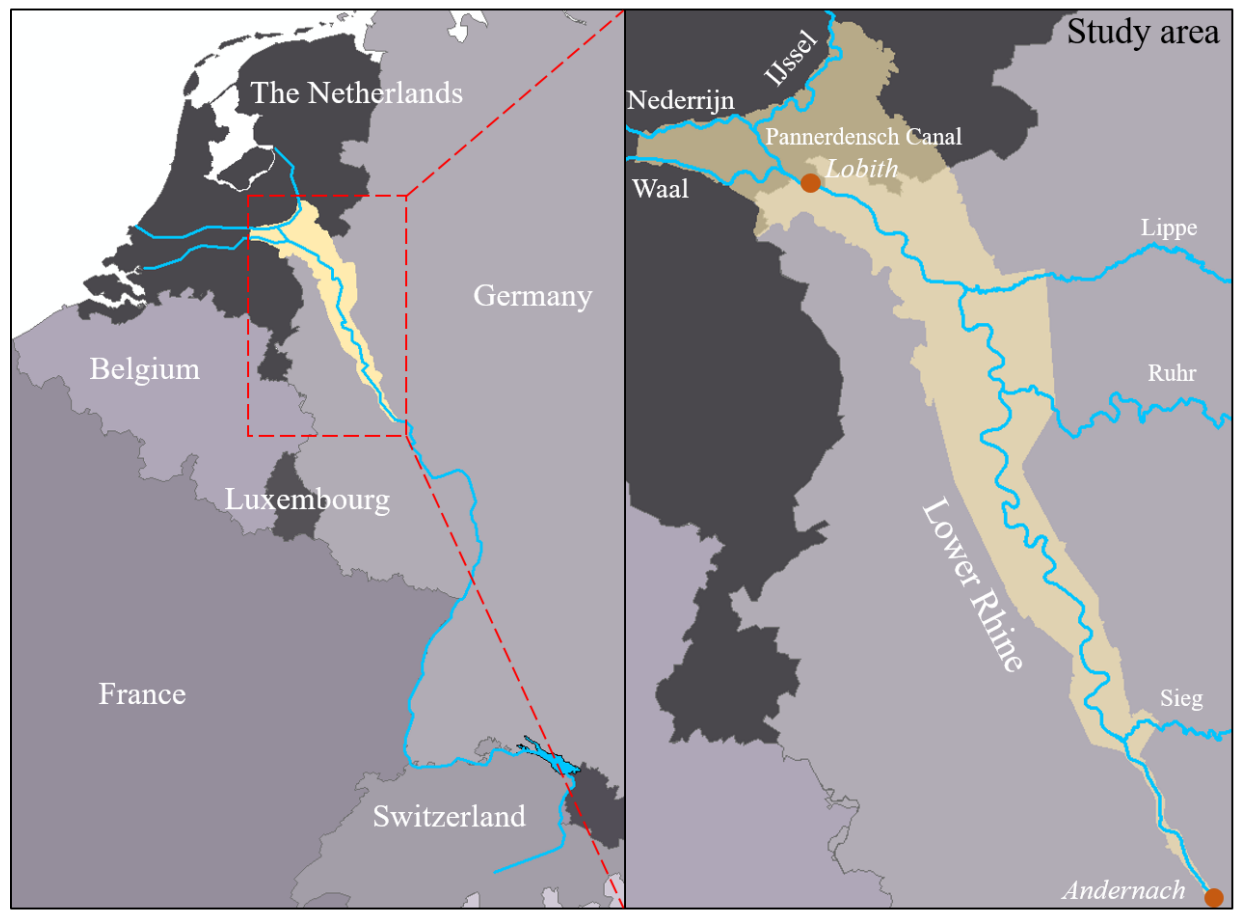

Figure 1.4

The course of the Rhine river (left figure) and the study area (right figure).

\subsubsection{Characteristics of the Rhine river basin}

The Rhine river originates in the Alps in Switzerland. It forms part of the boundary between France and Germany and flows through Germany towards the Dutch city of Lobith. In the Netherlands, the river bifurcates into three river branches 
which eventually flow into the North Sea directly or through the IJssel Lake and the Wadden Sea. The Rhine river catchment covers in total an area of 185,000 $\mathrm{km}^{2}$ (Liefveld and Postma, 2007). In this area, approximately 58 million people are living, of which 10.5 million inhabitants live in flood-prone areas (ICPR, 2001).

The Rhine river has a total length of about 1,320 km (Liefveld and Postma, 2007). With this length, the Rhine is not a large river relative to other major rivers in the world, but it comprises a large drainage area and flows through multiple highly developed countries. The flow regime of the Rhine river is dominated by snowmelt and precipitation runoff (Disse and Engel, 2001). Average annual precipitation across the basin varies from $500 \mathrm{~mm}$ to more than 2,000 $\mathrm{mm}$. Most of the precipitation occurs in the Alps. This part of the catchment area comprises only $20 \%$ of the total surface area of the basin, but contributes to about $50 \%$ of the discharge of the Rhine river (Brázdil et al, 1999). Most of the precipitation in the Alps occurs as snowfall. During the summer months, the precipitation occurs as rainfall and snowmelt evolves leading to an increase in the runoff. Contrarily, further downstream the flow regime is dominated by precipitation runoff from the uplands in the winter (Disse and Engel, 2001). This leads to a peak-shift in average annual discharge from the summer to the winter from the High and Upper Rhine (upstream part of the basin) towards the Middle and Lower Rhine (downstream part) (Disse and Engel, 2001; Lammersen, 2004). The two sources melt water and rain ensure that the Rhine is navigable all year round (Liefveld and Postma, 2007), making the Rhine river one of the most important industrial transport routes in Europe (Disse and Engel, 2001; Te Linde, 2011). The river connects the port of Rotterdam with the inland European markets.

\subsubsection{Study area and safety levels}

This study focuses on the area downstream of Andernach, Germany, where the flood-prone area widens, to the Rhine river delta in the Netherlands (Fig. 1.4). The high population densities and industrial activities along the river makes this area vulnerable to flood damage (Knepper, 2014). In the studied area, floods mainly evolve during winter months due to high precipitation events. In the annual maximum discharge series of the Lower Rhine of the last 120 years, $85 \%$ of the annual maxima took place in November until March (Apel et al, 2009). The shape and maximum value of the discharge wave depends on the location and period of the precipitation events. If earlier rainfall events have occurred, the soil may be saturated. This leads to more direct runoff (Silva, 2002) and a peaked discharge wave. Also the temperature may affect the discharge wave since high temperatures lead to snowmelt and hence to more runoff. Contrarily, low temperatures may lead to freezing of the soil which can also lead to more direct runoff (Silva, 2002). Along the Lower Rhine, water level measurements started around 1800. 
In this study, the discharge record at Lobith is extended to verify the proposed methodologies. The discharge at Lobith mainly depends on the inflow of the tributaries Sieg, Ruhr and Lippe rivers towards the Rhine river and the discharge of the Rhine river itself (Silva, 2002). Water level measurements have been performed since 1866 whereas daily discharge measurements are available since 1901 (Toonen et al, 2015). From 1901 until 1950, the discharges were based on velocity measurements performed with floating sticks on the water surface. Since these measurements were only performed at the surface, extrapolation techniques were used to compute the total discharge (Toonen et al, 2015). From 1950 until 2000, current meters were used to construct velocity-depth profiles which were translated into discharges. Since 2000, Acoustic Doppler Current Profiles have been used to perform the discharge measurements (Toonen et al, 2015). The annual average discharge at Lobith equals $2,200 \mathrm{~m}^{3} / \mathrm{s}$ (Te Linde, 2011). The highest measured discharge at Lobith so far equals $12,600 \mathrm{~m}^{3} / \mathrm{s}$ in 1926 . During this event, several dike breaches occurred which resulted in severe inundations of the hinterland.

In the Netherlands, the exceedance probability approach has been changed towards a flood risk approach. In this new approach, not only the probability of a flood event due to various dike failure mechanisms is considered but also its consequences. As a result, the maximum safety levels increased significantly in areas where the consequences of a potential flood event are large. These areas include locations with high population density, large economic value and vulnerable infrastructure (Van der Most et al, 2014). As a result, the new standards better reflect the expected consequences in case of flooding caused by dike breaches. While a maximum safety level of 1/1,250 years was defined along the Dutch Rhine river branches based on the exceedance probability approach, the new approach has a maximum safety level of 1/100,000 years (Van Alphen, 2016) based on the individual risk of becoming a victim of flooding, the societal disruption and the economic efficiency of investments in flood protection (Van der Most et al, 2014). This new safety standard is expressed in the probability of flooding and has as advantage that the impact of various dike failure mechanisms can be integrated in the analysis.

Using an FFA to determine design discharges corresponding with rare flood events up to a return period of 100,000 years results in large uncertainties because of the relatively short data set of measured discharges. Therefore, we study if historical information (e.g. flood marks, sedimentary data, diaries) can be used to extend the data set of measured discharges with historic events such that the flood frequency relation can be predicted with less uncertainty. 


\subsubsection{Historic flood events}

In the Netherlands, floods of the Rhine river have rarely been reported before the $12^{\text {th }}$ century. The number of flood reports gradually increased during the $13^{\text {th }}$ century and in the $14^{\text {th }}$ century river floods became a recurrent problem (Tol and Langen, 2000). Extreme flood events in the Rhine river basin of which numerous historic flood marks and sedimentary data is available are the flood events in 1342 , 1374 and 1651. Of the more recent floods in 1809 and 1926, also daily measured water levels are available. All these flood events were caused by high precipitation events.

The 1342 flood event was an exceptional event since it occurred during the summer months. An intense precipitation event in July in central Germany led to floods in the Rhine river basin. Many historical sources providing information about the water levels and damage are available (Herget et al, 2015). However, some of the sources contradict each other. This may be the result of the various flood events that occurred in 1342. Kiss (2009) distinguishes three flood periods, namely February, April and July. The floods in February were caused by ice jams, the floods in April by snowmelt and the floods in July by high rainfall intensities (Herget et al, 2015). The most severe event in July lasted several days resulting in extreme soil erosion and in enormous damage. Bridges, mills and buildings in several catchment areas of Central Europe were damaged or even destroyed (Herget et al, 2015). Especially the causalities in Cologne are well documented. These flood descriptions are sufficiently detailed to permit the estimation of water levels and hence the maximum discharge during the event.

The 1374 flood event represents the largest flood of the last 1,000 years. The flood produced high water levels around January $6^{\text {th }}$, January $25^{\text {th }}$ and around the $9^{\text {th }}$ to the $11^{\text {th }}$ of February (Herget and Meurs, 2010), all caused by high rainfall intensities. The flood in February resulted in the highest water levels and represents the largest flood ever observed at Cologne. Because of the exceptional high water levels during the flood event, many historical sources provide information about the severeness of the event. Some sources even state that it was possible to cross the city wall of Cologne by boat, giving information about the occurred water levels (Herget and Meurs, 2010).

The last large flood occurred in 1926 and represents the largest measured flood at Lobith so far. In West Europe, a great depression with high rainfall started in December 1925 (Dutch Ministry of Infrastructure and the Environment, 1926). Additionally, a large amount of melted snow increased the discharge of the rivers in the Rhine basin. Hence, the already large discharge of the Rhine river was accompanied with increased discharges of the tributaries. This resulted in severe inundations of the hinterland. 


\subsubsection{Climate change and land use change effects}

Reconstructions of the historic flood events can be used to extend the observational data set. However, a basic question dealing with a long temporal flood series is whether the flood-producing mechanisms in the past have a similar consequence as those of the present. This problem of non-stationary comprises two factors, namely: climate change and land use change (Murawski et al, 2018). Both factors influence the frequency, timing and peak value of flood events. As a result, the parameters of the fitted distribution function and the distribution itself may change over time (Khaliq et al, 2006). Although we are aware of the fact that climate variability influences flood frequency relations, it is difficult to consider its effect in an FFA. This is because flood frequency relations changed over time as a result of many factors, e.g. climate change, land use change and river training. Hence, including the effects of climate change in isolation is difficult and subject to many uncertainties and assumptions. So far, no consistent large-scale climate change signal in observed flood magnitudes has been identified (Blöschl et al, 2017). Therefore, the historic flood events in this thesis are only normalized for geometrical adaptations, assuming that the climate conditions did not change over the considered time period. This assumption is discussed in more detail in Section 7.2.

\subsection{Methodology}

To answer the questions presented in Section 1.5, hydraulic and surrogate models are developed in which the main objective is to keep computational time low while model accuracy remains sufficiently high. Firstly, we study which $2 \mathrm{D}$ grid is most efficient for hydraulic river modelling (Q1). However, since computational time of a fully $2 \mathrm{D}$ model is quite large, even with an efficient grid, this model is simplified in two manners. Both a lower-fidelity physically based surrogate model (Q2) as well as a response surface surrogate model (Q3) are developed. The lowerfidelity physically based surrogate model still relies on the physical processes of the original system whereas the response surface surrogate model has no physical interpretation.

The two types of surrogate models are used for historic flood reconstruction purposes. Furthermore, the lower-fidelity model is used to normalize historic flood events for anthropogenic and natural changes in the river system $(\mathbf{Q 4})$ such that the reconstructed historic flood events can be added to the data set of measured discharges. Finally, a bootstrap method is developed that creates a continuous data set of annual maximum discharges of approximately 700 years (Q5). With this data set, flood frequency relations can be predicted. The methodology of the research questions are further detailed below. 
Q1 Which computational 2D grid structure is most efficient in terms of model accuracy and computational time for hydraulic modelling of large river systems?

To answer research question Q1, the effect of different grid types on model accuracy and computational time is studied. Model accuracy is determined by evaluating the simulated water levels and flow velocities to study whether the physical processes are sufficiently captured by the various grids. Structured curvilinear, unstructured triangular and hybrid grids with curvilinear grid cells in the main channel and triangular grid cells in the floodplains are considered. Both a low resolution as well as a high resolution variant of these three grid types are evaluated. The Waal river is used as a case study. This river has large meander bends in the upstream part, while the downstream part has a quite straight pattern. Therefore, the analysis provides results for both a meandering and a straight river. Data of the 1995 flood wave is used for model calibration.

Q2 Which lower-fidelity physically based surrogate model can be used to reconstruct a historic flood event of which the upstream discharge wave is known?

With the use of a 1D-2D coupled model, a sensitivity analysis is performed to identify which uncertain input parameter mostly influences model output. This provides information on which feature to focus during historic flood reconstruction to minimize output uncertainty. To answer research question Q2, a fully 2D hydraulic model with the most efficient grid according to research question Q1 is simplified to reduce computational time. A lowerfidelity physically based model is developed in which the main channels are discretized by $1 \mathrm{D}$ profiles. These profiles are coupled to the embanked areas that are discretized on a 2D grid. The 1926 flood event of the Rhine river is used as a case study.

Q3 To what extend can a response surface surrogate model be used to reconstruct a historic flood event of which the upstream discharge wave is unknown?

To answer research question Q3, a response surface surrogate model is developed. Now, the 1809 flood event of the Rhine river is used as a case study. Of this event, the maximum upstream discharge is unknown. An infinite number of combinations of maximum upstream discharges and main channel roughness result in the same simulated water levels. Hence, model calibration is not possible to perform. Many model runs have to be performed to include the wide range of potential scenarios with varying maximum upstream discharge and main channel roughness. The use of a physically based model is inappropriate for this specific case because computational time is

\section{Chapter 1}


still relatively large. Therefore, an Artifical Neural Network (ANN) is developed. This model is trained with the use of model output of a $1 \mathrm{D}-2 \mathrm{D}$ coupled model as developed for research question Q2.

Q4 What are the most important elements in normalizing reconstructed historic flood events?

To answer research question Q4, a method is developed which enables the historic flood events to be normalized for antropoghenic and natural changes in the river system. Research question Q2 and Q3 showed how historic flood events can be reconstructed with the use of surrogate models. However, the reconstructed maximum discharges represent the discharges that occurred during the historic flood event. These discharges must be translated into maximum discharges that would occur under present geometrical conditions before they can be used to extend the data set of annual maximum discharges. To do so, a 1D-2D coupled model as developed for research question Q2 is used. The modelling approach is extended such that flood wave propagation can be simulated in which both overflow and dike breaches are possible to occur. The effects of various upstream discharge stages on overland flow patterns and hence flood risk in the Rhine river delta is studied to identify the most important elements in normalizing the reconstructed historic flood events.

Q5 How can maximum discharges of historic flood events be included into a flood frequency analysis to reduce the uncertainty interval of the flood frequency relation?

To answer research question Q5, the data set of measured discharges is extended with 12 large historic flood events. The method developed for research question Q4 is used to normalize these 12 historic flood events of the Rhine river. However, only using these events to extend the data set does not result in a continuous series. Therefore, an efficient bootstrap method is developed that creates a continuous data set of annual maximum discharges by re-sampling the measured data set over the missing years in the historical time period. As a result, the data set of measured discharges of approximately 100 years can be extended with 600 years. With this data set, an FFA is performed. Results are compared with the results of an FFA performed based on only measured annual maximum discharges. 


\subsection{Outline}

The thesis is structured as follows: In Chapter 2 research question Q1 is addressed by evaluating the effects of various grid structures on hydraulic modelling performance. In chapter 3 research question Q2 is answered by developing a 1D-2D coupled model for historic flood reconstruction. In Chapter 4 an ANN is developed which answers research question Q3. Chapter 5 addresses research question Q4 by providing insights in the modern system behaviour of the Rhine river delta. In Chapter 6 research Q5 is addressed by developing an efficient bootstrap method to include historic flood events in an FFA. Finally, in Chapter 7 the discussion is provided and in Chapter 8 the conclusions and recommendations are given. 


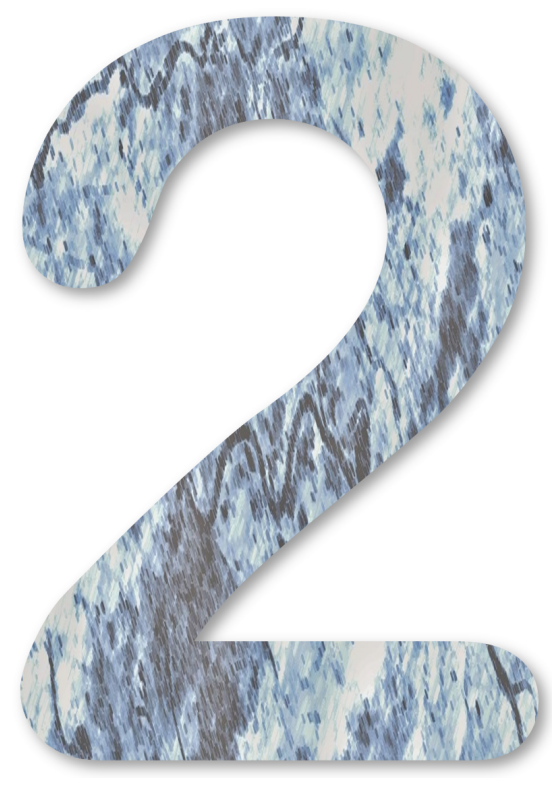

\section{The influence of grid shape and grid size on hydraulic modelling performance}

This chapter is published as A. Bomers, R.M.J. Schielen, and S.J.M.H. Hulscher (2019).

The influence of grid shape and grid size on hydraulic modelling performance, Environmental Fluid Mechanics, 19(5), 1273-1294. DOI:10.1007/s10652-019-09670-4 


\section{Abstract}

Grid shape (curvilinear/structured versus triangular/unstructured) and grid size affect model output. In this study structured, unstructured and hybrid grids with a high and low resolution were compared. As a case study, we used the Waal River (with main channel and floodplains). We studied simulated water levels using the six grids, considering equal main channel friction, which enabled to study the isolated effects of grid shape and size. The spread in simulated water levels was found to be rather large with a maximum deviation of 78 $\mathrm{cm}$. Therefore, calibration was performed such that simulated water levels resembled measured water levels by adjusting the main channel friction. This enabled us to draw conclusions on the choice of optimal usage of the grids in engineering studies. Bathymetry accuracy and numerical friction, both as a result of grid resolution, and numerical viscosity as a result of grid shape play a vital role. The analysis shows that unstructured grids are affected most by the calibration which is reflected in the wide spreading of calibrated friction values. From the six grids studied, the hybrid grid with curvilinear grid cells in the main channel and triangular grid cells in the floodplain is recommended for hydraulic modelling since computation time is low, while model output shows sufficient accuracy.

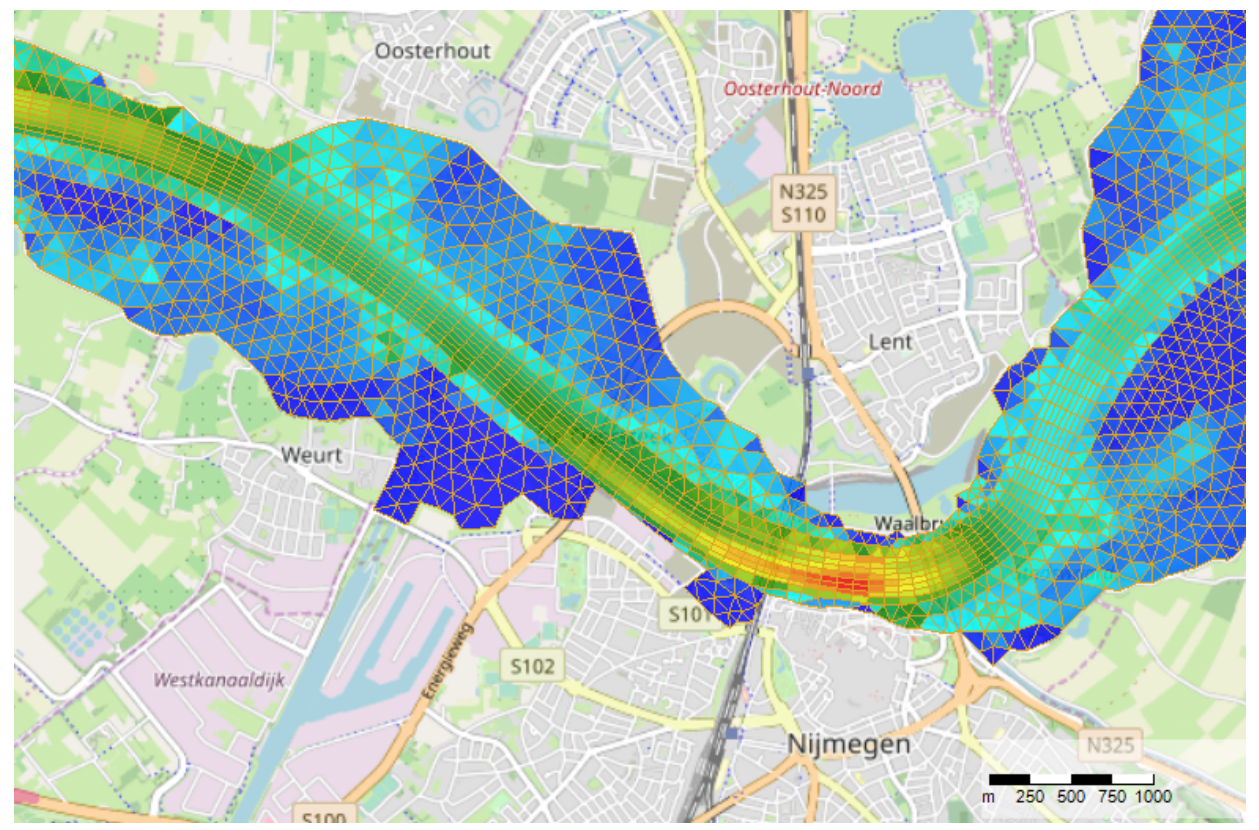

Impression of 2D model output (D-Flow FM) 


\subsection{Introduction}

Currently, sophisticated two dimensional horizontal (2DH) models are used to get a detailed and accurate representation of water levels, flood patterns and potential flood prone areas which help to define flood protection measures. Until now, structured curvilinear grids are commonly used for hydraulic modelling to discretize the model domain within the finite difference and finite volume framework (e.g. Lane et al (2004); Ye and McCorquondal (1997)). In general, curvilinear grid cells give accurate model output with added benefit of allowing cell stretching along the river main channel, while orthogonality (see Section 2.3 for an explanation of the orthogonality concept) stays within reasonable bounds (Lai, 2010). However, this grid type has several disadvantages. The use of curvilinear grid cells results in a high resolution in sharp inner bends since grid lines are focused in these bends (Fig. 2.1) (Kernkamp et al, 2011). Under the assumption that in a curvilinear grid the floodplains follow the same trajectory as the main channel course, it is not possible to locally refine or coarsen the grid since the resolution of the floodplain depends on the resolution of the curvilinear grid cells in the main channel. An unnecessary high resolution increases computation time of the model. In addition, the curvilinear cells are restrictive in representing a natural river system with different geometric features such as main channels, bifurcations and floodplains due to the rectangular shape of the grid cells (Lai, 2010).

Other commonly used grid types are unstructured grids in which the entire model domain is discretized by triangles (e.g. Cobby et al (2003); Heniche et al (2000); Horritt and Bates (2002); Sleigh et al (1998)). These grids have been widely used with the finite element or finite volume framework (Lai, 2010). Triangular grids are easy to generate and they overcome the problems of curvilinear grids, since triangular cells are more flexible in shape (Lai, 2010). However, stretching the triangular grid cells in the flow direction, results in less accurate model output

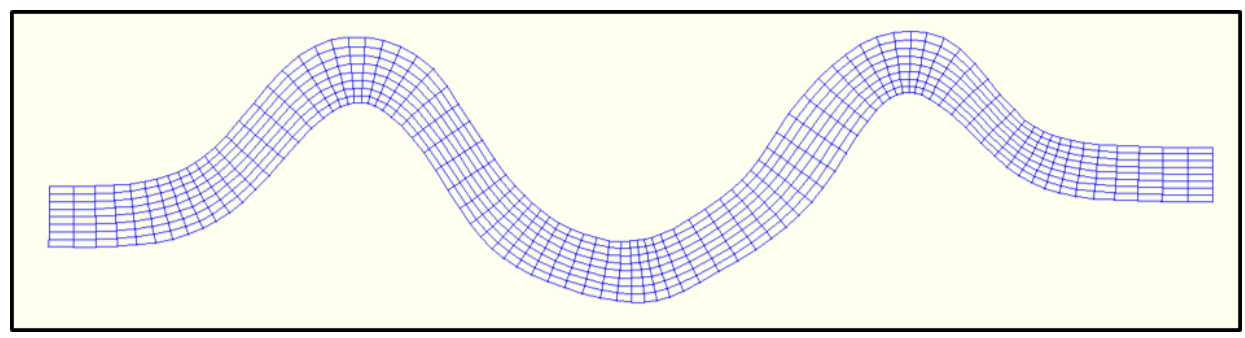

\section{Figure 2.1}

Grid lines of a curvilinear grid show higher density in inner bends resulting in high resolution in these areas. 
(Baker, 1996). There are two reasons for the lower accuracy of the model output. Firstly, stretching triangular grid cells in the flow direction results in low orthogonality (see Section 2.3), which can be kept under control by projecting the grid cells on the edge normal vector. Secondly, if the triangular grid cells are elongated, they tend to degenerate into lines and hence the area-edge length ratio is very small resulting in e.g. small time steps.

The advantages and disadvantages of the fully structured and fully unstructured grids leads to the question whether a combination of the two grid types might be a good alternative. A grid in which different grid shapes are used is referred to as a hybrid grid. In this study the hybrid grids have a structured curvilinear grid in the main channel, whereas the floodplains are discretized by triangular grid cells. A question is how such a hybrid grid affects numerical results. Caviedes-Voullième et al (2012) studied the effect of grid structure on model results with the use of a physically-based numerical model for runoff simulation in a mountain catchment. In their study, they found that mesh selection is of great importance since the model output was more sensitive to mesh properties (grid shape and grid size) than to the friction spatial distribution (Caviedes-Voullième et al, 2012). Horritt et al (2006) studied the effect of mesh resolution and input digital elevation model (DEM) resolution on the predictions of a $2 \mathrm{D}$ finite volume model of channel flow. The model was more sensitive to the size of the grid cells than to the resolution of the input DEM (Horritt et al, 2006). Kernkamp et al (2011) explored whether the application of a hybrid grid results in accurate model output and used the Northwest European Continental Shelf as a case study. Curvilinear grid cells were aligned with the main flow direction coupled with triangles for computational efficiency. For their application, they found that such a hybrid grid is capable of accurately representing complex boundaries in geometrically complicated areas. The model performance in terms of computation time and accuracy of the hybrid grid was comparable to the performance of a structured grid (Kernkamp et al, 2011). Hardy et al (1999) studied the importance of grid resolution for floodplain modelling using seven hybrid grids. In these grids, the main channel was discretized by curvilinear grid cells and the floodplains by triangular grid cells. They found that if resolution increases the inundation extent decreases, and that the effects of the different grid resolutions were at least as important as the surface roughness which is commonly used as typical calibration parameter (Hardy et al, 1999). Although Hardy et al (1999) made use of a combination of structured and unstructured grids for hydraulic modelling, they did not consider the performance of such a grid compared to fully structured and fully unstructured grids.

Using hybrid grids may be a good alternative of both a fully structured as of a fully unstructured grid (e.g. Bernard and Berger (1999); Hardy et al (1999); Kernkamp et al (2011); Lai (2010)). However, an extensive comparison on performance between the different grid types with the use of a case study has not been done so far. Therefore, the objective of this paper is to uncover the effects of grid shapes and sizes on model performance for hydraulic flood modelling. Model performance 
is expressed in terms of computation time, accurate prediction of maximum water levels and accurate simulation of depth-averaged flow velocity profiles in meander bends. To assess the model performance, six different grids are created covering structured, unstructured and hybrid grids with a high and low resolution variant. The grids are calibrated using the 1995 flood event of the Waal river, which is a bifurcation of the Rhine river, such that accurate maximum water levels are predicted by the six different models. The main channel of the Waal river and its floodplains are modelled.

The outline of the paper is as follow. In Section 2.2 the case study of the 1995 Waal river flood event and properties of the numerical model are described. Section 2.3 provides the different grids considered in this study. Section 2.4 shows the results focusing on the main differences in model performance. The paper ends with the main conclusions.

\subsection{Hydraulic modelling: Case study Waal}

The 1995 flood event of the Waal river is used as a case study (Fig. 2.2). The Waal river is a bifurcation of the Rhine river. The upstream boundary is located at the bifurcation point where the Rhine river bifurcates into the Pannerdensch Canal and the Waal river in the Netherlands. The downstream boundary is at the city of Tiel (Fig. 2.2). The Waal river is used in this study since it is a typical lowland river, ample data is available and schematizations of the study area are available from previous studies. The model domain consists of the main channel of the Waal river and its floodplains. The river has meander bends in the upstream part of the study area and it has a relatively straight course further downstream. For this reason, it is possible to consider the results for both a meandering stretch (Trajectory 1, Fig. 2.2) as well as for a relatively straight stretch (Trajectory 2, Fig 2.2).

The section of the Waal river used in this study has a trajectory length of approximately 46 kilometers, with an average main channel width of 260 meters. No large differences in the main channel width are present. The floodplain widths vary between 20 meters close to Nijmegenhaven (Fig. 2.2) to 1,650 meters in the upstream meander bends. The total model domain has an area of $66 \mathrm{~km}^{2}$ with a linear length of approximately 40 kilometers. At CS1 and CS2 the discharge partitioning in the main channel and floodplains are evaluated (Section 2.4). These two locations are chosen such that a comparison can be made between a location with wide floodplains (CS1) and almost no floodplains (CS2). 


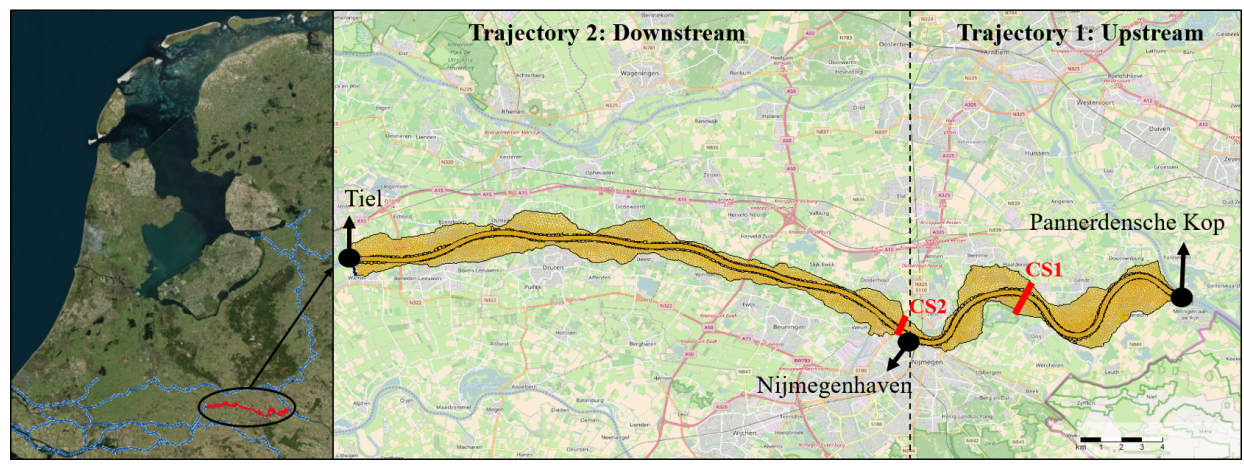

Figure 2.2

Location of the Waal river in the Netherlands and the model domain, in which Trajectory 1 represents a meandering stretch and Trajectory 2 a relatively straight stretch of the river. CS1 and CS2 are used to determine the discharge partitioning in the main channel and floodplains in Section 2.4.

\subsubsection{Hydraulic model}

Hydraulic modelling is performed with D-Flow Flexible Mesh (FM) in which the 2D Shallow Water equations are solved (Deltares, 2016b). The depth-averaged continuity equation and the momentum equations in $\mathrm{x}$ - and $\mathrm{y}$ - direction are given by:

$$
\begin{gathered}
\frac{\partial z}{\partial t}+\frac{\partial[(h+z) u]}{\partial x}+\frac{\partial[(h+z) v]}{\partial y}=0 \\
\frac{\partial u}{\partial t}+u \frac{\partial u}{\partial x}+v \frac{\partial u}{\partial y}=-g \frac{\partial z}{\partial x}-\frac{g u \sqrt{u^{2}+v^{2}}}{C_{\mathrm{z}}^{2}(h+z)} \\
\frac{\partial v}{\partial t}+u \frac{\partial v}{\partial x}+v \frac{\partial v}{\partial y}=-g \frac{\partial z}{\partial y}-\frac{g v \sqrt{u^{2}+v^{2}}}{C_{\mathrm{z}}^{2}(h+z)}
\end{gathered}
$$

where $u$ and $v$ represent the depth-averaged flow components in $\mathrm{x}$ - and y-directions respectively $[\mathrm{m} / \mathrm{s}], z$ is the water surface elevation $[\mathrm{m}], h$ is the water depth $[\mathrm{m}]$, $g$ represents the constant gravitational acceleration $\left[\mathrm{m} / \mathrm{s}^{2}\right]$, and $C_{z}$ is the Chézy friction coefficient $\left[\mathrm{m}^{1 / 2} / \mathrm{s}\right]$. 


\subsubsection{Computation schemes of the numerical grids}

In this study, for all grid types a finite volume solver on a staggered scheme is used to discretize the Shallow Water equations (Equations 2.1-2.3). On a staggered scheme, the scalar variables (water level, bed level etc.) at a certain time step are stored in the cell centers of the control volumes whereas the velocity variables are located at the cell faces (Harlow and Welch (1965); Kleptsova et al (2009)).In other words, the velocity variables are shifted half a grid cell in the $\mathrm{x}$ and $y$ - direction. Consequently, half of the control volumes of the velocity variables along the boundaries fall outside the model domain and are therefore omitted during the computation. This differs from a collocated scheme arrangement, in which all variables are stored in the same positions. Jones (2002) remarks that staggered schemes are commonly used for Shallow Water flow problems. According to Stelling (1983), a staggered scheme is very effective for the discretization of the Shallow Water equations, since the number of grid points is reduced with a factor four compared to a collocated grid. In addition, a staggered scheme allows for a simple treatment of the boundary conditions and it was found to be more robust compared to a collocated grid. For more information about the application of staggered schemes for Shallow Water flow problems, and the reasons why it has been used in many software packages (e.g. WAQUA, TRIWAQ, D-Flow FM), we refer to Stelling (1983).

Commonly, rectangular row-columns structured staggered schemes are used to solve the system. However, such a scheme is not applicable for the unstructured and hybrid grids since a rectangular row-columns structure is not present. A number of generalizations of the staggered schemes have been proposed for unstructured grids to retain the mass conservation properties of the classic structured method (Perot, 2000). The unstructured staggered scheme as described by Kleptsova et al (2009) is used in this study. The continuity equations are solved implicitly while the advection term in the momentum equation is solved explicitly (Deltares, 2016a). The advection term makes use of a reconstruction at the cell centre (Perot's method, see (Perot, 2000)), which is first-order accurate on unstructured staggered grids. Implicit time integration is used as iterative solver, and the resultant dynamic time step is based on the Courant criteria. In principle, the continuity equation has no time step restriction when using the implicit solver. However, the computed dynamic time step for the advection term is used for both the implicit as the explicit solvers to avoid a calculation scheme staggered in time. This dynamic time step is grid dependent. The Courant number $C$ can be computed with:

$$
C=\frac{u \Delta t}{\Delta x}
$$

where $u$ represents the flow velocity $[\mathrm{m} / \mathrm{s}], t$ the time step $[\mathrm{s}]$ and $x$ the length interval in flow direction $[\mathrm{m}]$. A maximum Courant number of 0.95 is used. We 
use the method proposed by Kernkamp et al (2011) to solve the system.

\subsubsection{Calibration procedure}

The 1995 discharge wave is used as upstream boundary condition and a $\mathrm{h}(\mathrm{t})$ relation is used as downstream boundary condition (Fig. 2.3) based on measured water levels available at https://waterinfo.rws.nl provided by the Dutch Ministry of Infrastructure and Water Management. Caviedes-Voullième et al (2012) showed that each grid has its own numerical friction caused by the resolution of the cells and structure of the grid. In their study, they found that mesh coarsening has a similar effect on the discharge wave as friction, i.e. a coarser mesh results in a dampened discharge wave and this effect can even become larger than that generated by physical friction (Caviedes-Voullième et al, 2012). Applying friction coefficients values selected from literature (e.g. the tables of Chow (1959)) may not result in proper results since the numerical friction of the grids is not considered in this way. Therefore, friction coefficients must be calibrated with each grid to compensate for numerical, grid generated friction (Caviedes-Voullième et al, 2012). In this study, model results are analysed for two situations, namely: one in which an equal main channel roughness is used for each grid (Section 2.4.1) and one in which each grid has its own calibrated main channel friction (Section 2.4.3). For the later situation, the grids are calibrated using hourly measured water levels at Pannerdensche Kop (PK) and Nijmegenhaven (NH) (Fig. 2.3). To perform the calibration, the open source software OpenDA is used (http://www.openda.org/). With this software, it is possible to select the input parameters that have to be adjusted, such that the desired output is established. The model domain is divided into two trajectories (Fig. 2.2) in which the main channel friction expressed in Nikuradse roughness coefficient is calibrated such that each trajectory influences a single measurement location (i.e. PK or NH). The Nikuradse roughness coefficient can be transformed into a Chézy coefficient with the use of the White-Colebrook formula:

$$
C_{\mathrm{z}}=18 \times{ }^{10} \log \left(\frac{12 R}{N_{\mathrm{k}}}\right)
$$

where $C_{z}$ represents the Chézy coefficient $\left[\mathrm{m}^{1 / 2} / \mathrm{s}\right], R$ the hydraulic radius $[\mathrm{m}]$ which can be computed by dividing the cross-sectional area by the wetted perimeter, and $N_{k}$ represents the Nikuradse roughness coefficient [m]. This equation shows that a constant Nikuradse roughness value results in different Chézy coefficients depending on the bathymetry (hydraulic radius) of the river and the local water depth. With the use of the White-Colebrook equation and a constant Nikuradse roughness value, the effect of channel bathymetry and water depth on friction is included, whereas a constant Chézy coefficient would neglect these dependencies. For this reason, Nikuradse roughness values and the White-Colebrook 


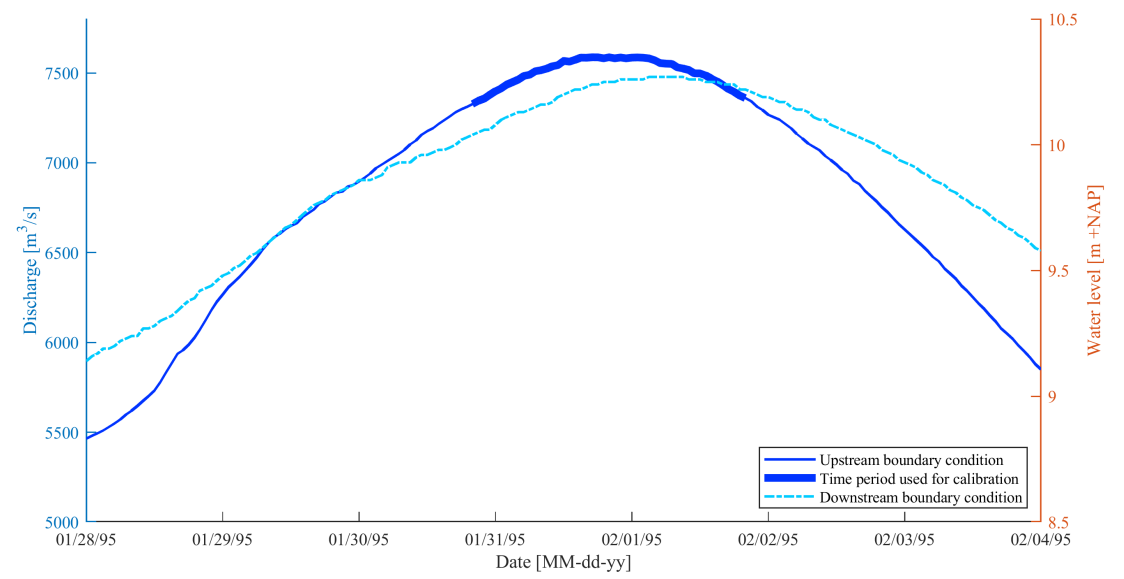

Figure 2.3

Discharge wave of the Waal river (upstream boundary condition), time period used for calibration of which hourly measured water levels are available, and water levels at Tiel (downstream boundary condition) during the 1995 flood event.

formula (Equation 2.5) are used to express the main channel friction in this study.

Calibration is performed on the three days with highest measured water levels (Fig. 2.3), since the main purpose of the calibration procedure is to ensure that the model is capable of predicting correct maximum water levels. The OpenDA procedure provides a main channel friction of the two trajectories such that the specified water levels at PK and NH are simulated with a Root Mean Square Error $($ RMSE $)<0.001$. Values of the calibrated friction parameters are given in Section 2.4.3.

\subsection{Grid properties}

In order to study the consequences of different grid shapes (fully structured, fully unstructured, hybrid) and different sizes (fine, coarse), we constructed six grids. Two structured grids, two unstructured grids and two hybrid grids with different resolutions are considered. With this spectrum of grids, we sufficiently cover the wide range of possible grid structures for hydraulic modelling.

Both structured and unstructured grids are commonly used in literature for hydraulic modelling. However, a major disadvantage of structured grids is that the 


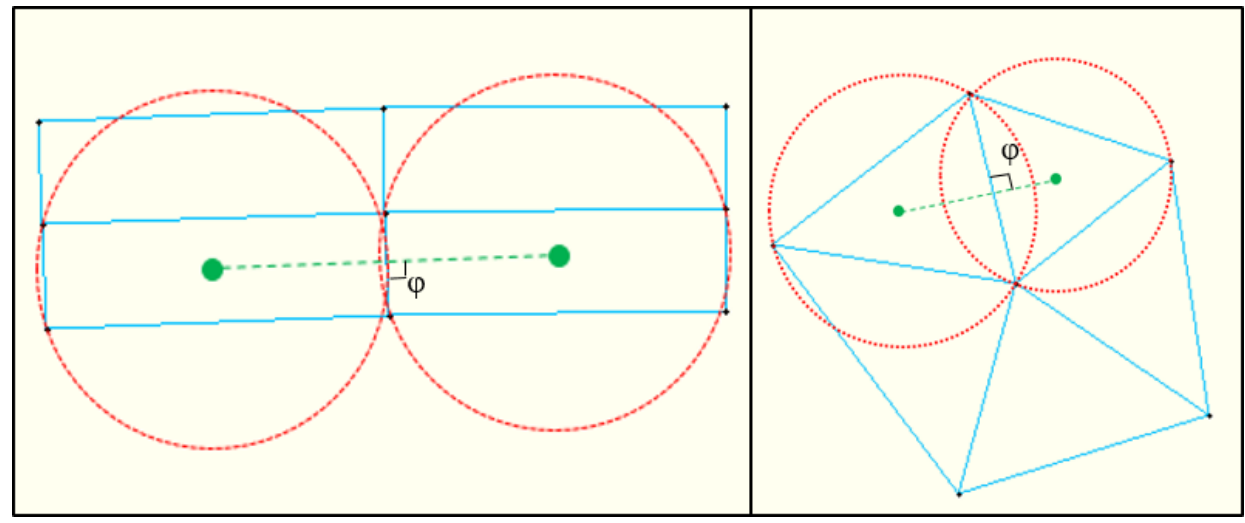

Figure 2.4

Example of the orthogonality principle for a structured and an unstructured grid where the grid boundaries represent the netlinks and the green dashed lines the flowlinks.

size of the grid cells of the main channel determines the resolution of the floodplains, whereas with unstructured triangular grids it is not possible to stretch the grid cells in flow direction while grid stretching in flow direction can reduce computation time. Therefore, also two hybrid grids are constructed with curvilinear grid cells in the main channel in combination with triangular grid cells in the floodplains to combine the advantages of a structured and an unstructured grid.

For computational efficiency, we use orthogonal grids such that the pressure gradients only depend on two pressure points, which reduces computation time and results in higher model accuracy. The orthogonality principle imposes the following criteria (Verwey et al, 2011). Firstly, the corners of two adjacent grid cells are situated on a common circle (Fig. 2.4: red dashed circles). Secondly, the line segment that connects the circumcenter of two adjacent cells (Flowlink, Fig. 2.4: dashed green line) intersect orthogonally with the interface between them (Netlink) (Kernkamp et al, 2011). For triangles, the location of the circumcenter is unique while for curvilinear grid cells there is some freedom in choosing the location of the circumcenter. Orthogonality is defined as the sine of the angle $\varphi$ between a flowlink and a netlink (Fig. 2.4). Perfect orthogonality is reached if this angle is equal to $90^{\circ}$ (resulting in an orthogonality equal to 1 ). We strive to have an angle $\varphi$ between $82^{\circ}$ and $98^{\circ}$ for all flowlink and netlink intersections, during the construction of the six numerical grids. For more information about the orthogonalisation principle and examples of (non-) orthogonal grids we refer to Kernkamp et al (2011). 
Table 2.1

Grid properties in which MC stands for main channel, Fl for floodplain, Curvi for curvilinear, Triang for triangular, and $\mathrm{min} / \mathrm{avg} / \mathrm{max}$ for minimum, average and maximum respectively.

\begin{tabular}{l|lcccc}
\hline Name & Grid shape & $\begin{array}{c}\text { Number of } \\
\text { grid cells } \\
\text { in MC }\end{array}$ & $\begin{array}{c}\text { Number of } \\
\text { elements/nodes }\end{array}$ & $\begin{array}{c}\text { min/avg/max } \\
\text { cell size }\end{array}$ & $\begin{array}{c}\text { min/avg/max) } \\
\text { cell edge length }\end{array}$ \\
\hline Stru_HR & Curvi & 12 & $75,848 / 77,755$ & $257 / 874 / 2066$ & $12 / 30 / 58$ \\
\hline Stru_LR & Curvi & 6 & $18,499 / 19,434$ & $1062 / 3484 / 7585$ & $24 / 60 / 114$ \\
Unstr_HR & Triang & 10 & $50,739 / 26,193$ & $265 / 1362 / 5241$ & $19 / 55 / 145$ \\
Unstr_LR & Triang & 5 & $11,885 / 6,351$ & $158 / 5667 / 18609$ & $13 / 113 / 228$ \\
Hybr_HR & $\begin{array}{l}\text { Curvi in MC } \\
\text { Triang in FI }\end{array}$ & 16 & $16,114 / 11,829$ & $186 / 4179 / 18609$ & $9 / 89 / 228$ \\
Hybr_LR & $\begin{array}{l}\text { Curvi in MC } \\
\text { Triang in FI }\end{array}$ & 8 & $12,747 / 8,458$ & $186 / 5284 / 18609$ & $13 / 101 / 228$ \\
\hline \hline
\end{tabular}

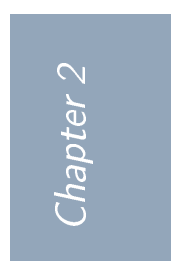

The following six grids are included in the analysis (Fig. 2.5 and Table 2.1):

1. Structured curvilinear high resolution (Stru_HR) grid: The model domain is discretized by structured curvilinear cells aligned with the flow direction. The resolution in the main channel equals approximately 12 grid cells in transverse flow direction such that the bathymetry of the cross section is well captured by the grid. The curvilinear grid cells allow cell stretching along the river main channel such that the length of the grid cell in flow direction is larger than the width of the grid cell in transverse flow direction. This cell stretching is beneficial for computation time. However, as a result of the high resolution in the main channel, also the resolution of the floodplains is high especially in sharp inner bends where grid lines are focused. To avoid that grid cell resolution in sharp inner bends go to zero, the resultant curvilinear grid has less sharp bends than the river course (Fig. 2.6). For this reason, the structured grid is capable of following the main channel course in straight and slightly meandering river sections. However, it is not capable of following the river course in highly meandering sections with wide floodplains.

2. Structured curvilinear low resolution (Stru_LR) grid: The width and length of the grid cells of the Stru_HR grid are decreased with a factor two. This results in a resolution of six grid cells in the main channel in transverse direction.

3. Unstructured triangular high resolution (Unstr_HR) grid: The model domain is discretized by triangles. The size of the triangles is adjusted such that approximately 10 grid cells are present in the cross section of the main channel. The resolution of the triangles in the floodplains are identical to 
the triangles in the main channel. Commonly, unstructured grids are constructed by randomly filling the model domain with triangular grid cells. In this study, firstly the main channel is discretized by triangles, where after the floodplains are discretized. The netlinks located at the boundary of the unstructured grid in the main channel (representing the grid boundary) are used to construct the unstructured grid in the floodplains, such that each triangular grid cell in the main channel is connected to a single triangular grid cell in the floodplains. This process is referred to as alignment with flow direction, resulting in a grid which is structurally well-oriented with the main channel course throughout the model domain. Unstructured grids do not have the problem of high resolution in sharp inner bends as is the case for the Stru_HR and Stru_LR grids. However, the high resolution of the triangular grid in the main channel still results in a high resolution in the floodplains.

4. Unstructured triangular low resolution (Unstr_LR) grid: The resolution of the Unstr_HR grid is decreased with a factor two in both the main channel as the floodplains. The same method as for the Unstr_HR grid is used to ensure alignment with flow direction. A disadvantage of this grid is that the relatively low resolution in the floodplains results in a low resolution in the main channel of approximately five cells in transverse flow direction.

5. Hybrid high resolution (Hybr_HR) grid: This grid is a mixture of the Stru_HR and Unstru_LR grids. The grid has 16 curvilinear grid cells in the transverse direction of the main channel aligned with the flow direction. The floodplains are discretized by triangles in which the size of the triangles is adjusted to the length of the curvilinear grid cells such that each triangular grid cell at the main channel-floodplain boundary is connected with a single curvilinear grid cell. The netlinks located at the boundary of the curvilinear grid are used to construct the triangular grid of the floodplains. This grid combines the advantages of high resolution in transverse flow direction in the main channel of the Stru_HR grid and the low resolution in the floodplains of the Unstr_LR grid.

6. Hybrid low resolution (Hybr_LR) grid: This grid is almost identical to the Hybr_HR grid. Only the width of the curvilinear grid cells is increased with a factor two, resulting in eight grid cells in the transverse direction of the main channel. The triangular grid in the floodplains is identical to the triangular grid of the Hybr_HR and Unstr_LR grids. 


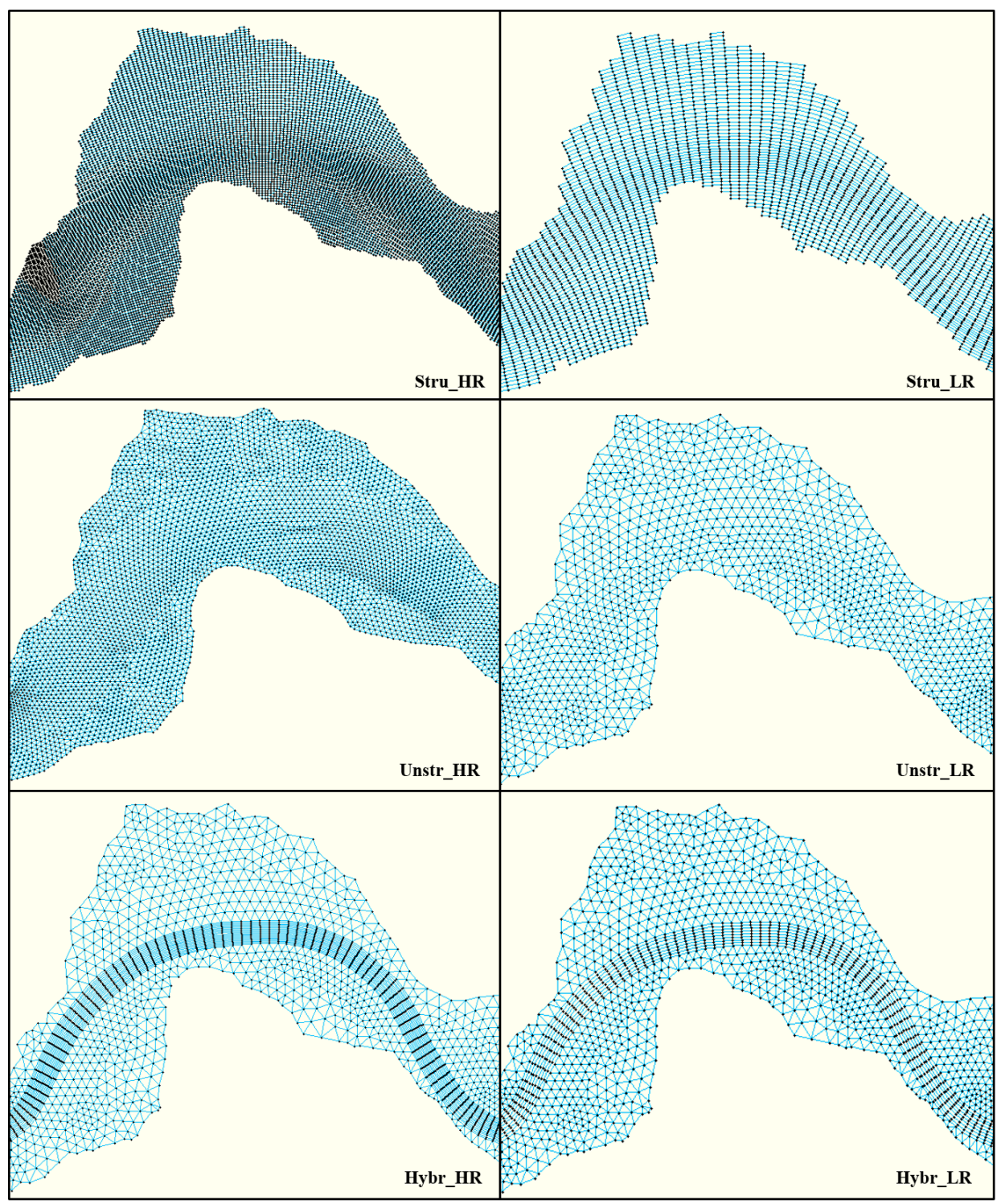

Figure 2.5

The six grids considered in this study. 


\subsection{Results}

In this section, the model results of the six grids presented in Section 2.3 are analysed. Firstly, model results with an equal main channel friction for the six grids are given (Section 2.4.1) to show the differences in simulated water levels solely caused by the use of different grid types. Then, the model performance after calibration and the effects of grid size and grid shape on calibrated main channel friction values are presented (Section 2.4.2 and Section 2.4.3, respectively). In Section 2.4.4 the depth-averaged velocities in a sharp meander bend are presented.

\subsubsection{Equal main channel friction}

The Stru_HR grid, having the highest resolution, was calibrated following the procedure described in Section 2.2.3, resulting in simulated water levels close to measurements (maximum deviation of $1 \mathrm{~cm}$ ). The calibrated main channel friction values in trajectories 1 and 2 (Fig. 2.2) are used to simulate the 1995 flood event with the remaining five grids. In this way, six simulations are performed in which the settings are kept constant. Only the grid is different.

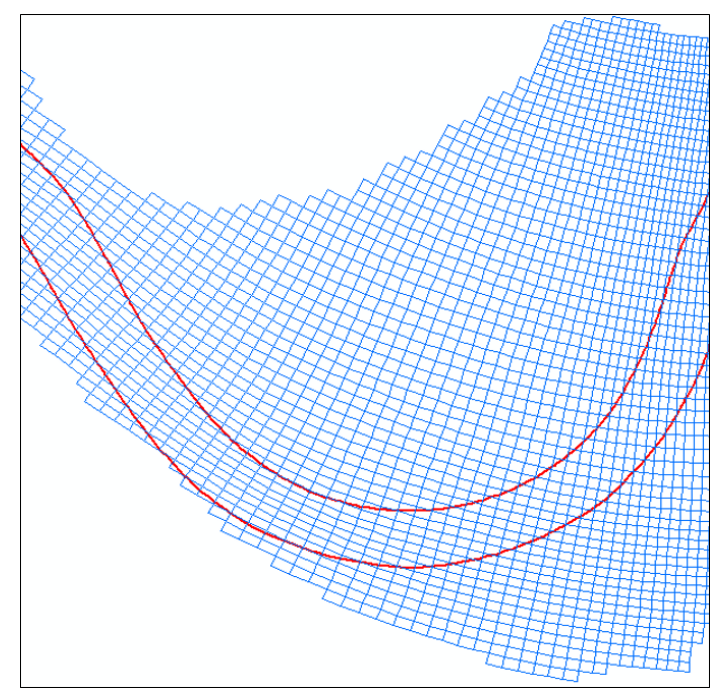

Figure 2.6

Part of the Stru_LR grid in a meander bend. In this part of the river, the curvilinear grid cells of the structured grid do not follow the course of the main river (red line), since this will result in grid cell sizes close to zero in meander bends with large floodplains. 


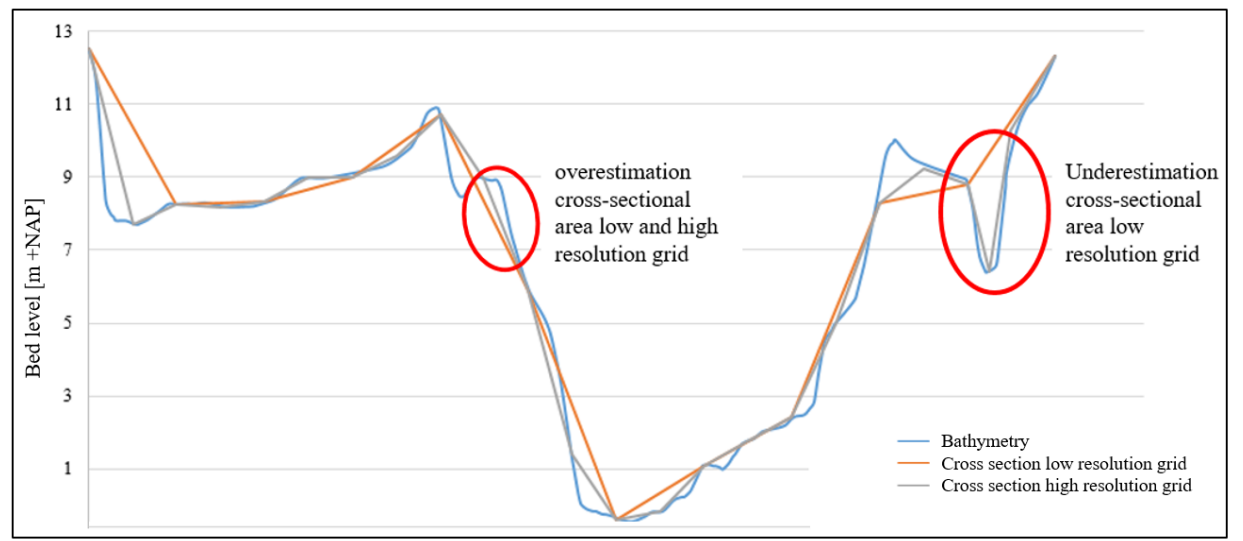

Figure 2.7

Representation of the bathymetry of the river (main channel and floodplains) and corresponding representations of a high resolution and a low resolution grid.

The six model runs resulted in a discharge exceeding the bank full-discharge of the main channel throughout the model domain. Hence, the floodplains discharged water during the entire simulations. In the upstream part of the model domain, where floodplains are wide, the discharge in the main channel and in the floodplains is more or less equal, while in the downstream part, where floodplains are much smaller, approximately $75 \%$ of the total discharge flows in the main channel. Although the general flood patterns are more or less identical predicted by the six grids, the simulated maximum water levels differ significantly (Table 2.2 and 2.3). In general, there are three factors related to the grid properties that influence the simulated water levels:

- Bathymetry accuracy caused by grid resolution: The resolutions of the grids determine how well the bathymetry of the river cross section is captured by the model based on an input DEM. A high resolution results in a good representation of the bathymetry, while a low resolution results in a strongly schematized bathymetry. A strongly schematized river cross section may result in an underestimation or an overestimation of the cross-sectional area of the river and hence its discharge capacity. This depends on the bathymetry of the river cross section and the location of the grid edges (Fig. 2.7). As a result of these overestimations and underestimations of the cross-sectional area, water levels are underestimated or overestimated respectively.

- Numerical friction caused by grid resolution: Caviedes-Voullième et al (2012) and Schubert et al (2008) found that, as a grid is coarsened, numerical friction increases. Grid coarsening has the same effect on model results 
as increasing the bed friction. A coarser grid results in dampening of the discharge wave and in a delay of the peak flow. Furthermore, simulated water levels increase. These consequences as a result of grid coarsening is referred to as numerical friction.

- Numerical viscosity created by grid shape: Caviedes-Voullième et al (2012) discuss that grids that follow the direction of the flow (i.e. that have grid edges perpendicular and parallel to the flow direction) have lower numerical viscosity compared to grids that do not follow the river course. Also numerical viscosity has the same effect on model results as increasing the bed friction. Numerical viscosity thus also results in attenuation of the discharge wave and in an increase in the simulated water levels.

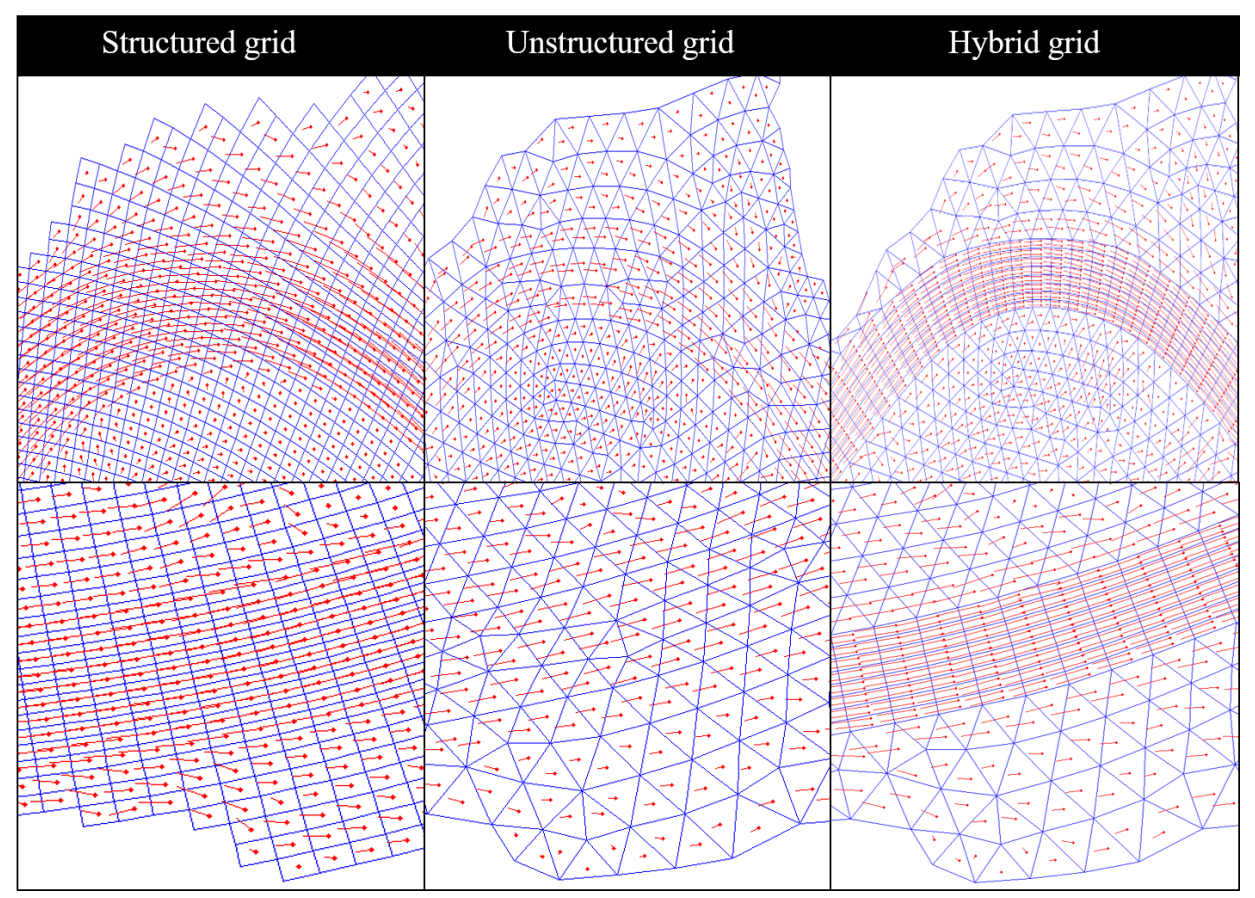

Figure 2.8

Flow directions of structured, unstructured and hybrid grids in a meander bend and straight river

Comparing the water levels generated by the six grids (Table 2.2 and 2.3), we find that the low resolution variants of each grid type predict higher water levels compared to the high resolution variants, throughout the model domain. As a grid is coarsened, numerical friction increases and hence water levels increase. 
Predicted maximum water levels (Max WL) at PK and discharge partitioning (Q) at CS1 (Fig. 2.2) with constant main channel friction among the six grids.

\begin{tabular}{l|ccc}
\hline \hline Grid & Max WL $[\mathrm{m}+\mathrm{NAP}]$ & $\mathrm{Q}$ main channel $\left[\mathrm{m}^{3} / \mathrm{s}\right]$ & $\mathrm{Q}$ floodplains $\left[\mathrm{m}^{3} / \mathrm{s}\right]$ \\
\hline Stru_HR & 15.84 & 3,851 & 3,733 \\
\hline Stru_LR & 16.13 & 4,092 & 3,492 \\
Unstr_HR & 15.35 & 3,593 & 3,989 \\
Unstr_LR & 15.48 & 3,471 & 4,111 \\
Hybr_HR & 15.50 & 3,722 & 3,860 \\
Hybr_LR & 15.71 & 3,700 & 3,882 \\
\hline \hline
\end{tabular}

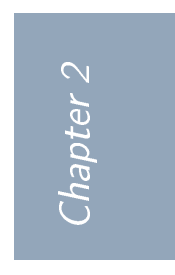

Moreover, we find that the structured grids predict higher water levels at PK and the unstructured grids at NH. This is a result of the numerical viscosity created by grid shape. The upstream part of the model domain has large meander bends. As explained in Section 2.3 and Fig. 2.6, the curvilinear structured grids are not capable of following these meanders and hence the flow direction differs from the course of the grids (Fig. 2.8). This results in an increase in the numerical viscosity and consequently in an increase in the water levels compared to a grid which is capable of following the river course. The unstructured grids and the hybrids grids are better oriented with the flow direction in the upstream part of the model domain (Fig. 2.8), resulting in lower numerical viscosity compared to the structured grids and thus to lower simulated water levels at PK. Contrarily, in the downstream part of the model domain, the river has a relatively straight course without great meander bends. For this reason, the curvilinear grid cells of the structured and hybrid grids are capable of following the course of the river (Fig. 2.8), resulting in low numerical viscosity. Although the unstructured grids are structurally well-oriented with the flow direction, triangular grid cells do not have grid edges perpendicular and parallel to the flow direction like the curvilinear grid cells of the structured and hybrid grids (Fig. 2.8). Therefore, the unstructured grids have higher numerical viscosity in the downstream part of the model domain, resulting in higher water levels at $\mathrm{NH}$ compared to the other grid types.

Comparing the simulated maximum water levels and discharge partitioning in the main channel and in the floodplains of the six grids (Table 2.2 and 2.3), we find that the grid that predicts highest water levels as a result of numerical viscosity (structured grids in upstream part and unstructured grids in downstream part of the Waal river), also predicts the highest discharge in the main channel. We would expect a similar trend for numerical friction: an increase in numerical friction results in an increase in the simulated water levels and to an increase in the discharge of the main channel. This trend between high and low resolution grids is not present (i.e. the low resolution grid with high numerical friction does not necessarily result in an increase in the discharge in the main channel). This 
Predicted maximum water levels (Max WL) at NH and discharge partitioning (Q) at CS2 (Fig. 2.2) with constant main channel friction among the six grids.

\begin{tabular}{l|ccc}
\hline \hline Grid & Max WL $[\mathrm{m}+\mathrm{NAP}]$ & $\mathrm{Q}$ main channel $\left[\mathrm{m}^{3} / \mathrm{s}\right]$ & $\mathrm{Q}$ floodplains $\left[\mathrm{m}^{3} / \mathrm{s}\right]$ \\
\hline Stru_HR & 13.53 & 5,564 & 2,018 \\
\hline Stru_LR & 13.65 & 5,427 & 2,156 \\
Unstr_HR & 13.67 & 5,501 & 2,079 \\
Unstr_LR & 13.87 & 5,853 & 1,727 \\
Hybr_HR & 13.62 & 5,515 & 2,065 \\
Hybr_LR & 13.65 & 5,476 & 2,104 \\
\hline \hline
\end{tabular}

trend is not present since also bathymetry accuracy influences the discharge capacity of the main channel. An underestimation of the cross-sectional area of the main channel caused by a low resolution grid may result in an underestimation of the main channels discharge capacity. Also the opposite may hold, in which an overestimation of the cross-sectional area may result in an overestimation of the discharge capacity.

In general, we find that the use of different grid shapes and grid sizes has a larger effect in river sections where floodplains are wide compared to sections where floodplains are much smaller. Comparing the differences in predicted water levels by the six grids in the upstream part $(\mathrm{PK})$ and downstream part $(\mathrm{NH})$, shows that the range of maximum water levels is much larger at PK than at NH. The maximum water levels at $\mathrm{PK}$ have a range of $0.65 \mathrm{~m}$, while the range at $\mathrm{NH}$ is just $0.34 \mathrm{~m}$. This larger range in the upstream part of the Waal river is also found for the discharge partitioning. At CS2, where floodplains are small, the maximum deviation in discharge in the main channel equals $426 \mathrm{~m}^{3} / \mathrm{s}$, while the deviation in the discharge in the main channel at CS1 equals approximately $620 \mathrm{~m}^{3} / \mathrm{s}$.

\subsubsection{Model performance after calibration}

For this case, the six grids were calibrated on two separate trajectories, following the procedure described in Section 2.2.3. The model results after calibration are compared based on model accuracy and computation time. No significant difference in accuracy among the different models was found, since the RMSE criteria (RMSE $<0.001$, see Section 2.2.3) was met for all models at both measurement locations. We found that the six calibrated models are capable of simulating maximum water levels at both $\mathrm{PK}$ and $\mathrm{NH}$, which were used during the calibration procedure, with a maximum deviation of one centimeter compared to measurements. Since the water depth at PK and NH during the 1995 flood event was 
Computation time $(T)$, average time step $(\Delta t)$ and calibrated Nikuradse main channel roughness height $\left(N_{k}\right)$. Traject. 1 indicates the upstream part of the model domain and Traject. 2 the downstream part. The Stru_HR grid is used as reference (ref).

\begin{tabular}{l|ccccccc}
\hline \hline Grid & $\begin{array}{c}\mathrm{T} \\
{[\mathrm{h}: \mathrm{min}: \mathrm{sec}]}\end{array}$ & $\mathrm{T} /$ Tref & $\Delta \mathrm{t}[\mathrm{s}]$ & $\begin{array}{c}\mathrm{N}_{\mathrm{k}}[\mathrm{m}] \\
\text { Traject. 1 }\end{array}$ & $\begin{array}{c}\text { N/Nref } \\
\text { Traject. 1 }\end{array}$ & $\begin{array}{c}\mathrm{N}_{\mathrm{k}}[\mathrm{m}] \\
\text { Traject. 2 }\end{array}$ & $\begin{array}{c}\text { N/Nref } \\
\text { Traject. 2 }\end{array}$ \\
\hline Stru_HR & $1: 51: 44$ & & 5.5 & 1.66 & & 0.85 & \\
\hline Stru_LR & $0: 09: 47$ & 0.09 & 14.6 & 0.63 & 0.38 & 0.65 & 0.76 \\
Unstr_HR & $1: 29: 22$ & 0.80 & 3.7 & 5.44 & 3.28 & 0.53 & 0.62 \\
Unstr_LR & $0: 29: 22$ & 0.26 & 1.9 & 4.92 & 2.96 & 0.29 & 0.34 \\
Hybr_HR & $0: 14: 03$ & 0.13 & 6.9 & 3.67 & 2.21 & 0.70 & 0.82 \\
Hybr_LR & $0: 13: 02$ & 0.12 & 5.7 & 2.85 & 1.72 & 0.60 & 0.71 \\
\hline \hline
\end{tabular}

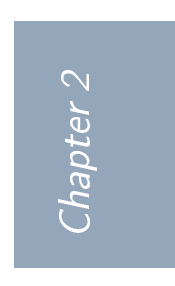

larger than $10 \mathrm{~m}$ at both measurement stations, a deviation of $1 \mathrm{~cm}$ is assumed to be acceptable.

Although the models predicted almost the same maximum water levels, the computation times of the six models differ in the order of hours to minutes (Table 2.4). Especially the computation time of the Stru_HR grid is much higher compared to the other grids because of the large number of grid cells (Table 2.1). Surprisingly, the computation time of the Hybr_LR and Hybr_HR grids are lower than that of the Unstr_LR grid, although the hybrid grids have more grid cells. This can be explained by the curvilinear grid cells in the main channel of the hybrid grids which are aligned with the flow direction. Since the curvilinear grid cells are aligned with the flow direction, the cell edge parallel to the flow is larger than the cell edge perpendicular to the flow. This alignment in flow direction of the curvilinear grid cells in the main channel of the hybrid grids results in a larger $\Delta x$ in flow direction compared to the triangular grid cells of the unstructured grid. This larger $\Delta x$ results in a larger time step $\Delta t$ (Equation 2.4). We can thus conclude that as a result of the curvilinear grid cells in the main channel, the computation of the hybrid grids is more stable (larger time steps for the same Courant numbers) compared to the unstructured grids, resulting in an increase in the average time step. We can therefore state that the differences in average time step as a result of the maximum Courant number (0.95, Section 2.2.2), determines the differences in computation time of the six models.

\subsubsection{Effects of grid size and structure on calibration}

Section 2.4.1 showed that different water levels are simulated by the six different grid types if the same main channel friction values are used. These differences in 
water levels are caused by the three factors (1) bathymetry accuracy, (2) numerical friction and (3) numerical viscosity. During the calibration procedure, the main channel friction values are calibrated such that the total friction of the model (representing the physical friction and the numerical friction generated by grid size and grid shape) is accurately captured, resulting in accurately simulated water levels (Section 2.4.2). Since the structured grids have high numerical viscosity in meandering parts of the river, the calibrated main channel friction is low in the upstream part of the river. Contrarily, in the downstream part of the model domain, where the river is quite straight, the unstructured grids have higher numerical viscosity compared to the structured and hybrid grids. Therefore, the unstructured grids have low calibrated main channel friction values in straight parts of a river course. Moreover, we find that for each grid type lower main channel friction values are calibrated for the low resolution variants compared to the high resolution grids throughout the model domain. A decrease in resolution results in an increase in the numerical friction and hence in a decrease of the computed main channel friction.

Although the flood propagation of the six models shows a similar pattern (i.e. timing of maximum discharge, Fig. 2.9), the predicted discharge in the main channel and floodplains differ significantly at CS1 (Table 2.5 and Fig. 2.9). We find that the differences in discharge partitioning is larger if calibrated main channel friction values are used compared to the situation in which an equal main channel friction was used (Section 2.4.1). Section 2.4.1 showed that the Unstr_LR grid simulated maximum water levels at PK which were approximately $30 \mathrm{~cm}$ higher than measurements. Therefore, a low main channel friction was computed during the calibration, which increases the discharge capacity of the main channel. The opposite accounts for the unstructured and hybrid grids which simulated water levels lower than measurements. Therefore, the main channel friction was increased during the calibration which decreases the capacity of the main channel. Consequently, the discharge in the floodplains increases.

We can thus state that the model calibration influences the discharge capacity of the main channel and hence the discharge partitioning between the main channel and floodplains during flood events. This specifically applies for river sections with wide floodplains. In the downstream part of the Waal river, where floodplains are small, the calibration procedure did not result in large changes in the main channel friction of the six grids since no large differences in predicted water levels by the six grids was observed if an equal main channel friction was used (Table 2.3). Hence, there is also no large change in the discharge partitioning between the main channel and the floodplains. 


\section{Table 2.5}

Predicted discharge partitioning (Q) at CS1 and CS2 (Fig. 2.2) with calibrated main channel friction for each grid.

\begin{tabular}{l|cccc}
\hline \hline Grid & $\begin{array}{c}\text { Q main channel } \\
{\left[\mathrm{m}^{3} / \mathrm{s}\right] \mathrm{CS} 1}\end{array}$ & $\begin{array}{c}\text { Q floodplains } \\
{\left[\mathrm{m}^{3} / \mathrm{s}\right] \mathrm{CS} 1}\end{array}$ & $\begin{array}{c}\text { Q main channel } \\
{\left[\mathrm{m}^{3} / \mathrm{s}\right] \mathrm{CS} 2}\end{array}$ & $\begin{array}{c}\text { Q floodplains } \\
{\left[\mathrm{m}^{3} / \mathrm{s}\right] \mathrm{CS} 2}\end{array}$ \\
\hline Stru_HR & 3,851 & 3,733 & 5,564 & 2,018 \\
\hline Stru_LR & 4,475 & 3,108 & 5,455 & 2,127 \\
Unstr_HR & 3,050 & 4,533 & 5,544 & 2,037 \\
Unstr_LR & 3,014 & 4,569 & 5,890 & 1,691 \\
Hybr_HR & 3,263 & 4,319 & 5,554 & 2,026 \\
Hybr_LR & 3,456 & 4,127 & 5,519 & 2,061 \\
\hline \hline
\end{tabular}

From the analysis, we find that unstructured grids tend to be most sensitive to the three factors influencing predicted water level and consequently calibrated main channel friction, since the range of calibrated main channel friction along the two trajectories of the Waal river is relatively wide (Nikuradse roughness height of between 0.29-5.44 $\mathrm{m}$ (Table 2.4)) compared to the ranges of the other grid types. The structured curvilinear grids tend to be less sensitive to the factors (Nikuradse roughness height of between 0.63-1.66 m (Table 2.4)). The hybrid grids combine the effects of the structured and unstructured grids. This explains why
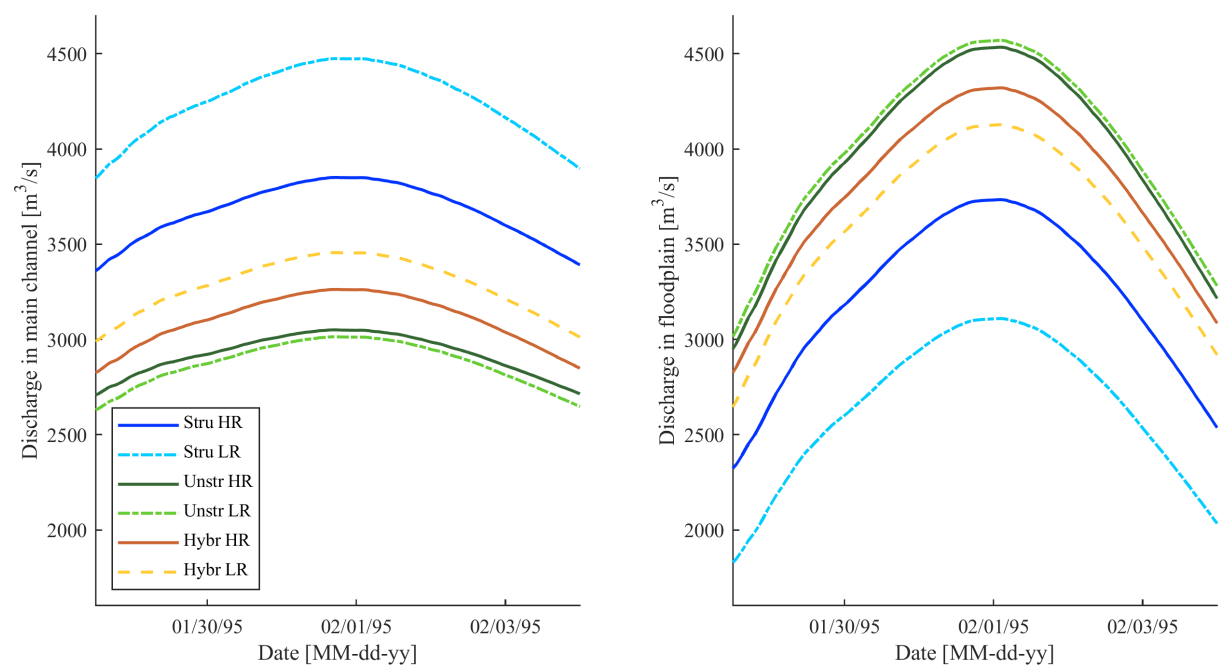

\section{Figure 2.9}

Discharges in the main channel and floodplains at location CS1 (Fig. 2.2). 
the calibrated friction values of the hybrid grid falls within the calibrated range of the two other grid types (Nikuradse roughness height of between 0.60-4.92 m (Table 2.4)).

In Section 2.4.2, we found that all grids were capable of predicting maximum water levels of the 1995 flood event with a maximum deviation of $1 \mathrm{~cm}$ compared to measurements. However, the question arises whether the unstructured grids, with large calibrated main channel friction in the meandering part of the river, are also capable to predict water levels at other discharge stages accurately. It is likely that the unstructured grids do not accurately predict water levels during low flow in meandering rivers as a result of the high calibrated friction in the main channel. During low flow, water only flows in the main channel. Consequently, the calibrated main channel friction has a larger influence on the simulated water levels compared to high flow situations, in which also the floodplains discharge water. Since water was flowing in the floodplains during the entire simulations presented in this study, the high calibrated main channel friction in the meandering part of the river of the unstructured grids will most likely result in an overestimation of the simulated water levels during low flow. Therefore, calibration at different discharge stages is recommended, resulting in a main channel friction-discharge relation which can be used to perform hydraulic computations accurately.

\subsubsection{Velocity magnitudes}

Although the six grids were capable of predicting maximum water levels with high accuracy after calibration, it is unknown to what extent the physical processes are well captured by the calibrated models. Simulated water levels are commonly used to validate the model performance. However, the model should also correctly simulate flow velocities based on physical processes that are generated by the geometry. This is important if the hydraulic model is coupled to e.g. prediction of morphodynamic changes of the river or vegetation development in the floodplains. To study this, depth-averaged flow velocities (at maximum water levels) in the meander bend near measurement station NH and near CS2 (Fig. 2.2) are qualitatively compared with experimental data provided in literature. Table 2.6 summarizes the results.

From literature it is known that high flow velocities occur near the outer bend, while flow velocities are lower in the inner bend (Bridge (2003); Ikeda et al (1981)). Sukhodolov (2012) measured depth-averaged flow velocities in a meander bend and found that the flow pattern at the entrance of the bend is more or less symmetrical while close to the bend apex, the flow gradually becomes asymmetric with maximum velocities close to the outer bank (Sukhodolov, 2012). The measurements show that at the bend apex the flow remains attached to the outer bank and downstream from the apex a narrow region of flow stagnation develops along 
Main properties of the six grids, in which $\mathrm{V}_{\max }$ represents the maximum depth-averaged velocity.

\begin{tabular}{l|cc}
\hline \hline Grid & $V_{\max }[\mathrm{m} / \mathrm{s}]$ & Physical processes captured? \\
\hline Stru_HR & 2.34 & Yes \\
\hline Stru_LR & 2.34 & No \\
Unstr_HR & 2.68 & Yes \\
Unstr_LR & 2.48 & No \\
Hybr_HR & 3.05 & No \\
Hybr_LR & 2.63 & Yes \\
\hline \hline
\end{tabular}

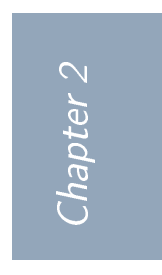

the outer bank (Sukhodolov, 2012).

Fig. 2.10 shows that the general pattern of high depth-averaged flow velocities (at maximum water levels) in the main channel and relatively low flow velocities in the floodplains is predicted by the different grid types. However, in more detail, several differences can be observed. Firstly, the high resolution grids result in higher maximum flow velocities compared to the low resolution grids, except for the structured grids where maximum flow velocities remain similar (Table 2.6). The low resolution grids have a lower calibrated main channel friction compared to the high resolution grids. Ignoring numerical friction and numerical viscosity generated by the grids itself, we would expect higher maximum flow velocities to occur for the low resolution grids, because of its low calibrated main channel friction values. Since this is not the case, we conclude that the lower maximum flow velocities of the low resolution grids are entirely a result of the numerical friction caused by grid resolution.

Sukhodolov (2012) shows in his measurements a gradual decrease in flow velocity from outer towards inner bend. Most grids tend to predict maximum flow velocities at the outer bend. Only the Stru_LR and Unstr_LR grids provide different results. Maximum flow velocities of the Stru_LR grid occurs at the middle part and inner bend of the meander which contradicts with the physical processes and with measurements given in Sukhodolov (2012). The Unstr_LR grid results in an even more unrealistic pattern of flow velocities caused by the low resolution in the main channel transverse direction (only 5 grid cells). This low resolution results in an extremely discretized bathymetry and hence the model is not capable of correctly predicting flow velocities. The Unstr_LR grid predicts high depth-averaged flow velocities (1.83-2.24 m/s) over the entire cross section of the main channel at location CS2 (bend apex). This results in a higher width and depth-averaged flow velocity compared to the other grid types. As a result, the discharge in the main channel at CS2 of the Unstr_LR is greater than those of the other grids (Table 2.5). Also the opposite occurs at several locations, where velocities in the main channel are underestimated and velocities in the floodplains are overestimated by 
the Unstr_LR grid (Fig. 2.11). Consequently, the Unstr_LR grid is not capable of correctly modelling the discharge partitioning between the main channel and the floodplains.

Moreover, we find that the high resolution in the transverse direction of the main channel of the Hybr_HR grid (16 grid cells, Table 2.1) results in flow separation in the meander bend (Fig. 2.10). A large part of the discharge wave flows towards the outer bend, while a part remains attached at the inner bend. This results in high velocities at the outer bend $(3.05 \mathrm{~m} / \mathrm{s})$ and the inner bend $(2.50 \mathrm{~m} / \mathrm{s})$, while

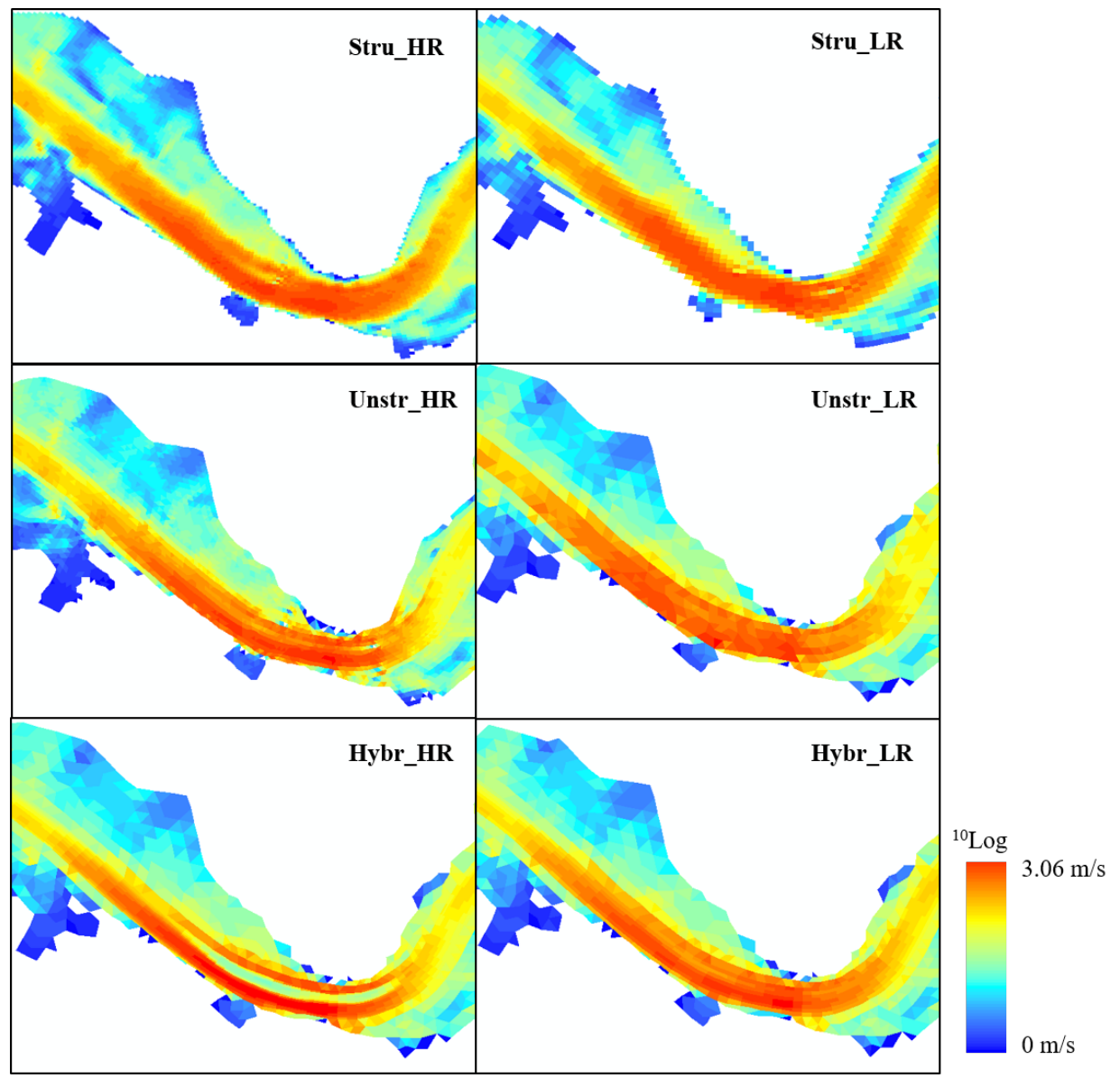

\section{Figure 2.10}

Depth-averaged flow velocities at the centers of the flow elements at the time of maximum water level plotted on a log-scale. 

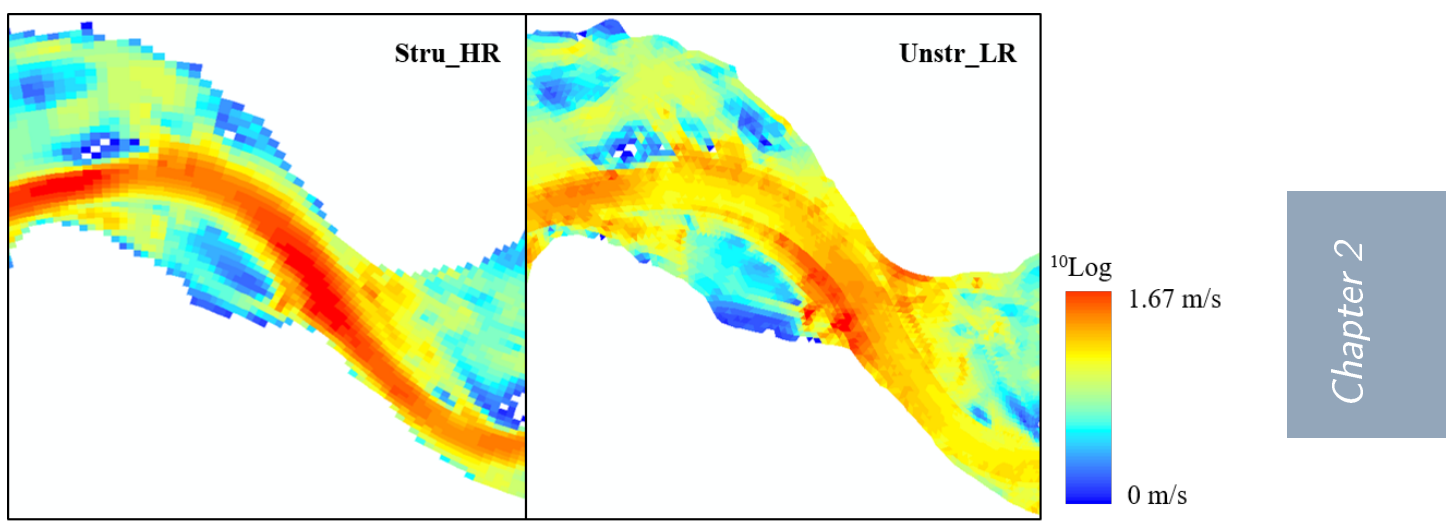

\section{Figure 2.11}

Depth-averaged flow velocities at the centers of the flow elements in a part of the river where the Unstr LR grid highly underestimates the flow velocities in the main channel and overestimates the flow velocities in the floodplains compared to the Stru HR grid which predicts the general flow velocity pattern accurately.

in the middle part of the main channel flow velocities are much lower $(0.68 \mathrm{~m} / \mathrm{s})$. The unrealistic flow pattern predicted by the Hybr_HR grid is most probably a result of the high width-length ratio of the curvilinear grid cells in the main channel. Generally, a maximum ratio of 1:5 is applied as a rule of thumb. The Hybr_HR grid has at some locations a much higher ratio up to 1:9. The high resolution in transverse direction of the main channel ensures that changes in flow characteristics in this transverse direction can be accurately captured by the model. However, since some grid cells have a length which is nine times greater than its width, the grid is most likely not capable of correctly modelling rapid flow changes in the direction of the flow, specifically in the case of sharp meandering bends.

From this analysis, we presume that two aspects are of high importance to correctly predict flow velocities in the main channel, and as a result the discharge partitioning between the main channel and the floodplains. These two aspects are: (1) the resolution in the main channel transverse direction, and (2) the width-length ratio of the curvilinear grid cells in the main channel. The cells of the Stru_LR grid and specifically for the Unstr_LR grid have sizes larger than the spatial scale of the physical processes, whereas the width-length ratio of the Hybr_HR grid is too large. Therefore, these three grids are not capable of correctly representing the depth-averaged flow velocity profiles in a meander bend. More research is recommended to verify these findings. 


\subsection{Conclusions}

In this paper, we studied the effect of grid shape and grid size on computation time and on model accuracy and we compared structured, unstructured and hybrid grids with each high and low resolutions. We found that all grids are capable of predicting accurate water levels with calibrated main channel friction values. However, a large range of calibrated main channel friction and computation time between the different grid types was found. We conclude that three factors influence simulated water levels and are thus important during the determination of the calibrated main channel friction, namely (1) bathymetry accuracy, and (2) numerical friction which are both caused by grid resolution, and (3) numerical viscosity which is caused by the grid shape. Low resolution grids are not able to correctly represent the cross-sectional area of the river as a result of low bathymetry accuracy. Consequently, the discharge capacity of the river is not correctly predicted. Furthermore, low resolution grids result in high numerical friction and hence in high simulated water levels. Moreover, it was found that grids that are well-aligned with the flow direction have low numerical viscosity. Numerical viscosity is predominant in meandering rivers, where the curvilinear grid cells of the structured grids were not capable of following the course of the main channel and hence the flow direction. In addition, it was found that the unstructured grids are most affected by the three factors since the range of calibrated main channel friction was larger for these grids than those of the hybrid and structured grids.

Furthermore, we can conclude that the pattern of depth-averaged flow velocities in a meander bend depends on the shape and size of the grid cells. If resolution in transverse direction of the main channel is too low, the physical processes are not accurately captured by the model. In addition, a too high width-length ratio of the curvilinear grid cells in the main channel results in unrealistic flow patterns in sharp bends.

Based on the model performance criteria (computation time, accurate prediction of maximum water levels and accurate simulation of flow velocities in meander bends), we recommend to use a hybrid grid with curvilinear grid cells in the main channel and triangles in the floodplains for hydraulic 2DH modelling, since it combines the advantages of both a structured and unstructured grid. With a hybrid grid, it is possible to have a high resolution grid in the main channel, resulting in good representation of the bathymetry. The resolution in the floodplains can be much lower as a result of the triangular grid cells, which is beneficial for computation time. However, we found that a high width-length ratio of the curvilinear grid cells in the main channel results in unrealistic flow velocity patterns. We therefore conclude that from the six grids studied, the Hybr_LR grid is most beneficial in terms of overall model performance. 


\section{Acknowledgements}

This research is supported by the Netherlands Organisation for Scientific Research (NWO, project 14506) which is partly funded by the Ministry of Economic Affairs and Climate Policy. Furthermore, the research is supported by the Ministry of Infrastructure and Water Management and Deltares. This research has benefited from cooperation within the network of the Netherlands Centre for River Studies.

The authors would like to thank the Dutch Ministry of Infrastructure for providing the data. Besides, the authors would like to thank Mrs. Becker and Mr. Van Dam from Deltares for their valuable insights. Finally, the authors would like to thank the two anonymous reviewers for their suggestions, which greatly improved the quality of the paper. 
64 Chapter 2 


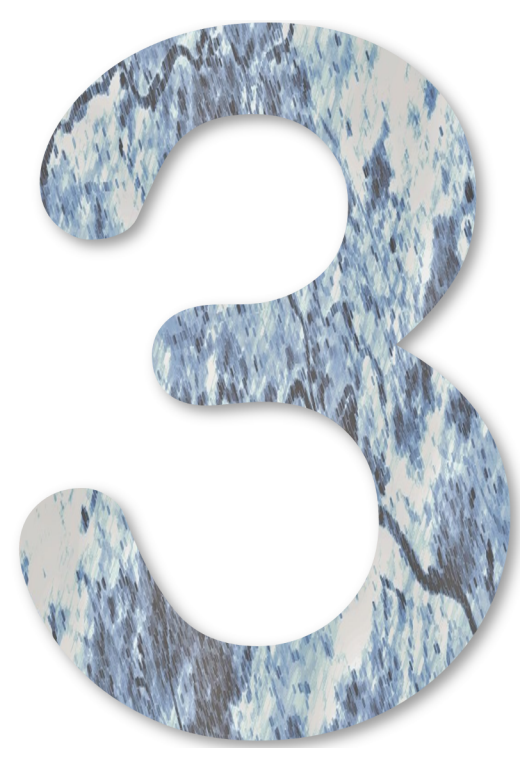

\section{Application of a lower-fidelity surrogate hydraulic model for historic flood recon- struction}

This chapter is published as A. Bomers, R.M.J. Schielen, and S.J.M.H. Hulscher (2019). Application of a lower-fidelity surrogate model for historic flood reconstruction, Environmental Modelling and Software, 117, 223-236. DOI:10.1016/j.envsoft.2019.03.019 


\section{Abstract}

Two dimensional hydraulic models are useful to reconstruct maximum discharges and uncertainties of historic flood events. Since many model runs are needed to include the effects of uncertain input parameters, a sophisticated 2D model is not applicable due to computational time. Therefore, this papers studies whether a lower-fidelity model can be used instead. The presented methodological framework shows that a 1D-2D coupled model is capable of simulating maximum discharges with high accuracy in only a fraction of the calculation time needed for the highfidelity model. Therefore, the lowerfidelity model is used to perform the sensitivity analysis. Multiple Linear Regression analysis and the computation of the Sobol' indices are used to apportion the model output variance to the most influential input parameters. We used the 1926 flood of the Rhine river as a case study and found that the roughness of grassland areas was by far the most influential parameter.

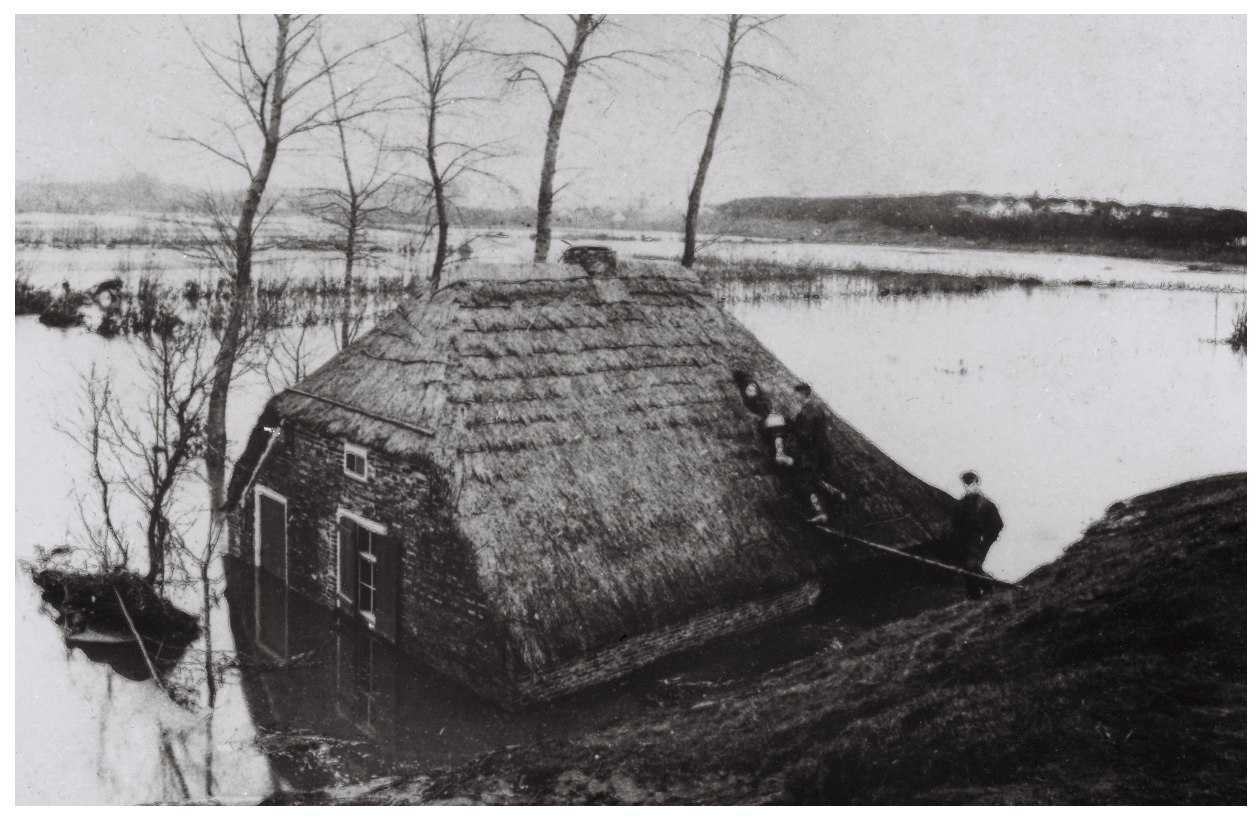

The 1926 flood event along the Waal river. Photo: https://beeldbank.rws.nl 


\subsection{Introduction}

Currently, the Dutch water policy is changing from a probability exceedance approach towards a risk based approach. In addition to the probabilities of floods due to multiple failure mechanisms, this new approach also considers the consequences of a flood. The risk based approach results in a significant increase in the safety levels in areas where the consequences are large (Dutch Ministry of Infrastructure and the Environment and Ministry of Economic Affairs, 2014). A maximum return period of 1,250 years was defined for the river areas in the probability exceedance approach, while the risk based approach has maximum return periods of 100,000 years. The prediction of design discharges corresponding to such rare events is highly uncertain. These predictions are most often based on relatively short data sets of measured weather conditions or discharges. Therefore, the data set does not include the natural phenomena characterised by a very low frequency (Barriendos et al, 2003).

The confidence interval of large design discharges can be reduced by extending the data set of measured discharges with historical and paleo data of extreme flood events (Neppel et al, 2010; Sheffer et al, 2003). Many studies have reconstructed historic floods to expand the data set of measured discharges (e.g Herget et al (2015); Herget and Meurs (2010); Llasat et al (2005); Neppel et al (2010); O'Connell et al (2002); Sheffer et al (2003); Toonen et al (2015); Zhou et al (2002)). Herget et al (2015) and Herget and Meurs (2010) reconstructed historic discharges in the city of Cologne, Germany, based on historical documents. They predicted mean flow velocities at the time of the historic flood events with the use of a reconstructed river channel and floodplain bathymetry. The empirical Manning's equation was used to estimate the historic discharges of a specific cross section near the city of Cologne. Neppel et al (2010) used hydraulic modelling of a reach of about two kilometres length to account for geomorphological changes. With this model, present and historic rating curves were constructed and applied to determine flood discharge series (Neppel et al, 2010). O'Connell et al (2002) used Bayesian statistics to create paleohydrologic bound data for flood frequency analysis. Paleohydrologic bound data represent stages and discharges that have not been exceeded since the geomorphic surface stabilized (O'Connell et al, 2002). These bounds are not actual floods, but are limits on flood stage over a measured time interval. O'Connell et al (2002) found that paleohydrologic bounds reduce the uncertainties of the flood distribution curve by placing large observed discharges in their proper long-term contexts. Toonen et al (2015) reconstructed Lower Rhine historical flood magnitudes of the last 450 years with the use of grain-size measurements of flood deposits at two separate research locations. They made use of linear regression plots between various grain-size descriptors and measured discharges to determine the discharges of the historic events. 
Above mentioned studies tried to gain insight in the maximum discharge of a historic flood. However, none of these studies used hydraulic models to describe maximum discharges and its uncertainties along a long stretch of a river including possible bifurcations during the historic events. However, the use of hydraulic models may decrease the confidence intervals of the predicted maximum discharges of the reconstructed flood events. Furthermore, hydraulic models provide insight in the flow patterns and inundation extents of the historic events. For these reasons, hydraulic models will be used for historic flood reconstructions in this study.

Hydraulic models require a reconstruction of the historical geometry as input data. In addition, they require proper boundary conditions to determine the flood wave propagation along the model domain. However, the data available to reconstruct historic flood events is limited. Measured discharges or water levels are generally not available. Also, the geometry of the river, its floodplains and the hinterland may be uncertain. This uncertainty is reflected in the uncertainty of the model input parameters, affecting the maximum discharges during a flood event. For this reason, a sensitivity analysis on the maximum discharge will be necessary to find the input parameter that mostly influences the model output. This analysis will also gain insight in the confidence interval of the reconstructed maximum discharge. This insight provides us with useful information for other historical geometry reconstructions, since parameter prioritization can be used during the reconstruction.

Commonly, sophisticated two dimensional (2D) hydraulic models (in this context also called a high-fidelity model, see Section 3.2.1) are used for hydraulic modelling. This is because they are capable of describing maximum discharges, flood extent and inundation patterns with high accuracy. However, they have the disadvantage that a single run of a discharge wave usually takes at least several hours. Since sensitivity analyses require many model runs, 2D models are not suitable for this purpose. To reduce computational time, a surrogate model will be set up. A lower-fidelity model is developed since this type of surrogate model does not lose many physical processes of the original system. Therefore, the objective of this paper is to study whether a lower-fidelity hydraulic model can be used for historic flood reconstructions.

Lower-fidelity surrogate modelling has just recently started to gain popularity in the water resources literature (Razavi et al, 2012b). The modelling approach has been applied to groundwater models to reduce model complexity for optimization and calibration purposes (e.g. Maschler and Savic (1999); McPhee and Yeh (2008); Ulanicki et al (1996)). It has also been applied in combination with the Monte Carlo framework for uncertainty analysis (e.g. Efendiev et al (2005); Keating et al (2010)). However, almost no studies have applied a lower-fidelity surrogate model for hydraulic modelling purposes. These models may have great benefits in this field since computational time can be reduced significantly while model accuracy remains sufficient. For an elaborated review on surrogate models in environmental 
modelling, see Razavi et al (2012b).

Razavi et al (2012b) argue that the response patterns of a lower-fidelity model and of a sophisticated 2D model can differ, even if both models are based on the same input data. Therefore, the results of a $2 \mathrm{D}$ model will be used for validation purposes. If the model output of the lower-fidelity model is close to those predicted by the $2 \mathrm{D}$ model, the lower-fidelity model is capable of accurately simulating the system behaviour. Hence, the lower-fidelity model can be used to perform the sensitivity analysis. For future work, the lower-fidelity model can be treated as a high-fidelity model. The proposed method (Fig. 3.1) will answer the following three research questions:

- Under what circumstances can a lower-fidelity model be used to simulate a historic flood event?

- How can we apply a lower-fidelity model to compute the maximum discharge and its uncertainty of a historic flood event?

- Which uncertain input parameter contributes most to the uncertainty of the maximum discharge?

We apply the proposed method to the 1926 flood of the Rhine river. Sufficient information is available to reconstruct the 1926 geometry. In addition, water levels were measured during the event. Due to high rainfall intensities in the Lower Rhine catchment area and increased amount of melting water as a result of relatively high temperatures in Switzerland, the 1926 discharge resulted in the highest discharge at Lobith since measurements have been performed.

The outline of the paper is as follows. Firstly, the high-fidelity (2D) model is described in Section 3.2.1, after which the surrogate model is set up (Section 3.2.2). Then, the 1926 case is provided and the methodology of the sensitivity analysis is given in Section 3.2.3 and Section 3.3, respectively. Subsequently, the calibration results of the high-fidelity model (Section 3.4.1) and the validation results of the surrogate model (Section 3.4.2) are provided. Finally, the results of the sensitivity analysis are elaborated on Section 3.4.3. The paper ends with a discussion and the main conclusions in Section 3.5 and 3.6, respectively.

\subsection{Methodology of surrogate modelling}

In this section, the model structure of a fully $2 \mathrm{D}$ model is explained. This model represents the high-fidelity model in this study and is used to validate the lowerfidelity model. Thereafter, the $2 \mathrm{D}$ model is simplified to decrease computational 


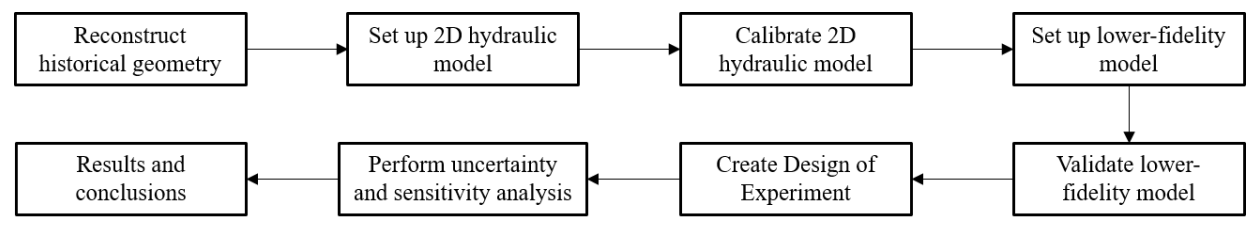

Figure 3.1

Methodology for historic flood reconstruction.

time significantly. Many methods exist to simplify a high-fidelity model to create a lower-fidelity model. Why a $1 \mathrm{D}-2 \mathrm{D}$ coupled model is used in this study, is explained in Section 3.2.2.

\subsubsection{High-fidelity model}

Most often, 2D flood models are used to get insight in the consequences of high discharge stages. With $2 \mathrm{D}$ models, it is possible to get a high detailed and accurate representation of potential floods along a river. Up till now, the $2 \mathrm{D}$ Shallow Water equations are usually solved with the use of a curvilinear grid (Fig. 3.2). The curvilinear grid cells are aligned with the flow direction since flow variations in the channel length direction are often smaller than those in channel cross direction (Kernkamp et al, 2011). This is convenient in terms of computational time. However, a curvilinear grid has several disadvantages. Firstly, grid lines are focused and sometimes even intersect in sharp inner bends (Fig. 3.2, where the dashed lines indicate the focused grid lines). The focused grid lines result in unnecessarily small grid cells if the model domain is extended in the inner bend. These small grid cells significantly increase computational time. Additionally, the grid will lead to a staircase representation along closed boundaries since the grid is not capable of following the smooth boundaries of the model domain (Kernkamp et al, 2011). Finally, the grid is restrictive in representing a natural river system with different geometric features such as main channels, junction points and wide floodplains due to the curvilinear shape of the grid cells (Lai, 2010).

Due to the above mentioned shortcomings of a curvilinear grid, a hybrid grid is used to solve the 2D Shallow Water equations in this study (Fig. 3.2). The summer bed is discretized by curvilinear grid cells. These cells are aligned with the flow direction. The winter bed is discretized by triangular grid cells such that each triangular grid cell is connected to a single curvilinear grid cell. As a result, a smooth transition exists between the curvilinear and triangular grid cells (Fig. 3.2). This hybrid grid overcomes the shortcomings of a curvilinear grid. It also reduces the computational time while model accuracy stays sufficient (Bomers 


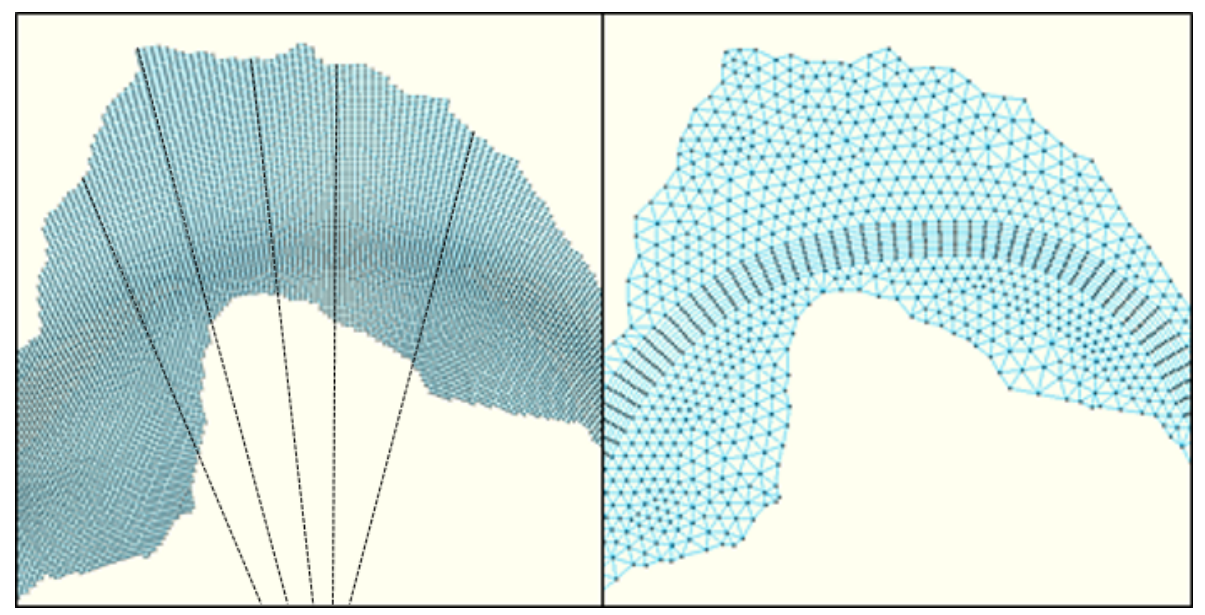

Figure 3.2

An example of a curvilinear grid in which the dashed lines represent the focused grid lines (left figure) and a hybrid grid (right figure) in a sharp meander bend.

et al, 2019d). Fig. 3.3 shows the hybrid grid and a typical example of model output. The open source software D-Flow Flexible Mesh (FM) is used to set up the 2D model (Deltares, 2016b). In each grid cell, parameters such as water level and flow velocity can be computed for every time step. A variable time step is used based on the maximum Courant number. As a result, the model stays stable during the simulation:

$$
C=\frac{u * \Delta t}{\Delta x}
$$

where $u$ represents the velocity magnitude $[\mathrm{m} / \mathrm{s}], \Delta t$ the time step $[\mathrm{s}]$ and $\Delta x$ the grid size in x-direction [m]. A maximum Courant number of 0.95 is used and $\Delta t$ is adapted accordingly.

D-Flow FM allows multiple roughness definitions to be implemented in a single model run, e.g. a Manning's value, a Nikuradse value or a Van Rijn predictor. In general, the land use classifications, and hence the roughness classes, are based on an input database. A database provided by the Dutch Ministry of Infrastructure and Water Management is used. This database includes multiple roughness definitions that coincide with the land use classification of the studied area.

Calibration of a $2 \mathrm{D}$ grid is required since each $2 \mathrm{D}$ grid has its own numerical friction caused by the resolution of the grid cells (Caviedes-Voullième et al, 2012). A coarser grid results in a somewhat dampened discharge wave. This effect can even 


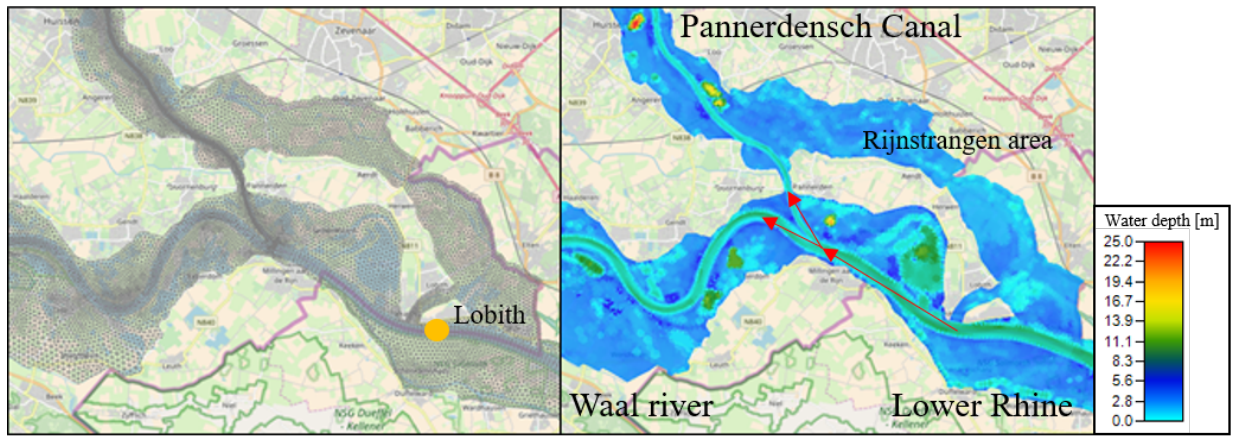

Figure 3.3

Example of a hybrid grid of a 2D hydraulic model (left figure) and computed water depths as a result of an upstream discharge wave (right figure). The red arrows indicate the flow direction.

become larger than those generated by physical friction (Caviedes-Voullième et al, 2012). During calibration, this numerical grid generated friction will be compensated such that reliable water levels are predicted. Hydraulic model calibration is most commonly done by changing the roughness of the summer bed until simulated water levels are close to measured water levels (e.g Bomers et al (2019d) and Caviedes-Voullième et al (2012)). In this study, the same approach was used. The calibration procedure was performed with the use of the open source software OpenDA (http://www.openda.org/). The basic idea of the procedures of OpenDA is to find the set of model parameters which minimizes the cost function measuring the distance between the measured water level and the model prediction (The OpenDA Association, 2016). The Quadratic Cost Function is used in combination with the Sparse DUD (Does not Use Derivate) algorithm. For N calibration parameters (in this study $\mathrm{N}=10$ ), the algorithm requires $(\mathrm{N}+1)$ set of parameter estimates. The cost function, based on the model predictions and measured data, is used to get a new estimate. If the cost function does not produce a better estimate, the Sparse DUD algorithm will search in opposite direction and/or decreases the searching-step until a better estimate is found (The OpenDA Association, 2016). In this study, the calibration procedure is stopped if the average RMSE of each measurement station is smaller than $0.05 \mathrm{~m}$. For more information on the calibration procedure of OpenDA, see The OpenDA Association (2016).

\subsubsection{Lower-fidelity physically based surrogate model}

A hybrid 2D grid reduces computational time compared to a curvilinear grid. However, the computational time of simulating a discharge wave of approximately 
three weeks is still in the order of many hours. For sensitivity analysis purposes, many model runs (120 in this study) have to be performed. Therefore, a model with a computational time in the order of minutes is desirable. For this reason, a surrogate model based on the high detailed 2D model is developed. This model is explained in more detail in the next sections.

\section{Types of surrogate modelling}

Surrogate models approximate the response pattern of a high detailed and computationally intensive simulation model (Razavi et al, 2012a). Many methods to construct a surrogate model exist in literature. These methods can be divided into two classes, namely (1) response surface surrogates which are statistical or empirical data-driven models emulating the original system, and (2) lower-fidelity physically based surrogates which are simplified models of the high detailed model (Razavi et al, 2012b).

Regardless of the type of response surface surrogates, usually three steps are involved (Simpson et al, 2001): (1) choosing a design of experiment for generating the training data, (2) choosing a statistical or empirical data-driven model (e.g. Artificial Neural Network, Support Vector Machine, Gaussian Progress Regression model) to represent the data, and (3) fitting the surrogate model to the training data. Response surface surrogates are commonly used for automatic model calibration (Razavi et al, 2012b). To fit the response surface surrogate, training data is required. Therefore, the high-fidelity model still needs to be run multiple times. Because of the relatively long simulation time of this model, the methods based on response surface surrogates are not desirable. For this reason, the high-fidelity model is simplified using method (2): creating a lower-fidelity physically based surrogate model. Lower-fidelity surrogate models are set up based on the original input data. Therefore, for lower-fidelity modelling, only a single run with the highfidelity model is required for validation purposes. Moreover, lower-fidelity models are more reliable in predicting the output of the high-fidelity model in unexplored regions of the input space since they predict model output based on the original input data (Razavi et al, 2012b). Different methods exist to simplify the original model, e.g. larger grid size, less strict numerical convergence tolerances or, ignoring or approximation physics of the original system (Razavi et al, 2012b). Those methods were not sufficient to reduce the computational time of the high-fidelity model significantly. Therefore, it was decided to approximate several physical processes of the original system by: (1) lowering the dimension of the model, (2) increasing the computational time step, and (3) simplifying the Shallow Water equations of the fully $2 \mathrm{D}$ model. The set-up of the lower-fidelity model is explained in the next section. 


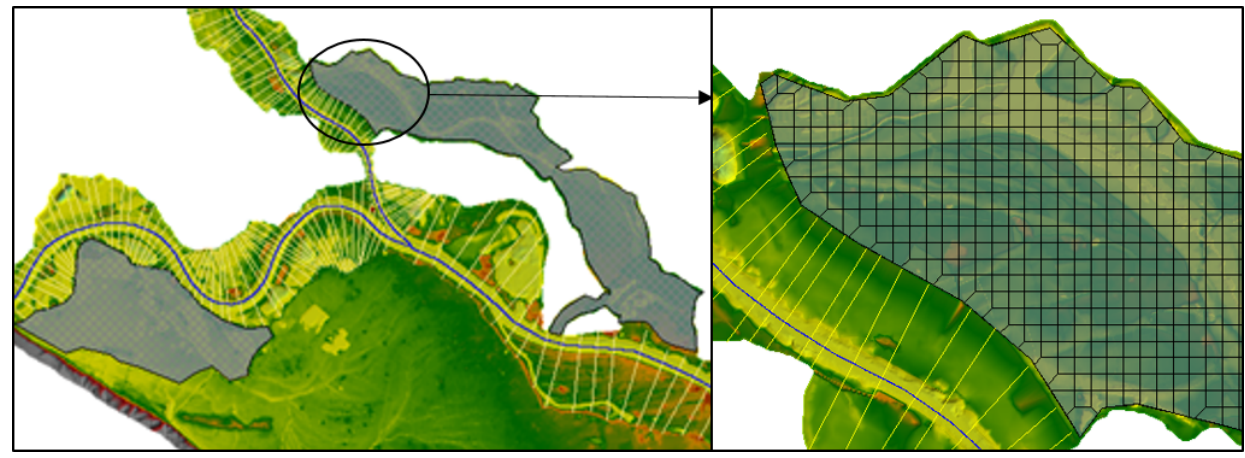

Figure 3.4

Set-up of the 1D-2D coupled model (left figure) in which the yellow lines indicate the 1D profiles and the grey areas the $2 \mathrm{D}$ embanked areas, and a close-up of the $2 \mathrm{D}$ grid which clearly shows the flexible grid shapes along the boundaries of the model domain (right figure).

\section{Set-up lower-fidelity model}

The surrogate model developed represents a 1D-2D coupled model to combine the advantages of both a fully $2 \mathrm{D}$ and a fully $1 \mathrm{D}$ model. $1 \mathrm{D}$ profiles give an accurate representation of flood wave propagation in case of in-channel flows (Tayefi et al, 2007). Additionally, the computational cost is relatively low compared to a fully $2 \mathrm{D}$ model. However, the use of $1 \mathrm{D}$ profiles may be insufficient for more complex flow patterns because of the simplified assumptions in the computational schemes. In the embanked areas rapid changes in flow velocity and direction may occur. For this reason, 1D profiles are solely used for the flow between the winter dikes, i.e. the summer bed and winter bed. The $1 \mathrm{D}$ profiles are coupled with $2 \mathrm{D}$ embanked areas that are possible to inundate. The embanked areas refer to the areas protected by dikes and are therefore not part of the river system. The embanked areas are discretized with a rectangular 2D grid. Flexible grid shapes are used along the boundaries of the model domain such that the $2 \mathrm{D}$ grid cells follow these boundaries. The flexible grid cells along the boundaries can have a maximum of eight boundary edges. Fig. 3.4 shows an example in which the $1 \mathrm{D}$ profiles of the rivers and the $2 \mathrm{D}$ embanked areas are given by yellow lines and grey areas, respectively. A closeup of the $2 \mathrm{D}$ grid and its flexible grid shapes along the grid boundaries is also provided.

HEC-RAS (v. 5.0.3), developed by the Hydrologic Engineering Centre (HEC) of the US Army Corps of Engineers, is used for the 1D-2D flood modelling. HECRAS is well known for its $1 \mathrm{D}$ flood modelling applications. Horritt and Bates (2002) even showed that HEC-RAS produces flood extents more accurately than the 2D models of LISFLOOD-FP and TELEMAC-2D in cases of a confined and 
relatively narrow river. In 2016, HEC-RAS 5.0 was officially released. With this version, it is possible to perform $1 \mathrm{D}-2 \mathrm{D}$ coupled computations.

Several studies have shown the applicability of 1D-2D flood modelling. Most software programs (e.g. Mike-11, HEC-RAS) that allow 1D-2D coupling are based on mass-conservation. The conservation of momentum is often neglected. Bladé et al (2012) argue that neglecting the momentum in the coupling of a $1 \mathrm{D}$ profile and the $2 \mathrm{D}$ grid cells affects flow patterns in the floodplains in most cases. The more connected the river and the floodplains are, e.g. in case of overland flows, the more important momentum becomes since an increase in flow velocity results in an increase in momentum (Bladé et al, 2012). Conservation of momentum can only be neglected if the $1 \mathrm{D}$ profiles are coupled with $2 \mathrm{D}$ grid cells by a weir/embankment since the hypothesis of the Shallow Water equations are not fulfilled for this specific case (Bladé et al, 2012). With HEC-RAS, the weir-equation can be used to compute the flow over the embankment using the results of the $1 \mathrm{D}$ and $2 \mathrm{D}$ solution algorithms on a time step by time step basis. This allows for direct feedback at each time step between the 1D profiles and 2D grid cells (Brunner, 2014a). Neglecting conservation of momentum is justified for this modelling purpose since the $1 \mathrm{D}$ profiles are coupled with the $2 \mathrm{D}$ grid cells by an embankment. Hence, the $1 \mathrm{D}-2 \mathrm{D}$ coupling can be treated as a weir-type connection.

\section{Differences between the high-fidelity and lower-fidelity model}

A $1 \mathrm{D}-2 \mathrm{D}$ coupled model requires the same input data as a fully $2 \mathrm{D}$ model. Therefore, we use the same input data of the high-fidelity model to set up the 1D-2D coupled model. The Digital Elevation model (DEM) of the 2D model is used to establish the $1 \mathrm{D}$ profiles and $2 \mathrm{D}$ grid cells of the 1D-2D coupled model. Also, the boundary conditions consisting of measured discharges and water levels, as well as the land use classification for both models are identical. Therefore, we can conclude that the differences in the representations of the input parameters of the high-fidelity and the lower-fidelity model are solely caused by the level of detail of the two models itself and the different settings of D-Flow FM and HEC-RAS. These differences are explained in more detail below and are summarized in Table

Firstly, the 2D Shallow Water equations of the high-fidelity model are simplified to the Diffusive Wave equations. The Diffusive Wave equations are applicable if flow separation and turbulence eddies can be neglected. This is the case if the inertial terms are much smaller than the gravity, friction and pressure terms. Test runs showed that neglecting the inertial terms of the momentum equations did not result in a change in model results. On the other hand, the use of the Diffusive Wave equations resulted in a significant reduction of the computational time. Therefore, the Diffusive Wave equations are used to compute the flow characteristics at each 1D profile and 2D grid cell. The applicability of the Diffusive Wave equations for flood modelling purposes has also been shown by e.g. Moya Quiroga et al (2016), 
Overview of the differences between the high-fidelity model and lower-fidelity model.

\begin{tabular}{|c|c|c|}
\hline & High-fidelity model & Lower-fidelity model \\
\hline Software & D-Flow FM & HEC-RAS \\
\hline Dimension & Fully 2D & $\begin{array}{l}1 \mathrm{D} \text { cross sections in summer bed and winter } \\
\text { bed, } 2 \mathrm{D} \text { in the embanked areas }\end{array}$ \\
\hline Nature & Shallow Water equations & Diffusive Wave equations \\
\hline Time step & $\begin{array}{l}\text { Variable time step based on } \\
\text { maximum Courant number }\end{array}$ & Fixed time step \\
\hline Roughness & Different roughness definitions & Manning's roughness coefficient \\
\hline Calibration & Calibrated summer bed roughness & Uncalibrated \\
\hline
\end{tabular}

Moussa and Bocquillon (2009) and Leandro et al (2014).

Secondly, the computational time step of the lower-fidelity model is increased compared to the fully $2 \mathrm{D}$ model to speed-up computational time. In a $2 \mathrm{D}$ model, the river is usually the time step limiting factor since the depths and velocities in the main channel are larger than in the embanked areas (Bladé et al, 2012) (see equation 3.1). The high-fidelity model had an average time step of 3.9 seconds, based on the maximum Courant number. A fixed time step of five minutes can be used for the lower-fidelity model. This time step is based on a convergence argument: reducing the time step further did not result in a reasonable improvement of the model accuracy.

The land use classification of the high-fidelity model is used as input for the lowerfidelity model. D-Flow FM allows multiple roughness definitions to be implemented in a single model. However, HEC-RAS only allows a Manning's roughness coefficient for the various land use classes. Therefore, the roughness classes as used in the high-fidelity model were transformed towards Manning's roughness values based on Table 5-6 of Chow (1959).

We recall that it is necessary to calibrate the summer bed roughness of the highfidelity model, since each $2 \mathrm{D}$ grid has its own numerical friction. On the other hand, it is decided to not calibrate the lower-fidelity model. As a result, the summer bed roughness can be included in the sensitivity analysis as a random parameter. This is justified since no inundations along the Lower Rhine occurred during the 1926 flood event. Therefore, correct prediction of the water levels becomes irrelevant. The lower-fidelity model is set up to accurately predict maximum discharges at Lobith during flood events instead. During the simulation, the entire discharge wave flows in downstream direction independent of simulated water levels, since inundations are not possible to occur. Consequently, it is expected that simulated maximum discharges of the uncalibrated surrogate model are close 
to those predicted by the calibrated high-fidelity model. However, validation is recommended to study whether the lower-fidelity model is capable of simulating the system behaviour sufficiently.

\section{Validation lower-fidelity model}

Razavi et al (2012b) argue that, even though the lower-fidelity model may be based on the same input parameters as the high-fidelity model, the response pattern can differ somewhat. This was also shown by Thokala and Martins (2007). They neglected the fluid viscosity in the Navier-Stokes equations to set up a lowerfidelity model. This resulted in less accurate results compared to the high-fidelity model. The discrepancies between the response patterns of the lower-fidelity and high-fidelity models mostly influence the local and global minimum and maximum of the system (Razavi et al, 2012b). Since this study tries to predict maximum discharges during a historic flood event, it is of high importance that the global maximum of the system is correctly modelled by the lower-fidelity model. If this is not the case, the discrepancies between the lower-fidelity and high-fidelity model can be addressed with a correction function (Razavi et al, 2012b). These kind of functions correct the response of the lower-fidelity model and align it with the response pattern of the high-fidelity model. It is thus of high importance to validate the lower-fidelity model to study whether a correction function is required to tune the model results.

If the response pattern of the lower-fidelity model is close to that of the high-fidelity model, the lower-fidelity model can be treated as the high-fidelity representation of the underlying system. Consequently, the lower-fidelity model can replace the sophisticated 2D model (Razavi et al, 2012b). The sensitivity analysis can then be safely performed with the lower-fidelity model since the input parameters of the lower-fidelity model are based on the input parameters of the high-fidelity model.

\subsubsection{The 1926 case}

The 1926 flood event of the Rhine river is used to examine the methodology of developing a lower-fidelity model for historic flood reconstruction. The study area stretches from the areas downstream of Andernach in Germany to the three Rhine river branches in the Netherlands (Fig. 3.5). In this paper, the German part of the river is referred to as the Lower Rhine. The river enters the Netherlands at Lobith, where it bifurcates into the Waal river and Pannerdensch Canal. Subsequently, the Pannerdensch Canal bifurcates into the Nederrijn and IJssel rivers. Only the summer bed, its floodplains and two embanked areas that are connected by an inlet (Ooijpolder and Rijnstrangen area, (Fig. 3.5)) are captured in the model domain. The term inlet is used for a dike section with a relatively low crest level. 


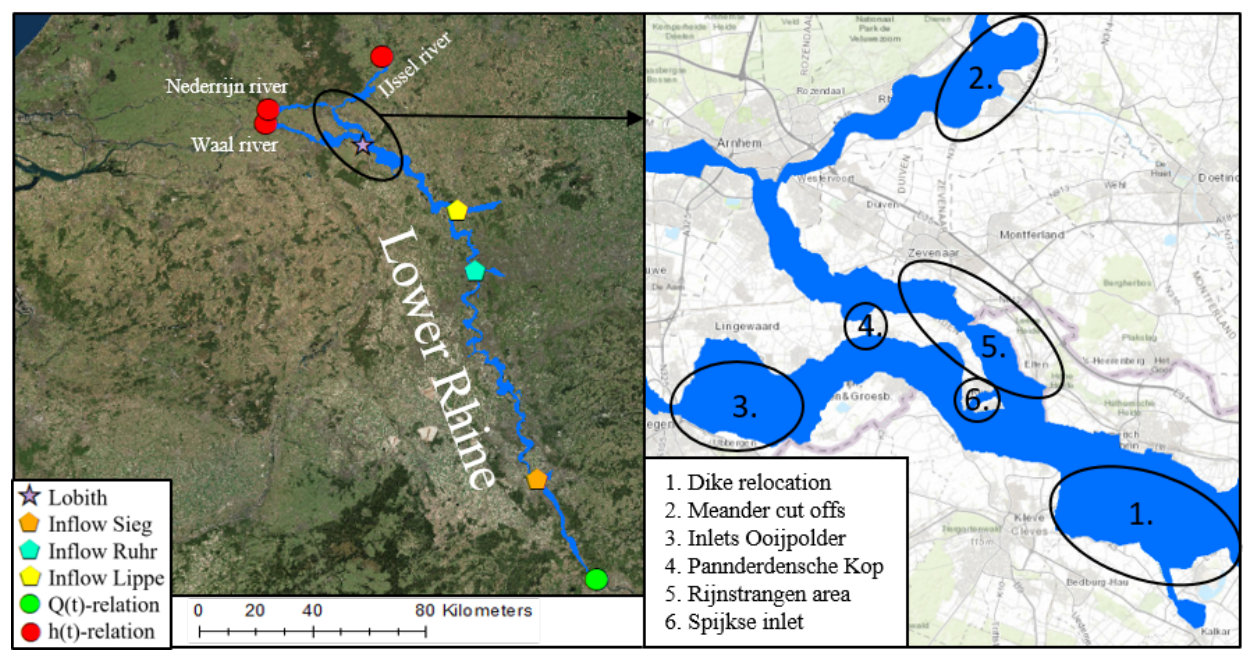

\section{Figure 3.5}

Boundaries of the study area and location of inflow (left figure) and location of artificial measures taken to change the 1995 geometry into the 1926 situation (right figure).

Due to this low crest level, a part of the discharge wave will enter the lower-lying area behind the inlet as soon as a certain water level is exceeded. As a result, the maximum discharge further downstream decreases. The dikes represent the boundaries of the model domain and are assumed not to overflow.

\section{Geographical situation}

To reconstruct a historical geometry, the changes in the river system between the current geometry and the historical period of interest must be defined. An existing data set representing the 1995 geometry is made available by the Dutch Ministry of Infrastructure and Water Management. This data set is used as starting point and is adapted such that it represents the historical geometry. The following measures were taken to create the 1926 situation (Fig. 3.5):

- Increase summer bed level due to erosion. Measurements of the summer bed levels were available for the entire model domain. The changes in summer bed level between the 1995 measurements and the oldest measurements available at each location were used to estimate the 1926 summer bed level by linear extrapolation. 
- Decrease winter bed level due to sedimentation. No measured sedimentation rates along the study area were available. Therefore, the following sedimentation rates were used to predict the 1926 winter bed level: 1 $\mathrm{mm} /$ year along the IJssel river, Pannerdensch Canal and Lower Rhine, 3 $\mathrm{mm} /$ year along the Waal river and $0.5 \mathrm{~mm} /$ year along the Nederrijn river (Silva et al, 2001). A linear decrease of the sedimentation rate in channel cross direction was assumed. As a result, the sedimentation near the summer bed equals the predicted sedimentation rates according to Silva et al (2001). The sedimentation near the outside border of the floodplain equals zero.

- Dike relocation. On the left side of the Lower Rhine, close to the city of Emmerich, Germany, the floodplains of the river were much larger in 1926 than they are nowadays. The 1926 dike locations and hence the 1926 winter bed were based on old maps dating back to 1895 (Fig. 3.5, Dike relocation), provided by the German Deichverband Xanten-KleveDer Oberdeichinspektor Dusseldorf (1895).

The current summer dikes along the Pannerdensch Canal close to the Pannerdensche Kop were the 1926 winter dikes. Therefore, the present floodplains were not part of the 1926 river system. The area outside the 1995 summer dikes were removed from the geometry (Fig. 3.5, Pannerdensche Kop).

- Restoration of inlets. In 1926, two retention areas were possible to inundate at high discharge stages as a result of inlets. The Spijke inlet caused inundation of the Rijnstrangen area when the water level exceeded $15 \mathrm{~m}+\mathrm{NAP}$, equal to the crest level of the inlet (Fig. 3.5, Rijnstrangen area).

In the Ooijpolder, three inlets were active. The total length of the inlets was $150 \mathrm{~m}$. The Ooijpolder started to inundate at a water level of $12.5 \mathrm{~m}+\mathrm{NAP}$, equalling the height of the three inlets. The location of the inlets was based on historical 1926 maps (Fig. 3.5, Ooijpolder).

- Restoration of meander cut offs. In 1955 and 1969 two meanders near Doesburg and Rheden were cut off (Fig. 3.5, Meander cut offs). Due to these meander cut offs the total length of the IJssel river decreased with almost nine kilometres. The location of the meander bends are based on historical 1926 maps.

\section{Boundary conditions}

The 1926 flood event is simulated for a period of approximately three weeks, starting on the $22^{\text {nd }}$ of December 1925 till the $8^{\text {th }}$ of January 1926 . From the $26^{\text {th }}$ of December onwards, the weather conditions changed drastically. High rainfall intensities occurred in almost the entire catchment area of the Rhine river (Dutch Ministry of Infrastructure and the Environment, 1926). This resulted in a rapid rise of the discharge wave, starting on the $27^{\text {th }}$ of December. 

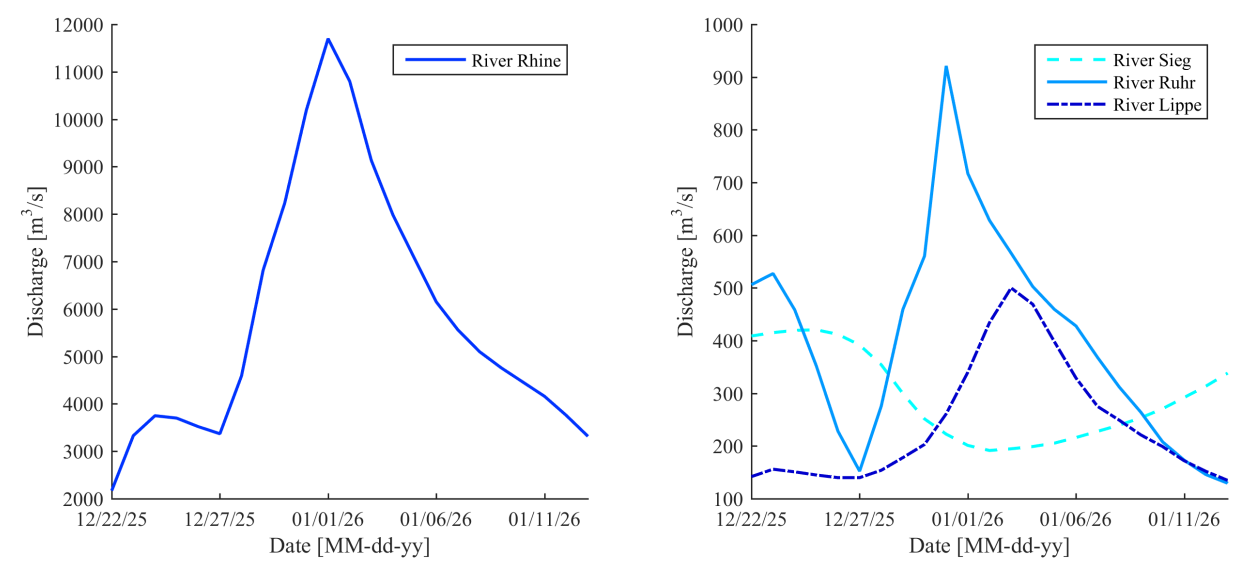

Figure 3.6

Discharge waves of the Rhine river at Andernach (left figure) and the three tributaries Sieg, Ruhr and Lippe (right figure). Note: only daily discharge measurements are available resulting in the sharp peaks of the different discharge waves.

Fig. 3.6 shows the discharge wave at Andernach, representing the upstream boundary condition (Data source: German Federal Waterways and Shipping Administration (WSV), communicated by the German Federal Institute of Hydrology (BfG)). The downstream boundary conditions consist of $\mathrm{h}(\mathrm{t})$-relations based on daily measured water levels available at http://waterinfo.rws.nl and provided by the Dutch Ministry of Infrastructure and Water Management. Three streams enter the Lower Rhine, namely the Lippe, Ruhr and Sieg rivers. These streams were included in the model domain by source points (discharge inflow, Fig. 3.5 and Fig. 3.6). The presented boundary conditions and source points are used in both the high-fidelity as well as the lower-fidelity model to set up the models.

\subsection{Methodology of Sensitivity Analysis}

In this study uncertainty and sensitivity analyses are performed. An uncertainty analysis is executed to compute the maximum discharge at Lobith with its standard deviation as a result of the uncertain input parameters. Next, a sensitivity analysis is performed to study which parameter mostly influence the uncertainty of the model output. The main objective of the sensitivity analysis is the so called factor prioritization. With this prioritization, it becomes clear on which parameter to focus during historical geometry reconstruction for flood modelling purposes in 
order to reduce the potential uncertainty in the model output.

During the analyses, we only focus on the parameters that influence the maximum discharge at Lobith. A test run was performed in which all roughness parameters along the Dutch river branches were increased with $20 \%$. In this run, the roughness values are close to the upper bound of the truncated normal distributions. The run showed that the increase in roughness resulted in only a minor decrease of the maximum discharge at Lobith of approximately $0.2 \%$, from 12,402 to $12,373 \mathrm{~m}^{3} / \mathrm{s}$. This minor decrease suggests that the Dutch river branches are sufficiently downstream such that the effects of different summer bed roughness on the maximum discharge are negligible. Therefore, the study only focuses on the uncertainties of the input parameters in the most upstream part of the model domain: the city of Andernach until the location where the Rhine river bifurcates into the Waal river and Pannerdensch Canal. The Dutch Rhine river branches are seen as fixed boundary conditions of the model since they do not influence model response. Therefore, they can be excluded from the global sensitivity analysis.

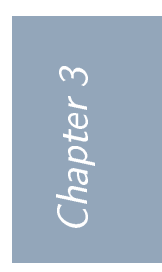

\subsubsection{Input parameters}

The lower-fidelity model is used to establish the uncertainty and sensitivity of the 1926 discharge at Lobith. Only the input parameters that are based on an estimation, i.e. those that are uncertain, are included in the analysis. In addition, parameters that require the development of a new surrogate model when changed (e.g. a planometric change) are excluded from the analysis for pragmatic reasons. The following parameters are considered during the sensitivity analysis: (1) roughness parameters of the various types of land use classes and (2) the bed levels of the summer bed and winter bed. In general, two kinds of uncertainties exist. The first uncertainty is as a result of the randomness of variations in nature (inherent uncertainty). The second uncertainty is caused by limited knowledge (epistemic uncertainty) (Warmink et al, 2013). The uncertainty of the different roughness classes is mainly caused by inherent uncertainty since it depends amongst others on the season (e.g. grass grows faster during summer periods resulting in a larger roughness) as well as on maintenance (e.g. the frequency of mowing grass fields). The uncertainty of the summer bed and winter bed levels are caused by epistemic uncertainty. No measured 1926 bed levels are present. Therefore, the bed levels are based on extrapolation techniques and estimated sedimentation rates.

For all roughness parameters, we link the value with the largest probability of occurrence as well as its minimum and maximum bounds to the tables of Chow (1959). Truncated normal distributions are used in this study since a normal distribution better fits the data if some information about the input parameters is available (tails of the distribution and the expected value). Contrarily, a uniform distribution assumes that there is no knowledge about the value with the largest 
Minimum, Maximum and Standard deviation of the different input parameters. The first top five rows represent the Manning's roughness coefficients.

\begin{tabular}{l|ccc}
\hline \hline Input parameter & Minimum value & Maximum value & Standard deviation \\
\hline Summer bed & $0.025 \mathrm{~s} / \mathrm{m}^{1 / 3}$ & $0.033 \mathrm{~s} / \mathrm{m}^{1 / 3}$ & $0.002 \mathrm{~s} / \mathrm{m}^{1 / 3}$ \\
Lakes & $0.024 \mathrm{~s} / \mathrm{m}^{1 / 3}$ & $0.034 \mathrm{~s} / \mathrm{m}^{1 / 3}$ & $0.003 \mathrm{~s} / \mathrm{m}^{1 / 3}$ \\
Grasslands & $0.037 \mathrm{~s} / \mathrm{m}^{1 / 3}$ & $0.075 \mathrm{~s} / \mathrm{m}^{1 / 3}$ & $0.009 \mathrm{~s} / \mathrm{m}^{1 / 3}$ \\
Forest & $0.098 \mathrm{~s} / \mathrm{m}^{1 / 3}$ & $0.178 \mathrm{~s} / \mathrm{m}^{1 / 3}$ & $0.020 \mathrm{~s} / \mathrm{m}^{1 / 3}$ \\
Urban areas & $0.029 \mathrm{~s} / \mathrm{m}^{1 / 3}$ & $0.039 \mathrm{~s} / \mathrm{m}^{1 / 3}$ & $0.003 \mathrm{~s} / \mathrm{m}^{1 / 3}$ \\
St. Winter bed level & $-0.070 \mathrm{~m}$ & $0.070 \mathrm{~m}$ & $0.035 \mathrm{~m}$ \\
St. Summer bed level (1) & $-0.150 \mathrm{~m}$ & $0.150 \mathrm{~m}$ & $0.075 \mathrm{~m}$ \\
St. Summer bed level (2) & $-0.520 \mathrm{~m}$ & $0.520 \mathrm{~m}$ & $0.260 \mathrm{~m}$ \\
St. Summer bed level (3) & $-0.090 \mathrm{~m}$ & $0.090 \mathrm{~m}$ & $0.045 \mathrm{~m}$ \\
\hline \hline
\end{tabular}

probability of occurrence. Only a range of input values is known. Therefore, we can conclude that for older historic events, the distributions of the uncertain input parameters will shift towards uniform distributions since less and less information is available.

The roughness parameters are divided into five land use classes: summer bed, lakes, grasslands, forest and urban areas. A smooth channel with no vegetation is assumed for the entire summer bed, having a minimum Manning's roughness of $0.025 \mathrm{~s} / \mathrm{m}^{1 / 3}$, a normal value of $0.028 \mathrm{~s} / \mathrm{m}^{1 / 3}$ which is used as the expected value, and a maximum value of $0.033 \mathrm{~s} / \mathrm{m}^{1 / 3}$ (Chow, 1959). These numbers are used to set up the truncated normal distribution. The same method was used to define the truncated normal distributions of the other roughness classes (Table 3.2).

A comparable method is used to set up the truncated normal distributions of the summer bed levels and winter bed levels. The 1926 summer bed levels were computed based on extrapolation of measured bed level changes (see Section 3.2.3). The uncertainty ranges of the summer bed levels were based on these extrapolation values. The minimum change in bed level corresponds to no change compared to the oldest measured bed value. Consequently, the 1926 bed level equals the oldest measured bed level. The maximum change in bed level equals the extrapolation of the trend between 1995 and the latest measured bed level multiplied with a factor two. A factor of two is chosen to include a large uncertainty range. The summer bed is divided into three classes:

1. From the most upstream location Andernach (river km 614) until Walsum (river km 789). Here, almost no erosion has occurred between 1995 and 1926. Additionally, the bed level has been compensated for bed level decrease due to mining activities at several locations.

\section{Chapter 3}


2. From Walsum until the German-Dutch border (river km 857). Here, there is relatively much uncertainty in the amount of erosion since the oldest measured bed level dates back to only 1960 .

3. From the German-Dutch border till the first bifurcation point of the Rhine river (river $\mathrm{km} \mathrm{867).} \mathrm{Here,} \mathrm{there} \mathrm{is} \mathrm{little} \mathrm{uncertainty} \mathrm{in} \mathrm{the} 1926$ bed level since the oldest measurements date back to 1934 .

The winter bed level consists of just one class since no deviations in uncertainty along the Lower Rhine exist. The estimated sedimentation rate of $1 \mathrm{~mm} /$ year is used to define the ranges of the winter bed level in the Lower Rhine (Silva et al, 2001). The minimum value equals no change in bed level compared to the 1995 situation. The maximum range equals the sedimentation rate of $1 \mathrm{~mm} /$ year multiplied with a factor of two. Again a factor of two is chosen to include a large uncertainty range since the $1 \mathrm{~mm}$ /year sedimentation rate is relatively speculative. Since the summer bed and winter bed levels vary along the study area, their truncated normal distributions and corresponding minimum and maximum values are given as change from its 1926 reference value (Table 3.2). These values will be referred to as Standardized (St.) bed levels from now on. A value equal to zero correspond with the reconstructed 1926 geometry.

\subsubsection{Design of Experiment}

Before a sensitivity analysis can be performed, a Design of Experiment (DoE) has to be defined. DoEs employ different space filling strategies to capture the behaviour of the underlying system over limited ranges of the input parameters (Razavi et al, 2012b). A DoE results in a sample in which the boundary values of the input parameters are based on physical conditions. This sample can be used in a Monte Carlo analysis. Most commonly used DoE methods in literature appear to be full factorial design, fractional factorial design, central composite design and latin hypercube sampling (LHS) (Razavi et al, 2012b). In general, a full factorial design, a fractional factorial design and a central composite design require a relatively large number of simulations to generate all combinations to represent the corners of the input space (Razavi et al, 2012b; Saltelli et al, 2008). Contrarily, LHS can easily scale to different numbers of input parameters without the need for extra simulation runs (Razavi et al, 2012b). Thus, a stratified LHS sample has as advantage that less model runs are requried since a stratified sample achieves a better coverage of the sample space of the input parameters (Saltelli et al, 2000). For this reason, a LHS design is used in this study.

The nine input parameters are divided into eight levels. Each level has an equal probability of occurrence of $12.5 \%$, based on the determined truncated normal distributions in Section 3.3.1. For each run, each level is randomly selected, con- 
Minimum and Maximum discharge at Lobith $\left(Q_{\min , \text { Lobith }} / Q_{\max , \text { Lobith }}\right)$ as a result of the two most extreme model runs and the 120 runs within the Monte Carlo (MC) analysis.

\begin{tabular}{l|ccc}
\hline \hline & Extreme case & MC runs & Difference \\
\hline$Q_{\min , \text { Lobith }}\left[\mathrm{m}^{3} / \mathrm{s}\right]$ & 12,285 & 12,293 & 17 \\
$Q_{\max , \text { Lobith }}\left[\mathrm{m}^{3} / \mathrm{s}\right]$ & 12,548 & 12,531 & 8 \\
\hline \hline
\end{tabular}

straining that if a level is already selected it cannot be selected again. This results in a set of eight simulations in which all eight levels of the nine input parameters are present.

No clear guidelines exist concerning the minimal number of runs required in a Monte Carlo analysis. This number depends on the number and range of the input parameters and on the shape of the response surface. Theses features are largely unknown in advance (Pappenberger et al, 2005). In this study convergence of the uncertainty of the discharge at Lobith, expressed as standard deviation, is used as stopping-criteria, following the method of Pappenberger et al (2005). If an additional run results in a change of the standard deviation smaller than 0.05 $\mathrm{m}^{3} / \mathrm{s}$, it is assumed that the sample sufficiently represents the input space of the different input parameters. This criteria resulted in 120 model runs, corresponding with 15 latin hypercube sets.

To check whether the input space is sufficiently captured by the sample, two additional model runs were performed with the most extreme situations. These scenarios represent the limits of the probability distribution functions of the input parameters. Table 3.3 and Fig. 3.7 show the range of maximum discharges at Lobith modelled in the 120 Monte Carlo runs and the range found with the two most extreme cases. Note that all runs are performed with the lower-fidelity surrogate model. The minimum and maximum values of the sample are close to the predicted values of the two most extreme runs. Therefore, we can conclude that the input space is sufficiently captured by the sampling data set.

\subsubsection{Stratified Monte Carlo analysis}

The results of the Monte Carlo analysis are used to determine the uncertainty in model predictions. Additionally, the results are used to apportion this uncertainty to the contribution of the individual input parameters. Two sensitivity analysis methods are used, namely Multiple Linear Regression analysis and Sobol' indices explained in Sections 3.3.3 and 3.3.3 respectively. 


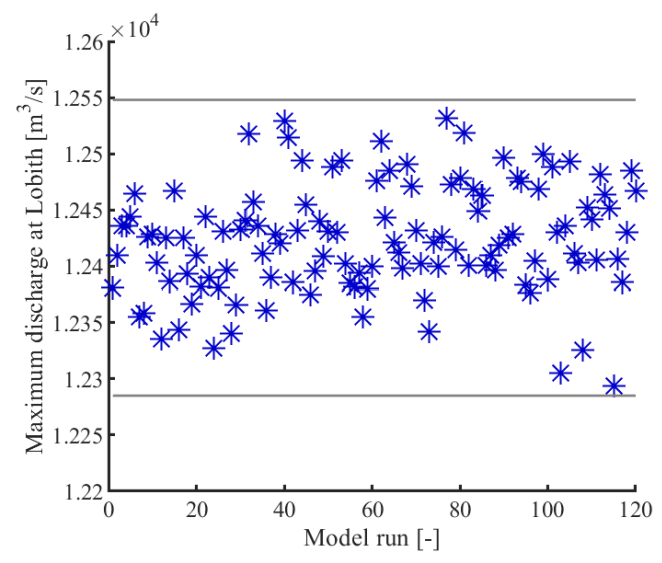

\section{Figure 3.7}

Input space of the LHS representing the maximum discharges at Lobith modelled during each model run. The grey lines indicate the results of the two most extreme model runs.

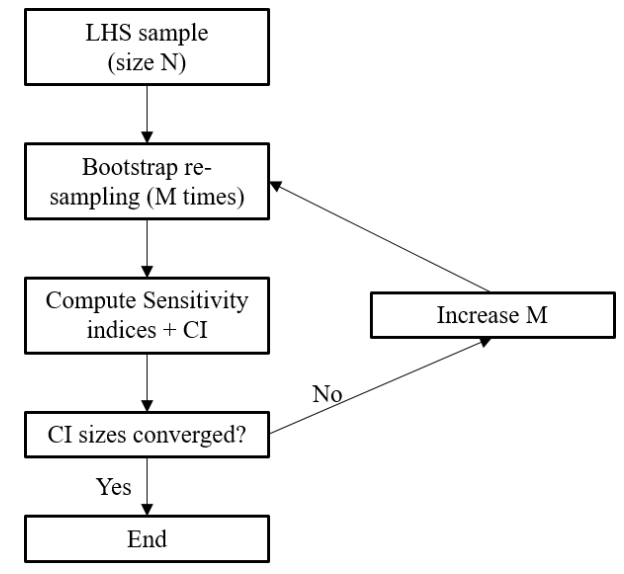

\section{Figure 3.8}

Bootstrap method for resampling in which $\mathrm{Cl}$ stands for confidence intervals. 


\section{Multiple Linear Regression Analysis}

If the number of simulations is much larger than the number of input parameters, a LHS can be very effective in revealing the influence of each parameter using a regression analysis (Saltelli et al, 2008). If the model does not contain any interactions between the input parameters (i.e. the model is additive), the linear regression function can be given as (Scheidt et al, 2018):

$$
y=\beta_{0}+\sum_{i=1}^{N} \beta_{\mathrm{i}} x_{\mathrm{i}}
$$

where $y$ represents the model output (in this study the maximum discharge at Lobith) and $x_{i}$ the different input parameters. The coefficients $\beta_{0}$ and $\beta_{\mathrm{i}}$ are determined by the least-square computation, based on the squared differences between the model output produced by the regression model and the actual model output produced by the surrogate model (Saltelli et al, 2008).

The coefficient $\beta_{\mathrm{i}}$ is used to determine the importance of each parameter $x_{i}$ with respect to the model output. If the input parameters are independent, the absolute standardized regression coefficient $\hat{\beta}_{\mathrm{i}}$ can be used as a measure of sensitivity (Scheidt et al, 2018):

$$
\hat{\beta}_{\mathrm{i}}=\left|\beta_{\mathrm{i}} \frac{\sigma_{\mathrm{i}}}{\sigma_{\mathrm{y}}}\right|
$$

where $\hat{\beta}_{\mathrm{i}}$ represents the standardized regression coefficient, and $\sigma_{\mathrm{i}}$ and $\sigma_{\mathrm{y}}$ represent the standard deviations for the input parameter $x_{i}$ and the model output respectively.

However, the applicability of a linear regression analysis depends on the degree of linearity of the model (Saltelli et al, 2008). A measure for linearity is expressed by (Saltelli et al, 2008):

$$
R^{2}=\sum_{i=1}^{N}\left(\hat{\beta}_{\mathrm{i}}\right)^{2}
$$

where $R^{2}$ represents the model coefficient of determination. This value is equal to the fraction of the variance of the original data that is explained by the regression model. A value of $R^{2}$ equal to one indicates that the model is linear (Saltelli et al, 2008) and that the multiple linear regression model is capable of expressing all variance of the original data. 


\section{Sobol' indices}

If the model is not linear, Sobol' indices can be used to determine the sensitivity of the input parameters. Sobol' indices are widely used as global sensitivity analysis method in literature. We are specifically interested in the first-order indices, i.e. the effect without interactions of input parameters, since the sensitivity analysis is used for factor prioritization purposes (Saltelli et al, 2008). Li and Mahadevan (2016) present an effective method to estimate the first-order Sobol' indices analytically. This method can be applied to any kind of data set and is not restricted to a specific sampling strategy. Furthermore, the method can be applied to models with correlated input parameters. Li and Mahadevan (2016) found that the method is highly efficient and that it is especially useful in ranking and identifying important parameters. The formula used is as follow ( $\mathrm{Li}$ and Mahadevan, 2016):

$$
S_{\mathrm{i}}=1-\frac{E_{\mathrm{xi}}\left(V_{\mathrm{x}-\mathrm{i}}\left(y \mid x_{\mathrm{i}}\right)\right)}{V_{\mathrm{y}}}
$$

where $S_{\mathrm{i}}$ represents the Sobol' first-order index, $V_{\mathrm{x}-\mathrm{i}}\left(y \mid x_{\mathrm{xi}}\right)$ indicates the conditional variance of y caused by all input parameters other than $x_{\mathrm{i}}, E_{\mathrm{xi}}$ represents the expected value as a result of fixing input parameter $x_{\mathrm{i}}$, and $V_{\mathrm{y}}$ represents the variance of $y$.

The Monte Carlo sample has a relatively small size. Therefore, the $95 \%$ confidence intervals of the Sobol' indices are computed based on a resampling strategy. The MATLAB Statistics Toolbox is used to perform the computation. The method to compute the $95 \%$ confidence intervals is based on the work of Dubreuil et al (2014) in which a bootstrap resampling strategy is used. Computation of confidence intervals by bootstrap resampling is widely used in global sensitivity analysis and has been used in combination with surrogate models by Gayton et al (2003) and Janon et al (2011). Bootstrap resampling aims at determining confidence intervals of a parameter of interest using only one design of experiment (Efron and Tibshirani, 1993). The method consists of the creation of new designs of experiment by drawing with replacement in the original design.

The method used is presented in Fig. 3.8. The LHS sample consisting of 120 model runs is resampled, after which the confidence intervals of the first-order Sobol' indices are computed. If these confidence intervals have not reached a specific convergence criterion yet, more bootstrap resamples are drawn. The computation is repeated until the convergence criterion is met. The criterion as suggested by Dubreuil et al (2014) is used. They suggested to stop the procedure at the iteration for which all confidence interval sizes have reached a range which is less than $\mathrm{x}$ percent of the maximum bootstrap mean of the sensitivity indices. The choice of parameter $\mathrm{x}$ depends on the goal of the sensitivity analysis. If the goal is only determining the most dominant input parameter, a relatively large value of $\mathrm{x}$ in the order of $30 \%$ can be used. However, if the model has many variables of equal 
sensitivity indices, it is better to look at the convergence graph at each bootstrap iteration and decide manually when to stop the procedure (Dubreuil et al, 2014). The first convergence criteria $(30 \%)$ is used which will be evaluated by checking the convergence graphs of the Sobol' indices as suggested by Dubreuil et al (2014).

\subsection{Results}

\subsubsection{Calibration high-fidelity model}

The river branches Lower Rhine, Waal river and Pannerdensch Canal were calibrated with the use of measured water levels. The discharge partitioning along the Dutch river branches was based on the report of the Dutch Ministry of Infrastructure and the Environment (1952). During the calibration procedure, this discharge partitioning had to be met. The IJssel and Nederrijn rivers were excluded from the calibration procedure since many inundations along the IJssel river have occurred during the 1926 flood event. These inundations influence the water levels at both river branches. Even a very low summer bed roughness near the locations of the inundations did not result in the correct water levels. For this study purpose, it is accepted that the water levels along the IJssel and Nederrijn rivers were not calibrated correctly. These branches are located more than $15 \mathrm{~km}$ downstream of Lobith such that backwater effects has vanished at Lobith. The IJssel and Nederrijn rivers have thus no effect on the maximum discharge at this location.

In the data set, only daily measured water levels are available. Hence, the maximum measured water level may be lower than the occurred maximum water level. Therefore, we calibrated on the three days with the highest water levels for each measurement station present along the river branches. If the model is capable of predicting the correct shape and correct water levels at three moments in time near the peak discharge, it is likely that also the correct maximum water level is predicted by the model.

The 1926 discharge wave was simulated. Maximum water levels at 10 measurement stations were validated after model calibration. It was found that simulated maximum water levels only deviated $2 \mathrm{~cm}$ on average compared to the measurements. Therefore, it can be concluded that the high-fidelity model is capable of simulating maximum water levels with high accuracy after calibration of the summer bed roughness. 
Maximum discharges along the Lower Rhine and discharge partitioning along the Dutch Rhine river branches predicted by the high-fidelity and lower-fidelity model, where $Q_{\max }$ represents the maximum discharge at the specific location.

\begin{tabular}{l|ccc}
\hline \hline & $\begin{array}{c}\text { High-fidelity } \\
\text { model }\end{array}$ & $\begin{array}{c}\text { Lower-fidelity } \\
\text { model }\end{array}$ & Difference [\%] \\
\hline$Q_{\max }$ Bonn $\left[\mathrm{m}^{3} / \mathrm{s}\right]$ & 11,509 & 11,580 & 0.6 \\
$Q_{\max }$ Cologne $\left[\mathrm{m}^{3} / \mathrm{s}\right]$ & 11,632 & 11,715 & 0.7 \\
$Q_{\max }$ Dusseldorf $\left[\mathrm{m}^{3} / \mathrm{s}\right]$ & 11,365 & 11,598 & 2.1 \\
$Q_{\max }$ Rees $\left[\mathrm{m}^{3} / \mathrm{s}\right]$ & 12,351 & 12,572 & 1.8 \\
$Q_{\max }$ Emmerich $\left[\mathrm{m}^{3} / \mathrm{s}\right]$ & 12,297 & 12,453 & 1.3 \\
$Q_{\max }$ Lobith $\left[\mathrm{m}^{3} / \mathrm{s}\right]$ & 12,282 & 12,402 & 1.0 \\
\hline \hline Waal river $[\%]$ & 70.3 & 71.9 & 1.5 \\
\hline Pannerdensch Canal [\%] & 29.7 & 28.0 & 1.7 \\
Nederrijn river [\%] & 58.7 & 56.2 & 2.4 \\
\hline IJssel river [\%] & 41.4 & 43.8 & 2.4 \\
\hline \hline
\end{tabular}

\subsubsection{Validation and uncertainty of the lower-fidelity model}

The model output was compared with the model output of the high-fidelity model to study whether it is justified to use the lower-fidelity model to perform the sensitivity analysis. We found that the high-fidelity model simulates a maximum discharge at Lobith of $12,282 \mathrm{~m}^{3} / \mathrm{s}$ with the 1926 measured discharge wave at Andernach as upstream boundary condition. The lower-fidelity model, with all random input parameters set to their expected value, predicts a maximum discharge of $12,402 \mathrm{~m}^{3} / \mathrm{s}$. This deviates less than $1.0 \%$ compared to the high-fidelity model. Although, correct prediction of the maximum discharge at Lobith has the focus in this study, it is also desirable that the lower-fidelity predicts correct discharge stages at other locations. Table 3.4 shows that the lower-fidelity model predicts maximum discharges along the Lower Rhine with high accuracy, having a maximum deviation of $2.1 \%$ compared to the high-fidelity model. In addition, the lower-fidelity model is capable of accurately predicting the discharge partitioning along the Dutch Rhine river branches (Table 3.4). These values indicate that the surrogate model is capable of representing the system behaviour of the high-fidelity model. Therefore, no correction-function is needed to tune the model results of the lower-fidelity model. We can thus conclude that the lower-fidelity model can be treated as a high-fidelity model from now on. Hence, the sensitivity analysis can be performed with the $1 \mathrm{D}-2 \mathrm{D}$ coupled model.

The results of the uncertainty analysis show that the average maximum discharge at Lobith as a result of the Monte Carlo sample equals $12,424 \mathrm{~m}^{3} / \mathrm{s}$. This value 
Results of the Multiple Linear Regression analysis in which the most influential parameter has a ranking equal to 1 and the least influential parameter a ranking equal to 9 .

\begin{tabular}{l|l|ccccc}
\hline \hline \multicolumn{2}{c|}{ Input parameter } & $\beta_{\mathrm{i}}$ & $\sigma_{\mathrm{i}}\left[\mathrm{m}^{3} / \mathrm{s}\right]$ & $\hat{\beta}_{\mathrm{i}}$ & $\begin{array}{c}\text { Ranking } \\
\text { Rurface } \\
\text { area [\%] }\end{array}$ \\
\hline \multirow{2}{*}{ Roughness class } & Summer bed & $-3.65 \times 10^{3}$ & $1.97 \times 10^{-3}$ & 0.15 & 2 & 13.3 \\
& Lakes & $-1.81 \times 10^{3}$ & $2.68 \times 10^{-3}$ & 0.10 & 5 & 13.2 \\
& Grasslands & $-4.81 \times 10^{3}$ & $8.71 \times 10^{-3}$ & 0.86 & 1 & 55.6 \\
& Forest & $-2.83 \times 10^{2}$ & $1.95 \times 10^{-2}$ & 0.11 & 4 & 6.4 \\
& Urban areas & $-2.29 \times 10^{2}$ & $2.73 \times 10^{-3}$ & 0.01 & 7 & 11.4 \\
\hline \hline \multirow{2}{*}{ Bed level } & Winter bed & -70.3 & $3.18 \times 10^{-2}$ & 0.05 & 6 & 9 \\
& Summer bed (1) & 1.2 & $7.00 \times 10^{-2}$ & 0.00 & 9 & \\
& Summer bed (2) & 27.5 & 0.25 & 0.13 & 3 & \\
& Summer bed (3) & 8.3 & 0.04 & 0.01 & 8 & \\
\hline \hline
\end{tabular}

has a standard deviation of $49 \mathrm{~m}^{3} / \mathrm{s}$ caused by the uncertainty in the input parameters. This relatively low standard deviation shows that uncertainties in the input parameters only have a limited effect on the maximum discharge at Lobith during the 1926 flood event.

\subsubsection{Sensitivity analysis}

\section{Multiple linear regression analysis}

A multiple linear regression analysis was performed in which it was assumed that the model response as a result of the varying input parameters was linear. This is not the case since the model coefficient of determination $R^{2}$ (equation 5.3) equals 0.81 . This value means that the regression model is capable of explaining $81 \%$ of the variance of the surrogate output. The remaining $19 \%$ is ignored by the regression model. However, Table 3.5 clearly shows that the roughness of grasslands highly influences the maximum discharge at Lobith because of its high sensitivity measure $\hat{\beta}_{\mathrm{i}}$ (equation 3.3 ). The high standardized regression coefficient of the roughness of grasslands can be explained by the fact that grassland is the most dominant land cover in the model domain with a surface area of $55.6 \%$ (Table 3.5). In addition, the uncertainty within the class itself is relatively large (Table 3.2) since grasslands most often have a higher roughness during summer periods due to growing season compared to the winter periods. Only the roughness of forest has a larger uncertainty range. However, the surface area covered by forest is much less $(6.4 \%)$. 
Computed Sobol' indices with the method of Li and Mahadevan (2016) in which the most influential parameter has a ranking equal to 1 and the least influential parameter a ranking equal to 9 .

\begin{tabular}{|c|c|c|c|c|}
\hline \multicolumn{2}{|c|}{ Input parameter } & \multirow{2}{*}{$\begin{array}{l}S_{i} \\
0.10\end{array}$} & \multirow{2}{*}{$\begin{array}{c}\text { Ranking } \\
2\end{array}$} & \multirow{2}{*}{$\begin{array}{c}\begin{array}{c}\text { Surface } \\
\text { area [\%] }\end{array} \\
13.3\end{array}$} \\
\hline Roughness class & Summer bed & & & \\
\hline & Lakes & 0.01 & 7 & 13.2 \\
\hline & Grasslands & 0.77 & 1 & 55.6 \\
\hline & Forest & 0.05 & 5 & 6.4 \\
\hline & Urban areas & -0.03 & 9 & 11.4 \\
\hline \multirow[t]{4}{*}{ Bed level } & Winter bed & 0.09 & 3 & \\
\hline & Summer bed (1) & 0.01 & 8 & \\
\hline & Summer bed (2) & 0.06 & 4 & \\
\hline & Summer bed (3) & 0.03 & 6 & \\
\hline
\end{tabular}

\section{Sobol' indices}

In the previous section it was shown that with the Multiple Linear Regression analysis only $81 \%$ of the variance of the surrogate model output could be explained. In order to check the results of the Multiple Linear Regression analysis, the Sobol' indices are computed. These indices are independent of model linearity. The results show that the roughness of grasslands is dominant with respect to influencing the uncertainty of the maximum discharge at Lobith (Table 3.6). This is in line with the results of the Multiple Linear Regression analysis.

If $\sum_{i=1}^{N} S_{\mathrm{i}}=1$, the variance of the model output is solely caused by the variance of the input parameters itself. In that case, there are no interactions between the different input parameters resulting in an increase in the variance of the model output. In other words, the model is additive. The results show that the first-order Sobol' indices are approximately 1 indicating that the model does not include any interactions of the input parameters.

In principle $\sum_{i=1}^{N} S_{\mathrm{i}}$ cannot be larger than 1 . In addition, the first-order Sobol' index computed for each uncertain input parameter cannot be lower than 0 (Saltelli et al, 2008). In this study, the computed $\sum_{i=1}^{N} S_{\mathrm{i}}$ is slight larger than 1 and the Sobol' index for the roughness of urban areas is smaller than 0 . This is caused by the relatively small sample size of only 120 runs. To overcome this problem, we resampled the 120 runs as explained in Section 3.3.3. With this resampled data set, the $95 \%$ 


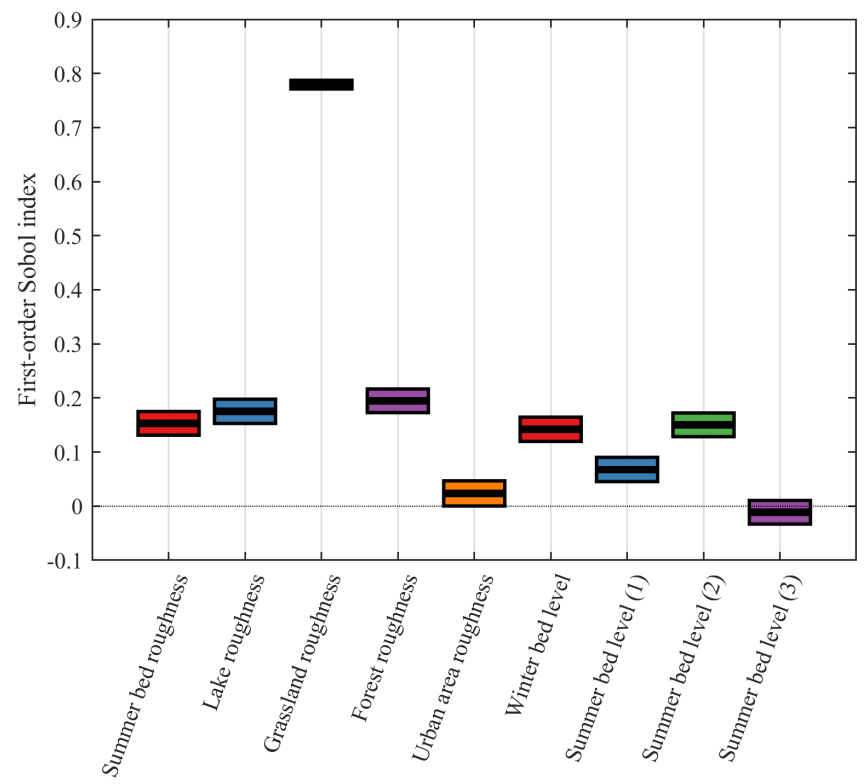

Figure 3.9

First-order Sobol' indices and its 95\% confidence intervals based on the bootstrap resamples.

confidence intervals of the first-order Sobol' indices are computed (Fig. 3.9). Fig. 3.10 shows that the first-order Sobol' indices have converged after approximately 700 bootstrap resamples. This results in a data set of $700 \times 120$ model runs. The outcomes then show that the roughness of grasslands remains the most dominant input parameter. The lower bound of its confidence interval is under any condition larger than the sensitivity index of the other input parameters. Therefore, we can conclude that for this specific case, most attention must be paid to the roughness class with the largest surface area and which has a relatively large uncertainty range. Correct prediction of this parameter will result in a significant reduction of the output variance. It must be noted that the uncertainty of the model output was small in this study. In general, the output variance depends on the probability distribution functions of the uncertain input parameters. It can be expected that the output variance will increase for older historic events. Hence, a significant reduction in model output variance can be reached if the most influential input parameter is correctly predicted. This influential input parameter can be found by applying the method for factor prioritization as presented in this study. 


\subsection{Discussion}

In this study, a methodology was developed to reconstruct historic flood events with the use of a lower-fidelity model. The maximum discharge is predicted as well as its uncertainty as a result of the uncertain input parameters. General problems that arose were mostly related to the choice of the surrogate model type and the characteristics of the flood event. Therefore, another historic event may ask for a different approach since the assumptions made for the 1926 event may not apply. To put things into perspective, an overview and discussion are presented of the problems that may arise during historic flood reconstruction and resulting sensitivity analysis.

1. To predict a historic discharge, an associated geometry should be reconstructed. The geometry during the 1926 event was well known since maps of this time period are available. However, for events further in the past the geometry might be more uncertain. These spatial uncertainties must be included in the analyses. A major drawback is that for each (uncertain) geometric situation a separate model must be set up. Consequently, for each

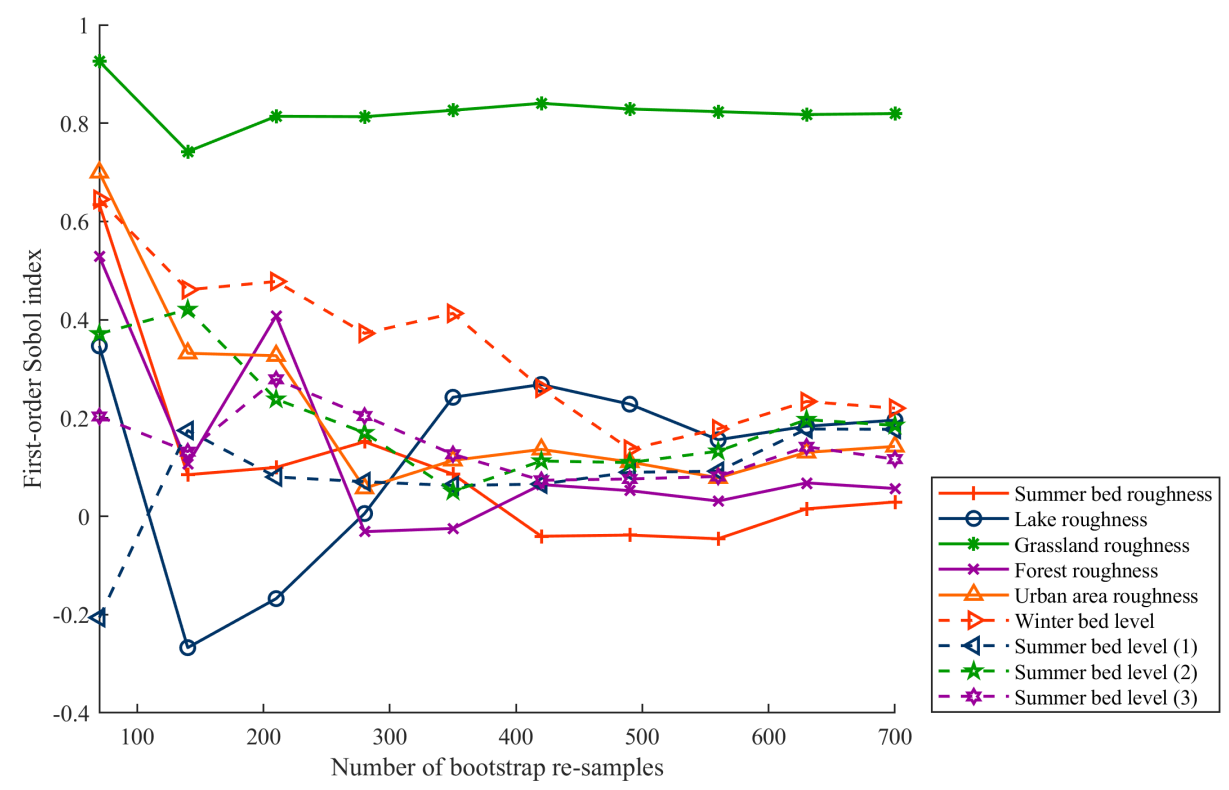

Figure 3.10

Convergence of the first-order Sobol' indices based on the bootstrap resamples. 
model, the sensitivity analysis must be performed separately. This significantly increases the total number of simulations. Furthermore, for older events the uncertainties in the input parameters may become larger. Hence, the shape of their probability distributions may change. We assumed that the uncertain input parameters of the 1926 flood event could be described by truncated normal distributions. These distributions will shift towards uniform distributions for older events if less information is available.

2. A lower-fidelity based surrogate model was developed to reduce computational time. Many other methods exist to set up a surrogate model, each with their own benefits and drawbacks. A different study approach may lead to the need of another type of surrogate model. In general, a 1D-2D coupled model is capable of simulating any kind of flood event. The 1D profiles enable correct prediction of discharge stages below bankfull conditions (Horritt and Bates, 2002). These 1D profiles can be coupled by 2D grid cells to include the possibility of simulating overland flows if the discharge exceeds the bankfull discharge, referring to the situation in which the discharge is larger than the main channel and floodplain capacity. Therefore, this type of lower-fidelity model can be used to accurately simulate flood wave propagation for both discharges below as well as above bankfull conditions.

3. The 1D-2D coupled model was not calibrated on maximum water levels. The objective of the surrogate model was accurate prediction of maximum discharges at Lobith. However, calibration on maximum water levels is required if dike breaches and/or overtopping have evolved during the flood event. For such a case, correct prediction of maximum water levels becomes important since this value indicates whether overtopping occurs. This influences the maximum discharge further downstream. Therefore, it is recommended to use the summer bed roughness of the lower-fidelity model as calibration parameter to correctly predict water levels in case of discharges exceeding bankfull conditions.

4. To perform the sensitivity analysis, a decision had to be made about the range of the truncated normal distributions of the input parameters. The ranges of the roughness parameters were based on the tables of Chow (1959). A smooth channel with no vegetation was assumed to determine the roughness of the summer bed. This results in a relatively low expected Manning's roughness value of 0.028 , with a total range of between 0.023 to 0.033 . It is expected that the dimensions of sand dunes during flood events are highly uncertain. This uncertainty may influence summer bed roughness significantly. The measured Manning's roughness of the summer bed during the 1998 event with a maximum discharge of $9,464 \mathrm{~m}^{3} / \mathrm{s}$ at Lobith ranges of between 0.030 to 0.035 (Julien et al, 2002). These values are higher than the values that we used. Paarlberg et al (2010) found a clear dependency between increase in the discharge and increase in the dune heights. However, it is still unclear to what extent dune heights increase during flood events. 
Some literature even suggest that the dunes are washed out under extreme conditions (e.g. Best (2005) and Naqshband et al (2014)), resulting in much lower values of the roughness parameter. It is not the roughness value itself that influences the uncertainty of the maximum discharge, but rather the uncertainty range of the summer bed roughness. Therefore, the relatively broad roughness range for the summer bed used in this study is considered appropriate for the 1926 flood event.

5. In this study, only geometrical uncertainties in the input parameters are included in the sensitivity analyses. These parameters are the bed levels of the summer bed and winter bed and the roughness of the various land use classes. However, much more uncertainties exist which can be related to the model structure, model parameters and boundary conditions. These inherent uncertainties can be considered in the sensitivity analysis by including them as random input parameters in the LHS. This will result in more insight in the most dominant type of uncertainty, i.e. uncertainty as a result of the input parameters, model parameters or model set-up. This study is recommended for future work since here, we only focused on the uncertainties of the geometrical input parameters to illustrate our method.

\subsection{Conclusions}

The objective of this paper was to study whether a lower-fidelity hydraulic model can be used for historic flood reconstruction. In this paper, a general framework is presented that shows which problems have to be tackled in order to enable historic flood reconstruction with the use of a surrogate model.

A 1D-2D coupled model was developed as lower-fidelity model that is capable of simulating flood wave propagation with high accuracy. It was found that model results predicted by the lower-fidelity model were close to those predicted by the high-fidelity model. The lower-fidelity model is thus capable of accurately predicting system behaviour. In addition, the proposed $1 \mathrm{D}-2 \mathrm{D}$ coupled model can be applied to any type of historic flood event. This is because it is capable of accurately simulating flood wave propagation for both discharges below as above bankfull conditions. However, if the simulated discharges exceed the bankfull discharge, model calibration is recommended since correct prediction of water levels becomes highly relevant for these cases.

A sensitivity analysis is required to determine the parameters that mostly influence the uncertainty in the model output. The lower-fidelity model could be used to perform this analysis. This significantly decreased computational time compared to the use of a fully 2D model. For future work, we propose that a 1D-2D coupled model can be treated as a high-fidelity model in general. Therefore, setting up a 
sophisticated 2D model for validation will not be needed.

The proposed methodology was tested with the use of the 1926 flood event of the Rhine river. The lower-fidelity model predicts a maximum discharge at Lobith of $12,402 \mathrm{~m}^{3} / \mathrm{s}$ for this historic event, deviating only $1.0 \%$ compared to the high-fidelity model $\left(12,282 \mathrm{~m}^{3} / \mathrm{s}\right)$. The uncertainty of this maximum discharge at Lobith equals $49 \mathrm{~m}^{3} / \mathrm{s}$. The uncertainty in model output is relatively small because a large amount of data of the 1926 flood event was available. Reconstruction of an older flood event will probably result in larger uncertainties of the input parameters since less information is available. As a result, the truncated normal distributions used to describe the uncertainty of the various input parameters will shift towards uniform distributions. This will have a negative effect on the model output uncertainty.

The sensitivity analysis showed that the model output was most sensitive to the roughness class with the largest share in surface area (in this case the roughness of the grassland areas). Moreover, the location of the roughness class was important since areas close to the river have a relatively large impact on model results. These two aspects in combination with the uncertainty range of the input parameter itself determined the influence on model response.

\section{Acknowledgement}

This research is supported by the Netherlands Organisation for Scientific Research (NWO, project 14506) which is partly funded by the Ministry of Economic Affairs and Climate Policy. Furthermore, the research is supported by the Ministry of Infrastructure and Water Management and Deltares. This research has benefited from cooperation within the network of the Netherlands Centre for River studies NCR (www.ncr-web.org).

The authors would like to thank the Dutch Ministry of Infrastructure and Water Management and the German Federal Institute of Hydrology for providing the data. Besides, the authors would like to thank the following persons for their suggestions and valuable insights: Prof. Dr. Herget (University of Bonn), Dr. Aguilar-Lopez (Technical University Delft), Dr. Lammersen (Dutch Ministry of Infrastructure and Water Management), Van Doornik Msc. (Lievense CSO), Berends Msc. (University of Twente) and Dr. Mara (University of La Réunion). In addition, the authors would like to thank the anonymous reviewer, Sheikholeslami Msc. (Unversity of Saskatchewan) and the associate editor Dr. Razavi for their suggestions during the review process, which greatly improved the quality of the paper. 


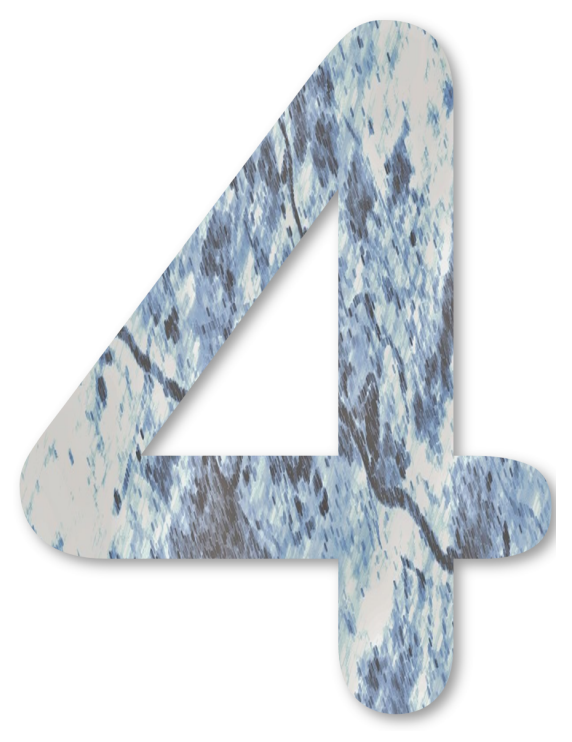

\section{Historic flood reconstruction with the use of an Artificial Neural Network}

This chapter is published as A. Bomers, B. van der Meulen, R.M.J. Schielen, and S.J.M.H. Hulscher (2019). Historic flood reconstruction with the use of an Artificial Neural Network, Water Resources Research. DOI:10.1029/2019WR025656 


\section{Abstract}

The uncertainty in flood frequency relations can be decreased by adding reconstructed historic flood events to the data set of measured annual maximum discharges. This study shows that an Artificial Neural Network trained with a 1D-2D coupled hydraulic model is capable of reconstructing river floods with multiple dike breaches and inundations of the hinterland with high accuracy. The benefit of an Artificial Neural Network is that it reduces computational times. With this Network, the maximum discharge of the 1809 flood event of the Rhine river and its $95 \%$ confidence interval was reconstructed. The study shows that the trained Artificial Neural Network is capable of reproducing the behaviour of the hydraulic model correctly. The maximum discharge during the flood event was predicted with high accuracy even though the underlying input data is, due to the fact that the event occurred more than 200 years ago, uncertain. The confidence interval of the prediction was reduced with $43 \%$ compared to earlier predictions that did not use hydraulic models.

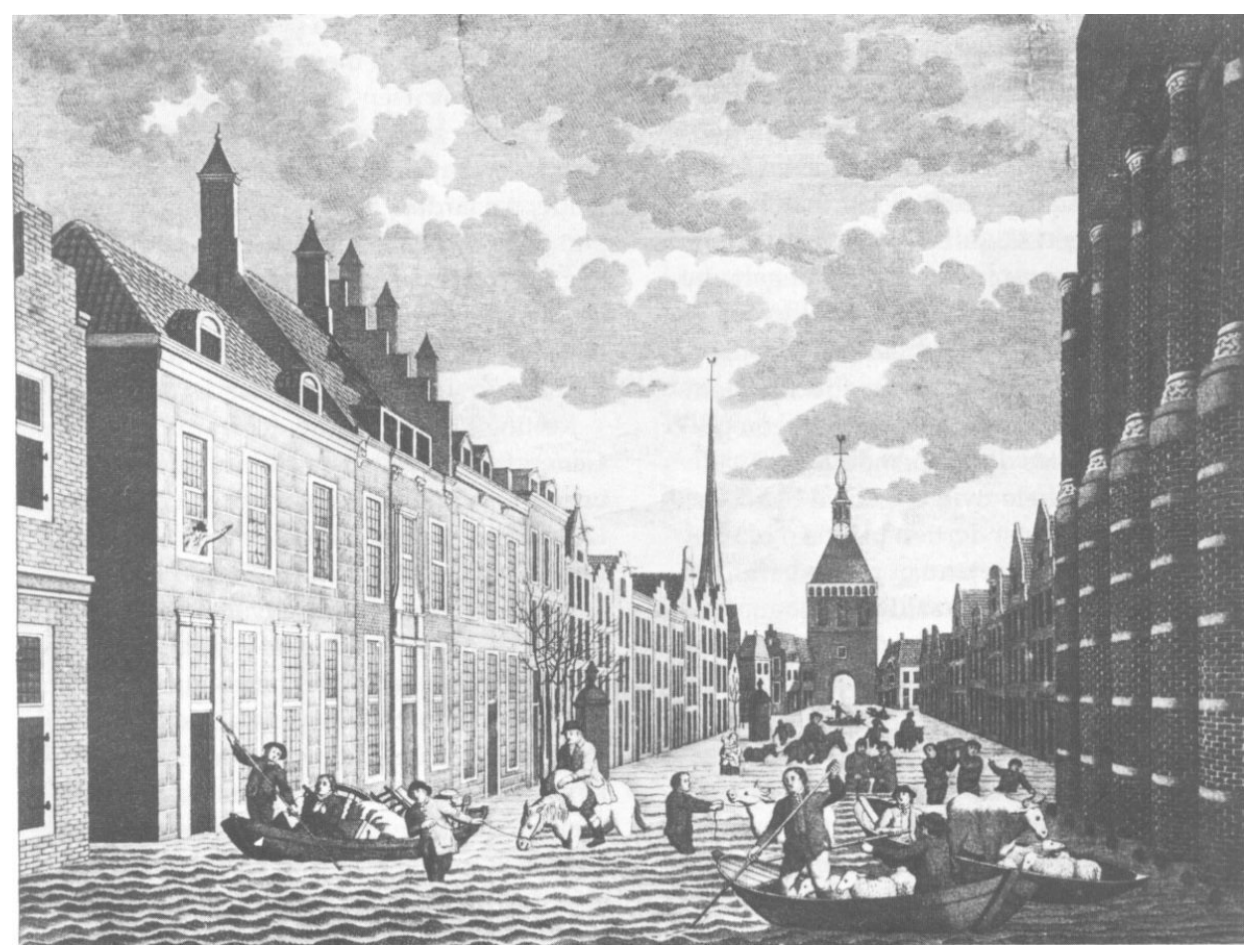

Painting of the 1809 flood event at Culemborg by J.G. Visser 


\subsection{Introduction}

River floods affect more people worldwide than any other natural hazard as they cause large economic damage and human casualties (Blöschl et al, 2017). To protect the hinterland from being inundated, flood defences are commonly designed such that they can withstand a flood event with a specific probability of occurrence. Most often, flood frequency analyses are used to establish such a discharge frequency relation. This relation is computed using measured discharges. The data set of measured discharges is generally limited because of the short time period that measurements have been performed. For example, in the Netherlands discharges have been measured since 1901 while the largest flood safety level along the river branches has a return period of 100,000 years (Van Alphen, 2016). As a result of the limited data set of measured discharges and because extreme events from pre-instrumental records are not included, the discharge frequency relation has a large uncertainty interval. This specifically accounts for discharges corresponding to rare events where extrapolation is required. The uncertainty interval of the relation can be reduced by extending the data set of measured discharges with historic flood events (Bomers et al, 2019c).

Many studies have attempted to reconstruct historic flood events based on various sources (e.g. flood marks, flood deposits, written records) to extend the data set of measured discharges. For instance, Herget and Meurs (2010) reconstructed maximum discharges of historic events near the city of Cologne. Historical information about occurred water levels was translated into discharges with the use of the empirical Manning's equation. Toonen et al (2015) used grain-size measurements of flood deposits to reconstruct historic flood magnitudes of the last 450 years of the Lower Rhine. Recently, many papers study how information of historic flood events can be included in a flood frequency analysis (e.g. Frances et al (1994); MacDonald et al (2014); O'Connell et al (2002); Reis and Stedinger (2005); Sartor et al (2010); Toonen et al (2015)). These studies showed that extending the data set with historic events significantly reduces uncertainty intervals of flood frequency relations. However, in most studies the uncertainty of the reconstructed historical discharges themselves were quite large. Reducing the uncertainty of these reconstructions has the potential to further decrease the uncertainty interval of flood frequency relations such that design discharges with large return periods can be predicted more accurately. We are specifically interested in reducing the uncertainty in the upper bound of the $95 \%$ confidence interval since this bound highly influences the design discharges corresponding to rare events as a result of extrapolation of data set of measured discharges. A way to decrease this uncertainty is to use hydraulic models.

Hydraulic models with a discharge wave as upstream boundary condition are commonly calibrated on measured water levels with the main channel friction as calibration parameter (Bomers et al, 2019d; Caviedes-Voullième et al, 2012; Domhof 
et al, 2018). Generally, for many historic flood events, one or multiple maximum water levels at several locations are known. However, corresponding discharges are often unknown. Therefore, it is not possible to calibrate the hydraulic model. This can be explained as follows: there is an infinite number of possible combinations of main channel friction and discharges that will result in correct prediction of water levels. A larger discharge can be compensated by a lower main channel friction and vice versa, resulting in the same simulated water levels. Therefore, to determine the potential maximum discharge of a historic flood event with the use of a hydraulic model, many model runs (in the order of 1,000 to reach convergence in model output) must be performed to capture all possible main channel frictiondischarge combinations. The use of a physical hydraulic model is unfeasible for this application. Therefore, the objective of this paper is to study whether a response surface surrogate (i.e. a data-driven model without any physical processes of the original system) can be used to predict maximum discharges of historic flood events of which only water levels are known at a few locations. Response surface surrogate models are considered since computational time for this category of models is most often in the order of seconds because the model consists of relatively simple mathematical functions without any physical interpretations.

In this study, the 1809 flood event of the Rhine river is used as a case study. This flood event resulted in multiple dike breaches and consequently to inundations of the hinterland. Simple linear regression models are not capable of reproducing the non-linear behaviour caused by dike breaches (Toonen, 2015). Therefore, we set up an Artificial Neural Network (ANN) as response surface surrogate model. ANNs are probably the most successful type of surrogate model with a flexible mathematical structure that is capable of identifying complex non-linear behaviour between input and output (Dibike and Solomatine, 2001). Many hydrological studies have shown the applicability of ANNs for flood forecasting purposes (e.g. Campolo et al (2003); Elsafi (2014); Lekkas et al (2004); Laio et al (2003); Kerh and Lee (2006)). These studies have set up an ANN to predict discharges and/or water levels at a specific site based on information of upstream gauge stations. It was found that the developed ANNs are well capable of describing flood propagation, making them a suitable forecasting tool.

Recently, ANNs are set up more frequently for flood routing modelling. Kia et al (2012) created flood maps of the Johor River basin, Malaysia. A hydrological model was used as a high-fidelity model having, among others, rainfall as input data. Peters et al (2006) and Shrestha et al (2005) set up an ANN to predict flood wave propagation in a river basin. A $1 \mathrm{D}$ hydraulic model was used to create the training data including flood events larger than measured so far. They found that the use of an ANN reduces computational times significantly compared to the hydraulic models, making them applicable for real-time control.

Most of the presented studies used measurements or hydrological modelling to create the training data, whereas the studies that made use of hydraulic mod- 
elling only focused on in-channel flood conditions. However, the large historic flood events typically resulted in dike breaches and inundations of the hinterland. Therefore, we are interested to what extent an ANN is capable of reproducing the physical behaviour of a flood event with multiple dike breaches. During the 1809 flood event, several ice jams were present in the studied area. These ice jams may influence the physical behaviour of the discharge propagation. However, we assume that the effects of these ice jams on maximum discharges were negligible, which is discussed in detail in Section 4.6.2.

The outline of the paper is as follows. Firstly, the 1809 flood event and the steps taken to reconstruct the 1809 geometry are presented in Section 4.2. Then, the high-fidelity model is given (Section 4.3) as well as the set-up of the ANN (Section 4.4). The ANN is validated and used to reconstruct the maximum 1809 discharge in Section 6.5. The paper ends with a discussion and main conclusions in Section 6.6 and Section 6.7 respectively.

\subsection{9 flood event of the Rhine river delta}

\subsubsection{Characteristics of the 1809 flood event}

The 1809 flood event resulted in high water levels and inundations of the embanked areas in the Rhine delta. In total, 100,000 people were affected by the flood and around 275 people died (Driessen, 1994). From half December 1808 till the $10^{\text {th }}$ of January 1809, the temperatures were far below zero in Germany and the Netherlands (Lintsen, 1993). Due to the extremely low temperatures, the Dutch Rhine river branches were frozen. Around the $10^{\text {th }}$ of January, the temperature started to rise and as a result, ice sheets started to move chaotically. This caused the formation of a large ice jam downstream of Arnhem (Fig. 4.2). Hence, the Nederrijn river was blocked and a larger discharge started to flow towards the IJssel river, resulting in multiple dike breaches. The second flood event followed around the $25^{\text {th }}$ of January. This resulted in even more dike breaches and inundations. We only focus on the first flood event which occurred around the $10^{\text {th }}$ of January since this event corresponds with the highest water levels measured during this flood. Hence, this moment most probably also corresponds with the largest maximum discharge at Lobith (Toonen, 2015) which we mainly aim to predict. This discharge can then be used to extend the data set of annual maximum discharges.

The study area stretches from Emmerich to the Dutch cities of Zutphen, Rhenen and Druten (Fig. 4.2). In this area, six dike breaches occurred in the period from the $12^{\text {th }}$ till the $15^{\text {th }}$ of January, resulting in inundations of the hinterland (Fig. 4.2). During the event, daily water level measurements were performed at four locations in the studied area, namely at Pannerden, Nijmegen, Arnhem and 
Doesburg (Fig. 4.1). Only the water level measurements closest to Lobith, which are Pannerden and Nijmegen, are used to determine the maximum discharge at Lobith. This is because the water levels at Arnhem and most probably also at Doesburg were affected by ice sheets in the Nederrijn river. Consequently, the hydraulic model is not able to correctly simulate the water levels at these two locations.

\subsubsection{Reconstruction of the 1809 geometry}

The 1809 topography, river position and bathymetry, dimensions of river embankments, and land use are reconstructed from different sources. To reconstruct the topography, a collection of elevation measurements obtained between 1950 and 1965 is used (Atlasproducties, 1987). Because this period predates major anthropogenic changes such as land levelling for agricultural practices, this data can be used to approximate the early 19th century topography (Alkema and Middelkoop, 2005). The point data is converted into a digital elevation model (DEM) by simple point to raster conversion in ArcGIS (ESRI, 2016), with a relatively large output cell size of $500 \times 500 \mathrm{~m}$. This rather large cell size was chosen in order to avoid artifacts from interpolation and to smooth out possible inaccuracies in the historical measurement data.

For the reconstruction of the river position and bathymetry, the first edition of the Algemene Rivierkaart (literally translated as General River map, and also known

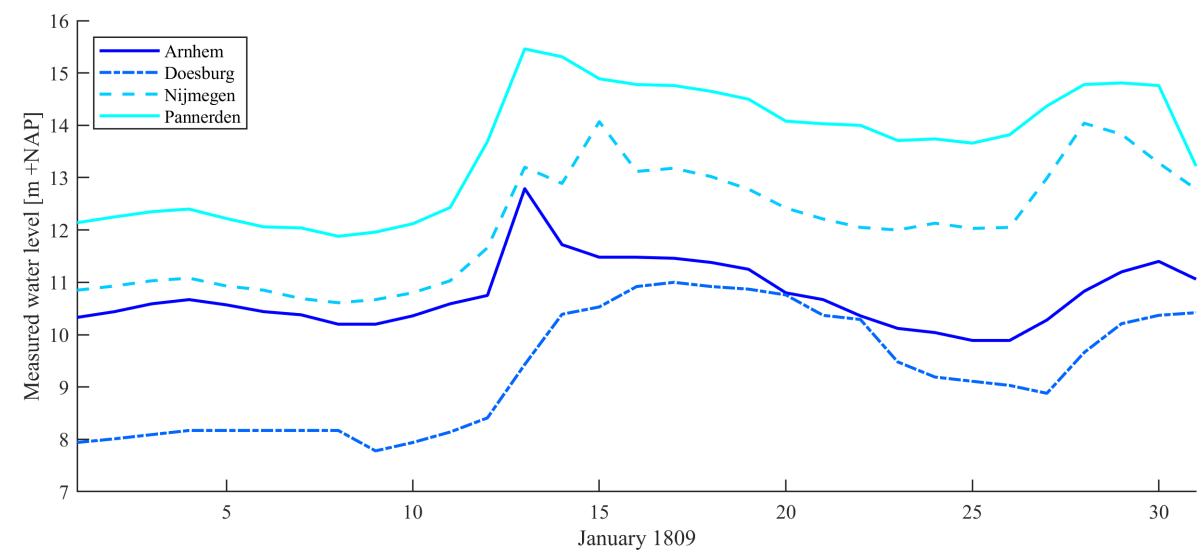

Figure 4.1

Daily measured water levels during the 1809 flood event. The locations are presented in Fig. 4.2. 
as "Goudriaankaarten" after the maker) map series is used, which completely covers the large rivers in the Netherlands at a scale of 1:10,000. The maps of the Rhine river branches Waal, Nederrijn and IJssel were produced in the periods 1830-1832, 1833-1839 and 1840-1844 respectively (Van den Brink, 2002), which is before the onset of major river normalization in the mid-19 ${ }^{\text {th }}$ century. The historical river planform geometry is obtained by first georeferencing the individual map sheets and subsequently tracing the river banks in ArcGIS (Van der Meulen et al, 2018). In the period when the maps were created, water depth profiles were measured across the river at intervals of one kilometer. This data accompanied the maps in separate registers (Boode, 1979) and were considered lost (Wierda and Zweerus, 1994), until recently (Van der Meulen et al, 2018). We copied the historical data, consisting of measured depths and distances between depths and assigned geographical locations to the measurement points by linking the data to their respective cross sections, which are indicated on the maps. The cross sections are interpolated using the cubic Hermite interpolation method, resulting in a DEM of the main channel of the various river branches. Since the cross sections had an interval of one kilometer, the accuracy near the bifurcation points of the Rhine river branches was not sufficient to correctly simulate the discharge partitioning along the Dutch Rhine river branches. Therefore, the DEM at the locations of the bifurcation points is replaced by the 1926 DEM which was available from previous work (Bomers et al, 2019a).

To reconstruct the river embankments in 1809, the first edition of the Algemene Rivierkaart are used, complemented by the first edition of the Dutch Waterstaatskaart (literally translated as Water Management map). The Algemene Rivierkaart is used to reconstruct the locations of the river dikes as vector lines in ArcGIS. The first edition of the Waterstaatskaart was created in the late $19^{\text {th }}$ century and covers the entire Netherlands at a scale of 1:50,000 (Heere and Storms, 2002; Blauw, 2005). The map sheets that cover our study area were produced between 1871 and 1879. These maps locally provide information on dike heights, which were implemented in ArcGIS, after which we linearly interpolated between the heights along the dike lines.

In order to supply the model with historically-accurate friction values, reconstructions of land use based on early (circa 1900) topographical maps of the Netherlands (Knol et al, 2004) are used. Largest changes to land use in the study area occurred in early historic times, when the entire area was taken into agricultural use, and in the $20^{\text {th }}$ century, when cities and road networks expanded at unprecedented scale. Therefore, the land use situation around 1900 can be applied to the situation in 1809. The land use classes provided in the maps were translated into Manning's roughness coefficients with the tables of Chow (1959). This translation is provided in Table 4.1. 
Translation of land use classes into Manning's roughness coefficients.

\begin{tabular}{lc}
\hline \hline Land use in 1900 (Knol et al., 2004) & Manning's roughness coefficients $\left[\mathrm{s} / \mathrm{m}^{1 / 3}\right]$ \\
\hline Grasslands & 0.030 \\
Agriculture & 0.030 \\
Moorland & 0.030 \\
deciduous forest & 0.150 \\
coniferous forest & 0.150 \\
Urban areas & 0.036 \\
Open water & 0.024 \\
Reed swamps & 0.070 \\
Drift sand & 0.029 \\
\hline \hline
\end{tabular}

\subsection{High-fidelity model}

\subsubsection{Set-up of the 1D-2D coupled model}

A one dimension-two dimensional (1D-2D) coupled model is used as a high-fidelity model, because such a simplified model has as advantage that computational time is decreased significantly compared to a fully $2 \mathrm{D}$ model, while not many physical processes of the original system are lost (Bomers et al, 2019a). The 1D-2D coupled model is run to create the training data to set up the ANN. The geometry is schematized by 1D nodes as much as possible to keep computational time minimal. Only at locations where a 2D component (Rijnstrangen area, Fig. 4.2) is required to correctly model the physical processes of the flood event, a $2 \mathrm{D}$ grid is used. This has as advantage that computational time can be relatively low compared to a fully 2D model, while model accuracy remains sufficient. HEC-RAS (v. 5.0.3), developed by the Hydrologic Engineering Centre (HEC) of the US Army Corps of Engineers, is used for the $1 \mathrm{D}-2 \mathrm{D}$ flood modelling.

The main channel and its floodplains are captured by 1D profiles since 1D profiles are capable of accurately predicting flood wave propagation in case of in-channel flows and under normal flow conditions (Tayefi et al, 2007). These 1D profiles are coupled with 1D storage areas (Fig. 4.2), representing the embanked areas (i.e. the areas that are not part of the river system and are protected by dikes against inundations). If the simulated water levels in the $1 \mathrm{D}$ profiles exceed the dike crest levels, water starts to flow into the storage areas corresponding with inundations of the hinterland. Bomers et al (2019b) showed that for the discharge range considered in this study, no significant overland flows are present. The water that leaves the river system is not capable of flowing back into the river 
at a downstream location. Hence, only a reduction of the maximum discharge in downstream direction as a result of overflow and/or dike breaches is found. This justifies the use of the 1D storage areas and neglecting the overland flow patterns.

Only the Rijnstrangen area (Fig. 4.2) is discretized with a $2 \mathrm{D}$ grid since it is important that the flow through the Rijnstrangen area is correctly simulated. This is because it influences the discharge at the Pannerdensch Canal and hence the simulated water levels at Pannerden. These water levels are used to determine the maximum discharge at Lobith during the flood event. The Rijnstrangen area is connected with the Lower Rhine by an inlet. An inlet refers to a dike section with a lower crest level compared to its surrounding dike sections. As a result of the lower crest level, water starts to flow into the Rijnstrangen area as soon as the water level exceeds the crest level of the inlet. For this specific case, the crest level of the inlet is equal to $10.78 \mathrm{~m}+\mathrm{NAP}$ (Ploeger, 1992).

A discharge wave at Emmerich is used as upstream boundary condition. Normal depths are used as downstream boundary conditions at the Waal, Nederrijn and IJssel rivers (Fig. 4.2). Normal depths can be computed with the use of the Manning's equation which can be written as (Brunner, 2016):

$$
V=\frac{R^{2 / 3}}{n} \sqrt{S_{f}}
$$

in which $V$ represents the cross sectional averaged flow velocity $[\mathrm{m} / \mathrm{s}], R$ the hydraulic radius $[\mathrm{m}]$ depending on the water depth, $n$ the Manning's roughness coefficient $\left[\mathrm{s} / \mathrm{m}^{1 / 3}\right]$, and $S_{f}$ the slope of the energy grade line [-]. Generally, the energy slope can be approximated by the slope of the main channel (Brunner, 2016). Because the flow velocity is computed at each time step during the simulation, the Manning's equation with an energy slope equal to the bed slope as input data produces a water level considered to be the normal depth in both the main channel and floodplains of the various river branches.

The reconstructed land use classifications (Table 4.1) are implemented in the model as Manning's roughness values with the use of the tables of Chow (1959). Only the main channel friction, which is commonly used as calibration parameter, is considered as a random input parameter to be used in a Monte Carlo framework (Section 4.3.2).

During the 1809 flood event, six dike breaches occurred in the studied area (Fig. 4.2, Dutch Ministry of Infrastructure and the Environment (1926)). These breaches are implemented in the model. Of each dike breach, the day of breaching is known (Dutch Ministry of Infrastructure and the Environment, 1926). In addition, historical maps of the dike breaches along the Waal river and Pannerdensch Canal are available. These clearly show the width of the dike breaches. The dike breach widths of the breaches along the Lower Rhine and Ouderijnstrangen area are assumed to be equal to 75 meter each, corresponding with the average dike breach width of the historical events reported in Apel et al (2008) and Verheij and Van 
der Knaap (2003). It is assumed that all dike breaches evolve to the level of the surrounding natural terrain within three hours (Dawson and Wilby, 2001). The settings of the dike breaches are provided in Table 4.2.

Because of the highly-detailed available information about the 1809 geometry, uncertainties in the bathymetry reconstruction are neglected in the analysis. Maps providing the exact location of the river course resulted in no plan metric un-

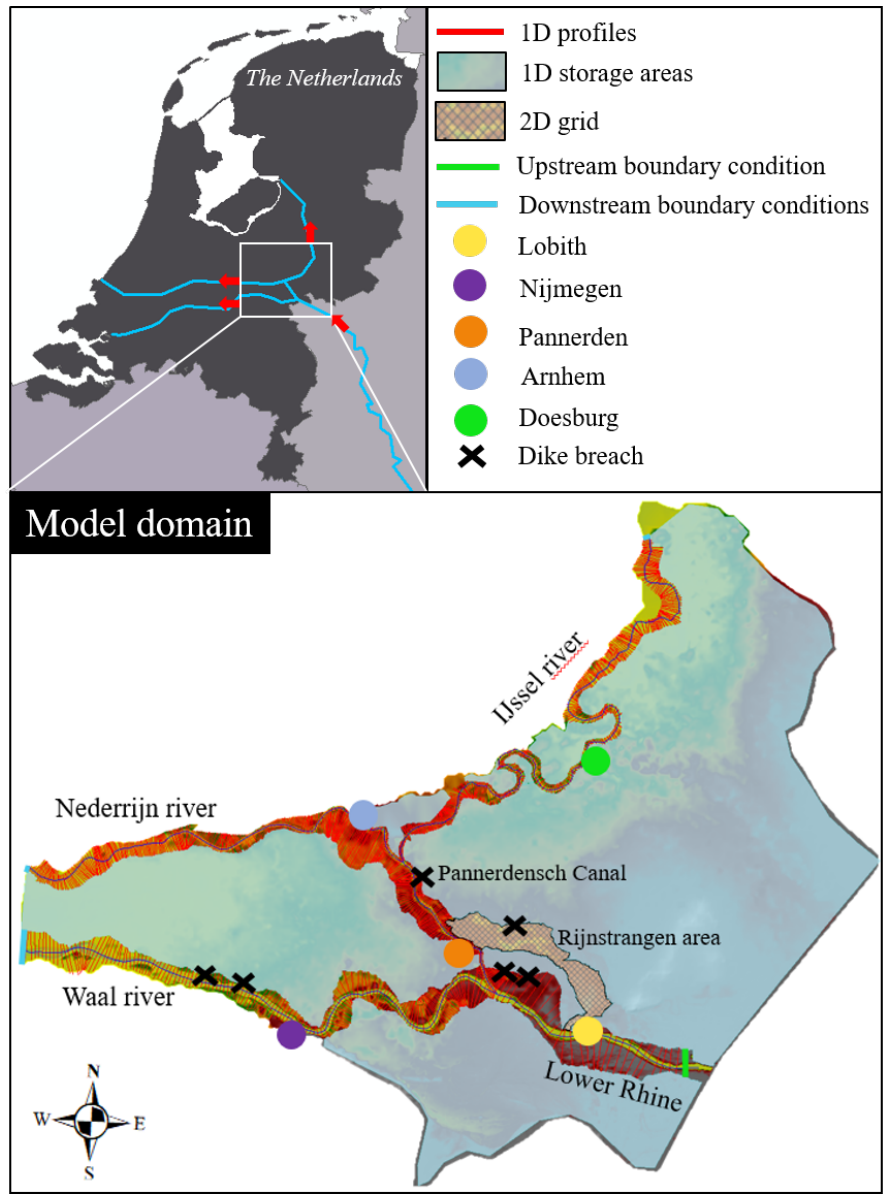

\section{Figure 4.2}

Model set-up of the high-fidelity 1D-2D coupled model used to create the training data. The flow direction is given by the red arrows in the left figure. The water flows from the Lower Rhine into the Waal river and Pannerdensch Canal. Subsequently, the Pannerdensch Canal bifurcates into the Nederrijn river and IJssel river. 
Dike breach settings. The locations of the dike breaches are provided in Fig. 4.2 in which the most upstream dike breaches along the Lower Rhine and Waal river correspond with number 1 and the downstream dike breaches with number 2 .

\begin{tabular}{l|cc|c}
\hline \hline Location & Date & Breach width $[\mathrm{m}]$ & Breach formation time $[\mathrm{h}]$ \\
\hline Lower Rhine 1 & 12 Jan & 75 & 3 \\
\hline Lower Rhine 2 & 12 Jan & 75 & 3 \\
Ouderijnstrangen area & 13 Jan & 75 & 3 \\
\hline Pannerdensch Canal & 13 Jan & 417 & 3 \\
Waal river 1 & 15 Jan & 188 & 3 \\
Waal river 2 & 15 Jan & 88 & 3 \\
\hline \hline
\end{tabular}

certainties. Only bed levels of the main channel and floodplains were uncertain caused by the interpolation of the measured cross sections (Section 4.2.2). However, Bomers et al (2019a) found that uncertainties in the floodplain bed levels and main channel bed levels only have a small effect on the maximum discharges throughout the model domain. This justifies to neglect these uncertainties.

\subsubsection{Design of Experiment}

To set up a surrogate model, a Design of Experiment (DoE) must be defined that determines the procedure of generating the training data with a high-fidelity model. DoEs employ different space filling strategies such that the behaviour of the underlying system over limited ranges of the input parameters is captured (Razavi et al, 2012b). In this study, six input parameters of the high-fidelity model are considered to be random since these were uncertain during the 1809 flood event. The uncertain input parameters are: the upstream discharge wave and the main channel friction of each Rhine river branch (five in total, Fig. 4.4).

Emmerich, Germany, which is located upstream of Lobith is used as upstream boundary (Fig. 4.3). The range of the maximum discharge wave at Emmerich is based on the work of Toonen (2015), who has reconstructed the 1809 maximum discharge based on average water level measurements of surrounding sites. Toonen (2015) determined the correlation between water level measurements at Lobith and surrounding sites based on measured time series. This regression curve was then used to predict the water level at Lobith based on the measured water levels at Emmerich, Pannerden and Nijmegen. Subsequently, the predicted water level at Lobith was translated into a maximum discharge during the 1809 flood event using a $\mathrm{Q}-\mathrm{h}$ relation. The confidence interval of the maximum discharge was based on the variation in predicted water levels at Lobith. Toonen (2015) found a maximum 


\begin{tabular}{|c|c|}
\hline \multicolumn{2}{|l|}{ High-fidelity model } \\
\hline $\begin{array}{l}\text { Input: } \\
\text { - Discharge wave at } \\
\text { Emmerich } \\
\text { - Main channel frictions }\end{array}$ & $\begin{array}{l}\text { Output: } \\
\text { - } \text { Maximum discharge at } \\
\text { Lobith } \\
\text { - Maximum water levels at } \\
\text { Pannerden and Nijmegen }\end{array}$ \\
\hline \multicolumn{2}{|l|}{ Training the ANN } \\
\hline $\begin{array}{l}\text { Input: } \\
\text { - Main channel frictions } \\
\text { - Maximum water levels } \\
\text { at Pannerden and } \\
\text { Nijmegen }\end{array}$ & $\begin{array}{l}\text { Output: } \\
\text { - Maximum discharge at } \\
\text { Lobith }\end{array}$ \\
\hline \multicolumn{2}{|c|}{1809 reconstruction with ANN } \\
\hline $\begin{array}{l}\text { Input: } \\
\text { - Main channel frictions } \\
\text { - Maximum measured } \\
\text { water levels at } \\
\text { Pannerden and } \\
\text { Nijmegen }\end{array}$ & $\begin{array}{l}\text { Output: } \\
\text { - Maximum discharge at } \\
\text { Lobith }\end{array}$ \\
\hline
\end{tabular}

\section{Figure 4.3}

Input and output data of the three steps to reconstruct the 1809 maximum discharge at Lobith: (1) Creating training data with the high-fidelity model, (2) setting up the ANN, (3) using the ANN to reconstruct the 1809 maximum discharge at Lobith.

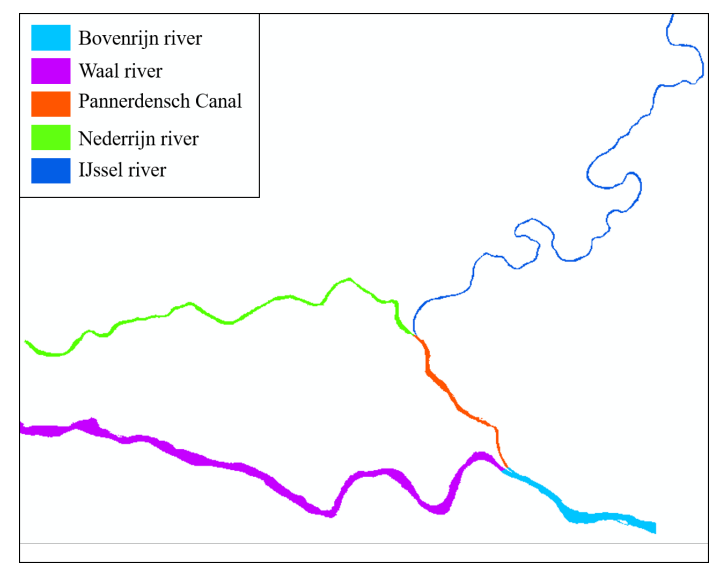

\section{Figure 4.4}

Each river branch has its own main channel friction section such that discharge partitioning can vary in the simulations. 
discharge range at Lobith of between $\sim 10,400-13,450 \mathrm{~m}^{3} / \mathrm{s}$. We use a range of $10,000-14,000 \mathrm{~m}^{3} / \mathrm{s}$ to ensure that the range at Emmerich is wide enough and captures the potential 1809 maximum value at Lobith. This can be evaluated during the first runs with the 1D-2D coupled model by assessing whether the measured maximum water levels are in the range of the simulated values. Besides, not only the peak value of the discharge wave is unknown, but also its shape. Therefore, three different shapes are considered in the analysis. However, since the maximum discharge at Lobith is mostly influenced by the peak value at Emmerich, and not by the shape of the discharge wave, the discharge wave shape is not considered as an input parameter to set up the ANN (Fig. 4.3).

Since the exact discharge partitioning over the various Rhine river branches is unknown during the 1809 flood event, each river branch has its own main channel friction in the model (Fig. 4.4). In this manner, the discharge partitioning can vary in the hydraulic simulations to create the training data since a river branch with a low friction value will receive more discharge than a river with a high friction value.

Although many research has been done on the main channel friction due to river dune dynamics during flood events (e.g. Warmink (2014); Naqshband et al (2014); Paarlberg et al (2010)), the value of this parameter as function of varying discharges is still largely unknown. Therefore, this parameter is commonly used to calibrate hydraulic models. During calibration, the main channel friction is adapted such that simulated water levels are close to measurements (Domhof et al, 2018). As a result, the calibrated main channel friction values capture the following features: the physical friction of the main channel caused by e.g. dune growth (Paarlberg and Schielen, 2012), channel irregularity and vegetation (Herget and Meurs, 2010); a model-generated friction caused by e.g. simplifications in the model set-up (Warmink et al, 2013) and discretization of the model domain (Bomers et al, 2019d); and an artificial friction to compensate for errors in the remaining input parameter (Warmink et al, 2013). The main channel friction is thus treated as a garbage bin to capture both the physical phenomena and model errors (Domhof et al, 2018). As a result, the calibrated friction value do not describe the physical friction as encountered in the field anymore (Bomers et al, 2019d). Therefore, it is impossible to find a friction range that covers the total range of possible values for a calibrated model. Including an infinitely wide range in the analysis, results in an infinitely wide range of the upstream maximum discharge. This is because a low discharge with a high main channel friction results in a similar simulated water level as a high discharge with a low main channel friction. Therefore, a 1D-2D coupled model calibrated with the 1995 flood event, available from previous work (Bomers et al, 2019b), is used to determine the friction range used. The range is set equal to the minimum and maximum Manning's friction values found after calibration. This range equals $0.010-0.145 \mathrm{~s} / \mathrm{m}^{1 / 3}$ and is used randomly for each river branch to generate the training data. 
Only above mentioned six input parameters (upstream discharge wave and main channel friction of the various Rhine river branches) are considered to be random since only these parameters were highly uncertain. Latin Hypercube sampling (LHS) is used as sampling method to create the set of model runs used to generate the training data. This sampling strategy has as advantage that it can easily consider a large number of input parameters without the need for extra simulations (Razavi et al, 2012b). The six random input parameters are divided into eight levels in which each level has an equal probability of occurrence of $12.5 \%$, following the method of Bomers et al (2019a). For each run, the values in each level can randomly be sampled, constraining that if a level is already sampled it cannot be sampled again (Saltelli et al, 2008). In total, 160 simulations with the highfidelity model are performed such that the continuous distributions of the input parameters are sufficiently captured (Section 4.5.2). The maximum discharge at Lobith and the maximum simulated water levels at Pannerden and Nijmegen are considered to be the output data. These water levels, the maximum discharge at Lobith and the main channel friction of each river branch are used to train the ANN (Fig. 4.3).

\subsection{Surrogate model}

Many different response surface surrogate models exist (e.g. Artificial Neural Network, Support Vector Regression Machine, Regression models). In this study, an Artificial Neural Network (ANN) is set up. ANNs are the most commonly used response surface surrogate models in environmental and water resources optimization problems (Razavi et al, 2012a). This is because they provide an appealing solution to the problem in complex systems since they can, theoretically, handle incomplete and noisy data (Dawson and Wilby, 2001). In addition, many studies have shown the applicability of ANNs for river flow and flood forecasting for inchannel flow conditions (e.g. Campolo et al (1999); Dibike and Solomatine (2001); Matta et al (2018); Kia et al (2012); Peters et al (2006); Shrestha et al (2005)).

An ANN can be seen as a black-box model that is capable of identifying complex non-linear relationships between input and output data sets (Dibike and Solomatine, 2001). ANNs can be described as a network of interconnected neurons/nodes. Each neuron has several inputs, coming from other neurons or from outside the network (i.e. the input parameters), and a number of outputs, which in turn represents input data of another neuron or results in the final output of the ANN (Dawson and Wilby, 2001) (Fig. 4.5). Each neuron is connected to other neurons by direct communication links. The output of a neuron is based on the weighted sum of all its inputs according to an activation function (e.g. linear function, threshold function, Gaussian function, sigmoid function). The type of activation function used depends on the type of network and training algorithm employed 
(Dawson and Wilby, 2001).

The ANN is developed with the use of the MATLAB Neural Network Toolbox (Beale and Demuth, 2004), since this toolbox can fit multi-dimensional problems well, given consistent input data and enough neurons in the hidden layers. We set up a feed-forward network in which the connections between neurons flow in one direction: from an input layer through one or more hidden layers, to an output layer (Dawson and Wilby, 2001; Kia et al, 2012). The neurons in the hidden layer compute an output based on the weighted sum of all its inputs according to an activation function. The sigmoid activation function is often used in literature since it is relatively easy to compute and capable of introducing nonlinear behaviour to the network (Dawson and Wilby, 2001; Hagan and Menhaj, 1994; Peters et al, 2006).

To set up an ANN, the number of hidden layers and neurons in each hidden layer of the ANN must be specified by the modeller. One hidden layer is used since this type of ANN is suitable for our purpose (Hornik et al, 1989; Leshno et al, 1993; Peters et al, 2006). The choice of the number of neurons is case specific since it depends on the complexity of the original system (Xiang et al, 2005) as well as on the training data availability (Razavi et al, 2012a). For example, if there are too few neurons in the hidden layers, the network may not be possible to describe the underlying function of the original system because it has not enough parameters to map all points in the training data. On the other hand, if there are too many neurons present in the hidden layer, the network may over-fit the training data (Dawson and Wilby, 2001). Commonly, a trial and error procedure is used to determine the appropriate number of neurons in the hidden layer (Dawson and Wilby, 2001; Campolo et al, 1999; Coulibaly et al, 2000). In this study, the following procedure is applied. We started with an ANN with 20 neurons, which we simplified to an ANN with 10 neurons without loss of information. Subsequently, we decreased the number of neurons by steps of one. We found that an ANN with one hidden layer and two neurons (Fig. 4.5) was sufficient to accurately predict model output based on the training data for this specific flood event. The validation results are presented in Section 6.5.

We recall that the ANN is trained with the training data generated with the $1 \mathrm{D}-$ $2 \mathrm{D}$ coupled model. A general problem with training ANNs is over-fitting (Kia et al, 2012; Shrestha et al, 2005) which leads to the issue that the ANN fits the noise existing in the training data rather than the underlying function (Razavi et al, 2012a). In environmental and water resources modelling literature, two wellknown approaches exist to avoid ANN over-fitting: early stopping and Bayesian regularization (Dawson and Wilby, 2001; Razavi et al, 2012a). Both approaches are efficiently implemented in the MATLAB neural network toolbox (Beale and Demuth, 2004). The two approaches were tested and it was found that the Bayesian regularization resulted a slightly more accurate ANN set-up (i.e. a slightly higher Nash-Sutcliffe coefficient) compared to the early stopping approach. The regu- 
larization approach stops training according to the adaptive weight minimization (MacKay, 1992). The remaining samples, i.e. the samples not used to train the ANN, are used as test data. This data set represents an independent measure of network performance after training.

To train the ANN, the main channel friction of the various river branches (five in total) and the measured maximum water levels at Pannerden and Nijmegen are used as input data, resulting in seven input nodes (Fig. 4.3 and Fig. 4.5). The output that must be correctly predicted by the ANN represents the maximum discharge at Lobith, corresponding to one output layer (Fig. 4.3 and Fig. 4.5). Since training the ANN multiple times will result in different ANN structures as a result of different starting conditions, 10 training trials are performed. Maximum discharges at Lobith predicted by the ANN are compared with the results of the high-fidelity model. We found that all ANNs were able to reproduce the behaviour of the high-fidelity model with high accuracy. The Root Mean Square error had a range of between $70-98 \mathrm{~m}^{3} / \mathrm{s}$. This shows that the ANN structure as developed in this study is able to accurately reproduce flood wave propagation. The ANN

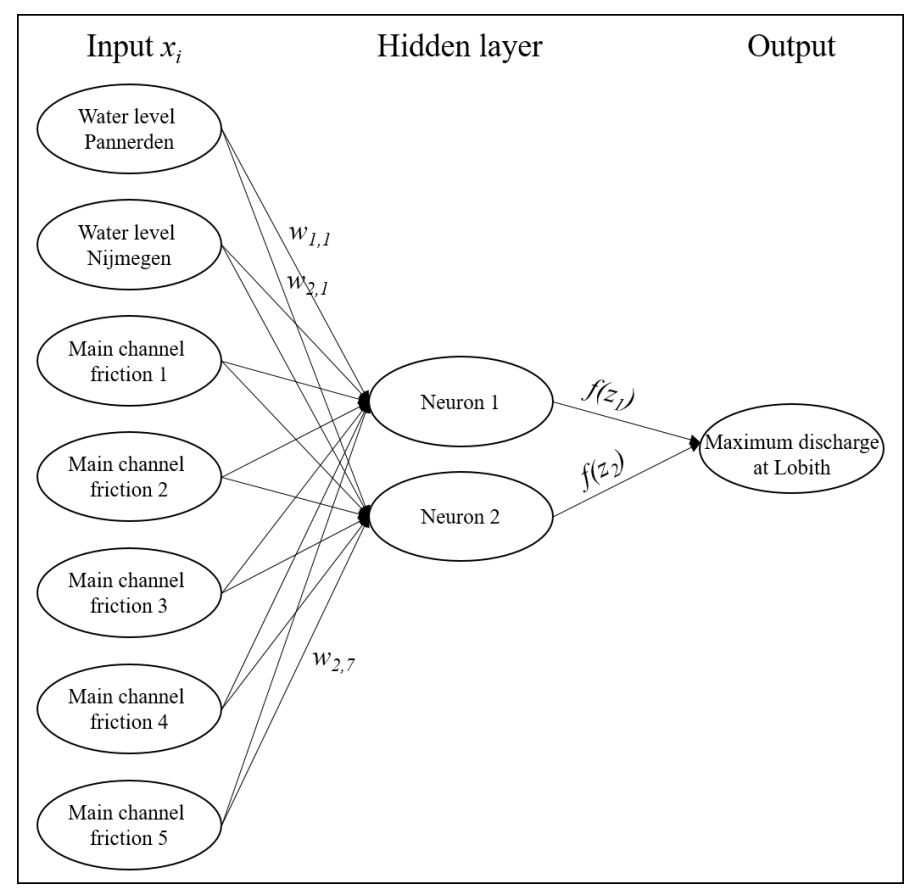

\section{Figure 4.5}

Set-up of the Artificial Neural Network with seven input parameters, one hidden layer having two neurons and a single output parameter. 
with the lowest Root Mean Square error is used to reconstruct the 1809 maximum discharge, following the method of Kerh and Lee (2006) and Razavi et al (2012a).

\subsection{Results}

\subsubsection{Reconstruction results}

The 1809 reconstruction shows important differences compared to the present-day situation (Fig. 4.6). Firstly, the topography has been restored to a situation preceding large-scale anthropogenic modifications to the terrain during the second half of the $20^{\text {th }}$ century. The reconstructed situation has no higher grounds caused by the highways and only has few pits resulting from clay and sand mining, whereas these features define the topography in the present situation (Fig. 4.6). Secondly, the river position and bathymetry have been restored to their seminatural state before river normalization, which in the Netherlands commenced around 1850. The historic river shows wider bends than the present river and has multiple within-channel bars (Fig. 4.6). Thirdly, the embankments along the rivers have been restored to their $19^{\text {th }}$ century dimensions. These are rather similar compared to the present-day embankments, but locally less wide and up to a meter lower. The positions of the embankments have hardly changed over the past 200 years (Fig. 4.6). Finally, the friction of the land cover has been restored to a pre- $20^{\text {th }}$ century situation. Many locations in the reconstructed study area have friction values similar to present-day. This is because these have been in use as grasslands since medieval times. Locally, friction values are significantly lower in the reconstruction, because these have been taken in use for residential purposes in the past century.

\subsubsection{Validation of the Artificial Neural Network}

We recall that the ANN was trained with varying main channel friction (representing the calibrated values of the hydraulic model) along the various river branches and maximum simulated water levels at Pannerden and Nijmegen as input data (Fig. 4.3). The maximum discharge at Lobith was used as output. The results during the training and testing procedures are provided in Fig. 4.7. The accuracy of the model is evaluated by computing the Nash-Sutcliffe model efficiency coefficient (NSE) (Nash and Sutcliffe, 1970):

$$
N S E=1-\frac{\sum_{n=1}^{N}\left(Q_{m}^{n}-Q_{o}^{n}\right)^{2}}{\sum_{n=1}^{N}\left(Q_{o}^{n}-\overline{Q_{o}}\right)^{2}}
$$




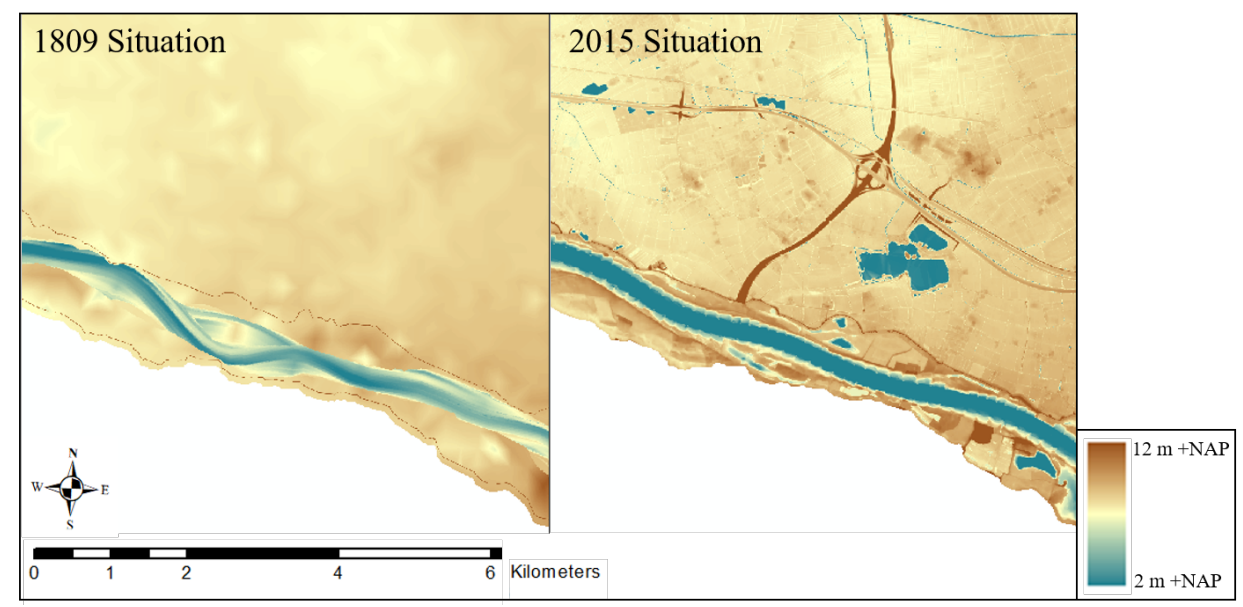

Figure 4.6

Elevation map of the 1809 and present-day situation along the Waal river near the highway A50. Note that there are large sand pits present in 2015 which were absent in 1809.

where $\mathrm{Q}_{\mathrm{m}}$ is the modelled discharge by the $\mathrm{ANN}\left[\mathrm{m}^{3} / \mathrm{s}\right], \mathrm{Q}_{\mathrm{o}}$ the target discharge modelled by the hydraulic model $\left[\mathrm{m}^{3} / \mathrm{s}\right]$ and $\overline{Q_{\mathrm{o}}}$ the average of the target discharge $\left[\mathrm{m}^{3} / \mathrm{s}\right]$. A value of NSE equal to 1 corresponds with a perfect fit between the output of the ANN and the output of the hydraulic model, whereas a value of 0 indicates that the ANN output is as accurate as the mean discharge predicted by the hydraulic model. The results show that the ANN is well capable of predicting maximum discharges as a function of varying main channel friction and maximum water levels because of the high NSE values for both the training and test data sets (Fig. 4.7). Based on this finding, we have enough confidence in the accuracy of the ANN. Hence, the ANN can be used to reconstruct the maximum discharge at Lobith during the 1809 flood event.

\subsubsection{Reconstruction of the 1809 maximum discharge}

The objective of the ANN was to determine the maximum discharge at Lobith during the 1809 flood event. Two maximum measured water levels at surrounding sites (Pannerden and Nijmegen) are available (Fig. 4.1). The corresponding discharge is uncertain as a result of uncertain main channel friction of the various river branches. The input main channel friction values represent the calibrated frictions and are variable since these are highly uncertain due to hydraulic model calibration (Section 4.3.2). Therefore, a Monte Carlo analysis is performed with the ANN in which the two water levels are set to their maximum measured values 
and in which the five main channel friction values can vary within the continuous ranges of between $0.010-0.145 \mathrm{~s} / \mathrm{m}^{1 / 3}$ (Fig. 4.3). This range is equal to the range used to generate the training data. Hence, the ANN is not used outside its training values and therefore the ANN provides reliable results. In total, 10,000 runs are performed in less than a second. This number of runs was sufficient to obtain a proper approximation of the probability distribution function of the maximum discharge at Lobith. This function is presented in Fig 4.8. The 95\% confidence bound of the 1809 maximum discharge is equal to $\sim 10,920-12,050 \mathrm{~m}^{3} / \mathrm{s}$, with an expected discharge of $11,270 \mathrm{~m}^{3} / \mathrm{s}$.
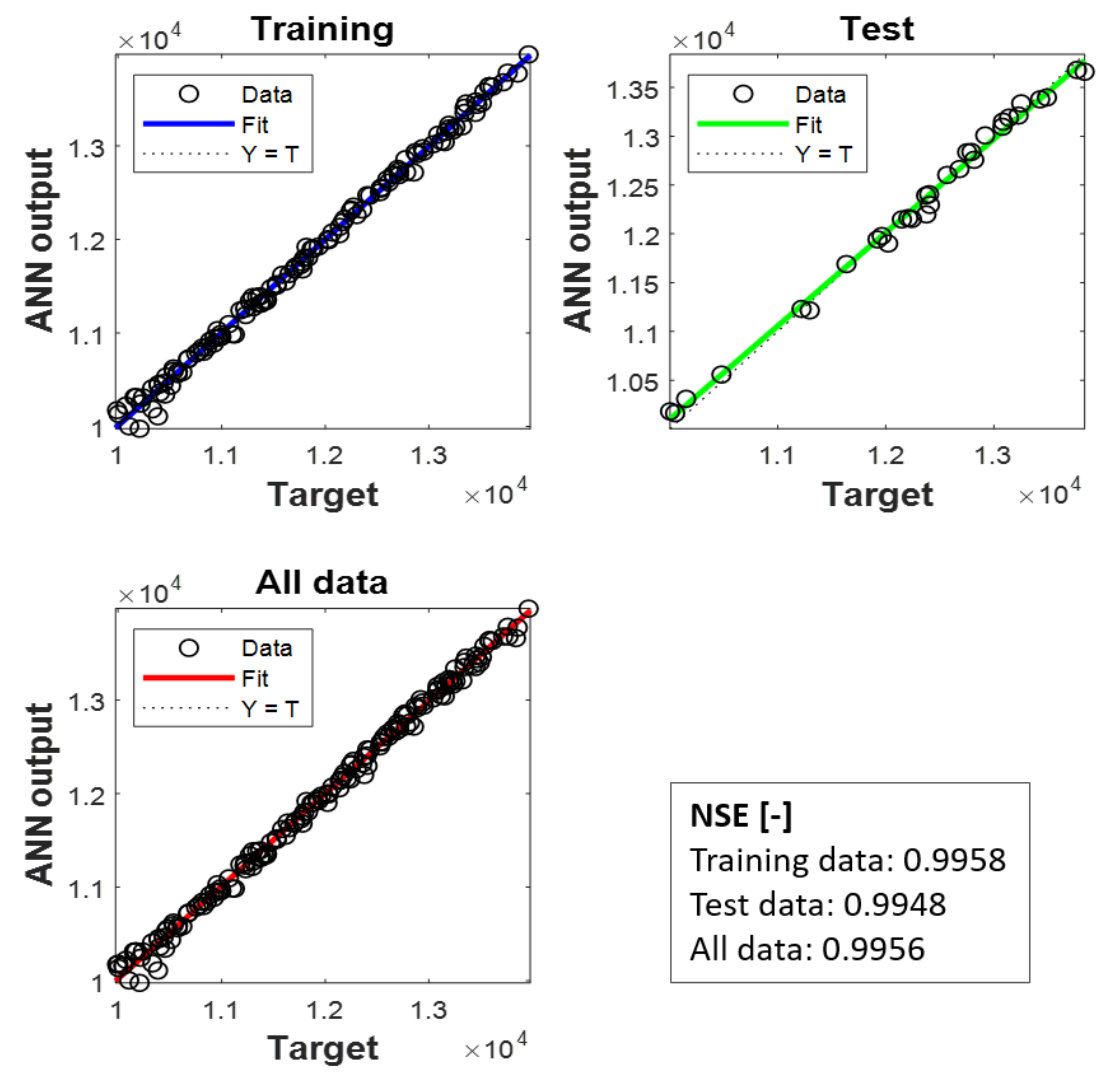

\section{NSE [-]}

Training data: 0.9958

Test data: 0.9948

All data: 0.9956

\section{Figure 4.7}

Regression plots of the maximum discharges predicted by the ANN and the 1D-2D coupled model (target) for the training, validation and testing data sets and for the sets combined. 
Toonen (2015) found an expected 1809 maximum discharge of approximately $11,820 \mathrm{~m}^{3} / \mathrm{s}$, with a $95 \%$ confidence interval of between $\sim 10,400-13,450 \mathrm{~m}^{3} / \mathrm{s}$. We can thus state that the proposed methodology reduces the $95 \%$ confidence interval with $63 \%$ compared to the method of Toonen (2015). Specifically the upper $95 \%$ bound is reduced which is highly beneficial to reduce uncertainty in flood frequency relations.

\subsection{Discussion}

The proposed methodology can be applied to any kind of historic flood event caused by high rainfall intensities if sufficient information about the bathymetry and the event itself is available. Important input data is the course of the main channel, the locations of the dike breaches and some records of maximum water levels. In this section, the following is discussed: the training data, the effects of ice jams on model results, the uncertainty in measured water levels, the applicability of

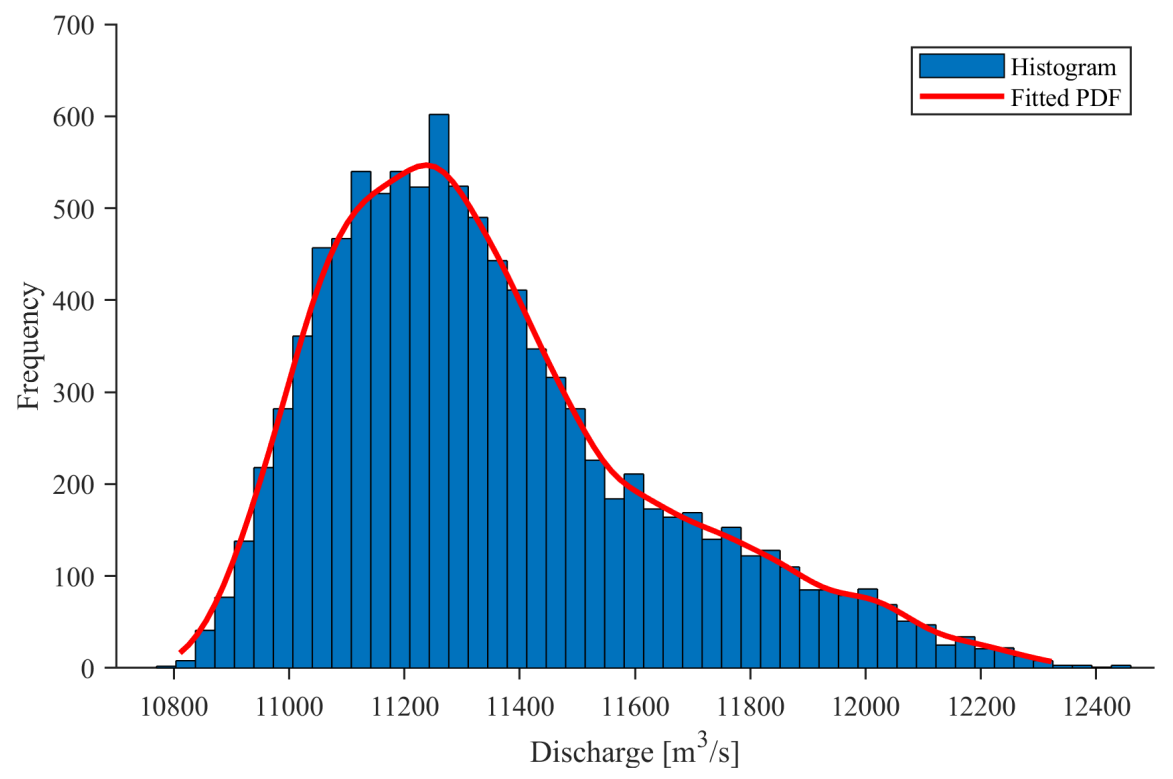

Figure 4.8

Probability distribution function of the 1809 maximum discharge as a result of the MCA performed with the Artificial Neural Network. 
an ANN and the efforts of the proposed methodology in terms of time investment.

\subsubsection{Training data}

The maximum upstream discharge functioned as an input parameter of the 1D$2 \mathrm{D}$ coupled model to create the training data (Fig. 4.3). We found that the $95 \%$ confidence interval of the 1809 flood event with a range of between 10,920-12,050 $\mathrm{m}^{3} / \mathrm{s}$ falls within the range considered to create the training data. Therefore, we conclude that the chosen upstream discharge range, i.e. $10,000 \mathrm{~m}^{3} / \mathrm{s}-14,000 \mathrm{~m}^{3} / \mathrm{s}$, was sufficiently large.

Furthermore, the main channel friction of each river branch was used as an independent input parameter to set up the ANN. Even though the Nederrijn and IJssel rivers are located more than $15 \mathrm{~km}$ downstream of Lobith, we found that using their main channel friction values as input parameter of the ANN resulted in a more accurate ANN set-up than if these two parameters were not considered in the set-up. This indicates that the main channel friction values of these two downstream river branches still have an effect on the maximum discharge at Lobith caused by backwater curves. Therefore, we conclude that none of the input parameters are redundant and that all input parameters contribute to the accuracy of the ANN.

The range of the main channel friction was based on a calibrated model available from previous work (Bomers et al, 2019a). This range influences the confidence interval of the predicted 1809 discharge since a larger range will result in a larger confidence interval. To study the sensitivity of the $95 \%$ confidence interval to the input range of the main channel friction values, we have performed some additional runs with the hydraulic model in which a maximum main channel friction of 0.29 is used corresponding with a value which is a factor two larger than the considered maximum main channel friction $\left(0.145 \mathrm{~s} / \mathrm{m}^{1 / 3}\right)$ to create the training data. We found that increasing the main channel friction from 0.145 to $0.29 \mathrm{~s} / \mathrm{m}^{1 / 3}$ results in an increase of the maximum water level by $45 \mathrm{~cm}$ at Pannerden having a fixed upstream discharge. Therefore, we state that the simulated water levels are highly dependent on the main channel friction. Hence, the reconstructed 1809 flood events depends on the considered range. However, we also found that increasing the main channel friction to a value of $0.29 \mathrm{~s} / \mathrm{m}^{1 / 3}$ results in simulated water levels that are higher than measured, even for a maximum upstream discharge of only 10,000 $\mathrm{m}^{3} / \mathrm{s}$. On the other hand, for a main channel friction of $0.145 \mathrm{~s} / \mathrm{m}^{1 / 3}$, simulated water levels are below measurements for an upstream discharge of $10,000 \mathrm{~m}^{3} / \mathrm{s}$ and higher than measurements for an upstream discharge of $14,000 \mathrm{~m}^{3} / \mathrm{s}$. Since the training data produces maximum water levels at Nijmegen and Pannerden that are in the range of measurements, we conclude that the main channel friction range is selected properly. However, if no earlier study is available providing insights in 
the range of potential maximum upstream discharges the problem of selecting an appropriate main channel friction range becomes more severe.

\subsubsection{The effects of ice jams on model results}

This study shows that an ANN can be used to predict maximum discharges of historic flood events if measured water levels are available. However, it must be noted that the developed ANN is only as good as its high-fidelity hydraulic model. Hydraulic models are typically used to simulate flood wave propagation under normal flow conditions. Flood events caused by e.g. ice jams are difficult to simulate because of the complex physical processes. Furthermore, for historic flood events the exact locations, sizes and behaviour of the ice jams are generally unknown. Therefore, we recommend to only use the proposed methodology for flood events caused by high rainfall intensities or snow melt. During the 1809 flood event, an ice jam was present along the Nederrijn river. As a consequence, the Nederrijn river was more or less blocked and more water started to flow towards the IJssel river. As a result, the high-fidelity model did not predict water levels at Arnhem (located along the Nederrijn river) and Doesburg (located along the IJssel river) in the correct range. Although we have no strong indication from literature, it might be that also the water levels at Pannerden and Nijmegen were affected to a certain extent by ice jams. If this is the case, the water levels could have been lower under normal flow conditions. Subsequently, the reconstructed maximum discharge at Lobith achieved in this study might have been overestimated. Therefore, we highlight that the 1809 flood event had a discharge at maximum equal to the reconstructed maximum discharge. For flood safety assessments, this is the most important information since it is of high importance that the uncertainty in the upper bound of the $95 \%$ confidence interval is reduced.

Not only downstream of Lobith ice jams were present, but also upstream near Emmerich, Germany (Terfehr, 2008). However, according to literature, this ice jam fell apart quite fast. Flow pulses generated by ice jam melting is not considered in this study because we do not have evidence that such flow pulses were present during the flood event. Consequently, it might be that the discharge wave shape used as boundary condition is not correct since this has a typical shape of a normal flood event generated by a precipitation event. However, the work of Bomers et al (2019b) shows that the discharge wave shape only has a little effect on downstream maximum discharges. Hence, the reconstructed discharge at Lobith represents a reliable maximum number. 


\subsubsection{Uncertainty in the measured water levels}

In Section 4.5.3, it was assumed that the measured water levels were not subject to any uncertainties. However, this is generally not the case during flood events. To study the influence of potential uncertainty in measured water levels, a variation of $50 \mathrm{~cm}$ is included in the analysis (i.e. the actual water levels at Nijmegen and Pannerden can be $25 \mathrm{~cm}$ lower or higher than measured). It is assumed that the uncertainty follows a normal distribution.

Including the uncertainty of measured water levels in the analysis results in a predicted maximum discharge of $11.345 \mathrm{~m}^{3} / \mathrm{s}$ and a $95 \%$ confidence interval of between $\sim 10.500-12.190 \mathrm{~m}^{3} / \mathrm{s}$. The uncertainty in measurements results thus in an increase in the confidence interval by $560 \mathrm{~m}^{3} / \mathrm{s}$. Even though the interval increases, it is still much lower compared to the findings of Toonen et al (2015) who also did not include the effect of uncertain measurements in the analysis. This shows the robustness of the presented methodology and the applicability of the use of hydraulic models for accurate historic flood predictions.

\subsubsection{Applicability of an Artificial Neural Network}

In section 4.5.2, we found that the ANN with one hidden-layer and two neurons is capable of reproducing the physical behaviour of the hydraulic model with high accuracy. The simplicity of the ANN may indicate that the set up of an ANN is redundant and that a simpler method might have worked as well. To test this, three other types of surrogate models are set up, namely: a linear regression model, a Gaussian process regression model and a Quadratic Support Vector Machine. For more information about the set up and applicability of these types of models, we refer to Chau et al (2005), Han et al (2007), Liong and Sivapragasam (2002), Raghavendra and Deka (2014), Rezaeianzadeh et al (2014), Yu et al (2006) and Wasimi and Kitanidis (1983).

All types of surrogate models are capable of reproducing the output of the hydraulic model with high accuracy (Table 4.3). However, the ANN performs best. Contrarily, the linear regression model is less capable of predicting the target behaviour since the physical processes during the 1809 flood do not have a fully linear nature. This is mainly caused by the flow through the Ouderijnstrangen area and the various dike breaches along the Rhine river branches. Furthermore, the ANN is capable of predicting the maximum discharge at Lobith with the smallest $95 \%$ confidence interval (Table 4.3). This interval is at least $700 \mathrm{~m}^{3} / \mathrm{s}$ smaller compared to the computed intervals of the other surrogate models. Specifically, the upper bound is lower which is highly beneficial for flood frequency analyses. 
Results of the Artificial Neural Network (ANN), a linear regression model (LRM), a Gaussian process regression model (GRM) and a Quadratic Support Vector Machine (SVM). NSE represents the NashSutcliffe model efficiency coefficient and RMSE the Root Mean Squared error, $Q_{a v}$ is the maximum average discharge predicted, $2.5 \%$ and $97 . \%$ represent the lower and upper bounds of the $95 \%$ confidence interval respectively.

\begin{tabular}{l|cccccc}
\hline \hline Surrogate & NSE $[-]$ & RMSE $\left[\mathrm{m}^{3} / \mathrm{s}\right]$ & $Q_{\mathrm{av}}$ & $2.5 \%$ & $97.5 \%$ & $95 \%$ interval \\
\hline ANN & 0.996 & 70 & 11.485 & 10.920 & 12.050 & 1.130 \\
LRM & 0.981 & 165 & 11.525 & 10.470 & 12.580 & 2.110 \\
GRM & 0.996 & 112 & 11.535 & 10.590 & 12.480 & 1.890 \\
SVM & 0.991 & 123 & 11.605 & 10.690 & 12.520 & 1.830 \\
\hline \hline
\end{tabular}

\subsubsection{Geometry reconstruction and hydraulic modelling efforts}

The use of a $2 \mathrm{D}$ hydraulic model to create the training data is quite time consuming. Therefore, a 1D-2D coupled model was used in which a single simulation was typically in the order of 30 minutes. However, collecting the data required to perform the geometry reconstruction, and performing the reconstruction itself is quite time consuming especially for older events for which the available information becomes even scarcer. Sheffer et al (2003) found for the Ardèche river, France, that flood events are generally clustered in time. We advise to reconstruct such clustered flood events (e.g. the Rhine river floods in 1496 and 1497) since then the bathymetry reconstruction only has to be performed once while it can be used to reconstruct multiple historic floods. Furthermore, we advise to use the proposed method solely for flood events capturing highly complex physical processes caused by e.g. dike breaches. For these situations, the use of simpler methods such as regression functions is less suitable.

\subsection{Conclusions}

An Artificial Neural Network (ANN) was set up to reconstruct the maximum discharge of the 1809 flood event. Training data was created with a 1D-2D coupled model that is capable of correctly simulating the complex physical processes during a flood event. It was found that an ANN with one hidden layer and two neurons is capable of reproducing the input-output relations of the 1D-2D coupled model with high accuracy. The ANN was capable of predicting a flood event with multiple dike breaches resulting in inundations of the hinterland with high accuracy. Therefore, this surrogate model was used to perform a Monte Carlo analysis with varying input data to find the 1809 maximum discharge and its $95 \%$ confidence interval. 
The predicted 1809 flood event had an expected maximum discharge of 11,270 $\mathrm{m}^{3} / \mathrm{s}$ with a $95 \%$ confidence interval of between $\sim 10,920-12,050 \mathrm{~m}^{3} / \mathrm{s}$. This study showed that the range of this confidence interval has significantly been reduced by applying the proposed method compared to methods that did not use hydraulic models to reconstruct historic floods. Therefore, it can be concluded that the use of hydraulic models, and a trained ANN based on such a hydraulic model, can reduce the uncertainty of historic flood reconstructions since these models are capable of accurately simulating the complex physical processes of flood events. If these reconstructions are used to extend the data set of measured discharges, also the flood frequency analyses can be performed with less uncertainty (Bomers et al, 2019c).

\section{Acknowledgement}

This research is supported by the Netherlands Organisation for Scientific Research (NWO, project 14506) which is partly funded by the Ministry of Economic Affairs and Climate Policy. Furthermore, the research is supported by the Ministry of Infrastructure and Water Management and Deltares. This research has benefited from cooperation within the network of the Netherlands Centre for River Studies. The final data of this manuscript will be uploaded on researchdata.4tu.nl with the following DOI: 10.4121/uuid:2068ddc3-1726-4d9d-bbe7-37477767b220.

The authors would like to thank the Dutch Ministry of Infrastructure and Water Management for providing the data. Furthermore, the authors thank Marco van Egmond (Utrecht University library) and Menne Kosian (Cultural Heritage Agency) for help with obtaining historical cartographical data. In addition, the authors would like to thank Yorick Fredrix (Royal HaskoningDHV) for the help in reconstructing the 1809 geometry and Koen Berends (University of Twente) for his valuable insights and suggestions regarding the proposed methodology. Finally, the authors thank Kim Cohen (Utrecht University; Deltares research institute) and Hans Middelkoop (Utrecht University) for the discussions and their cooperation in the NWO Project Floods of the past-Design for the future. 
122 Chapter 4 


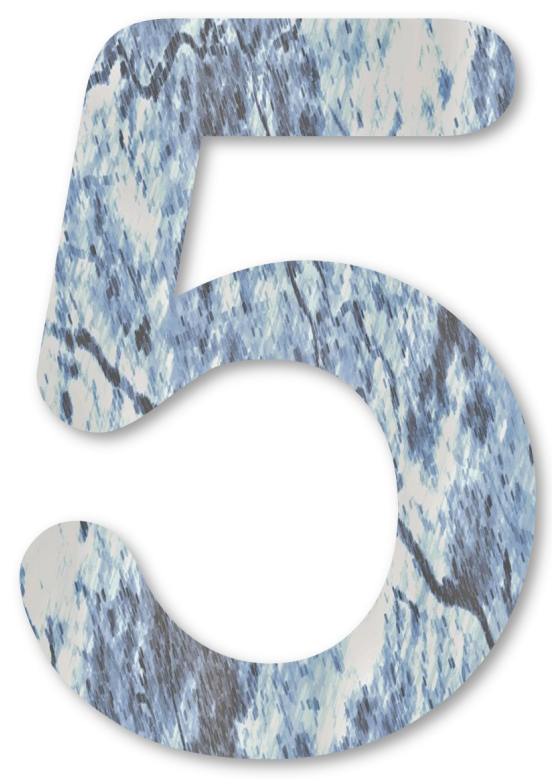

\section{Consequences of dike breaches and dike overflow in a bifurcating river system}

This chapter is published as A. Bomers, R.M.J. Schielen, and S.J.M.H. Hulscher (2019). Consequences of dike breaches and dike overflow in a bifurcating river system, Natural Hazards, 97(1), 309-334. DOI:10.1007/s11069-01903643-y 


\section{Abstract}

Currently, the effect of dike breaches on downstream discharge partitioning and flood risk is not addressed in flood safety assessments. In a bifurcating river system, a dike breach may cause overland flows which can change downstream flood risk and discharge partitioning. This study examines how dike breaches and overflow affect overland flow pat- terns and discharges of the rivers of the Rhine delta. For extreme discharges, an increase in flood risk along the river branch with the smallest discharge capacity was found, while flood risk along the other river branches was reduced. Therefore, dike breaches and resulting overland flow patterns must be included in flood safety assessments.

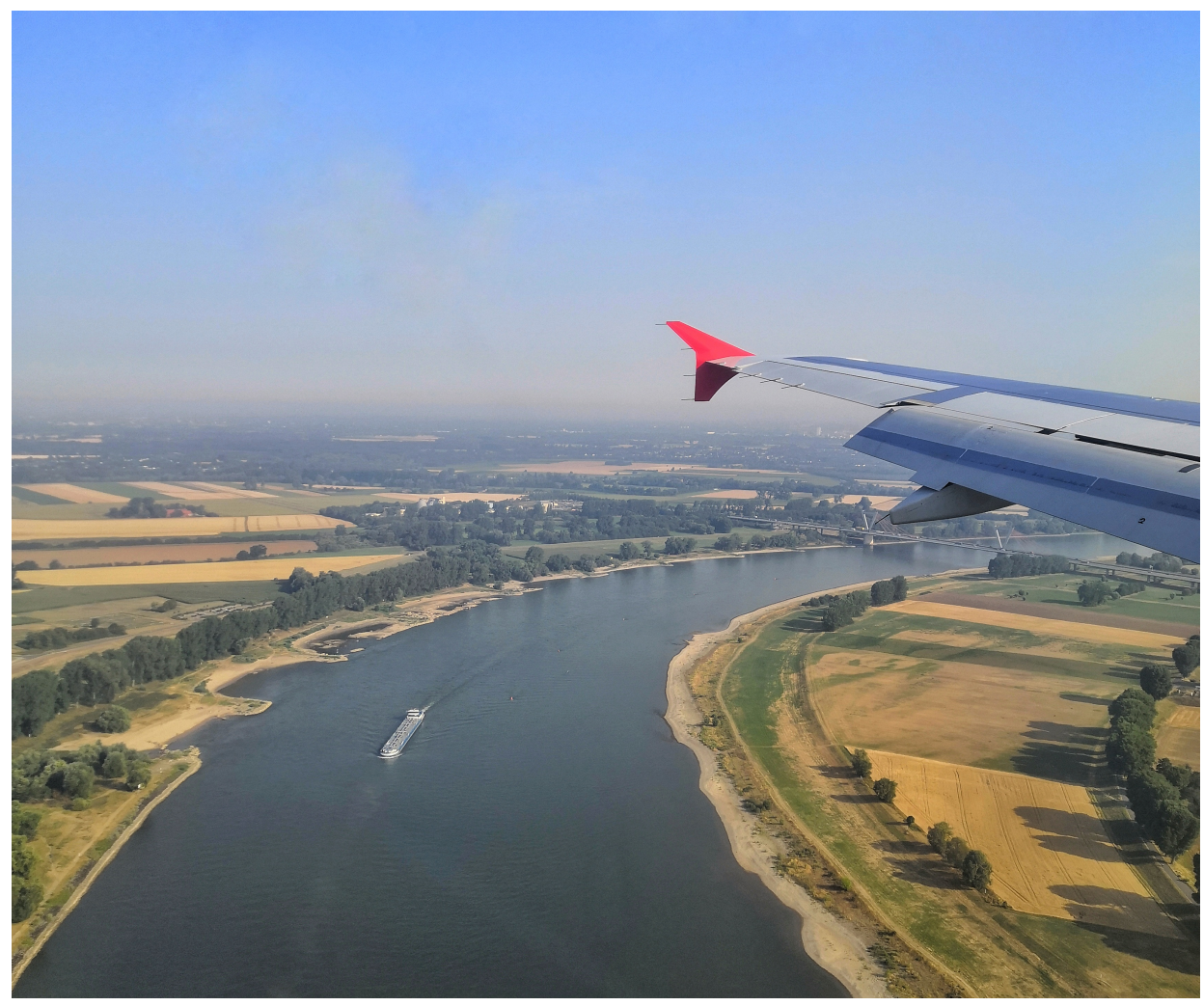

The Rhine river near the city of Düsseldorf, Germany. Photo by: A. Bomers 


\subsection{Introduction}

Throughout Europe, flood frequency analyses are widely used to estimate discharges associated with various return periods (Benito et al, 2004). The common procedure of a flood frequency analysis is to select the annual extreme discharges of the observational data, or peak values that exceed a certain threshold (Hegnauer et al, 2014). These extreme values are then used to identify the parameters of a probability distribution that provides statistical data about the selected extreme values. From this fitted distribution, discharges corresponding to any return period can be derived (Hegnauer et al, 2014).

However, a major drawback of the flood frequency analysis is that the effects of inundations as a result of upstream overflow and dike breaches on the downstream discharge wave cannot be incorporated in the analysis unless such events have occurred during the measurement period. In the case of a single branch river system, a dike breach results in a decrease in the maximum discharge further downstream and hence in a reduction in the hydraulic load downstream (De Bruijn et al, 2014; Schweckendiek et al, 2008; Vorogushyn et al, 2010) if the water does not flow back into the river at a downstream location. For all river systems, dike breaches can result in serious flooding. However, a dike breach in a river system with multiple bifurcations can result in a change of the discharge partitioning of these bifurcations since water may flow through the embanked areas towards another river or river branch. This may specifically result in a change in flood risk if the discharge capacity of the other river is much lower than the capacity of the river in which the dike breach occurred. This situation is applicable in every region where two or more rivers are situated close to each other and where the natural terrain allows that a part of the discharge that leaves a specific river system flows towards another river branch. Such inundation patterns are possible in almost any deltaic areas (e.g. Lower Mississippi river and Atchafalaya river (Coleman et al, 1998), the Mekong delta (Triet et al, 2017) and the Rhine delta (Bomers et al, 2018; Klerk et al, 2014)).

Excluding overland flows from flood frequency analysis results in an inaccurate prediction of design discharges since overland flows may alter downstream discharge partitioning. In recent years, awarenesses of the effects of dike breaches, resultant inundations and hence potential changes in downstream flood risk has increased. Apel et al (2009) studied the effects of dike breaches on downstream flood peak reductions for the Lower Rhine in Germany. They developed a dynamic-probabilistic model that combines simplified flood process modules in a Monte Carlo simulation framework. In their study area, no bifurcation points were present. Apel et al (2009) showed that for extreme floods, significant retention effects are expected as a result of dike breaches. These retention effects lead to a reduction in the maximum discharge downstream of the dike breach and hence result in a changed flood frequency curve. A similar approach was used by Vorogushyn et al (2010) 
who ran a Monte Carlo simulation in which the uncertainty of parameters that influence the breaching process was accounted for by treating them as random variables. They used the Elbe river in Germany as their case study and created hazards maps showing the most vulnerable regions in terms of inundation. Although Apel et al (2009) and Vorogushyn et al (2010) included the capping effect of dike breaches, they assumed that once a part of the discharge wave left the river system, it was not capable of flowing back into the river at a downstream location. Furthermore, they did not include the backwater effects caused by downstream dike breaches. However, overland flow patterns may alter the discharge partitioning of downstream river branches and flood risk, whereas backwater effects may increase the maximum discharge upstream of the dike breach location. Therefore, the objective of this paper is to study the effect of overland flow patterns on downstream discharge partitioning and flood risk capturing the full dynamics of a river delta (therefore including all possible flow patterns due to multiple dike breaches and backwater effects). The method proposed by Apel et al (2009) is used as a starting point and extended such that overland flow patterns and backwater effects are included in the model approach. The upstream part of the Rhine delta is used as a case study to apply the proposed methodology. A large number of potential flood scenarios are simulated in a Monte Carlo framework. The model results are compared with the method proposed by Apel et al (2009) to determine whether overland flows and backwater effects can change inundation patterns and peak discharges in a river delta.

Firstly, the Rhine river delta and its flow regime are described in Section 5.2. Section 5.3 presents the hydraulic model used. The methodology of the Monte Carlo analysis is explained in Section 5.4 and the results are presented in Section 5.5. The results of the sensitivity analysis are provided in Section 5.6. The paper ends with a discussion and the main conclusions in Section 5.7.

\subsection{Study area}

The Rhine delta is used as a case study. The Rhine river originates in the Alps in Switzerland and flows through Germany where the flood-prone area widens until it becomes a river delta in the Netherlands (Hooijer et al, 2004). The study area stretches from Andernach, Germany, to the Dutch Rhine river branches (Fig. 5.1). Only the discharge-dominated upper part of the Dutch Rhine river branches is included in the domain. The downstream part that is influenced by the tide of the North Sea is not included to decrease model complexity.

The German part of the river is referred to as the Lower Rhine. Along the Lower Rhine three major tributaries are present: the Sieg, Ruhr and Lippe rivers. Their discharges contribute to the peak discharge of the Lower Rhine. In the upstream 
region, between the upstream boundary condition and the confluence with the river Sieg, no embanked areas are present in the model domain. In this region, inundations of the embanked areas are not possible to occur since the river is surrounded by higher ground on both sides. The Lower Rhine enters the Netherlands at Lobith, where it bifurcates into the Waal river and the Pannerdensch Canal. Subsequently, the Pannerdensch Canal bifurcates into two branches: the Nederrijn river and the IJssel river.

Floods along the Lower Rhine in Germany mainly evolve during the winter months due to heavy precipitation events in combination with frozen or saturated soil. In the annual maximum discharge series for the previous 120 years, $85 \%$ of the annual maxima took place between November and March (Apel et al, 2009). All river branches are almost completely protected by dikes in order to protect the hinterland from flooding. The safety levels along the Lower Rhine vary between a return period of 100 to 500 years for the large winter dikes (ICPR, 2001). In

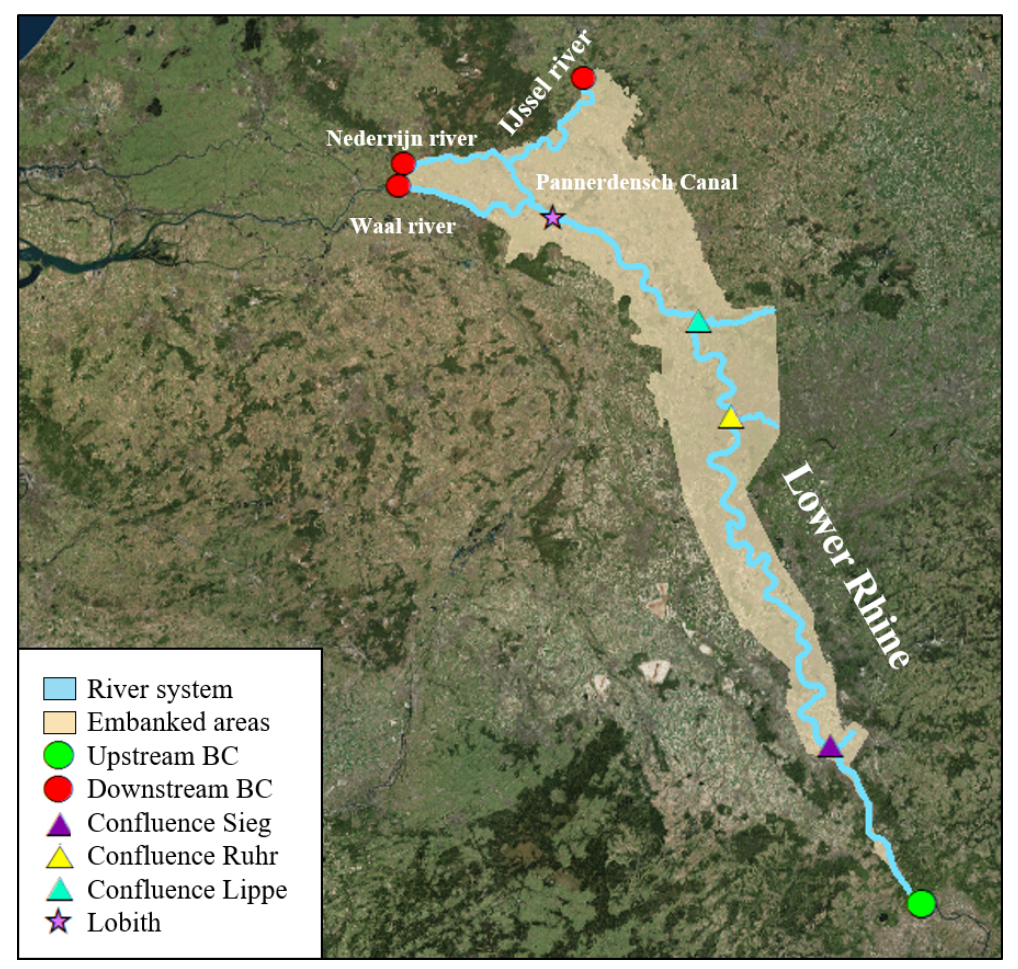

Figure 5.1

Representation of the model domain in which Lobith represents the German-Dutch border and BC represents the boundary conditions. 


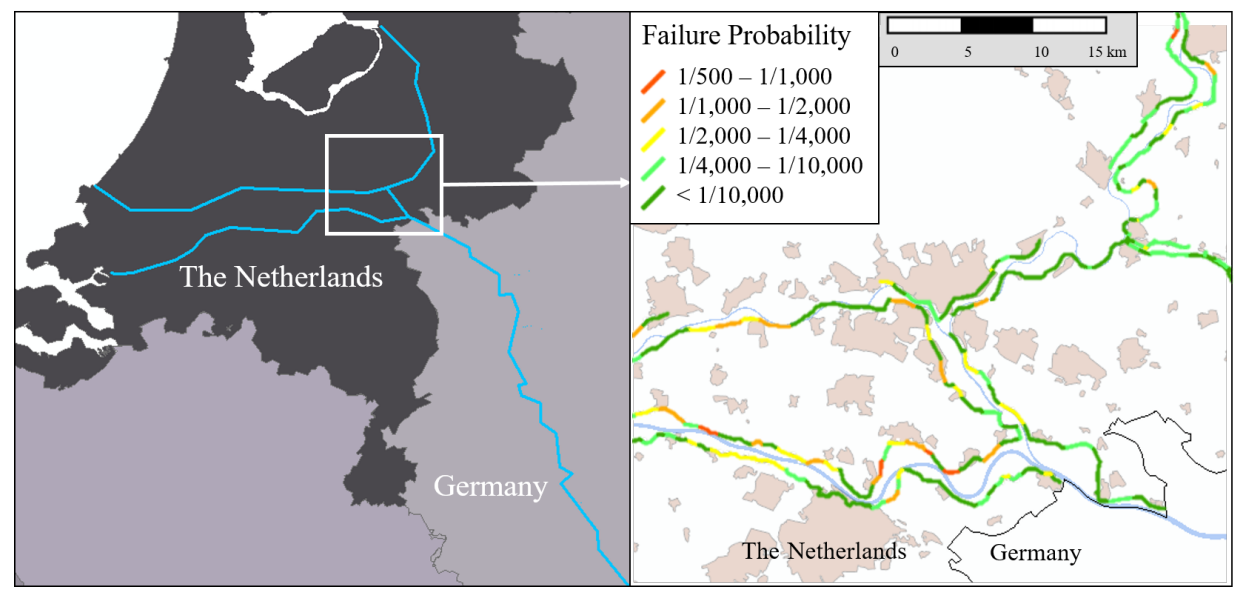

Figure 5.2

Current failure probabilities of the Dutch dike sections. Source: Ministry of Infrastructure and Water Management (retrieved from https://professional.basisinformatieoverstromingen. $\mathrm{nl} /$ liwo/\#/viewer/41, in Dutch).

2050, the main levees along the Dutch Rhine river branches need to have a safety standard expressed in probability of flooding up to $10^{-5}$. These probabilities are based on a risk-based analysis. In this analysis, not only the probability of a flood is considered but also the predicted consequences (Van Alphen, 2016). In our study, we focus on the actual failure probabilities since many dike sections do not cope with the future safety standard yet (Fig. 5.2). The differences in the current dike failure probabilities (Fig. 5.2) may lead to a situation of a dike breach at a relatively weak spot. Resulting overland flows may change the flood risk and discharge partitioning along the downstream river branches.

Currently, the Dutch water policy assumes a fixed discharge partitioning along the various Rhine river branches at extreme discharges. It is assumed that of the total discharge at Lobith approximately $65 \%$ flows to the Waal river, $19 \%$ to the Nederrijn river and $16 \%$ to the IJssel river (Spruyt and Asselman, 2017). In the new risk-based approach, the flood event with a return period of 100,000 years has a maximum discharge below $18,000 \mathrm{~m}^{3} / \mathrm{s}$ at Lobith (Hegnauer et al, 2014). The analysis of Hegnauer et al (2014) shows that this discharge cannot become larger as a consequence of overflow and dike breaches along the Lower Rhine. Using the predefined discharge partitioning means that theoretically a maximum discharge of approximately $11,775 \mathrm{~m}^{3} / \mathrm{s}$ can flow towards the Waal river, around $3,376 \mathrm{~m}^{3} / \mathrm{s}$ towards the Nederrijn river and only around $2,850 \mathrm{~m}^{3} / \mathrm{s}$ towards the IJssel river at maximum (Spruyt and Asselman, 2017). 
To study if overland flow patterns may change this discharge partitioning and corresponding flood risk in the Rhine delta, a hydraulic model is required. This model is described in the next section.

\subsection{Model environment}

A one dimensional-two dimensional (1D-2D) coupled hydraulic model is developed in order to simulate the discharge propagation from Andernach, Germany, to the Dutch deltaic area (Fig. 5.1). HEC-RAS (v. 5.0.3), developed by the Hydrologic Engineering Centre (HEC) of the US Army Corps of Engineers is used to perform the simulations. Andernach is used as upstream boundary location since it has a measurement station and is situated in the narrow valley of the Middle Rhine. In our modelling approach, the main channel and floodplains are discretized by $1 \mathrm{D}$ profiles representing the cross sections of the river. These $1 \mathrm{D}$ profiles are coupled with the embanked areas (located outside the protection of the dike system) which are discretized on a 2D grid since $1 \mathrm{D}$ profiles are not capable of capturing the complex hydrodynamic conditions inside these areas (Fig. 5.3). The $2 \mathrm{D}$ grid is aligned with line segments with higher grounds such as elevated highways to sufficiently capture the characteristics of the DEM. In most part of the model domain rectangular grid cells are used, where only flexible grid shapes (e.g. triangular, rectangular, pentagonal cells) are located along the boundaries and line segments such that the $2 \mathrm{D}$ grid is capable of following the boundaries of the model domain and higher grounds (Fig. 5.3).

The 1D profiles and 2D grid cells are coupled by a structure corresponding with the dimensions of the dike that protects the hinterland from flooding. If the computed water level of a $1 \mathrm{D}$ profile exceeds the dike crest, water starts to flow into the $2 \mathrm{D}$ grid cells corresponding with inundations of the embanked areas.

HEC-RAS is capable of solving the Full Momentum equations as well as the Diffusive Wave equations in which the inertial terms of the momentum equations are neglected. Test runs with both sets of equations were performed. Both runs provided almost the same results, as was also found by Moya Quiroga et al (2016). The maximum discharge at Lobith deviated only $0.3 \%$, and also no significant deviation in flood extent was found. However, the computation time of the run solving the diffusive wave equations was significantly faster. Therefore, the diffusive wave equations are used to compute the flow characteristics (e.g. water level, flow velocity) at each $1 \mathrm{D}$-profile and $2 \mathrm{D}$ grid cell.

As upstream boundary condition a discharge wave is used. Besides the upstream discharge wave, also the hydrographs of the three main tributaries influence the maximum discharge along the Lower Rhine. Therefore, the hydrographs of the 
tributaries are included in the model approach as lateral inflows (Fig. 5.1). Normal depths are used as downstream boundary conditions. Normal depths are computed with the use of the Manning's equation which can be written as (Brunner, 2016):

$$
V=\frac{R^{2 / 3}}{n} \sqrt{S_{f}}
$$

in which $V$ represents the cross sectional averaged flow velocity $[\mathrm{m} / \mathrm{s}], \mathrm{R}$ the hydraulic radius $[\mathrm{m}]$ depending on the water depth, $\mathrm{n}$ the Manning's roughness coefficient $\left[\mathrm{s} / \mathrm{m}^{1 / 3}\right]$, and $S_{f}$ the slope of the energy grade line [-]. Since the flow velocity is known, the Manning's equation with a user entered energy slope produces a water depth considered to be the normal depth as the hydraulic radius is the only unknown in the Manning's equation. In general, the energy slope can be approximated by the slope of the main channel (Brunner, 2016). This approximation is used to determine the downstream boundary conditions along the three Dutch river branches and downstream ends of the $2 \mathrm{D}$ grids (Fig. 5.3).

For dike breach modelling, the built-in time growth template in HEC-RAS is used in which an S-function is assumed such that the dike breach width increases slowly at first and then accelerates as time advances, and finally slows down again when the breach is almost fully developed (Gee, 2010). Prediction of dike breach growth is highly uncertain and many models exist. However, Brunner (2014b) showed that overland flows are not sensitive to the dike breach model used. He found that the use of different breach models resulted in a different outflow hydrograph, but once the hydrographs are routed downstream through the embanked areas, the hydrographs will tend to converge to each other and become very similar. There are two main reasons for this convergence. Firstly, the total volume of water in each of the different hydrographs predicted by the different breach models was more or less the same. Secondly, as the hydrographs move through the embanked areas, a sharp hydrograph attenuates faster than a flat hydrograph as a result of bed roughness (Brunner, 2014b). The above finding justifies the use of the simple built-in time growth template in HEC-RAS since we are not interested in correct prediction of the outflow hydrographs at breach locations, but in the large-scale overland flow patterns. Although the breach model used does not significantly change model results, the input parameters (dike breach threshold, formation time and final breach width) of these models are uncertain and may affect the overland flow patterns. Therefore, these input parameters are considered as random input variables in the Monte Carlo analysis (Section 5.4).

An existing data set of the 2025 geometry is provided by the Dutch Ministry of Infrastructure and Water Management and the Landesamt für Natur, Umwelt und Verbraucherschutz (LANUV) of Northrhine-Westfalia for use in this project. This data set contains a DEM, roughness information and the location and height of the dikes of the present situation in the Netherlands and Germany. The data covers the entire study area except for the embanked area enclosed by the Waal river, Pan- 


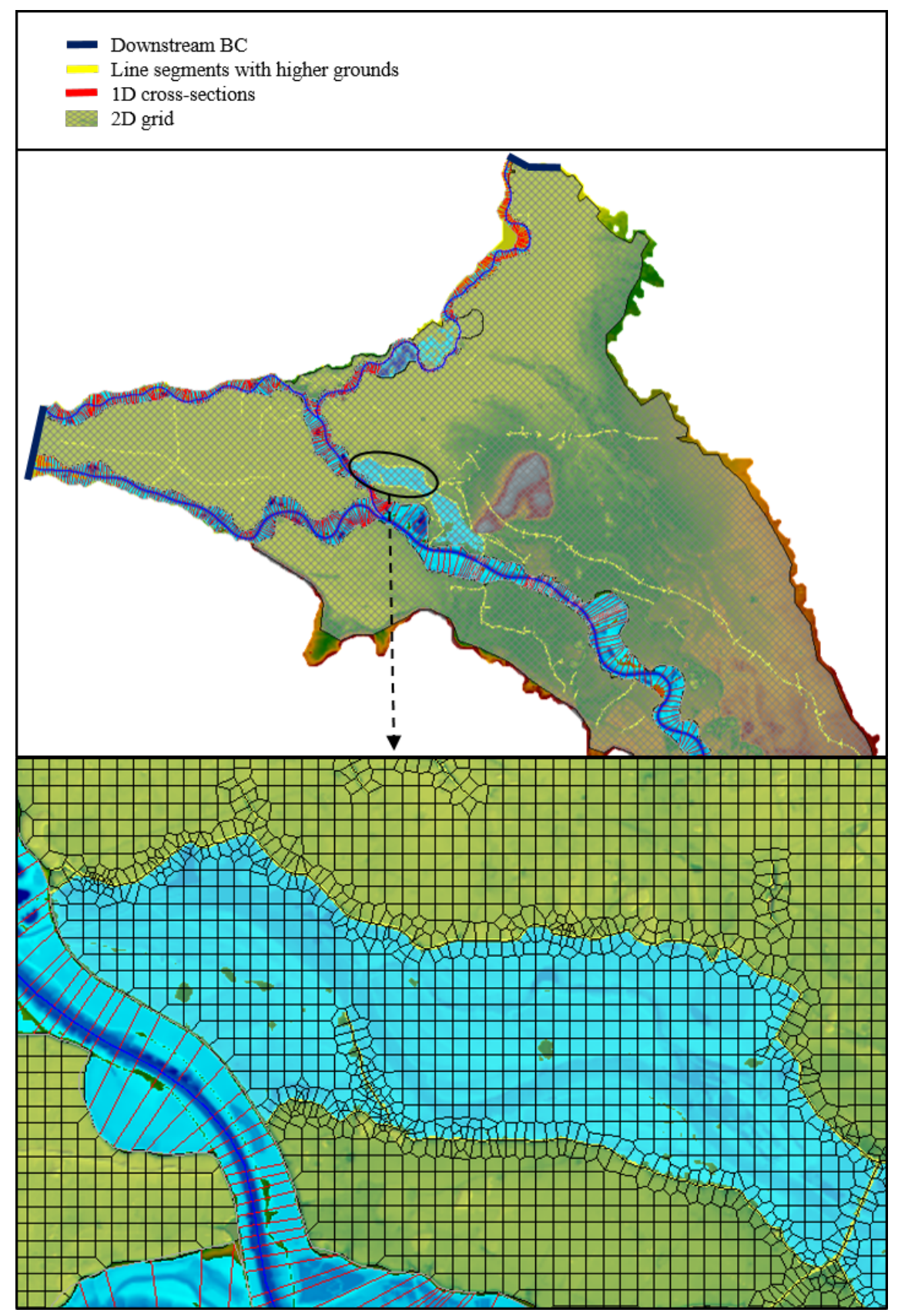

Figure 5.3

Model set-up where $\mathrm{BC}$ represents the boundary condition (upper figure) and an impression of a part of the 2D grid which is aligned with line segments with high grounds (lower figure). 
nerdensch Canal and Nederrijn river (Fig. 5.1). This latter area is reconstructed with the use of open-source data AHN (Algemeen Hoogtekaart Nederland) available at http://www.ahn.nl/ which represents the Dutch DEM in high resolution (5x5 m) raster format. OpenStreetMap (https://www.openstreetmap.org) is used to schematize the roughness classes of this area. Only the five most dominant roughness classes are considered resulting in an almost entirely covered land classification map. The five roughness classes considered are: urban areas, grasslands, alluvial forest, orchard and open surface water. In essence, the 2025 geometry corresponds with the 2015 situation. Because of the ongoing dike reinforcements along the Lower Rhine, only the German dike locations and heights are based on the future 2025 situation. Therefore, data representing the 2015 situation can be applied in the modelling framework.

The model is calibrated such that measured water levels are accurately predicted. Hydraulic model calibration is most commonly done by changing the roughness of the main channel until simulated water levels are close to measured water levels (Bomers et al, 2019d). In this study, the same approach was used with the criterion that the calibration must lead to a maximum difference between measured and simulated water levels of $10 \mathrm{~cm}$. The model is calibrated with the 1995 flood wave data. This flood event had a maximum discharge at Andernach of 10,100 $\mathrm{m}^{3} / \mathrm{s}$. This discharge in combination with the discharge waves of the tributaries along the Lower Rhine resulted in a maximum discharge of around $12,060 \mathrm{~m}^{3} / \mathrm{s}$ at Lobith, corresponding with a return period of approximately 60 years (Tijssen, 2009). After calibration, maximum water levels are predicted with an average difference of $1 \mathrm{~cm}$ compared to measurements (Table 5.1). The Dutch water levels are available at http://waterinfo.rws.nl and provided by the Dutch Ministry of Infrastructure and Water Management, whereas the German water levels are available at the German Federal Waterways and Shipping Administration (WSV) and communicated by the German Federal Institute of Hydrology (BfG).

The 1993 discharge wave with a maximum discharge of $10,500 \mathrm{~m}^{3} / \mathrm{s}$ at Andernach is routed for validation. This discharge wave resulted in a maximum discharge of around $11,100 \mathrm{~m}^{3} / \mathrm{s}$ at Lobith as a result of the lower inflow of the tributaries along the Lower Rhine compared to the 1995 flood event. The 1993 flood event at Lobith has a return period of approximately 30 years (Tijssen, 2009). It was found that simulated maximum water levels deviate less than $7 \mathrm{~cm}$ averaged over the 14 measurement stations compared to measured maximum water levels during the 1993 flood event (Table 5.1). Furthermore, the maximum discharges along the Rhine river branches are predicted with high accuracy. The maximum deviation was found along the Waal river, where the simulated maximum discharge differs only $3.7 \%$ from measurements (Table 5.2). These results give confidence in the accuracy of the model. Both the 1993 and 1995 discharge waves did not lead to any dike breaches in the study area and hence no overland flows were present. Therefore, it is not possible to validate the model for such situations. However, many studies showed the applicability of a 1D-2D coupled model (e.g. Bomers 
et al (2019a); Domeneghetti et al (2013)) and of the Diffusive Wave equations for flood modelling purposes (e.g. Moya Quiroga et al (2016); Moussa and Bocquillon (2009); Leandro et al (2014)). Therefore, it is assumed that this model is also capable of simulating large overland flows as a result of overflow and dike breaches with sufficient accuracy.

\section{Table 5.1}

Calibration water level (WL) results with the 1995 flood wave and validation WL results with the 1993 flood wave in which Diff. represents the differences between measured and simulated WL.

\begin{tabular}{l|ccc|ccc}
\hline \hline Location & $\begin{array}{c}\text { Measured WL } \\
\text { WL 1995 } \\
{[\mathrm{m}+\mathrm{NAP}]}\end{array}$ & $\begin{array}{c}\text { Simulated } \\
\text { WL 1995 } \\
{[\mathrm{m}+\mathrm{NAP}]}\end{array}$ & $\begin{array}{c}\text { Diff. } \\
{[\mathrm{m}]}\end{array}$ & $\begin{array}{c}\text { Measured } \\
\text { WL 1993 } \\
{[\mathrm{m}+\mathrm{NAP}]}\end{array}$ & $\begin{array}{c}\text { Simulated } \\
\text { WL 1933 } \\
{[\mathrm{m}+\mathrm{NAP}]}\end{array}$ & $\begin{array}{c}\text { Diff. } \\
{[\mathrm{m}]}\end{array}$ \\
\hline Andernach & 61.77 & 61.76 & -0.01 & 61.98 & 61.87 & -0.11 \\
\hline Bonn & 52.76 & 52.77 & 0.01 & 52.79 & 52.81 & 0.02 \\
Cologne & 45.67 & 45.69 & 0.02 & 45.60 & 45.69 & 0.09 \\
\hline Ruhrort & 27.79 & 27.78 & -0.01 & 27.51 & 27.56 & 0.05 \\
Wesel & 22.42 & 22.43 & 0.01 & 22.14 & 22.24 & 0.10 \\
\hline Rees & 19.33 & 19.33 & 0.00 & 19.03 & 19.13 & 0.10 \\
Emmerich & 17.84 & 17.84 & 0.00 & 17.52 & 17.64 & 0.12 \\
Lobith & 16.66 & 16.67 & 0.01 & 16.39 & 16.49 & 0.10 \\
Pannerdensche Kop & 15.84 & 15.85 & 0.01 & 15.58 & 15.68 & 0.10 \\
\hline Nijmegenhaven & 13.53 & 13.54 & 0.01 & 13.35 & 13.38 & 0.03 \\
\hline Isselkop & 13.98 & 13.99 & 0.01 & 13.77 & 13.85 & 0.08 \\
\hline Driel Boven & 11.97 & 11.94 & -0.03 & 11.73 & 11.74 & 0.01 \\
\hline Driel Beneden & 11.88 & 11.88 & 0.00 & 11.66 & 11.67 & 0.01 \\
\hline Doesburgbrug & 10.59 & 10.59 & 0.00 & 10.43 & 10.41 & -0.02 \\
Average & & & 0.01 & & & 0.07 \\
\hline \hline
\end{tabular}

\section{Table 5.2}

Calibration and validation results of the discharge (Q) partitioning along the Dutch Rhine river branches with the 1995 and 1993 flood waves, respectively. Diff. represents the differences (\%) between measurements and model predictions.

\begin{tabular}{l|ccc|ccc}
\hline \hline River branch & $\begin{array}{c}\text { Measured Q } \\
1995\left[\mathrm{~m}^{3} / \mathrm{s}\right]\end{array}$ & $\begin{array}{c}\text { Simulated Q } \\
1995\left[\mathrm{~m}^{3} / \mathrm{s}\right]\end{array}$ & $\begin{array}{c}\text { Diff. } \\
{[\%]}\end{array}$ & $\begin{array}{c}\text { Measured Q } \\
1993\left[\mathrm{~m}^{3} / \mathrm{s}\right]\end{array}$ & $\begin{array}{c}\text { Simulated Q } \\
1933\left[\mathrm{~m}^{3} / \mathrm{s}\right]\end{array}$ & $\begin{array}{c}\text { Diff. } \\
{[\%]}\end{array}$ \\
\hline Bovenrijn & 11,878 & 12,018 & 1.2 & 11,093 & 11,420 & 2.9 \\
Waal & 7,587 & 7,719 & 1.7 & 7,112 & 7,372 & 3.7 \\
Pannerdensch Canal & 4,291 & 4,300 & 0.2 & 3,982 & 4,051 & 1.7 \\
Nederrijn & 2,513 & 2,531 & 0.7 & 2,336 & 2,421 & 3.6 \\
IJssel & 1,780 & 1,765 & -0.9 & 1,643 & 1,624 & -1.2 \\
\hline \hline
\end{tabular}




\subsection{Monte Carlo analysis}

To determine the influence of dike breaches on downstream discharges and flood risk, we use a Monte Carlo analysis. It is assumed that dike breaches can only occur along the river branches downstream of the confluence with the Lippe river since dike breaches further upstream will not influence the discharge partitioning of the Dutch river branches. Upstream of this location, only the capping effect of high discharges is included as a result of overflow. Hence, is assumed that the dikes have an infinite strength (i.e. will never breach).

In total, 33 dike breach locations are implemented in the model (Fig. 5.4). These locations are based on a run in which all dikes were removed from the geometry. A reasonable large discharge wave (i.e. larger than bankfull) selected from the historical measured series was released to identify the locations where water may leave the river system resulting in overland flow. In addition, the locations where the overland flow may re-enter the river system were identified. In this way, the dike breach locations that will result in great overland flows, and hence may change the downstream discharge partitioning, were identified.

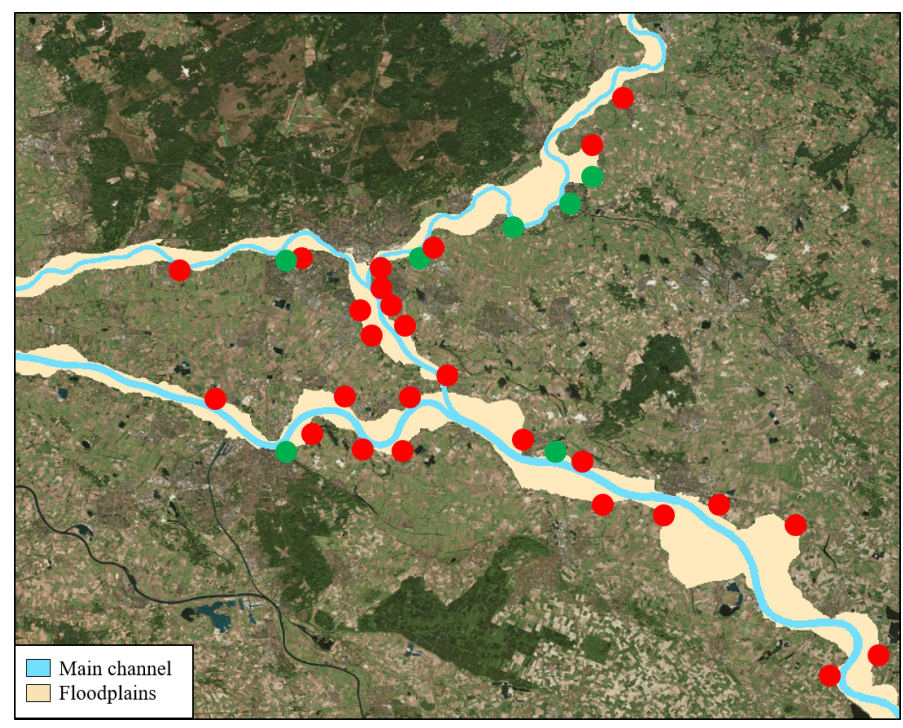

\section{Figure 5.4}

Dike breach locations in which the red bullets indicate the locations where water most probably will leave the river system and flow into the embanked areas and where the green bullets represent the areas where water will re-enter the river system again. 
In the analysis, only the parameters that influence dike breach outflow are included as uncertain input parameters. Following the method of Apel et al (2009) and Vorogushyn et al (2010) these parameters are:

- Upstream flood wave in terms of hydrograph shape and peak value

- Flood waves of the main tributaries dependent on the upstream flood wave

- Dike breach threshold in terms of critical water level (based on fragility curves) indicating when the dike starts to breach

- Dike breach formation time

- Final breach width

For each Monte Carlo simulation an upstream discharge wave and corresponding discharge waves of the three main tributaries are sampled. The hydraulic model computes the water levels along the river branches as a result of the upstream boundary condition and lateral inflows. At every time step, the model evaluates at each potential dike breach location whether the water level exceeds the dike breach threshold in terms of critical water level. If the critical water level is exceeded, the dike starts to breach based on the sampled dike breach formation time and final breach width. It is assumed that a dike breaches to the level of the natural terrain in case of failure (Dawson et al, 2005). An overview of the Monte Carlo analysis is given in Fig. 5.5. The next sections describe the five uncertain input parameters in more detail.

\subsubsection{Upstream hydrograph and hydrographs main tributaries}

For flood modelling, an upstream hydrograph is required as boundary condition. Sampling this hydrograph includes two steps, namely: sampling both a peak value and a discharge wave shape. A peak value of between 12,000 and $23,500 \mathrm{~m}^{3} / \mathrm{s}$ is used such that a wide variety of potential flood scenarios is included in the analysis. This range is chosen since we are solely interested in the scenarios resulting in dike breaches and/or overflow causing overland flow patterns that have the potential to change downstream flood risk and the discharge partitioning of the Dutch Rhine river branches. Discharges smaller than $12,000 \mathrm{~m}^{3} / \mathrm{s}$ do not result in significant flooding upstream of Lobith as has been seen during the historical flood in 1995 . Hence, a simulation with those discharges in which overflow and dike breaches are neglected provides similar results as a model run in which both overflow and dike breaches are possible to occur (Hegnauer et al, 2014). Therefore, only discharges larger than $12,000 \mathrm{~m}^{3} / \mathrm{s}$ are considered in the Monte Carlo analysis.

The upper bound of the discharge range has a value of $23,500 \mathrm{~m}^{3} / \mathrm{s}$. This rather high value is a result generated with GRADE (Generator of Rainfall and Discharge 


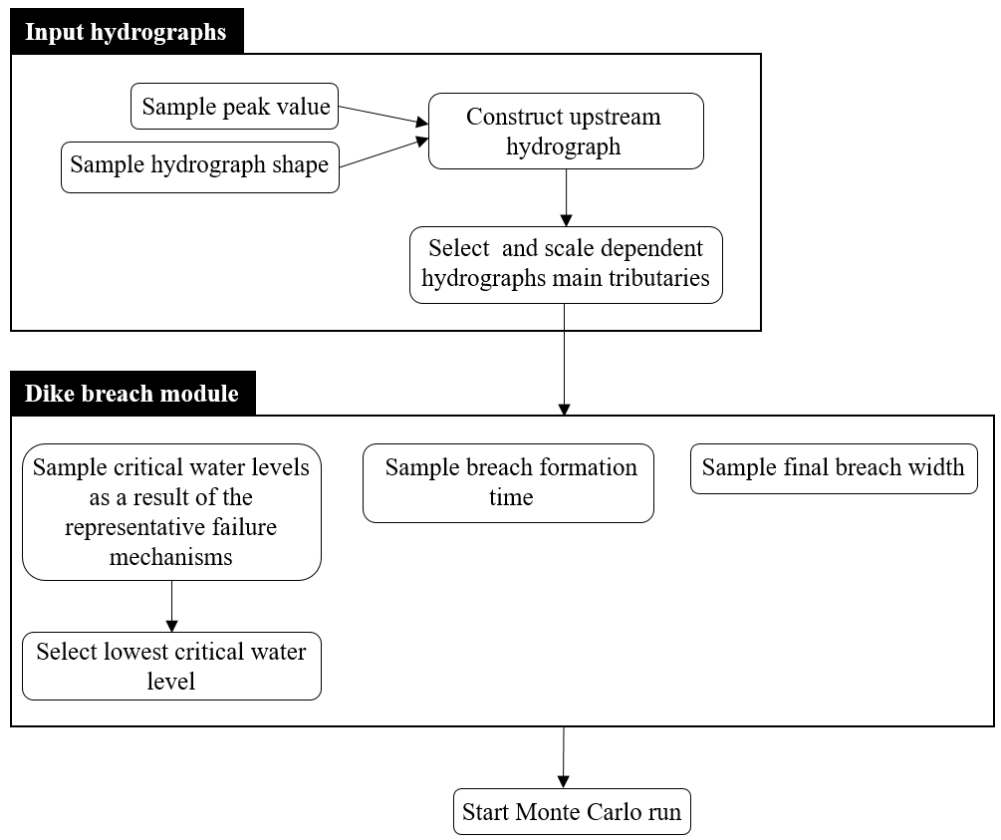

Figure 5.5

Overview of the Monte Carlo sampling strategy.

Extremes), a new method to derive the design discharge for the Rhine and Meuse rivers in the Netherlands (Hegnauer et al, 2014). Under climate change conditions, this discharge corresponds with an expected return period of 30,000 years in 2085 (Hegnauer, 2017) taking into account a rather wet climate change scenario in which an increase in temperature of $3.5{ }^{\circ} \mathrm{C}$ and a high influence of changing air flow patterns is assumed (KNMI, 2015). A return period of 30,000 years seems very high. However, for Dutch flood safety assessments, where a return period of 30,000 years is still within the safety standards considered in 2050, it is reasonable to use this large discharge at Andernach. Currently, the discharge corresponding to this return period at Andernach is equal to $17,110 \mathrm{~m}^{3} / \mathrm{s}$ (Hegnauer, 2017).

Also the shape of the flood wave is based on GRADE. The GRADE data set consists of 50,000 years of discharge data based on re-sampled measured weather conditions (e.g. precipitation, temperature) and expected climate change conditions. Of this data set, peak discharges with a value larger than $12,000 \mathrm{~m}^{3} / \mathrm{s}$ at Andernach were identified. A 30 days time window was used in which the peak value occurs around day 20 such that the continuous data set of 50,000 years is divided into a set of potential upstream hydrographs (Fig. 5.6). Corresponding discharge waves of the Sieg, Ruhr and Lippe rivers were selected as well. Fi- 


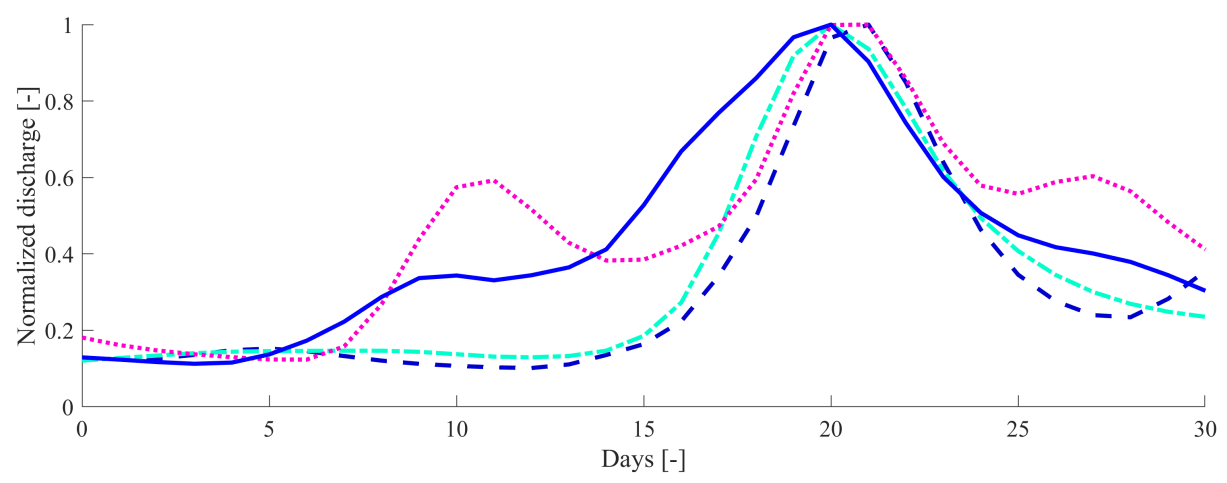

Figure 5.6

Examples of normalized potential discharge wave shapes.

nally, the hydrographs are normalized such that the peak value is equal to 1.0 for rescaling purposes (Fig. 5.6). This method results in a data set of 276 potential upstream hydrograph shapes and corresponding hydrograph shapes of the main tributaries. For each Monte Carlo run, the selected upstream hydrograph is scaled such that the maximum discharge corresponds with the peak value sampled. In addition, corresponding discharge wave shapes of the tributaries are selected and scaled to the peak values sampled. Historic flood events have shown that there is a strong correlation between the maximum discharges of the main tributaries and of the maximum discharge along the Lower Rhine (Apel et al, 2009). Following the proposed method, the dependency of the hydrographs of the tributaries and Lower Rhine in terms of discharge wave shape and peak value is included in the analysis.

We chose to use the discharge wave shapes of the GRADE data set instead of measured discharge waves (as was done by Apel et al (2004) and Vorogushyn et al (2011)), since the GRADE data set includes a much larger variety of potential discharge wave shapes compared to the measured data set (e.g. a single sharp peak, a single broad peak or two peaks). Moreover, the GRADE data set has a larger spread of maximum values that are larger than $12,000 \mathrm{~m}^{3} / \mathrm{s}$ that may occur under current climate conditions (Fig. 5.6). The measured data set goes back to 1901, and only the three largest flood events (1926, 1993 and 1995) had maximum discharges near 12,000 $\mathrm{m}^{3} / \mathrm{s}$ (Hegnauer et al, 2014). 


\subsubsection{Dike breach threshold}

Whether dike failure occurs can be computed using the equation $Z=R-L$ in which $Z<0$ represents failure, $R$ the strength of the dike structure and $L$ the hydraulic load. In this study, dike failure is assumed to be similar to a dike breach. The load is expressed as the water level during a flood event. For the Dutch dikes, the following four most dominant failure mechanisms are included in the analysis: wave overtopping, overflow, piping and macro-stability (Diermanse et al, 2015; De Bruijn et al, 2014). The normal distributions of the critical water levels of these four failure mechanisms are based on 1D fragility curves. Failure mechanisms wave overtopping and overflow are combined in a single fragility curve and referred to as wave overtopping from now on. The fragility curves used are based on the 2015 dike dimensions (van Vuren et al, 2017) and are provided by the Dutch Ministry of Infrastructure and Water Management. A 1D fragility curve expresses the reliability of a flood defence as a function of a defined dominant stress variable (Hall et al, 2003). The curves are 1D since they are a function of one variable, which in this case is the water level during the flood event. The use of fragility curves enables estimation of what failure mechanism will be dominant for a certain water level if multiple failure mechanisms are considered (Van der Meer et al, 2008). An example is given in Fig. 5.7a, in which the probability of failure is given as a function of the exceedance of a certain water level. This curve can be transformed into a normal distribution in which the probability of failure is given as a function of a specific water level (Fig. 5.7b). Using this principle, a dike may also breach during low flow although the probability of failure is relatively low. To exclude flood scenarios with an extremely low probability of occurrence from the analysis, we only focus on water levels within the $95 \%$ confidence interval (Fig. 5.7b).

The use of 1D fragility curves has the consequence that a dike breach always develops in the rising stage of the discharge wave. As a result, the dike breach has a relatively large influence on the resulting overland flow and maximum discharge further downstream. To overcome this problem, a time-dependent component can be included in the analysis such that a dike breach is triggered by a certain water level and a duration that this water level is exceeded (Curran et al, 2018). However, no 2D fragility curves (describing the probability as a function of water level and duration of exceedance) were available and hence it must be noted that the scenarios presented in this paper represent the most extreme situations.

For the German dikes, no 1D fragility curves for any of the failure mechanisms were available. Therefore, it is assumed that the Dutch 1D fragility curves of the part between the German-Dutch border and the first bifurcation point (where the Rhine river bifurcates into the Waal river and Pannerdensch Canal) for failure mechanism wave overtopping/overflow are representative for the dikes along the Lower Rhine downstream of the confluence with the Lippe river. Note that dike failure can already occur before the water level reached the dike crest caused by 

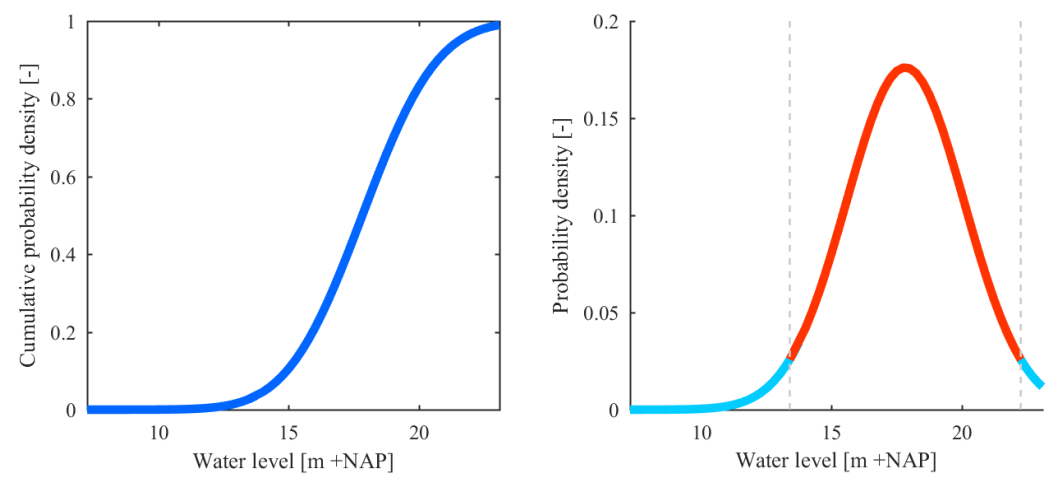

\section{Figure 5.7}

Example of a fragility curve (left figure) and its normal distribution (right figure) in which the orange line indicates the $95 \%$ confidence interval.

overflow. In reality, dikes can fail as a result of many failure mechanisms. However, it is assumed that only the failure probabilities caused by wave overtopping are significant and that hence the effects of other failure mechanisms can be neglected along the Lower Rhine. This assumption is in line with the work of Apel et al (2009) and Prinsen et al (2015). Apel et al (2009) mention that the dikes along the Lower Rhine are well maintained and that the authorities responsible for dike safety state that the only mechanism influencing dike breaching along the Lower Rhine is overtopping. Furthermore, the proposed method is in line with the study of Lammersen and Hegnauer (2019) which also only includes the consequences of dike breaches caused by wave overtopping on downstream discharges.

Note that each potential dike breach location can fail caused by high water levels at the outer side (river system) and inner side (embanked areas) of the dike. However, no data about the strength of the dikes in case of hydraulic load on the inner side of the dike slope is available. It is assumed that the dikes in the study area are symmetric in shape and hence the fragility curves of the outer side of the dikes can be applied for the inner side as well. For each Monte Carlo simulation, critical water levels are sampled for each dike breach location. This results in three critical water levels for the Dutch dike breach locations as a result of failure mechanisms piping, wave overtopping and macro-stability, and in one critical water level for the German dike breach locations caused by wave overtopping. For the Dutch dike breach location, the lowest sampled critical water level is used as dike breach threshold in the simulation (Fig. 5.5). 


\subsubsection{Dike breach formation time and final breach width}

The dike breach formation time represents the time until a breach has developed until its final width. Since there is not enough information available to quantify the relation between breach width, formation time and dike strength, the formation time and breach width are assumed as random variables. The distribution of the dike breach formation time is based on historical data. Data of Verheij and Van der Knaap (2003) are used resulting in a data set of 28 dike breaches with an average formation time of $13 \mathrm{~h}$ and a standard deviation of $17 \mathrm{~h}$. We assume a normal distribution since this distribution best represents the distribution of the data set. The normal distribution is bounded by a minimum formation time of 6 min and a maximum formation time of $50 \mathrm{~h}$, corresponding with the minimum and maximum values present in the data set.

Data of Apel et al (2008) and data of Verheij and Van der Knaap (2003) are combined to determine the distribution of the final dike breach width, resulting in a data set of 46 dike breaches. The average dike breach width equals $75 \mathrm{~m}$ with a standard deviation of $55.5 \mathrm{~m}$. Again a normal distribution is assumed. The normal distribution is bounded by a minimum width of $3 \mathrm{~m}$ and a maximum width of $200 \mathrm{~m}$, representing the minimum and maximum values present in the data set. A maximum width of $200 \mathrm{~m}$ is also in line with the work of De Bruijn et al (2014).

There are many parameters that may influence dike breach development (e.g. dike stability, failure mechanism, pace of rising and falling water level). For example, a rapid decline in water level will result faster in a stable dike breach width than a slowly decreasing water level (Verheij and Van der Knaap, 2003). This explains the large range present in the data set. Since no information is available about the relation between all parameters that influence dike breach development, the full ranges (although relatively large) in formation time and final breach width present in the data sets are used in the analysis.

\subsubsection{Sampling Strategy}

Most often a fully random Monte Carlo analysis is performed in which the uncertain input parameters are randomly sampled based on their distributions. This has as disadvantage that many runs are required to sufficiently capture the distributions of the input parameters. This is because it is likely that gaps or clusters are present in the sample when not enough samples are taken (Saltelli et al, 2008). Many sophisticated sampling techniques can be found in literature that attempt to reduce the amount of runs required while the input space of the parameters is still sufficiently captured. Most commonly used sampling methods appear to be full factorial design, fractional factorial design, central composite design and Latin Hypercube sampling (LHS) (Razavi et al, 2012b). The first three methods still 
require a relatively large number of simulations to generate all combinations to represent the corners of the input space if many uncertain input parameters are included in the analysis (Razavi et al, 2012b; Saltelli et al, 2008). Contrarily, the LHS approach does not need extra simulation runs if more input parameters are included in the analysis (Razavi et al, 2012b). Since the dike breach module (Fig. 5.5) includes many uncertain input parameters (water level threshold, final dike breach width and formation time for the 33 potential dike breach locations), LHS is used in which the distributions of the input parameters are divided into eight slices each having a probability of occurrence of $12.5 \%$. More information on how to set up an LHS can be found in Saltelli et al (2008). For the input hydrograph shapes (Fig. 5.5), a random sampling technique is used, because the data set does not have a probability distribution as the previous mentioned input parameters. The data set consists of 276 different discharge wave shapes, each having equal probability of occurrence.

\subsection{Results: Overland flow patterns and discharge partitioning}

During the Monte Carlo analysis, 227 runs were performed for a maximum upstream discharge ranging from 12,000 to $23,500 \mathrm{~m}^{3} / \mathrm{s}$. Using the method proposed by Apel et al (2009) to study the effect of dike breaches on downstream discharges, we expect to find a significant reduction in the maximum discharge in downstream direction since overland flows and backwater effects were not included in their analysis.

Our results only focus on the areas downstream of the confluence with the Lippe river since solely flow patterns caused by dike breaches and overflow in this part of the model domain can change flood risk and discharge partitioning of the Rhine delta. We found that the maximum discharge at Andernach can be divided into three discharge ranges, each range having its own flood characteristics. These ranges are explained in more detail in the following sections.

\subsection{1 $Q_{\max }$ Andernach $<16,000 \mathrm{~m}^{3} / \mathrm{s}$}

It was found that up to a discharge wave with an upstream peak value of approximately $16,000 \mathrm{~m}^{3} / \mathrm{s}$, corresponding with a return period of approximately 7,700 years under current climate conditions (Hegnauer, 2017), overland flows have almost no influence on the downstream discharge partitioning. Overflow and/or dike breaches did occur resulting in inundation of the embanked area. However, because of the relatively low upstream maximum discharge, no significant flow 


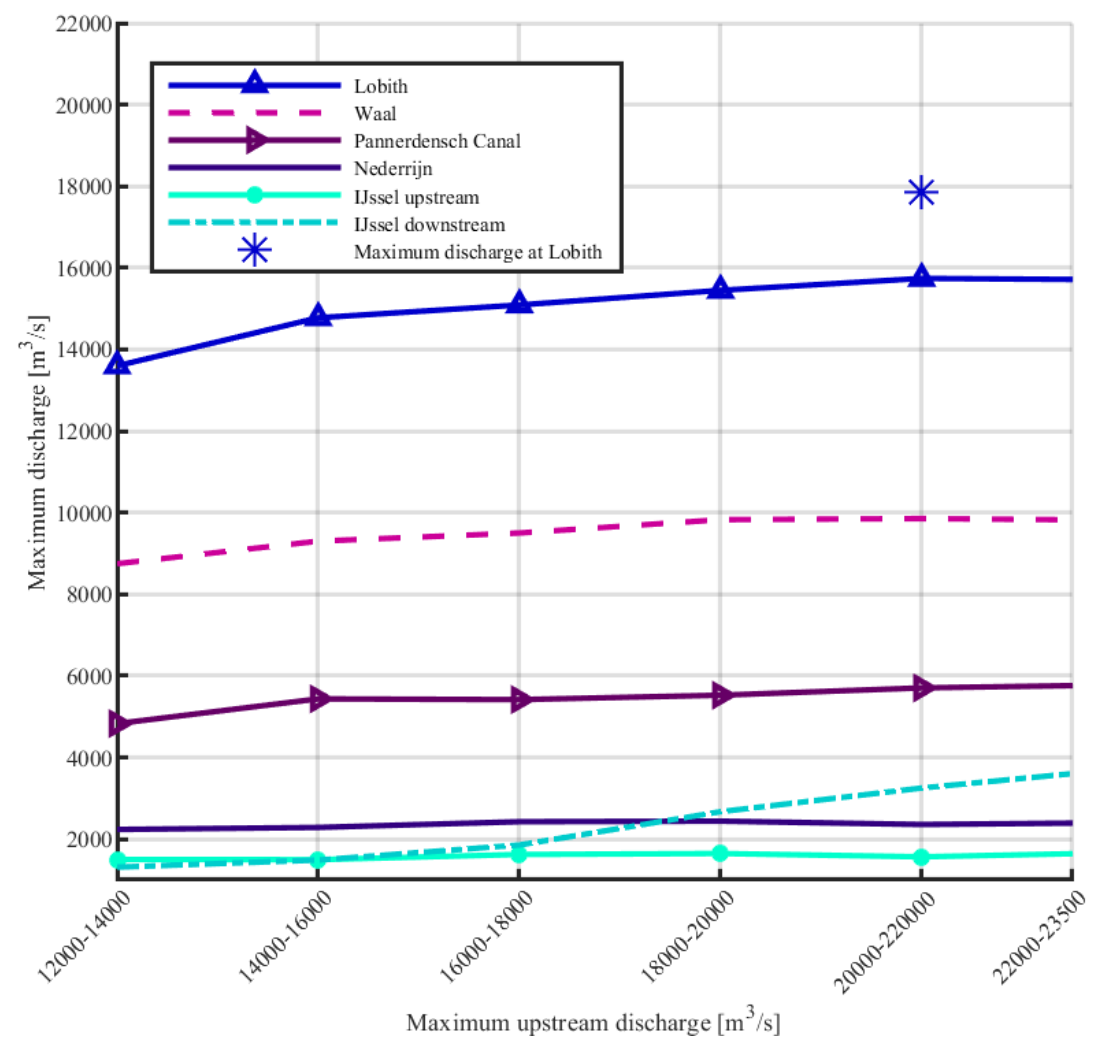

\section{Figure 5.8}

Average maximum discharge per class at Lobith and along the Dutch Rhine river branches as a function of the maximum upstream discharge at Andernach. The blue star represents the maximum discharge at Lobith present in the MCA and has a value of $17,870 \mathrm{~m}^{3} / \mathrm{s}$.

patterns were found for most of the scenarios present in the Monte Carlo analysis. In general, the water that left the river system did not re-enter the river system again at a downstream location. Hence, only a reduction in the maximum downstream discharge was found (Fig. 5.8). For this situation, the results correspond to the results of Apel et al (2009).

The most dominant flow patterns for an upstream maximum discharge smaller than $16,000 \mathrm{~m}^{3} / \mathrm{s}$ are presented in Fig. 5.9. These flow patterns are caused by dike breaches. Specifically the Pannerdensch Canal is vulnerable to dike breaches resulting in overland flow patterns 1 and 2. Flow pattern 2 first flows parallel to the IJssel river. Thereafter, its discharge starts to flow in two direction, where 
$2 \mathrm{a}$ continues to flow parallel to the river and $2 \mathrm{~b}$ starts to flow into the Old IJssel Valley. Furthermore, two dike breaches along the Waal and Nederrijn rivers result in inundations of the embanked areas and hence in a reduction in the maximum discharge further downstream (flow patterns 3 and 4 in Fig. 5.9).

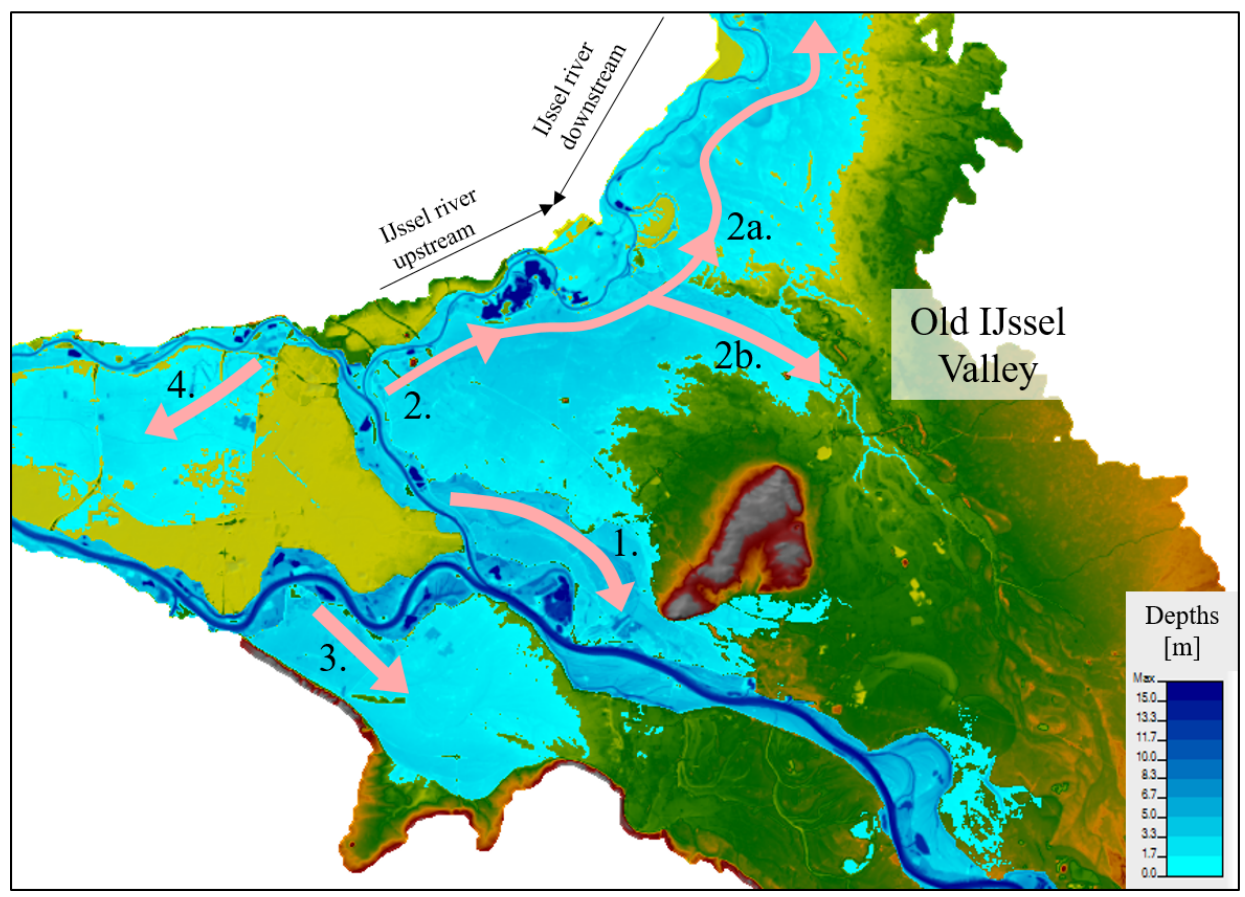

Figure 5.9

The most dominant flow patterns if the maximum discharge at Andernach is smaller than 16,000 $\mathrm{m}^{3} / \mathrm{s}$. These flow patterns only result in a decrease of the maximum discharge further downstream.

We recall that for most scenarios with an upstream maximum discharge smaller than $16,000 \mathrm{~m}^{3} / \mathrm{s}$, the discharge that has left the river system as a result of dike breaches along the Dutch Rhine river branches did not flow back into the river system again at a more downstream location. However, still some severe flow patterns are possible to occur even though their probabilities are low. The Monte Carlo analysis showed that dike breaches along the Lower Rhine caused by wave overtopping are possible to occur if the discharge at Andernach is larger than $14,500 \mathrm{~m}^{3} / \mathrm{s}$, corresponding with a return period of approximately 1,100 years under current climate conditions (Hegnauer, 2017). For such a relatively low maximum upstream discharge, the water levels are still below the dike crest level along the Lower Rhine. The dike thus breaches as a result of wave overtopping. Although the probability of dike breaches is low for this upstream discharge, the effects are significant. A large amount of water starts to flow through the Old 
IJssel Valley (Flow pattern 5 in Fig. 5.10). Even for a discharge of approximately $14,500 \mathrm{~m}^{3} / \mathrm{s}$ at Andernach, the discharge through the Old IJssel Valley can be as large as $3,400 \mathrm{~m}^{3} / \mathrm{s}$. This water mainly stays within the embanked areas of the Old IJssel Valley. According to Mens et al (2014), the worst-case discharge that can enter the IJssel river in the coming 50-100 years as a result of climate change is estimated at $3,250 \mathrm{~m}^{3} / \mathrm{s}$. Hence, the inundations along the IJssel river caused by the overland flow through the Old IJssel Valley are much more severe than we would expect if this area can only be inundated as a result of dike breaches and overflow along the IJssel river itself. Therefore, it is highly important that such overland flow patterns are considered in flood safety assessments.

\subsubsection{6,000 $\mathrm{m}^{3} / \mathrm{s}<\mathrm{Q}_{\max }$ Andernach $<18,700 \mathrm{~m}^{3} / \mathrm{s}$}

For upstream discharge waves having a peak value larger than $16,000 \mathrm{~m}^{3} / \mathrm{s}$, dike breaches along the Lower Rhine start to occur more often as a result of higher water levels. The overland flow through the Old IJssel Valley with a discharge larger than $500 \mathrm{~m}^{3} / \mathrm{s}$ occurred in $44 \%$ of the cases for this specific upstream discharge range. The water that flows through the Old IJssel Valley starts to divide into two flow patterns when the water almost reaches the IJssel river. A part of the water flows into the IJssel river at the most upstream red box (Fig. 5.10) if the water level in the embanked areas exceeds the dike crest level. The remaining part starts to flow parallel to the IJssel river in downstream direction following flow pattern 2a. A part of this water may re-enter the IJssel river at the downstream red box (Fig. 5.10).

The water flowing through the Old IJssel Valley reaches the IJssel river later than the peak value of the discharge wave that flows through the IJssel river itself. This is because of the higher surface roughness in the embanked areas compared to the roughness of the main channel. Nevertheless, the discharge of the overland flow can be significantly larger than the discharge that enters the IJssel river through the river system. Hence, this overland flow pattern is capable of increasing the maximum discharge of the IJssel river during a flood event.

\subsection{3 $Q_{\max }$ Andernach $>18,700 \mathrm{~m}^{3} / \mathrm{s}$}

For upstream discharge waves having a peak value larger than approximately $18,700 \mathrm{~m}^{3} / \mathrm{s}$, the discharge along the downstream end of the IJssel river (near the downstream boundary) starts to increase significantly as a result of the overland flow through the Old IJssel Valley. This is caused by both the large overflow and the increase in dike breach probability along the Lower Rhine. Although the discharge capacity of the Old IJssel river itself is relatively small, the discharge 


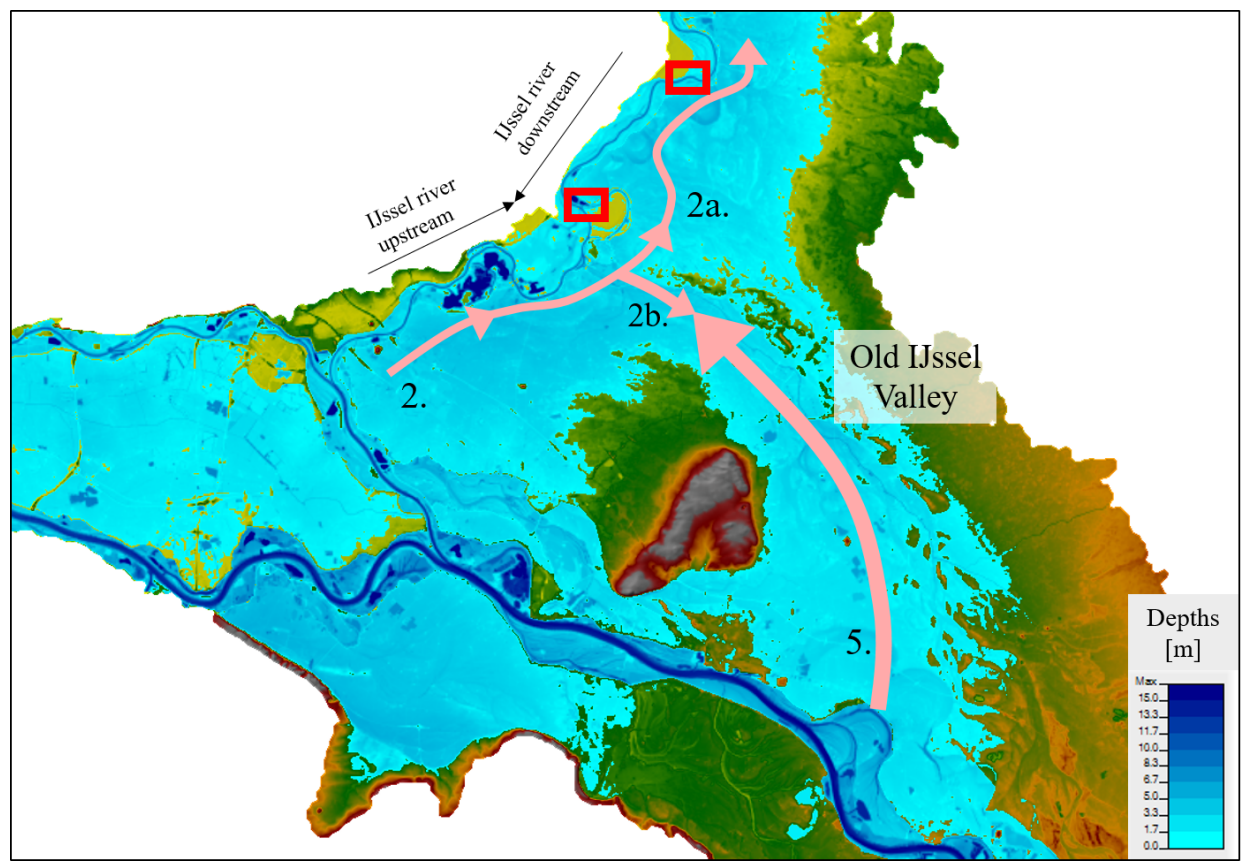

\section{Figure 5.10}

The most dominant overland flow patterns if the discharge at Andernach is larger than $16,000 \mathrm{~m}^{3} / \mathrm{s}$. Flow pattern 5 can change the discharge partitioning along the Dutch Rhine river branches and flood risk, and can already occur if the maximum discharge at Andernach exceeds $14,500 \mathrm{~m}^{3} / \mathrm{s}$. The two red boxes indicate the locations along the IJssel river where overland flows may re-enter the river. The location where flow patterns $2 \mathrm{~b}$ and 5 coincide depends mostly on the maximum upstream discharge. The larger the maximum discharge at Andernach, the larger the flow through the Old IJssel Valley. Hence, the location where the two flows coincide is relatively close to the IJssel river. Contrarily, if the maximum discharge at Andernach is relatively low, the two flow patterns will coincide somewhere in the Old IJssel Valley further away from the IJssel river.

through the entire valley can be much larger than this capacity. Consequently, the increased flood risk in the Old IJssel Valley caused by flow pattern 5 (Fig. 5.10) increases only further. For a maximum discharge larger than $18,700 \mathrm{~m}^{3} / \mathrm{s}$, the most downstream potential dike breach location along the IJssel river (Fig. 5.4) breached for $47 \%$ of the scenarios present in the Monte Carlo analysis. This breach was mostly caused by the high water levels in the embanked areas, resulting in an increase in the discharge at the IJssel river.

Although many overland flow patterns exist, only the flow through the Old IJssel Valley results in a change in downstream discharge partitioning and flood risk. Since the other river branches are not affected by overland flow patterns, the 
maximum potential discharge of these rivers converges towards a maximum value (Fig. 5.8). Only the maximum discharge at the downstream end of the IJssel river shows a strong positive correlation with the maximum discharge at Andernach. The flood defences along the IJssel river are not designed to withstand the large increase in maximum discharges at the downstream end of the IJssel river. Under normal conditions, we would expect that the discharge along the IJssel river is only as large as $50 \%$ of the discharge of the Nederrijn river. This discharge partitioning still holds for the upstream part of the IJssel river. Contrarily, for the downstream part of the IJssel river, a much larger discharge is found. Although a large flood event causing severe inundations is required to increase the discharge of the IJssel river as a result of overland flow patterns, this increased discharge may lead to even more inundations further downstream (located downstream of the model domain).

The dike breaches along the Lower Rhine result in a considerably reduction in the flood probability along the Waal river, the Pannerdensch Canal and the Nederrijn river. In the new risk-based approach (Section 5.2), the safety standards along these river branches will be much higher compared to the safety standards along the IJssel river. This is because a dike breach in the western part of the Netherlands has a much larger impact because of its higher population density, more vulnerable infrastructure and higher economic value compared to the eastern part of the Netherlands. It is expected that the consequences of a flood in the western part only increase further in the near future because people tend to move towards these areas because of their large economic value and job perspectives (Klijn et al, 2012). Therefore, the reduction in flood risk along the Waal river, Pannerdensch Canal and Nederrijn river as a result of upstream dike breaches may balance the increased flood risk along the downstream end of the IJssel river.

\subsubsection{Summary all discharges}

From the potential flood scenarios modelled, we find that the method proposed by Apel et al (2009) can be applied to flood events that have a maximum upstream discharge lower than $16,000 \mathrm{~m}^{3} / \mathrm{s}$. For larger upstream flood events, significant overland flow patterns start to occur. This results in a change in flood risk and in an increase in the maximum discharge along the downstream end of the IJssel river. To correctly predict flood risk and the maximum discharge during extreme flood events for this river section, overland flows must be included in the analysis. This is because the method proposed by Apel et al (2009) will underestimate the flood risk in the Old IJssel Valley and the maximum discharge along the downstream end of the IJssel river. For the other Rhine river branches, flood risk and the maximum discharge were not affected by overland flow patterns. However, backwater effects of dike breaches may still increase upstream discharges. Therefore, we conclude that it is of great importance to include overland flow patterns and backwater effects during flood modelling. 


\subsection{Sensitivity Analysis}

\subsubsection{Quantitative results}

Section 5.5 shows that dike breaches affect downstream flood risk and the maximum discharge along certain river sections. Several uncertain input parameters were included in the analysis, raising the question of which parameter mostly influences the change in downstream discharge partitioning. Therefore, this section presents a brief sensitivity analysis to determine which potential flood scenario results in a major increase in the maximum discharge at the downstream end of the IJssel river and hence mostly changes the discharge partitioning along the Dutch Rhine river branches. The uncertain parameters in the Monte Carlo analysis that influence the discharge along the downstream end of the IJssel river and that are included in the sensitivity analysis are:

- Maximum upstream discharge

- Shape of the upstream hydrograph: a single peak or two peaks

- Number of dike breaches along the Lower Rhine (north side) which is a function of the sampled dike breach thresholds

- Average final width of the dike breaches along the Lower Rhine

- Average formation time of the dike breaches along the Lower Rhine

The purpose of the sensitivity analysis is screening of the most important input parameters, i.e. factor prioritization. If the number of simulations is much higher than the number of input parameters, Multiple Linear Regression analysis can be highly effective in revealing the influence of each parameter (Saltelli et al, 2008). If the model does not contain any interactions between the input parameters (i.e. the model is additive), the linear regression function can be expressed as (Scheidt et al, 2018):

$$
y=\beta_{0}+\sum_{i=1}^{N} \beta_{\mathrm{i}} x_{\mathrm{i}}
$$

where $y$ represents the model output (in this study, the maximum discharge at the downstream end of the IJssel river) and $x_{i}$ the various input parameters. The coefficients $\beta_{0}$ and $\beta_{\mathrm{i}}$ are determined by the least-square computation, based on the squared differences between the model output produced by the regression model and the actual model output produced by the hydraulic model (Saltelli et al, 2008). 
Results of the Multiple Linear Regression analysis where $\beta_{\mathbf{i}}$ is determined by the least-square computation based on the squared differences between the model output produced by the regression model and the actual output produced by the hydraulic model, for each input parameter $x_{i} . \sigma_{\mathbf{i}}$ represents the standard deviation and $\hat{\beta}_{\mathbf{i}}$ the standardized regression coefficient for each input parameter $x_{i}$.

\begin{tabular}{l|ccc}
\hline \hline Input parameter & $\beta_{\mathrm{i}}$ & $\sigma_{\mathrm{i}}$ & $\hat{\beta}_{\mathrm{i}}$ \\
\hline Maximum discharge & 0.25 & $3290\left[\mathrm{~m}^{3} / \mathrm{s}\right]$ & $5.63 \times 10^{-1}$ \\
Shape hydrograph & 2.88 & $0.39[-]$ & $1.07 \times 10^{-6}$ \\
Nr. of dike breaches & 29.24 & $0.59[-]$ & $2.53 \times 10^{-4}$ \\
Average breach width & 4.61 & $52.1[\mathrm{~m}]$ & $5.00 \times 10^{-2}$ \\
Average formation time & -3.46 & $13.4[\mathrm{~h}]$ & $1.86 \times 10^{-3}$ \\
\hline \hline
\end{tabular}

In the case of independent input parameters, the absolute standardized regression coefficient $\hat{\beta}_{\mathrm{i}}$ can be used as a measure of sensitivity (Scheidt et al, 2018):

$$
\hat{\beta}_{\mathrm{i}}=\left|\beta_{\mathrm{i}} \frac{\sigma_{\mathrm{i}}}{\sigma_{\mathrm{y}}}\right|
$$

where $\hat{\beta}_{\mathrm{i}}$ represents the standardized regression coefficient, and $\sigma_{\mathrm{i}}$, and $\sigma_{\mathrm{y}}$ represent the standard deviations for input parameter $x_{i}$ and the model output respectively. In general, we state that the larger the computed value of $\hat{\beta}_{\mathrm{i}}$ the larger the influence of the corresponding input parameter on the model output.

Table 5.3 shows the results of the Multiple Linear Regression analysis. This clearly indicates that the maximum upstream discharge greatly influences the maximum discharge at the downstream end of the IJssel river and thus the discharge partitioning because of its relatively large $\hat{\beta}_{\mathrm{i}}$ value. The average breach width has the second highest $\hat{\beta}_{\mathrm{i}}$ value. However, its value is more than one order of magnitude smaller than the value of the upstream maximum discharge. This indicates that only the latter significantly influences the change in flood risk in the Old IJssel Valley and the maximum discharge at the downstream end of the IJssel river. The influence of the remaining parameters is also relatively low compared to the maximum upstream discharge.

The number of dike breaches along the Lower Rhine, which is a function of the fragility curves used, has only a low influence on the overland flow patterns as a result of the great amount of overflow that occurs, specifically for the large upstream maximum discharges. Hence, the assumptions made about the German fragility curves only have a little effect on the large-scale flow patterns and hence flood risk. 


\subsubsection{Qualitative results}

A drawback of the Multiple Linear Regression analysis is that it depends on the degree of linearity of the model (Saltelli et al, 2008). A measure for linearity is expressed by $\mathrm{R}^{2}$ (Saltelli et al, 2008):

$$
R^{2}=\sum_{i=1}^{N}\left(\hat{\beta}_{\mathrm{i}}\right)^{2}
$$

where $R^{2}$ is also referred to as the model coefficient of determination and is equal to the fraction of the variance of the original data that is explained by the regression model. A value of $R^{2}$ equal to one means that the model is linear (Saltelli et al, 2008) and that the multiple linear regression model is capable of expressing all variance of the original data. The regression model applied in this study has a model coefficient of determination equal to 0.67 , indicating that only $67 \%$ of the variance of the original hydraulic model is explained by the regression model. However, the scatter plots and box plots in Figs. 5.11 and 5.12 confirm the results predicted by the Multiple Linear Regression Analysis. The scatter plots clearly show that there is a positive correlation between the maximum upstream discharge and the discharge at the downstream end of the IJssel river. As explained in Section 5.5, overflow and dike breaches along the Lower Rhine result in overland flow increasing the discharge of the IJssel river (Fig. 5.10). The discharge of this overland flow increases if the maximum upstream discharge increases. The random point cloud for the final breach width and formation time (Fig. 5.11) indicates that these parameters do not influence downstream maximum discharges, which is in line with the Multiple Linear Regression analysis. Note that the points at which $\mathrm{x}=0$ in both scatter plots (final average breach width and average formation time) represent the scenarios in which no dike breaches occur along the Lower Rhine.

Fig. 5.12 shows that the maximum discharge at the downstream end of the IJssel river increases with the number of dike breaches along the Lower Rhine, which is a function of the sampled dike breach thresholds. However, the box plot shows a wide spread represented by the blue boxes ( $50 \%$ confidence interval) indicating that the positive correlation is only weak. This agrees with the results of the Multiple Linear Regression analysis in which the computed $\hat{\beta}_{\mathrm{i}}$ value was low compared to that of the maximum upstream discharge. Moreover, Fig. 5.12 shows that there is no correlation between the shape of the upstream hydrograph and the maximum discharge at the downstream end of the IJssel river.

From the sensitivity analysis, we conclude that the breach characteristics in terms of breach development do not have a significant influence on predicted overland flows and hence downstream discharges, as was also found by Brunner (2014b). Therefore, it can be stated that a sophisticated breach model is indeed not required for flood modelling purposes. Simplified assumptions as applied in this 

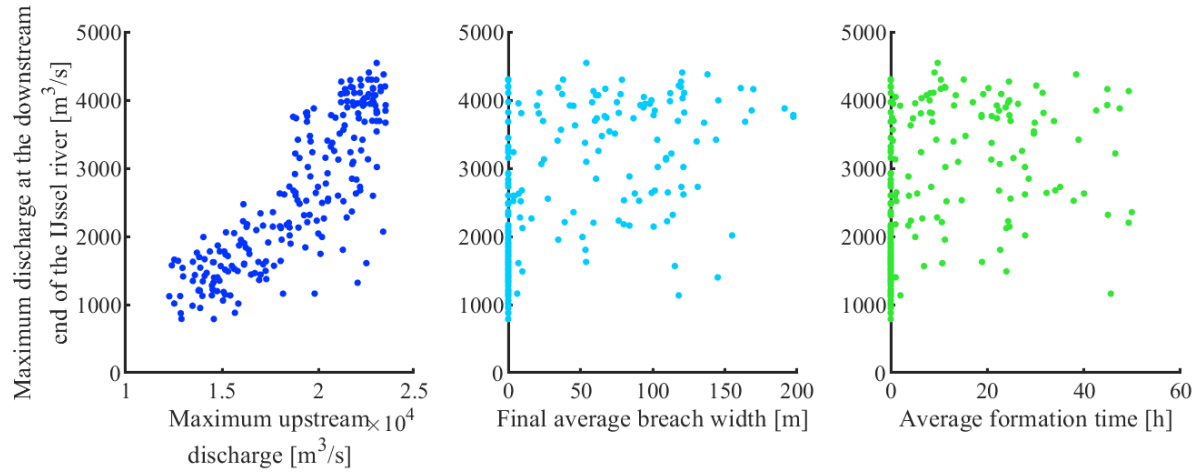

\section{Figure 5.11}

Scatter plots which represent the correlation between the maximum upstream discharge, final breach width and formation time and the maximum discharge at the downstream end of the IJssel river.
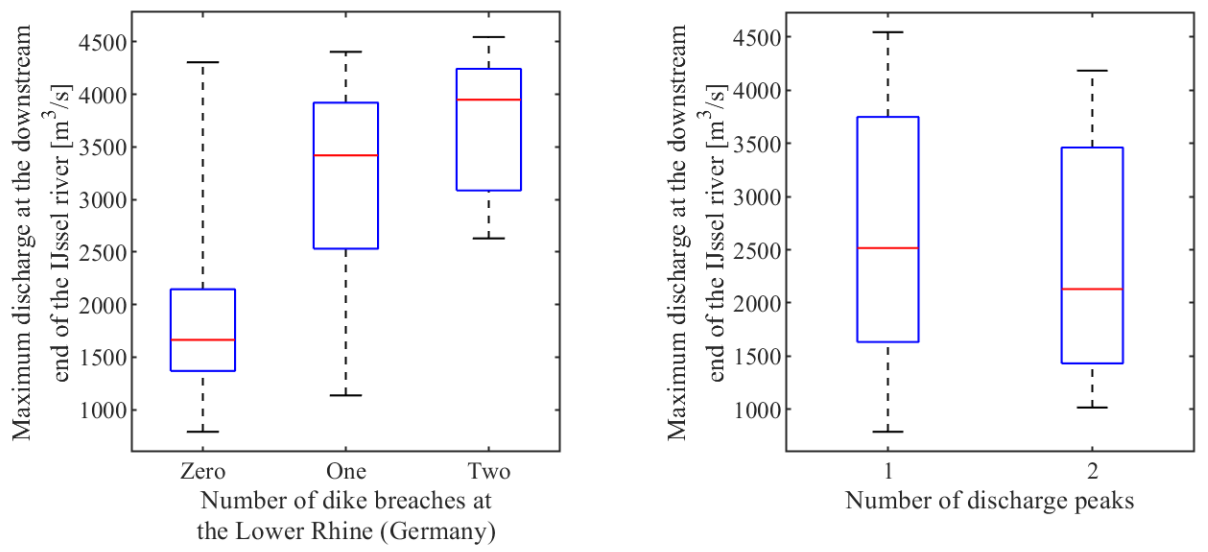

\section{Figure 5.12}

Relation between the number of dike breaches along the Lower Rhine and resulting maximum discharge at the downstream end of the IJssel river (left figure) and the relation between discharge wave shape (a single peak or two peaks) and resulting maximum discharge at the downstream end of the IJssel river (right figure). 
study can be used instead. More important for accurate prediction of potential flood scenarios, are the upstream boundary conditions in terms of the maximum discharge.

\subsection{Discussion and Conclusions}

We extended the method proposed by Apel et al (2009) to study the effects of dike breaches and overflow on maximum discharges and flood risk in a bifurcating river system. A 1D-2D coupled model was developed that was able to predict water levels during flood events with high accuracy. The Rhine delta was used as a case study, but the proposed method can be applied to any river system if a highresolution DEM is available. Applying this method will generate, amongst others, knowledge on the effect of dike breaches on the potential maximum discharges along various river branches.

The analysis has shown that dike breaches can change the maximum discharges of downstream rivers. However, this effect is not only beneficial in terms of a reduction in the maximum discharge further downstream, as was found by Apel et al (2009). Large overland flows may change downstream discharge partitioning and flood risk. Furthermore, backwater effects may increase the maximum discharge upstream of a dike breach. For this specific case study, it was found that overflow and dike breaches along the Lower Rhine result in great inundations in the Old IJssel Valley. Although this overland flow pattern only occurs in very extreme cases, its effect on flood risk is relevant to consider. If the discharge of the overland flow through the Old IJssel Valley is extremely large, a part may enter the IJssel river. This consequently increases the maximum discharge at the downstream end of the IJssel river. In the most extreme scenario present in the Monte Carlo analysis, the maximum discharge at the downstream end of the IJssel river increased with $316 \%$. This increase is so severe, not only because of the large amount of water that is flowing through the Old IJssel Valley, but also because the discharge at the upstream part of the IJssel river, near the bifurcation point with the Nederrijn river, is relatively small. This is because only a small amount of water is flowing in the main channels as a result of the dike breaches along the Pannerdensch Canal and Lower Rhine. All other Rhine river branches were not affected by overland flow patterns. Hence, only a reduction in maximum discharge as a result of upstream dike breaches was found. Therefore, flood risk decreases along the Waal river, Pannerdensch Canal and Nederrijn river.

Overall, we conclude that dike breaches, resulting overland flow patterns and backwater effects must be included in the analysis of safety assessments since it may change downstream flood risk. This study shows that dike breaches may have a beneficial effect on some downstream river branches in terms of discharge reduc- 
tion, while it may also cause severe problems along other river branches, especially if the discharge capacity of the specific river is relatively low compared to the discharge capacity of the other river branches. This is because an upstream dike breach and/or overflow can cause inundations that are much more severe than would be the case if only overflow and/or dike breaches occurs along the river with a relatively low discharge capacity.

Finally, the sensitivity analysis showed that a change in downstream discharge partitioning and flood risk is mostly influenced by the upstream maximum discharge, whereas breach characteristics (formation time and final breach width) do not have a significant impact on the predicted overland flow patterns.

\section{Acknowledgements}

This research is supported by the Netherlands Organisation for Scientific Research (NWO, project 14506) which is partly funded by the Ministry of Economic Affairs and Climate Policy. Furthermore, the research is supported by the Ministry of Infrastructure and Water Management and Deltares. This research has benefited from cooperation within the network of the Netherlands Centre for River Studies.

The authors would like to thank the Dutch Ministry of Infrastructure and Water Management and the German Federal Institute of Hydrology for providing the data. Furthermore, the authors would like to thank Dr. Lammersen from the Dutch Ministry of Infrastructure and Water Management and Mrs. Becker from Deltares for their suggestions and valuable insights. Finally, the authors would like to thank Utrecht University for its cooperation in the NWO project Floods of the past - Design for the future. 


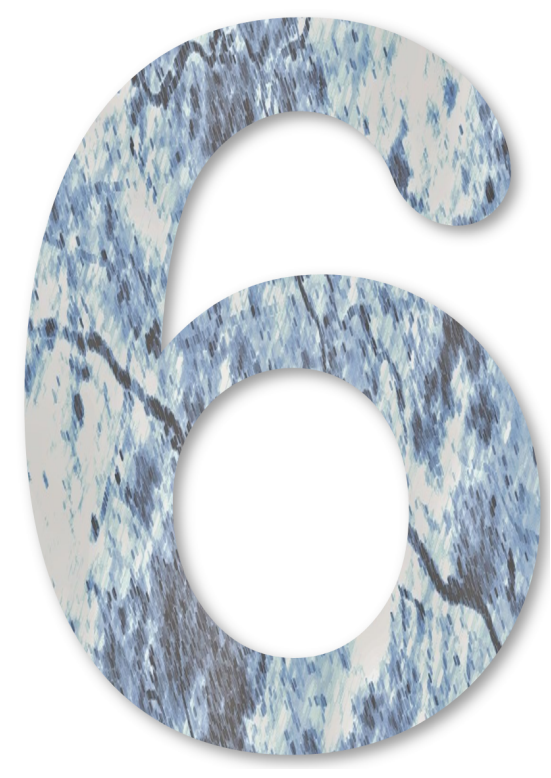

Decreasing uncertainty in flood frequency analyses by including historic flood events in an efficient bootstrap approach

This chapter is published as A. Bomers, R.M.J. Schielen, and S.J.M.H. Hulscher (2019). Decreasing uncertainty in flood frequency analyses by including historic flood events in an efficient bootstrap approach, Natural Hazards and Earth System Sciences, 19, 1895-1908. DOI:10.5194/nhess-19-1895-2019 


\section{Abstract}

Flood frequency curves are usually highly uncertain since they are based on short data sets of measured discharges or weather conditions. To decrease the confidence intervals, an efficient bootstrap method is developed in this study. The Rhine river delta is considered as a case study. We use a hydraulic model to normalize historic flood events for anthropogenic and natural changes in the river system. As a result, the data set of measured discharges could be extended by approximately 600 years. The study shows that historic flood events decrease the confidence interval of the flood frequency curve significantly, specifically in the range of large floods. This even applies if the maximum discharges of these historic flood events are highly uncertain themselves.

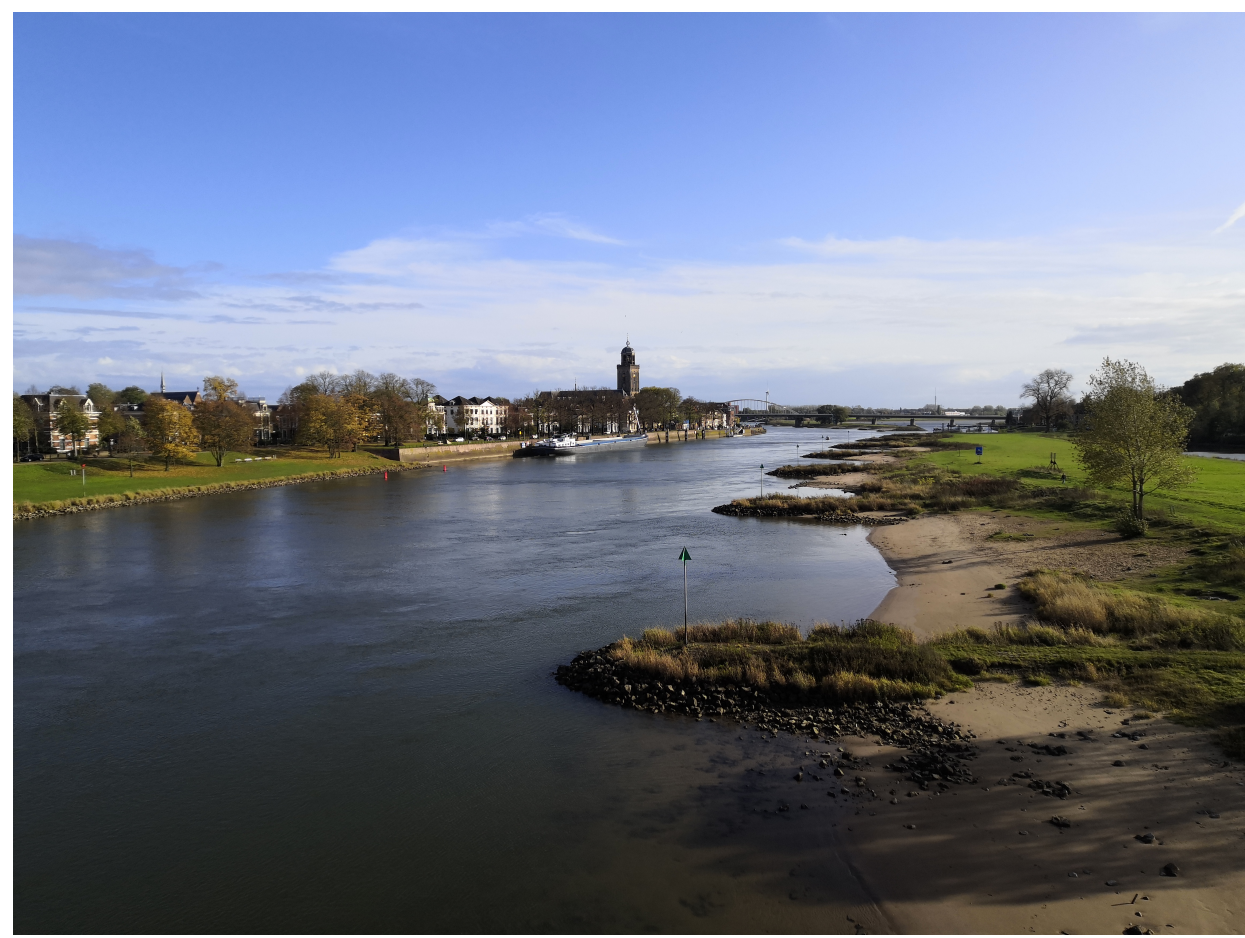

The IJssel river near the City of Deventer. Photo by: A. Bomers 


\subsection{Introduction}

Floods are one of the main natural hazards to cause large economic damage and human casualties worldwide as a result of serious inundations with disastrous effects. Design discharges associated with a specific return period are used to construct flood defences to protect the hinterland from severe floods. These design discharges are commonly determined with the use of a flood frequency analysis (FFA). The basic principle of an FFA starts with selecting the annual maximum discharges of the measured data set, or peak values that exceed a certain threshold (Schendel and Thongwichian, 2017). These maximum or peak values are used to identify the parameters of a probability distribution. From this fitted distribution, discharges corresponding to any return period can be derived.

Return periods of design discharges are commonly of the order of 500 years or even more, while discharge measurements have been performed only for the last 50-100 years. For the Dutch Rhine river delta (used as a case study in this paper), water levels and related discharges have been registered since 1901 while design discharges have a return period up to 100,000 years (Van der Most et al, 2014). Extrapolation of these measured discharges to such return periods results in large confidence intervals of the predicted design discharges. Uncertainty in the design discharges used for flood risk assessment can have major implications for national flood protection programs since it determines whether and where dike reinforcements are required. A too wide uncertainty range may lead to unnecessary investments.

To obtain an estimation of a flood with a return period of 10,000 years with little uncertainty, a discharge data set of at least 100,000 years is required (Klemeš, 1986). Of course, such data sets do not exist. For this reason, many studies try to extend the data set of measured discharges with historic and/or paleo flood events. The most common methods in literature to include historical data into an FFA are based on the traditional methods of frequentist statistics (Frances et al, 1994; MacDonald et al, 2014; Sartor et al, 2010) and Bayesian statistics (O'Connell et al, 2002; Parkes and Demeritt, 2016; Reis and Stedinger, 2005).

While frequentist statistics are generally applied by decision makers, Bayesian statistics have significantly increased in popularity in the last decade. Reis and Stedinger (2005) have successfully applied a Bayesian Markov chain Monte Carlo (MCMC) analysis to determine flood frequency relations and their uncertainties using both systematic data and historic flood events. A Bayesian analysis determines the full posterior distribution of the parameters of a probability distribution function (e.g. Generalized extreme value (GEV) distribution). This has the advantage that the entire range of parameter uncertainty can be included in the analysis. Contrarily, classical methods based on frequentist statistics usually only provide a point estimate of the parameters where their uncertainties are commonly 
described by using the assumption of symmetric normal distributed uncertainty intervals (Reis and Stedinger, 2005). The study of Reis and Stedinger (2005) shows that confidence intervals of design discharges were reduced significantly by extending the systematic data set with historic events using the proposed Bayesian framework. This finding is important for the design of future flood-reduction measures since these can then be designed with less uncertainty.

However, Bayesian statistics also have several drawbacks. Although no assumption about the parameter uncertainty of the distribution function has to be made, the results depend on the parameter priors which have to be chosen a priori. The influence of the priors on the posterior distributions of the parameters and hence on the uncertainty of flood frequency relations can even be larger than the influence of discharge measurement errors (Neppel et al, 2010). The prior can be estimated by fitting the original data with the use of the maximum likelihood method. However, we do not have any measurements in, or near, the tail of the frequency distribution functions. In this way, the benefits of the Bayesian method compared to a traditional flood frequency analysis are at least questionable.

In this study, we propose a systematic approach to include historic flood information in flood safety assessments. The general methodology of a flood frequency analysis remains, only the data set of measured discharges is extended with the use of a bootstrap approach. As a result, this method is close to current practice of water managers. We extend the data set of measured discharges at Lobith, the German-Dutch border, with historic events to decrease uncertainty intervals of design discharges corresponding to rare events. A bootstrap method is proposed to create a continuous data set after which we perform a traditional FFA to stay in line with the current methods used for Dutch water policy. Hence, the results are understandable for decision makers since solely the effect of using data sets with different lengths on flood frequency relations and corresponding uncertainty intervals is presented. The objective of this study is thus to develop a straightforward method to consider historic flood events in an FFA, while the basic principles of an FFA remain unchanged.

The measured discharges at Lobith (1901-2018) are extended with the continuous reconstructed data set of Toonen (2015) covering the period 1772-1900. These data sets are extended with the most extreme, older historic flood events near Cologne reconstructed by Meurs (2006), which are routed towards Lobith. For this routing, a one dimensional-two dimensional (1D-2D) coupled hydraulic model is used to determine the maximum discharges during these historic events based on the current geometry. In such a way, the historic floods are corrected for anthropogenic interventions and natural changes of the river system, referred to as normalization in this study. Normalizing the historic events is of high importance since flood patterns most likely change over the years as a result of dike reinforcements, land use change or decrease in floodplain area (dike shifts). The normalized events almost always lead to a higher discharge than the historic event. This is 
because more water is capable of flowing through the river system as a result of the heightened dikes along the Lower Rhine. Today, floods occur for higher discharge stages compared to the historical time period. In any case, the normalized events give insight into the consequences of an event with the same characteristics of a historic flood event translated to present times. To create a continuous data set, a bootstrap resampling technique is used. The results of the bootstrap method are evaluated against an FFA based on solely measured annual maximum discharges (1901-2018 and 1772-2018). Specifically, the change in the design discharge and its $95 \%$ confidence interval of events with a return period of 100,000 years is considered because this design discharge corresponds with the highest safety level used in Dutch flood protection programs (Van Alphen, 2016).

In Section 6.2 the different data sets used to construct the continuous discharge data set are explained, as well as the 1D-2D coupled hydraulic model. Next, the bootstrap method and FFA are explained (Section 6.3 and Section 6.4 respectively). After that, the results of the FFA are given (Section 6.5). The paper ends with a discussion (Section 6.6) and the main conclusions (Section 6.7).

\subsection{Annual maximum discharges}

\subsubsection{Discharge measurements covering the period 1901 - 2018}

Daily discharge observations at Lobith have been performed since 1901 and are available at https://waterinfo.rws.nl. From this data set, the annual maximum discharges are selected, in which the hydrologic time period, starting at the $1^{\text {st }}$ of October and ending at the $30^{\text {th }}$ of September, is used. Since changes to the system have been made in the last century, Tijssen (2009) has normalized the measured data set from 1901 to 2008 for the year 2004. In the $20^{\text {th }}$ century, canalization projects were carried out along the Upper Rhine (Germany) and were finalized in 1977 (Van Hal, 2003). After that, retention measures were taken in the trajectory Andernach-Lobith. First, the 1901 to 1977 data set has been normalized with the use of a regression function describing the influence of the canalization projects on the maximum discharges. Then, again a regression function was used to normalize the 1901-2008 data set for the retention measures (Van Hal, 2003). This results in a normalized 1901-2008 data set for the year 2004. For the period 2009-2018, the measured discharges without normalization are used.

During the discharge recording period, different methods have been used to perform the measurements. These different methods result in different uncertainties (Table 6.1) and must be included in the FFA to correctly predict the $95 \%$ confidence interval of the FF curve. From 1901 until 1950, discharges at Lobith were based on velocity measurements performed with floating sticks on the water sur- 
face. Since the velocity was only measured at the surface, extrapolation techniques were used to compute the total discharge. This resulted in an uncertainty of approximately 10\% (Toonen, 2015). From 1950 until 2000, current meters were used to construct velocity-depth profiles. These profiles were used to compute the total discharge, having an uncertainty of approximately 5\% (Toonen, 2015). Since 2000, acoustic Doppler current profiles have been used, for which an uncertainty of $5 \%$ is also assumed.

\section{Table 6.1}

Uncertainties and properties of the various data sets used. The 1342-1772 data set represents the historical discharges (first row in the table), whereas the data sets in the period 1772-2018 are referred to as the systematic data sets (rows 2-7).

\begin{tabular}{|c|c|c|c|c|}
\hline Time period & Data source & Property & Cause uncertainty & Location \\
\hline $1342-1772$ & Meurs (2006) & $\begin{array}{l}12 \text { single } \\
\text { events }\end{array}$ & $\begin{array}{l}\text { Reconstruction uncertainty } \\
\text { caused by main channel } \\
\text { bathymetry, bed friction, } \\
\text { and maximum occurring } \\
\text { water levels }\end{array}$ & Cologne \\
\hline $1772-1865$ & Toonen (2015) & $\begin{array}{l}\text { Continuous } \\
\text { data set }\end{array}$ & $\begin{array}{l}\text { Reconstruction uncertainty } \\
\text { based on measured water } \\
\text { levels of surrounding sites } \\
(\sim 12 \%)\end{array}$ & $\begin{array}{l}\text { Emmerich, } \\
\text { Pannerden } \\
\text { and } \\
\text { Nijmegen }\end{array}$ \\
\hline $1866-1900$ & Toonen (2015) & $\begin{array}{l}\text { Continuous } \\
\text { data set }\end{array}$ & $\begin{array}{l}\text { Uncertainty caused by } \\
\text { translation of measured water } \\
\text { levels into discharges } \\
(\sim 12 \%)\end{array}$ & Lobith \\
\hline $1901-1950$ & Tijssen (2009) & $\begin{array}{l}\text { Continuous } \\
\text { data set }\end{array}$ & $\begin{array}{l}\text { Uncertainty caused by } \\
\text { extrapolation techniques } \\
\text { to translate measured } \\
\text { velocities at the water } \\
\text { surface into discharges } \\
(10 \%)\end{array}$ & Lobith \\
\hline $1951-2000$ & Tijssen (2009) & $\begin{array}{l}\text { Continuous } \\
\text { data set }\end{array}$ & $\begin{array}{l}\text { Uncertainty caused by } \\
\text { translation of velocity-depth } \\
\text { profiles into discharges } \\
(5 \%)\end{array}$ & Lobith \\
\hline $2001-2008$ & Tijssen (2009) & $\begin{array}{l}\text { Continuous } \\
\text { data set }\end{array}$ & Measurement errors (5\%) & Lobith \\
\hline $2009-2018$ & $\begin{array}{l}\text { Measured water levels } \\
\text { available at } \\
\text { https://waterinfo.rws.nl }\end{array}$ & $\begin{array}{l}\text { Continuous } \\
\text { data set }\end{array}$ & Measurement errors (5\%) & Lobith \\
\hline
\end{tabular}




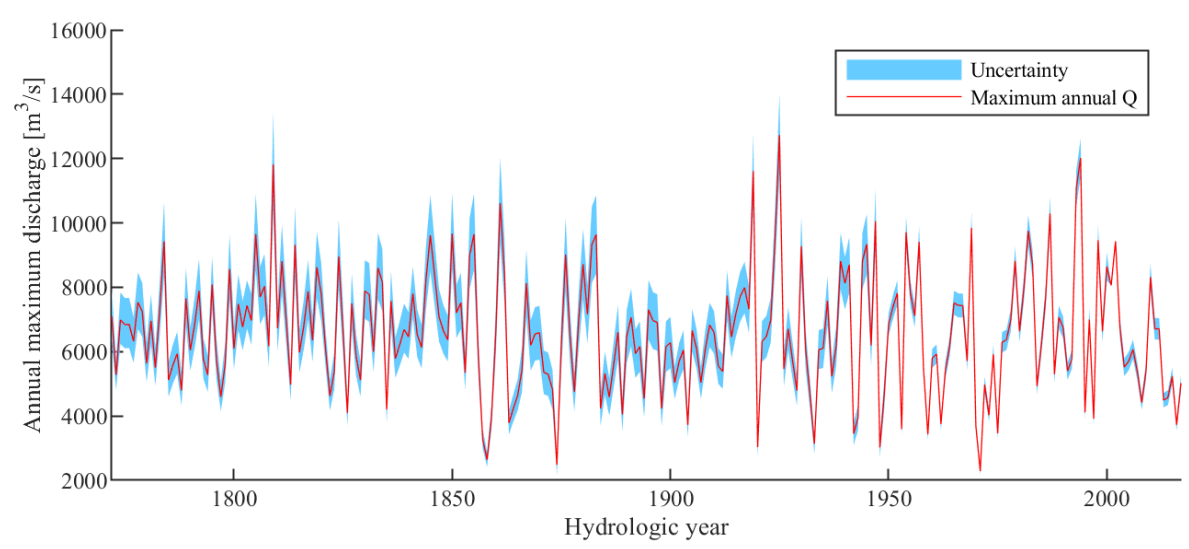

\section{Figure 6.1}

Maximum annual discharges $(\mathrm{Q})$ and their $95 \%$ confidence interval during the systematic time period (1772-2018).

\subsubsection{Water level measurements covering the period 1772 - 1900}

Toonen (2015) studied the effects of non-stationarity in flooding regimes over time on the outcome of an FFA. He extended the data set of measured discharges of the Rhine river at Lobith with the use of water level measurements. At Lobith, daily water level measurements are available since 1866. For the period 1772-1865 water levels were measured at the nearby gauging locations Emmerich, Germany (located $10 \mathrm{~km}$ in upstream direction), and Pannerden (located $10 \mathrm{~km}$ in downstream direction) and Nijmegen (located $22 \mathrm{~km}$ in downstream direction) in the Netherlands. Toonen (2015) used the water levels of these locations to compute the water levels at Lobith and their associated uncertainty interval with the use of a linear regression between the different measurement locations. Subsequently, he translated these water levels, together with the measured water levels for the period 1866-1900, into discharges using stage-discharge relations at Lobith. These relations were derived based on discharge predictions adopted from Cologne before 1900 and measured discharges at Lobith after 1900, as well as water level estimates from the measurement locations Emmerich, Pannerden, Nijmegen and Lobith. Since the discharge at Cologne strongly correlates with the discharge at Lobith, the measured discharges in the period 1817-1900 could be used to predict discharges at Lobith. The $95 \%$ confidence interval in reconstructed water levels propagates in the application of stage-discharge relations, resulting in an uncertainty range of approximately $12 \%$ for the reconstructed discharges (Fig. 6.1) (Toonen, 2015). 
The reconstructed discharges in the period 1772-1900 represent the computed maximum discharges at the time of occurrence and these discharges have not been normalized for changes in the river system. They thus represent the actual annual maximum discharges that occurred. Toonen (2015) argues that, based on the work of Bronstert et al (2007) and Vorogushyn and Merz (2013), the effect of recent changes in the river system on discharges of extreme floods of the Lower Rhine is small. Hence, it is justified to use the presented data set of Toonen (2015) in this study as normalized data. Fig. 6.1 shows the annual maximum discharges for the period 1772-2018 and their $95 \%$ confidence intervals. This data represents the systematic data set and consists of the measured discharges covering the period 1901-2018 and the reconstructed data set of Toonen (2015) covering the period 1772-1900.

\subsubsection{Reconstructed flood events covering the period 1300 - 1772}

Meurs (2006) has reconstructed maximum discharges during historic flood events near the city of Cologne, Germany. The oldest event dates back to 1342 . Only flood events caused by high rainfall intensities and snowmelt were reconstructed because of the different hydraulic conditions of flood events caused by ice jams. The used method is described in detail by Herget and Meurs (2010), in which the 1374 flood event was used as a case study. Historic documents providing information about the maximum water levels during the flood event were combined with the reconstruction of the river cross section at that same time. Herget and Meurs (2010) calculated mean flow velocities near the city of Cologne at the time of the historic flood events with the use of Manning's equation:

$$
Q_{\mathrm{p}}=A_{\mathrm{p}} R_{\mathrm{p}}^{2 / 3} S^{1 / 2} n^{-1}
$$

where $Q_{\mathrm{p}}$ represents the peak discharge $\left(\mathrm{m}^{3} / \mathrm{s}\right), A_{\mathrm{p}}$ the cross-sectional area $\left(\mathrm{m}^{2}\right)$ during the highest flood level, $R_{\mathrm{p}}$ the hydraulic radius during the highest flood level $(\mathrm{m}), S$ the slope of the main channel and $n$ its Manning's roughness coefficient $\left(\mathrm{s} / \mathrm{m}^{1 / 3}\right)$. However, the highest flood level as well as the Manning's roughness coefficient are uncertain. The range of maximum water levels was based on historical sources, whereas the range of Manning's roughness coefficients was based on the tables of Chow (1959). Including these uncertainties in the analysis, Herget and Meurs (2010) were able to calculate maximum discharges of the specific historic flood events and associated uncertainty ranges (Fig. 6.4).

In total, 13 historic flood events that occurred before 1772 were reconstructed. Two of the flood events occurred in 1651. Only the largest flood of these two is considered as a data point. This results in 12 historic floods that are used to extend the systematic data set. The reconstructed maximum discharges at 
Cologne (Meurs, 2006) are used to predict maximum discharges at Lobith with the use of a hydraulic model to normalize the data set. Although Cologne is located roughly $160 \mathrm{~km}$ upstream of Lobith, there is a strong correlation between the discharges at these two locations. This is because they are located in the same fluvial trunk valley and only have minor tributaries (Sieg, Ruhr and Lippe rivers) joining in between (Toonen, 2015). This makes the reconstructed discharges at Cologne applicable to predict corresponding discharges at Lobith. The model used to perform the hydraulic calculations is described in Section 6.2.3. The maximum discharges at Lobith of the 12 historic flood events are given in Section 6.4.

\section{Model environment}

In this study, the 1D-2D coupled modelling approach as described by Bomers et al (2019b) is used to normalize the data set of Meurs (2006). This normalization is performed by routing the reconstructed historical discharges at Cologne over modern topography to estimate the maximum discharges at Lobith in present times. The study area stretches from Andernach to the Dutch cities of Zutphen, Rhenen and Druten (Fig. 6.2). In the hydraulic model, the main channels and floodplains are discretized by $1 \mathrm{D}$ profiles. The hinterland is discretized by $2 \mathrm{D}$ grid cells. The $1 \mathrm{D}$ profiles and $2 \mathrm{D}$ grid cells are connected by a structure corresponding with the dimensions of the dike that protects the hinterland from flooding. If the computed water level of a $1 \mathrm{D}$ profile exceeds the dike crest, water starts to flow into the $2 \mathrm{D}$ grid cells corresponding with inundations of the hinterland. A discharge wave is used as the upstream boundary condition. Normal depths, computed with the use of Manning's equation, were used as downstream boundary conditions. HECRAS (v. 5.0.3) (Brunner, 2016), developed by the Hydrologic Engineering Center (HEC) of the US Army Corps of Engineers, is used to perform the computations. For more information about the model set-up, see Bomers et al (2019b).

We use the hydraulic model to route the historical discharges at Cologne, as reconstructed by Meurs (2006), to Lobith. However, the reconstructed historical discharges were uncertain. Therefore, the discharges at Lobith are also uncertain. To include this uncertainty in the analysis, a Monte Carlo analysis (MCA) is performed in which, among others, the upstream discharges reconstructed by Meurs (2006) are included as random parameters. These discharges have large confidence intervals (Fig. 6.4). The severe 1374 flood, representing the largest flood of the last 1,000 years with a discharge of $23,000 \mathrm{~m}^{3} / \mathrm{s}$, even has a confidence interval of more than $10,000 \mathrm{~m}^{3} / \mathrm{s}$. To include the uncertainty as computed by Meurs (2006) in the analysis, the maximum upstream discharge is varied in the MCA based on its probability distribution. However, the shape of this probability distribution is unknown. Herget and Meurs (2010) only provided the maximum, minimum and mean values of the reconstructed discharges. We assumed normally distributed discharges since it is likely that the mean value has a higher probability of oc- 


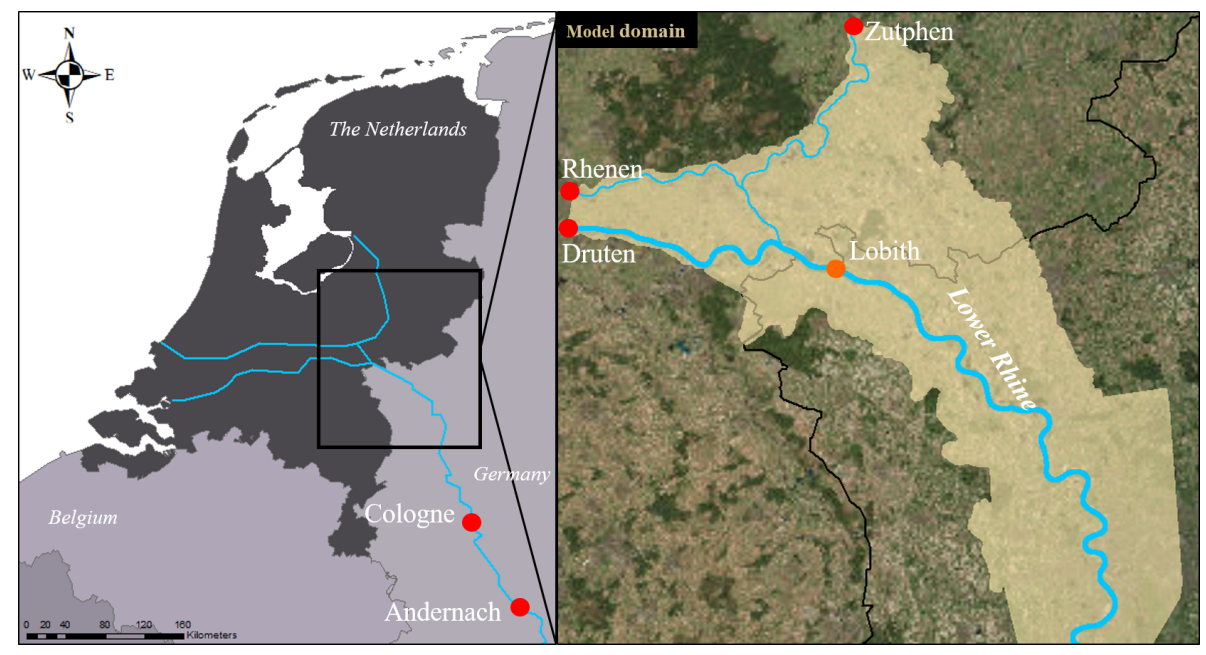

Figure 6.2

Model domain of the 1D-2D coupled model.

currence than the boundaries of the reconstructed discharge range. However, we found that the assumption of the uncertainty distribution has a negligible effect on the $95 \%$ uncertainty interval of the FF curve at Lobith. Assuming uniformly distributed uncertainties only led to a very small increase in this $95 \%$ uncertainty interval.

Not only the maximum discharges at Cologne, but also the discharge wave shape of the flood event are uncertain. The shape of the upstream flood event may influence the maximum discharge at Lobith. Therefore, the upstream discharge wave shape is varied in the MCA. We use a data set of approximately 250 potential discharge wave shapes that can occur under current climate conditions (Hegnauer et al, 2014). In such a way, a broad range of potential discharge wave shapes, e.g. a broad peak, a small peak, or two peaks, are included in the analysis. For each run in the MCA, a discharge wave shape is randomly sampled and scaled to the maximum value of the flood event considered (Fig. 6.3). This discharge wave represents the upstream boundary condition of the model run.

The sampled upstream discharges, based on the reconstructed historic discharges at Cologne, may lead to dike breaches in present times. Since we are interested in the consequences of the historic flood events in present times, we want to include these dike breaches in the analysis. However, it is highly uncertain how dike breaches develop. Therefore, the following potential dike breach settings are included in the MCA (Fig. 6.3): 
1. Dike breach threshold

2. Final dike breach width

3. Dike breach formation time

The dike breach thresholds (i.e. the critical water level at which a dike starts to breach) are based on 1D fragility curves provided by the Dutch Ministry of Infrastructure and Water Management. A 1D fragility curve expresses the reliability of a flood defence as a function of the critical water level (Hall et al, 2003). The critical water levels thus influence the timing of dike breaching. For the Dutch dikes, it is assumed that the dikes can fail due to failure mechanisms of wave overtopping and overflow, piping, and macro-stability, whereas the German dikes only fail because of wave overtopping and overflow (Bomers et al, 2019b). The distributions of the final breach width and the breach formation time are based on literature and on historical data (Apel et al, 2008; Verheij and Van der Knaap, 2003). Since it is unfeasible to implement each dike kilometer as a potential dike breach location in the model, only the dike breach locations that result in significant overland flow are implemented. This results in 33 potential dike breach locations, whereas it is possible for overflow (without dike breaching) to occur at every location throughout the model domain (Bomers et al, 2019b).

Thus, for each Monte Carlo run an upstream maximum discharge and a discharge wave shape are sampled. Next, for each of the 33 potential dike breach locations the critical water level, dike breach duration and final breach widths are sampled. With this data, the Monte Carlo run representing a specific flood scenario can be run (Fig. 6.3). This process is repeated until convergence of the maximum discharge at Lobith and its confidence interval are found. For a more in-depth explanation of the Monte Carlo analysis and random input parameters, we refer to Bomers et al (2019b).

The result of the MCA is the normalized maximum discharge at Lobith and its $95 \%$ confidence interval for each of the 12 historic flood events. Since the maximum discharges at Cologne are uncertain, the normalized maximum discharges at Lobith are also uncertain (Fig. 6.4). Fig 6.4 shows that the extreme 1374 flood with a maximum discharge of between $18,800 \mathrm{~m}^{3} / \mathrm{s}$ and $29,000 \mathrm{~m}^{3} / \mathrm{s}$ at Cologne, significantly decreases in the downstream direction as a result of overflow and dike breaches. Consequently, the maximum discharge at Lobith turns out to be between 13,825 and $17,753 \mathrm{~m}^{3} / \mathrm{s}$. This large reduction in the maximum discharge is caused by the major overflow and dike breaches that occur in present times. Since the 1374 flood event was much larger than the current discharge capacity of the Lower Rhine, the maximum discharge at Lobith decreases. The reconstruction of the 1374 flood over modern topography is presented in detail in Bomers et al (2019e). On the other hand, the other 11 flood events were below this discharge capacity and hence only a slight reduction in discharges was found for some of the events as a result of dike breaches, whereas overflow did not occur. Some other events 


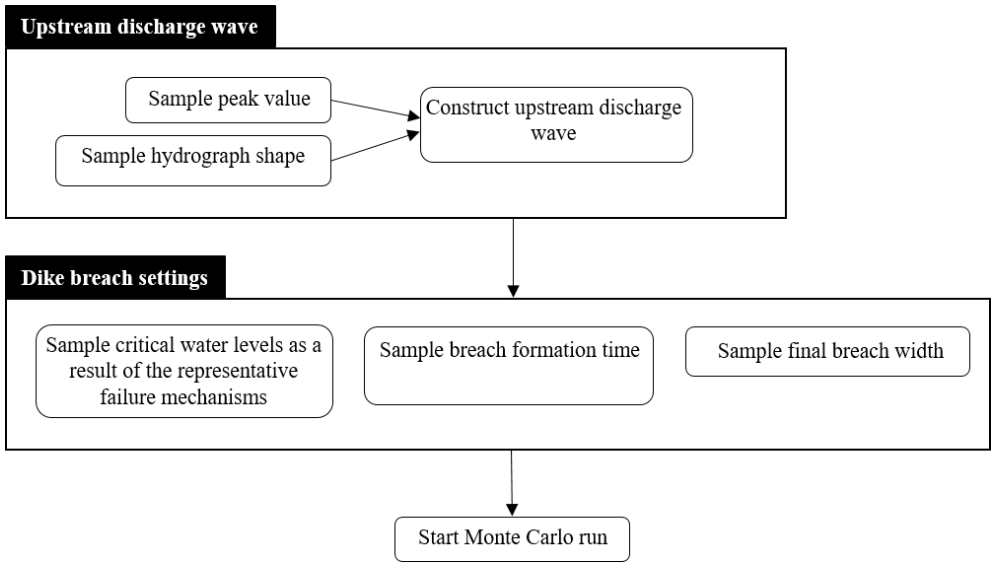

Figure 6.3

Random input parameters considered in the Monte Carlo analysis.

slightly increased as a result of the inflow of the tributaries Sieg, Ruhr and Lippe rivers along the Lower Rhine. This explains why the 1374 flood event is much lower at Lobith compared to the discharge at Andernach, while the discharges of the other 11 flood events are more or less the same at these two locations (Fig. 6.4). The reduction in maximum discharge of the 1374 flood event in the downstream direction shows the necessity to apply hydraulic modelling since the use of a linear regression analysis based on measured discharges between Cologne and Lobith will result in an unrealistically larger maximum discharge at Lobith.

The reconstructed discharges at Lobith are used to extend the systematic data set presented in Fig. 6.1. In the next section, these discharges are used in an FFA with the use of a bootstrap method.

\subsection{The bootstrap method}

The systematic data set covering the period 1772-2018 is extended with 12 reconstructed historic flood events that occurred in the period 1300-1772. To create a continuous data set, a bootstrap method based on sampling with replacement is used. The continuous systematic data set (1772-2018) is resampled over the missing years from the start of the historical period to the start of the systematic record. Two assumptions must be made such that the bootstrap method can be applied: 


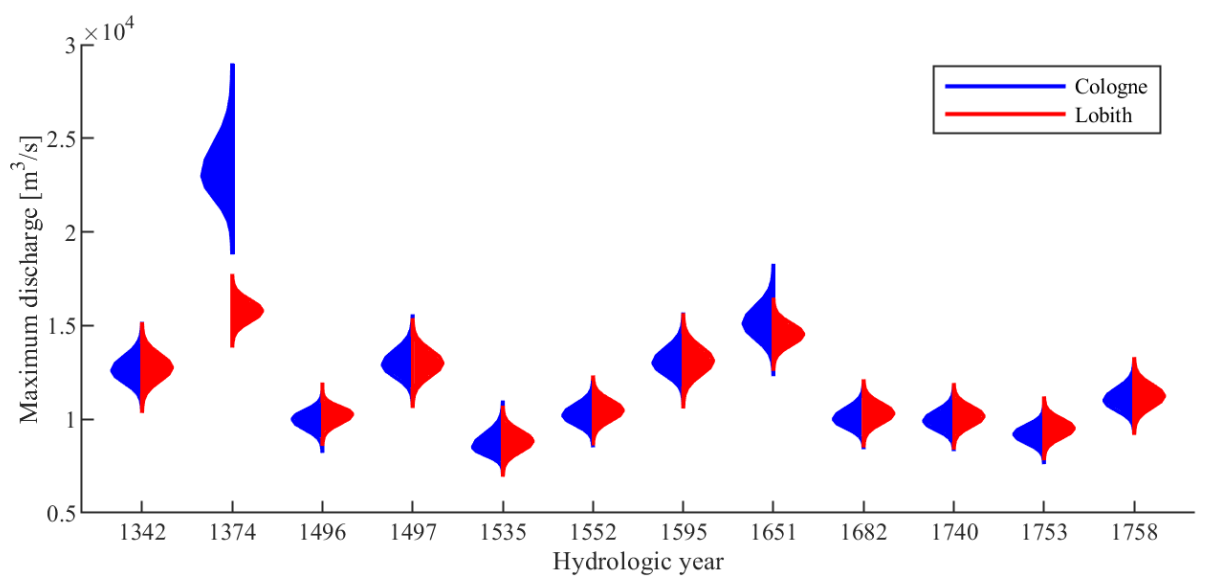

\section{Figure 6.4}

Maximum discharges and their 95\% confidence intervals of the reconstructed historic floods at Cologne (Herget and Meurs, 2010) and simulated maximum discharges and their $95 \%$ confidence intervals at Lobith for the 12 historic flood events.

1. The start of the continuous discharge series since the true length of the historical period is not known.

2. The perception threshold over which floods were recorded in the historical times before water level and discharge measurements were conducted is known.

Assuming that the historical period starts with the first known flood (in this study 1342) will significantly underestimate the true length of this period. This underestimation influences the shape of the FF curve (Hirsch and Stedinger, 1987; Schendel and Thongwichian, 2017). Therefore, Schendel and Thongwichian (2017) proposed the following equation to determine the length of the historical period:

$$
M=L+\frac{L+N-1}{k}
$$

where $M$ represents the length of the historical period (years), $L$ the number of years from the first historic flood to the start of the systematic record (431 years), $N$ the length of the systematic record (247 years), and $k$ the number of floods exceeding the perception threshold in both the historical period and the systematic record ( 28 in total). Using equation 6.2 results in a length of the historical period of 455 years $(1317-1771)$.

The perception threshold is considered to be equal to the discharge of the smallest flood present in the historic period, representing the 1535 flood with an expected 
discharge of $8,826 \mathrm{~m}^{3} / \mathrm{s}$ (Fig. 6.4). We follow the method of Parkes and Demeritt (2016) assuming that the perception threshold was fairly constant over the historical period. However, the maximum discharge of the 1535 flood is uncertain and hence the perception threshold is also uncertain. Therefore, the perception threshold is treated as a random uniformly distributed parameter in the bootstrap method, the boundaries of which are based on the $95 \%$ confidence interval of the 1535 flood event.

The bootstrap method consists in creating a continuous discharge series from 1317 to 2018. The method includes the following steps (Fig. 6.5).

1. Combine the 1772-1900 data set with the 1901-2018 data set to create a systematic data set.

2. Select the flood event with the lowest maximum discharge present in the historic time period. Randomly sample a value in between the $95 \%$ confidence interval of this lowest flood event. This value is used as the perception threshold.

3. Compute the start of the historical time period (equation 6.2).

4. Of the systematic data set, select all discharges that have an expected value lower than the sampled perception threshold.

5. Use the data set created in Step 4 to create a continuous discharge series in the historical time period. Randomly draw an annual maximum discharge of this systematic data set for each year within the historical period for which no data is available following a bootstrap approach.

6. Since both the reconstructed as well as the measured discharges are uncertain due to measurement errors, these uncertainties must be included in the analysis. Therefore, for each discharge present in the systematic data set and in the historical data set, its value is randomly sampled based on its $95 \%$ confidence interval.

7. Combine the data sets of Steps 5 and 6 to create a continuous data set from 1317 to 2018.

The presented steps in the bootstrap method are repeated 5,000 times in order to create 5,000 continuous discharge data sets resulting in convergence in the FFA. The FFA procedure itself is explained in the next section. 


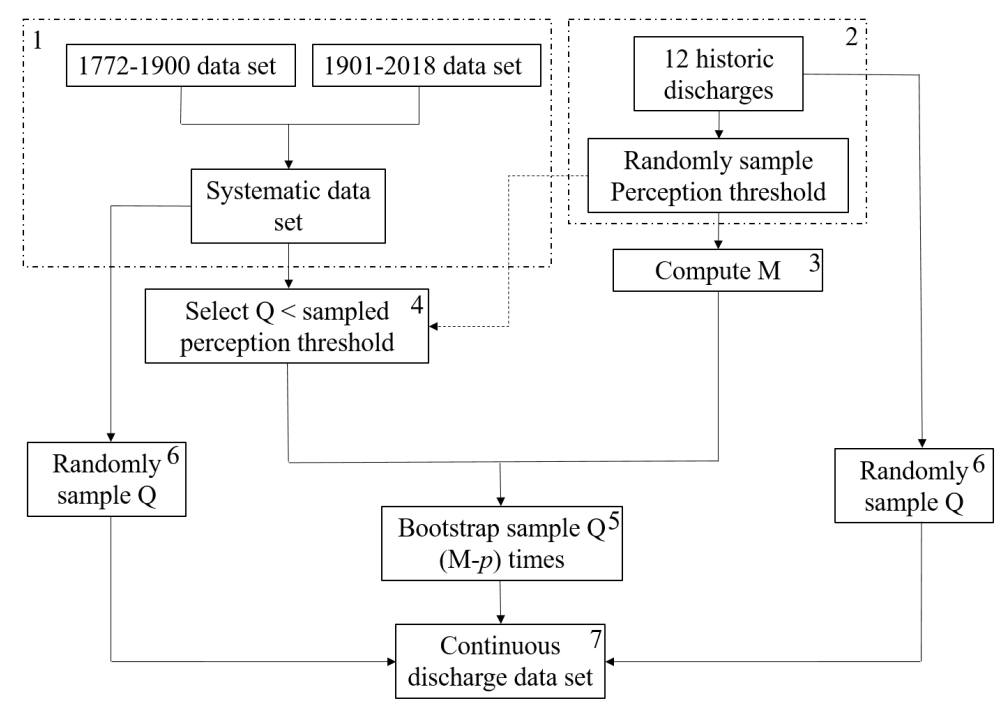

Figure 6.5

Bootstrap method to create a continuous discharge series in which $M$ represents the length of the historical period and $p$ the number of floods exceeding the perception threshold in the historical period.

\subsection{Flood frequency analysis}

An FFA is performed to determine the FF relation of the different data sets (e.g. systematic record, historical record). A probability distribution function is used to fit the annual maximum discharges to their probability of occurrence. Many types of distribution functions and goodness-of-fit tests exist, all with their own properties and drawbacks. However, the available goodness-of-fit tests for selecting an appropriate distribution function are often inconclusive. This is mainly because each test is more appropriate for a specific part of the distribution, while we are interested in the overall fit since the safety standards expressed in probability of flooding along the Dutch dikes vary from $10^{-2}$ to $10^{-5}$. Furthermore, we highlight that we focus on the influence of extending the data set of measured discharges on the reduction in uncertainty of the FF relations rather than on the suitability of the different distributions and fitting methods.

We restrict our analysis to the use of a generalized extreme value (GEV) distribution since this distribution is commonly used in literature to perform an FFA (Parkes and Demeritt, 2016; Haberlandt and Radtke, 2014; Gaume et al, 2010). Additionally, several studies have shown the applicability of this distribution to 
the flooding regime of the Rhine river (Toonen, 2015; Chbab et al, 2006; Te Linde et al, 2010). The GEV distribution has an upper bound and is thus capable of flattening off at extreme values by having a flexible tail. We use a bounded distribution since the maximum discharge that is capable of entering the Netherlands is limited to a physical maximum value. The crest levels of the dikes along the Lower Rhine, Germany, are not infinitely high. The height of the dikes influences the discharge capacity of the Lower Rhine and hence the discharge that can flow towards Lobith. Using an upper-bounded distribution yields that the FF relation converges towards a maximum value for extremely large return periods. This value represents the maximum discharge that is capable of occurring at Lobith.

The GEV distribution is described with the following equation:

$$
F(x)=\exp \left\{-\left[\xi \frac{x-\mu}{\sigma}\right]^{\frac{1}{\xi}}\right\}
$$

where $\mu$ represents the location parameter indicating where the origin of the distribution is positioned, $\sigma$ the scaling parameter describing the spread of the data, and $\xi$ represents the shape parameter controlling the skewness and kurtosis of the distribution, both influencing the upper tail and hence the upper bound of the system. The maximum likelihood method is used to determine the values of the three parameters of the GEV distribution (Stendinger and Cohn, 1987; Reis and Stedinger, 2005).

The FFA is performed for each of the 5,000 continuous discharge data sets created with the bootstrap method (Section 6.3), resulting in 5,000 fitted GEV curves. The average of these relations is taken to get the final FF curve and its $95 \%$ confidence interval. The results are given in the next section.

\subsection{Results}

\subsubsection{Flood frequency relations}

In this section the FFA results (Fig. 6.6 and Table 6.2) of the following data sets are presented.

- The 1901 data set with measured discharges covering the period 1901-2018.

- The 1772 data set is as above and extended with the data set of Toonen (2015), representing the systematic data set and covering the period 17722018 . 
- The 1317 data set is as above and extended with 12 reconstructed historic discharges and the bootstrap resampling method to create a continuous discharge series covering the period 1317-2018.

If the data set of measured discharges is extended, we find a large reduction in
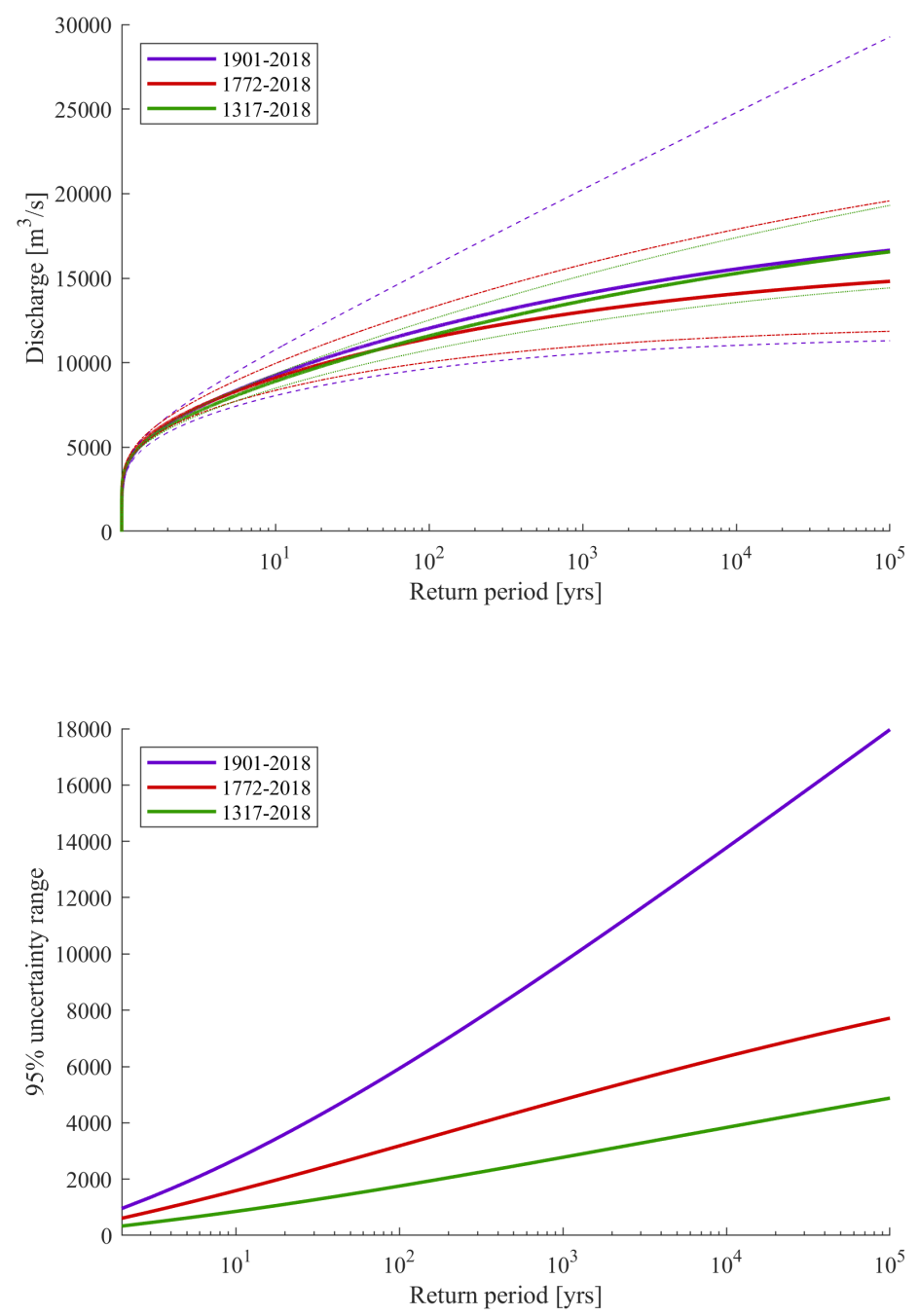

\section{Figure 6.6}

Fitted GEV curves and their 95\% confidence intervals of the 1901, 1772 and 1317 data sets. 
Discharges $\left[\mathrm{m}^{3} / \mathrm{s}\right]$ and their $95 \%$ confidence interval corresponding to several return periods for the 1901,1772 and 1317 data sets.

\begin{tabular}{l|ccc|ccc|ccc}
\hline \hline Data & $Q_{10}$ & $Q_{100}$ & $Q_{1,000}$ & $2.5 \%$ & $Q_{1,250}$ & $97.5 \%$ & $2.5 \%$ & $Q_{100,000}$ & $97.5 \%$ \\
\hline 1901 & 9,264 & 12,036 & 14,050 & 10,594 & 14,215 & 20,685 & 11,301 & 16,649 & 29,270 \\
1772 & 9,106 & 11,442 & 13,008 & 11,053 & 13,130 & 16,027 & 11,858 & 14,813 & 19,576 \\
1317 & 8,899 & 11,585 & 13,655 & 12,514 & 13,830 & 15,391 & 14,424 & 16,562 & 19,303 \\
\hline \hline
\end{tabular}

the confidence interval of the FF curve (Fig. 6.6 and Table 6.2). Only extending the data set with the data of Toonen (2015) reduced this confidence interval by $5,200 \mathrm{~m}^{3} / \mathrm{s}$ for the floods with a return period of 1,250 years (Table 6.2). Adding the reconstructed historic flood events in combination with a bootstrap method to create a continuous data set results in an even larger reduction in the confidence interval of $7,400 \mathrm{~m}^{3} / \mathrm{s}$ compared to the results of the 1901 data set. For the discharges with a return period of 100,000 years, we find an even larger reduction in the confidence intervals (Table 6.2).

Furthermore, we find that using only the 1901 data set results in larger design discharges compared to the two extended data sets. This is in line with the work of Toonen (2015). Surprisingly however, we find that the 1772 data set predicts the lowest discharges for return periods $>100$ years (Table 6.2), while we would expect that the 1317 data set predicts the lowest values according to the findings of Toonen (2015). The relatively low positioning of the FF curve constructed with the 1772 data, compared to our other 1317 and 1901 data sets, might be explained by the fact that the data of Toonen (2015) covering the period 1772-1900 have not been normalized. This period has a relatively high flood intensity (Fig. 6.1). However, only two flood events exceeded $10,000 \mathrm{~m}^{3} / \mathrm{s}$. A lot of dike reinforcements along the Lower Rhine were executed during the last century. Therefore, it is likely that before the $20^{\text {th }}$ century, flood events with a maximum discharge exceeding $10,000 \mathrm{~m}^{3} / \mathrm{s}$ resulted in dike breaches and overflow upstream of Lobith. As a result, the maximum discharge of such an event decreased significantly. Although Toonen (2015) mentions that the effect of recent changes in the river system on discharges of extreme floods of the Lower Rhine is small, we argue that it does influence the flood events with maximum discharges slightly lower than the current main channel and floodplain capacity. Currently, it is possible for larger floods to flow in the downstream direction without the occurrence of inundations compared to the $19^{\text {th }}$ century. Therefore, it is most likely that the $1772-1900$ data set of Toonen (2015) underestimates the flooding regime of that specific time period influencing the shape of the FF curve. 


\subsubsection{Hypothetical future extreme flood event}

After the 1993 and 1995 flood events of the Rhine river, the FF relation used in Dutch water policy was recalculated taking into account the discharges of these events. All return periods were adjusted. The design discharges with a return period of 1,250 years, which was the most important return period at that time, was increased by $1,000 \mathrm{~m}^{3} / \mathrm{s}$ (Parmet et al, 2001). Such an increase in the design discharge requires more investments in dike infrastructure and floodplain measures to re-establish the safety levels. Parkes and Demeritt (2016) found similar results for the river Eden, UK. They showed that the inclusion of the 2015 flood event had a significant effect on the upper tail of the FF curve, even though their data set was extended from 1967 to 1800 by adding 21 reconstructed historic events to the data set of measured data. Schendel and Thongwichian (2017) argue that if the flood frequency relation changes after a recent flood, and if this change can be ambiguously attributed to this event, the data set of measured discharges must be expanded since otherwise the FF results will be biased upward. Based on their considerations, it is interesting to see how adding a single extreme flood event influences the results of our method.

Both the 1317 and 1901 data sets are extended from 2018 to 2019 with a hypothesized flood in 2019. We assume that in 2019 a flood event has occurred that equals the largest measured discharge so far. This corresponds with the 1926 flood event (Fig. 6.1), having a maximum discharge of $12,600 \mathrm{~m}^{3} / \mathrm{s}$. No uncertainty of this event is included in the analysis. Fig. 6.7 shows that the FF curve based on the 1901 data set changes significantly as a result of this hypothesized 2019 flood. We calculate an increase in the discharge corresponding to a return period of 100,000 years of $1,280 \mathrm{~m}^{3} / \mathrm{s}$. Contrarily, the 2019 flood has almost no effect on the extended 1317 data set. The discharge corresponding to a return period of 100,000 years only increased slightly by $180 \mathrm{~m}^{3} / \mathrm{s}$. Therefore, we conclude that the extended data set is more robust to changes in FF relations as a result of future flood events. Hence, we expect that the changes in FF relations after the occurrence of the 1993 and 1995 flood events would be less severe if the analysis was performed with an extended data set as presented in this study. Consequently, decision makers might have made a different decision since fewer investments were required to cope with the new flood safety standards. Therefore, we recommend using historical information about the occurrence of flood events in future flood safety assessments.

\subsection{Discussion}

We developed an efficient bootstrap method to include historic flood events in an FFA. We used a 1D-2D coupled hydraulic model to normalize the data set of 

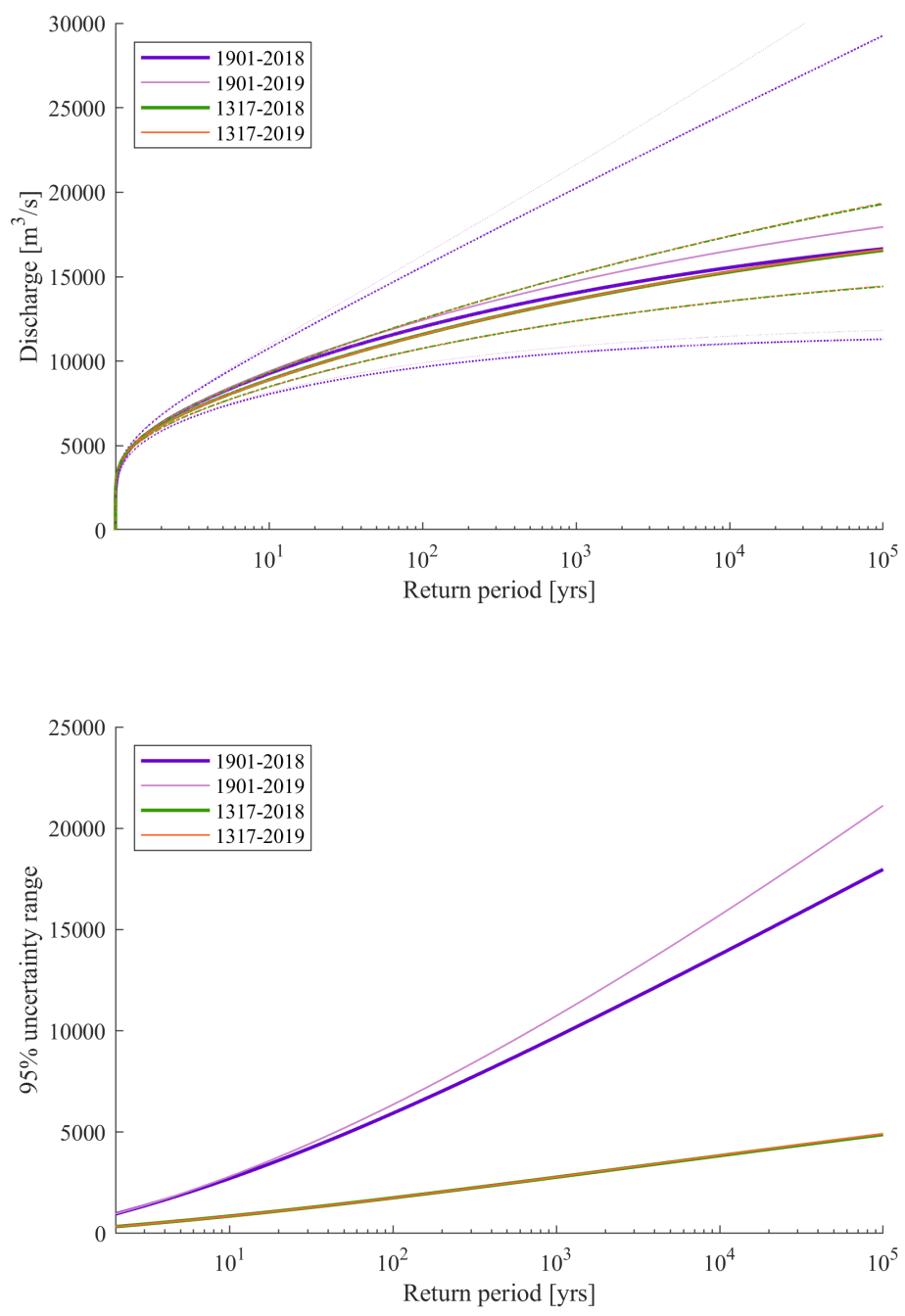

\section{Figure 6.7}

Fitted GEV curves and their 95\% confidence intervals of the 1901 and 1317 data sets if they are extended with a future flood event.

Meurs (2006) for modern topography. An advantage of the proposed method is that any kind of historical information (e.g. flood marks, sediment depositions) can be used to extend the data set of annual maximum discharges as long as the information can be translated into discharges. Another great advantage of the proposed method is the computational time to create the continuous data sets 
and to fit the GEV distributions. The entire process is completed within several minutes. Furthermore, it is easy to update the analysis if more historical information about flood events becomes available. However, the method is based on various assumptions and has some drawbacks. These assumptions and drawbacks are discussed below.

\subsubsection{The added value of normalized historic flood events}

The results have shown that extending the systematic data set with normalized historic flood events can significantly reduce the confidence intervals of the FF curves. This is in line with the work of O'Connell et al (2002), who claim that the length of the instrumental record is the single most important factor influencing uncertainties in flood frequency relations. However, reconstructing historic floods is time-consuming, especially if these floods are normalized with a hydraulic model. Therefore, the question arises of whether it is required to reconstruct historic floods to extend the data set of measured discharges. Another, less time-consuming, option might be to solely resample the measured discharges in order to extend the length of the data set. Such a method was applied by Chbab et al (2006) who resampled 50 years of weather data to create a data set of 50,000 years of annual maximum discharges.

To test the applicability of solely using measured discharges, we use the bootstrap method presented in Section 6.3. A data set of approximately 700 years (equal to the length of the 1317 data set) is created based on solely measured discharges in the period 1901-2018. The perception threshold is assumed to be equal to the lowest measured discharge such that the entire data set of measured discharges is used during the bootstrap resampling. Again, 5,000 discharge data sets are created to reach convergence in the FFA. This data is referred to as the $\mathrm{Q}_{\text {Bootstrap }}$ data set.

We find that the use of the QBootstrap data set, based on solely resampling the measured discharges of the 1901 data set, results in lower uncertainties of the FF curve compared to the 1901 data set (Fig. 6.8). This is because the length of the measured data set is increased through the resampling method. Although the confidence interval decreases after resampling, the confidence interval of the

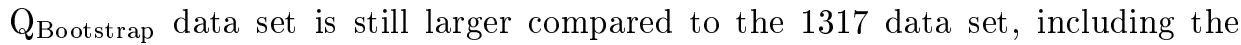
normalized historic flood events (Fig. 6.8). This is because the variance of the

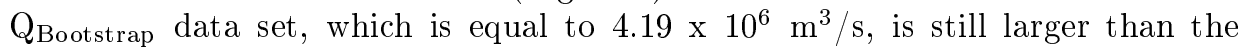
variance of the 1317 data set. For the $\mathrm{Q}_{\text {Bootstrap data set, the entire measured }}$ data set (1901-2018) is used for resampling, while for the 1317 data set only the discharges below a certain threshold in the systematic time period (1772-2018) are used for resampling. The perception threshold was chosen to be equal to the lowest flood event in the historical time period having a discharge of between 6,928 and 

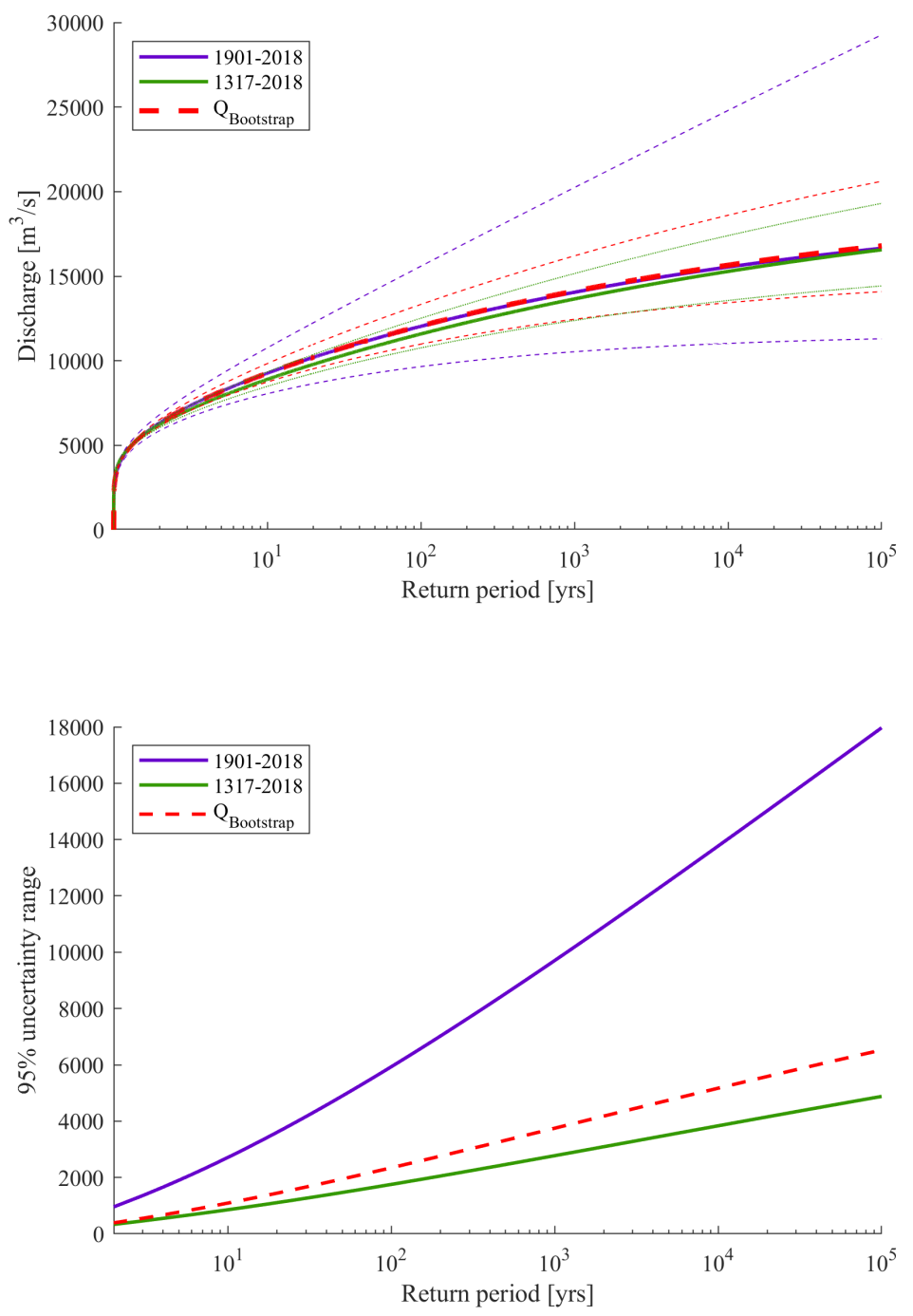

\section{Figure 6.8}

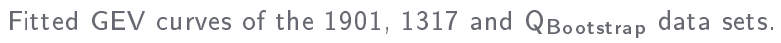

$10,724 \mathrm{~m}^{3} / \mathrm{s}$. Hence, the missing years in the historical time period are filled with relatively low discharges. Hence, the variance of the 1317 data set is relatively low $\left(3.35 \times 10^{6} \mathrm{~m}^{3} / \mathrm{s}\right)$. As a result of the lower variance, the uncertainty intervals are also smaller compared to the $\mathrm{Q}_{\text {Bootstrap }}$ data set. 
Furthermore, the FF curve of the Q Bootstrap data set is only based on a relatively short data set of measured discharges and hence only based on the climate conditions of this period. Extending the data set with historic flood events gives a better representation of the long-term climatic variability in flood events since these events have only been normalized for changes in the river system and thus still capture the climate signal. We conclude that reconstructing historic events, even if their uncertainty is large, is worth the effort since it reduces the uncertainty intervals of design discharges corresponding to rare flood events, which is crucial for flood protection policymaking.

\subsubsection{Resampling the systematic data set}

The shape of the constructed FF curve strongly depends on the climate conditions of the period considered. If the data set is extended with a period which only has a small number of large flood events, this will result in a significant shift of the FF curve in the downward direction. This shift can be overestimated if the absence of large flood events only applies to the period used to extend the data set. Furthermore, by resampling the measured data set, we assume that the flood series consists of independent and identically distributed random variables. This might not be the case if climate variability plays a significant role in the considered time period resulting in a period of extreme low or high flows. However, up till now no consistent large-scale climate change signal in observed flood magnitudes has been identified (Blöschl et al, 2017).

In Section 6.5, we found that extending the data set from 1901 to 1772 resulted in a shift in the downward direction of the FF curve. This is because in the period 17721900, a relatively small number of floods exceeded a discharge larger than 10,000 $\mathrm{m}^{3} / \mathrm{s}$. Since no large flood events were present in the period $1772-1900$, this data set has a lower variance compared to the 1901 data set. Using both the 1772 and 1901 data sets for resampling purposes influences the uncertainty of the FF curve. To identify this effect, we compared the results if solely the measured discharges (1901-2018) are used for resampling purposes and if the entire systematic data set (1772-2018) period is used. We find that using the entire systematic data set results in a reduction in the $95 \%$ confidence intervals compared to the situation in which solely the measured discharges are used caused by the lower variance in the period 1772-1900. However, the reduction is a maximum of $12 \%$ for a return period of 100,000 years. Although the lower variance in the 1772-1900 data set might be explained by the fact that these discharges are not normalized, the lower variance may also be caused by the natural variability in climate. 


\subsubsection{Distribution functions and goodness-of-fit tests}

In Section 6.5, only the results for a GEV distribution were presented. We found that the uncertainty interval of the flood event with a return period of 100,000 years was reduced by $73 \%$ by extending the data set of approximately 120 years of annual maximum discharges to a data set with a length of 700 years. Performing the analysis with other distributions yields similar results. A reduction of $60 \%$ is found for the Gumbel distribution and a reduction of $76 \%$ for the Weibull distribution. This shows that, although the uncertainty intervals depend on the probability distribution function used, the general conclusion of reduction in uncertainty of the fitted FF curve holds.

However, by only considering a single distribution function in the analysis, model uncertainty is neglected. One approach to manage this uncertainty is to create a composite distribution of several distributions each allocated a weighting based on how well it fits the available data (Apel et al, 2008). Furthermore, the uncertainty related to the use of various goodness-of-fit tests was neglected since only the maximum likelihood function was used to fit the sample data to the distribution function. Using a composite distribution and multiple goodness-of-fit tests will result in an increase in the uncertainties of FF curves.

\subsubsection{The length of the extended data set and the considered perception threshold}

The measured data set starting at 1901 was extended to 1317 . However, the extended data set still has limited length compared to the maximum return period of 100,000 years considered in Dutch water policy. Preferably, we would like to have a data set with at least the same length as the maximum safety level considered such that extrapolation in FFAs is not required anymore. However, the proposed method is a large step to decrease uncertainty.

Furthermore, the systematic data set was used to create a continuous data set using a bootstrap approach. However, preferably we would like to have a continuous historical record since now the low flows are biased on climate conditions of the last 250 years. Using this data set for resampling influences the uncertainty intervals of the FF curves. If the historical climate conditions highly deviated from the current climate conditions, this approach does not produce a reliable result. In addition, the perception threshold influences the variance of the considered data set and hence the uncertainty of the FF curve. Using a smaller threshold results in an increase in the variance of the data set and hence in an increase in the uncertainty intervals. The proposed assumption related to the perception threshold can only be used if there is enough confidence that the smallest known flood event 
in the historical time is indeed the actual smallest flood event that occurred in the considered time period.

\subsubsection{A comparison with Bayesian statistics}

The FFA was performed based on frequentist statistics. The maximum likelihood function was used to fit the parameters of the GEV distribution function. However, only point estimates are computed. To enable uncertainty predictions of the GEV parameter estimates, the maximum likelihood estimator assumes symmetric confidence intervals. This may result in an incorrect estimation of the uncertainty which is specifically a problem for small sample sizes. For large sample sizes, maximum likelihood estimators become unbiased minimum variance estimators with approximate normal distributions. Contrarily, Bayesian statistics provide the entire posterior distributions of the parameter estimates and thus no assumptions have to be made. However, a disadvantage of the Bayesian statistics is that the results are influenced by the priors describing the distributions of the parameters (Neppel et al, 2010). For future work, we recommend studying how uncertainty estimates differ between the proposed bootstrap method and a method which relies on Bayesian statistics such as the study of Reis and Stedinger (2005).

Moreover, a disadvantage of the proposed bootstrap approach is that, by resampling the systematic data set to fill the gaps in the historical time period, the shape of the flood frequency curve is influenced in the domain corresponding to events with small return periods (i.e. up to $\sim 100$ years corresponding with the length of the 1901 data set). Methods presented by Reis and Stedinger (2005) and Wang (1990) use historical information solely to improve the estimation of the tail of the FF curves, while the systematic part of the curve stays untouched. Table 6.2 shows the discharges corresponding to a return period of 100 years for both the 1901 data set and the extended 1317 data set following the bootstrap method described in Section 6.3. We find that this discharge decreases from 12,036 $\mathrm{m}^{3} / \mathrm{s}$ to $11,585 \mathrm{~m}^{3} / \mathrm{s}$ by extending the systematic data set. This decrease in design discharge by $3.7 \%$ indicates that resampling the systematic data set over the historical time period only has a little effect on the shape of the flood frequency curve corresponding with small return periods. This finding justifies the use of the bootstrap method.

\subsection{Conclusions}

Design discharges are commonly determined with the use of flood frequency analyses (FFAs) in which measured discharges are used to fit a probability distribution function. However, discharge measurements have been performed only for the last 
50-100 years. This relatively short data set of measured discharges results in large uncertainties in the prediction of design discharges corresponding to rare events. Therefore, this study presents an efficient bootstrap method to include historic flood events in an FFA. The proposed method is efficient in terms of computational time and set-up. Additionally, the basic principles of the traditional FFA remain unchanged.

The proposed bootstrap method was applied to the discharge series at Lobith. The systematic data set covering the period 1772-2018 was extended with 12 historic flood events. The historic flood events reconstructed by Meurs (2006) had a large uncertainty range, especially for the most extreme flood events. The use of a 1D-2D coupled hydraulic model reduced this uncertainty range of the maximum discharge at Lobith for most flood events as a result of the overflow patterns and dike breaches along the Lower Rhine. The inclusion of these historic flood events in combination with a bootstrap method to create a continuous data set, resulted in a decrease in the $95 \%$ uncertainty interval of $72 \%$ for the discharges at Lobith corresponding to a return period of 100,000 years. Adding historical information about rare events with a large uncertainty range in combination with a bootstrap method thus has the potential to significantly decrease the confidence interval of design discharges of extreme events.

Since correct prediction of flood frequency relations with little uncertainty is of high importance for future national flood protection programs, we recommend using historical information in the FFA. Additionally, extending the data set with historic events makes the flood frequency relation less sensitive to future flood events. Finally, we highlight that the proposed method to include historical discharges in a traditional FFA can be easily implemented in flood safety assessments because of its simple nature in terms of mathematical computations as well as its computational efforts.

\section{Acknowledgements}

This research is supported by the Netherlands Organisation for Scientific Research (NWO, project 14506) which is partly funded by the Ministry of Economic Affairs and Climate Policy. Furthermore, the research is supported by the Ministry of Infrastructure and Water Management and Deltares. This research has benefited from cooperation within the network of the Netherlands Centre for River studies NCR (www.ncr-web.org).

The authors would like to thank the Dutch Ministry of Infrastructure and Water Management, Prof. Dr. Herget (University of Bonn) and Dr. Toonen (KU Leuven) for providing the data. Furthermore, the authors would like to thank Dr. Toonen (KU Leuven) for his valuable suggestions that improved the paper. In addition, 
the authors would like to thank Dr. Volpi (Roma Tre University) and the two anonymous reviewers for their suggestions during the discussion period, which greatly improved the quality of the paper. Finally, the authors would like to thank Van der Meulen Msc, Dr. Cohen and Prof. Dr. Middelkoop from Utrecht University for their cooperation in the NWO project "Floods of the past-Design for the future". 
180 Chapter 6 


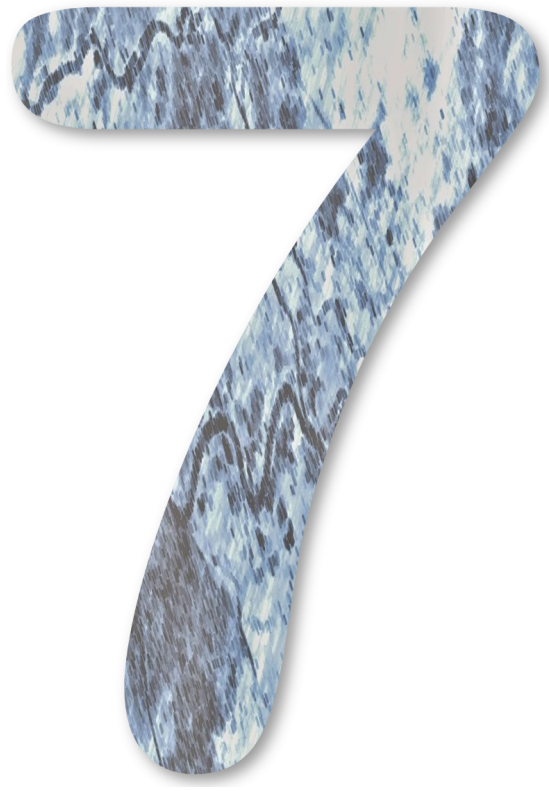

Discussion 
The aim of this study was to extend the data set of measured discharges with historic flood reconstructions using various kinds of hydraulic models such that uncertainties in flood frequency relations can be decreased. Several efficient hydraulic modelling tools were developed that reduce computational time compared to a fully $2 \mathrm{D}$ model. In this chapter, we first discuss the applicability of the proposed methods. Next, we discuss the effect of climate change on flood frequency relations. Then, the applicability of the proposed methods to other fields and the co-benefits are presented. The Chapter ends with remaining knowledge gaps and a comparison with GRADE which is a new modelling approach used by the Dutch water policy to create a synthetic data set of 50,000 years of discharge series.

\subsection{The applicability of hydraulic modelling}

\subsubsection{The applicability to other extreme events}

In this study, the Rhine river was used as a case study. However, the proposed methodologies can be applied to any river of which data about the historical bathymetry and some water level records are available. Furthermore, the methodologies can be applied to reconstruct other extreme events as well. While we only focused on river floods, also e.g. floods from sea and storm events can be reconstructed. However, it must be noted that if a surrogate model is used, it is only as good as its high-fidelity model. Therefore, only extreme events that are accurately simulated by the high-fidelity model can be predicted with the surrogate model as well. We found, for example, that the hydraulic models were not able to reproduce correct water levels for flood events affected by ice jams since the physical processes of normal flow conditions do not hold. For this reason, the causes of the extreme events must be determined and afterwards it must be evaluated whether the hydraulic model is capable of reproducing these processes before setting up a surrogate model.

\subsubsection{Hydraulic and surrogate modelling methods}

In Chapter 2, a fully 2D model with a hybrid grid was developed. Furthermore, a 1D-2D coupled lower-fidelity physically based surrogate model was developed in Chapter 3 in which $1 \mathrm{D}$ profiles were located in the main channels and their floodplains. The embanked areas were discretized on a $2 \mathrm{D}$ grid. Finally, an Artificial Neural Network (ANN) was developed in Chapter 4. However, much more hydraulic and surrogate modelling methods exist, all with their own benefits and drawbacks. The 1D-2D coupled modelling strategy might be inappropriate if many model runs have to be performed, as computational time of such a physically based 
model is still relatively large compared to a response surface surrogate model which represents a statistical or empirical data-driven model emulating the original system. On the other hand, an ANN structure, as set up in Chapter 4, might be inappropriate if the objective of the study is to reconstruct the entire discharge wave shape of the historic event. This is because this type of ANN is only capable of predicting output parameters at a specific moment in time. There are other kinds of ANN structures that are capable of reproducing the entire discharge wave shape. However, these were not considered in the analysis of this thesis since we were only interested in the maximum discharge at Lobith. We advice to clearly identify the main purpose of the study and which uncertain input parameters have to be considered, before deciding on which type of surrogate model to set up. If the purpose of the study is to get insight in the system behaviour of the historical time period considered, we advise to use a lower-fidelity physically based surrogate model. These types of models are still based on the original input and they capture most of the physical processes of the system. On the other hand, response surface surrogate models are more applicable if many uncertain input parameters have to be considered in the analysis. The computational time of response surface surrogate models is very low such that many model runs can be performed within a couple of seconds. However, a drawback is that the model does not provide any information about physical processes like flow patterns and inundated areas throughout the model, because the model is based on a data-driven (non-physical) approach.

\subsubsection{Uncertainty of historical geometrical reconstructions}

In Chapter 3 and 4, the 1926 and 1809 flood events of the Rhine river were reconstructed. Relatively much data was available of these events, such as measured main channel bathymetry profiles and land use maps. Hence, we assumed that the river course was not subject to any uncertainties. Therefore, only one river course was considered in the analysis. Although for the Rhine river much historical information is available from the first maps dating back to $\sim 1700$, such information might not exist for rivers in other parts of the world (e.g. developing countries). As a consequence, those geometrical reconstructions will be more uncertain (Van Leeuwe, 2018). This increased uncertainty affects the uncertainty of the reconstructed maximum discharges in the studied area. Consequently, this influences the uncertainty of flood frequency relations. Therefore, the uncertainty in geometrical reconstructions must be included in the analysis.

A way to do this is to develop a hydraulic model and corresponding surrogate model for each potential river course and bathymetry. If the course of the main channel is uncertain, but the locations of the boundaries of the floodplains are known, a 1D-2D coupled model is most convenient. In these models, the main channel and floodplains are schematized with 1D profiles. These profiles can easily be updated 
such that various potential main channel courses can be included in a Monte Carlo analysis. Contrarily, for a fully 2D model using an efficient hybrid grid (Chapter 2) including various potential river courses is quite time consuming since for each potential river course a grid has to be constructed. The curvilinear grid cells in the hybrid grid must follow the course of the main channel.

If also the boundaries of the floodplains are unknown, the use a 1D-2D coupled model as surrogate model becomes less attractive since now for each potential bathymetry a new model must be set up. Now the locations of the boundaries between the $1 \mathrm{D}$ profiles and $2 \mathrm{D}$ grid change. Hence, the new bathymetry cannot be altered by just updating the $1 \mathrm{D}$ profiles as described above. Consequently, the Monte Carlo analysis should be performed with each of the different models. As a result, the total number of computations that has to be performed to include all potential uncertainties in bathymetry increases significantly. A response surface surrogate model such as an Artificial Neural Network (ANN) is most convenient for these cases since the computational time is low. However, to train each ANN, training data has to be created with their corresponding high-fidelity model. Setting up these models and performing simulations is quite time consuming. Therefore, it is important that much effort is put into the geometrical reconstruction in order to decrease its uncertainty as much as possible. It is thus desired that all existing data providing information about the river course is gathered. Although time demanding, it may reduce the overall time investment since the number of simulations can be reduced.

\subsubsection{Future normalization steps}

In this study, we have normalized the historic flood events for anthropogenic and natural changes in the river system with the use of a hydraulic 1D-2D coupled model. The question may arise whether these time-consuming normalization steps must be repeated when again changes in the river system occur such as dike heightening or dike shifts along the Lower Rhine. If the flood defences along the Lower Rhine are heightened or reinforced, the maximum discharge that may reach the Netherlands increases. Furthermore, the dike breach thresholds along the Lower Rhine changes. Indeed, the historic flood events must again be normalized for these changes to correctly establish a flood frequency curve for the new altered situation. However, the use of a regression function is most probably more suitable since the effect of these changes on flood wave propagation are relatively small, compared to the changes between e.g. 1374 and present times. Identifying the influence of the altered river system on flood wave propagation, by simulating hydraulic model runs with various scenarios in terms of maximum upstream discharge and dike breach characteristics, can be used to set up such a regression function. Hence, the maximum discharges of the historic flood events in the altered river system can easily be computed with the use of such a regression function. The relatively 
time-consuming normalizations steps performed in this study thus only have to be performed once.

\subsubsection{Efficient two dimensional grids}

Chapter 2 showed that the structure of a two dimensional grid can highly influence model results. It was found that both grid shape and grid size influence computational times as well as model accuracy. Commonly, hydraulic models are calibrated by altering the friction of the main channel until simulated water levels are close to measurements. Validation is then performed by routing another discharge wave and again simulated water levels are compared with measurements. Other physical processes, such as velocity profiles, are generally not considered while these may be unrealistic even though water levels are simulated accurately. Therefore, we recommend not only to validate model results on water levels but to also validate other physical processes.

Although we showed that a combination of curvilinear and triangular grid cells can be highly beneficial in terms of computational times while model accuracy remains sufficient, still most hydraulic studies use grid types that consist of only curvilinear or only triangular grid shapes. This, while other research fields (e.g. aerodynamic, fluid mechanics) are generally applying grids with multiple cell shapes to solve the system. Even adaptive grids, which are updated with time, are applied with great success. These grids may specifically be useful in case of complex geometries and if the locations of rapid variations in the flow are not known a priori (Tysell, 2010). An adaptive grid has as advantage that grid refinement can be executed during the simulations at locations where more detail is required. Tysell (2010) distinguishes four different strategies to generate adaptive grids.

1. The number of grid nodes is constant, but the grid nodes are redistributed

2. New nodes are inserted into the existing grid

3. Cells which are too large are divided into smaller ones

4. The entire grid is regenerated

Liang et al (2008) did use an adaptive grid to simluate flood inundation over an urban area of $36 \mathrm{~km}^{2}$. They made use of an adaptive quadtree grid to solve the Shallow Water equations. This adaptive grid could be locally refined by splitting a single square grid cell into four square grid cells. The grid was dynamically adapting to dominant flow features such as steep water surface gradients and wet-dry fronts. They found that the approach is efficient in terms of computational times and model accuracy. Another approach was shown by Volp et al (2016). They 
developed a subgrid based approach which is typically applicable in areas characterized by sub-critical flow such as estuaries, coastal areas and lowland rivers. This method uses different resolutions to compute the hydrodynamics and morphodynamics. The hydrodynamic computations were carried out on a coarse $2 \mathrm{D}$ grid in which only the bathymetry and surface friction were based on a high-resolution grid to compute volumes, friction and advection (Volp et al, 2016). The morphodynamic computations were entirely carried out on a high resolution grid. The different grid resolutions were coupled by interpolating water levels and velocities from the coarse grid to the high resolution grid. Volp et al (2016) found that the subgrid approach leads to a substantial increase in accuracy of the morphodynamic results at a minimal computational cost.

Although some studies showed the benefits of using adaptive grids in the hydraulic field, it still seems that other fields are far ahead of using efficient grid structures compared to the hydraulic field. Therefore, for future work we want to highlight the importance of studying the applicability of more efficient hybrid and adaptive grids for hydraulic modelling purposes such that computational time can be reduced even further while model accuracy remains sufficient.

\subsection{Climate change}

In this study, climate stationarity was assumed which means that climate conditions did not change over the considered time period. However, literature shows consensus that varying climate conditions during the considered time period influence flood frequency relations (e.g. Khaliq et al (2006); Murawski et al (2018)). Therefore, it must be evaluated to what extent the assumption of a constant climate is justified in this study. Furthermore, the foreseen global warming is expected to have an impact on the magnitude, frequency and timing of future floods. Both historical climate variability as well as future climate change conditions are discussed below.

\subsubsection{Historical climate variability}

Using historical flood events to extend the data set of measured discharges introduces a climate signal in the data set. By definition, the historic flood reconstructions cover the variability of climate since these are reconstructed based on the historical data. However, the flood producing mechanisms may have changed over time caused by a changed climate and altered land-use conditions. Therefore, the use of long historical records in FFAs brings in the question of flood stationarity since climate and land-use conditions can affect the relevance of past flooding as 
a predictor of future flooding (Machado et al, 2015). Although we have normalized the historic flood events for natural and anthropogenic changes in the river system, we assumed that the flood producing mechanisms in climate conditions did not change over the period 1300-2018. Thus, we assume climate stationarity which represents the idea that the natural systems fluctuate within an unchanging envelope of variability (Milly et al, 2008). In other words, the variability in climate conditions have been constant over time. This assumption is made because it is difficult to include the effects of changing historical climate variability in the analysis since the flood regime is also affected by other factors, such as land use change and river training. On a local scale, Hewitson and Crane (2006) found that land use changes can modify the link between floods and weather patterns. This is one of the main reasons why, up till now, no consistent large-scale climate change signal in observed flood magnitudes has been identified (Blöschl et al, 2017). Furthermore, the temporal inconsistency (not with a constant frequency measured over time) of the data sets of measured discharges and their limited spatial extents makes it unfeasible to identify a large-scale climate change signal. More specific for central Europe, Beck et al (2007) found that large parts of the climate variability between 1780 and 1995 could not be explained by variability in regional scale weather patterns. The assumption of flood stationary is thus in line with the finding that the flood producing mechanisms regarding peak discharges did not change over time.

Regarding the timing of flood events, Blöschl et al (2017) did find a correlation between this timing and changing weather patterns in Europe. For the Rhine delta, a shift was found towards the timing of floods caused by the shift in the timing of extreme winter precipitation events (Blöschl et al, 2017). The study shows that floods occur later in the winter period as a result of later winter storms. Although a change in timing of the annual maximum discharge may have considerable economic and environmental consequences, it does not influence the results of flood frequency analyses since we solely consider the annual maximum discharges. Hence, it is not required to cope with this changing climate pattern in the proposed bootstrap method (Chapter 6).

Although we have normalized the historical flood events for anthropogenic and natural changes in the river system in the study area, we did not normalize the historic flood events for changes upstream of our study area. The reconstructed historic flood events at Cologne by Herget and Meurs (2010) were used as upstream boundary conditions to predict corresponding discharges at Lobith in present times. It might be that, as a result of e.g. deforestation, the historical maximum discharges were lower than they will be now if the same rainfall event will happen nowadays. Now, most probably, water is discharged faster to the rivers as a result of a larger direct runoff. Furthermore, the increase in dike heights in the trajectory upstream of our study area may result in an increase in the maximum discharge at Cologne since the discharge capacity of the Rhine river has been increased over the years. Ideally, we would like to know the rainfall events that caused the various 
historical flood events of the entire Rhine basin. These events can subsequently be routed with the use of a hydrological model and consequently a hydraulic model, to compute corresponding discharges at Lobith in present times. However, it is impossible to reconstruct the historical weather pattern with reasonable uncertainty. Furthermore, it is expected that the effect of upstream anthropogenic and natural changes in the river system only have a little effect on the maximum discharge of the historical flood events reconstructed at Cologne since the intensive rainfall events would lead to large amount of direct run-off for both historical and present times. For future work, we suggest to study the effect of upstream changes in the river system on the maximum discharges at Cologne in more detail.

\subsubsection{Future climate change}

Typically, flood protection programs are established to protect the hinterland from floods over a time period of 50 till 100 years. The flood frequency analyses predict design discharges based on the climate conditions of the considered data set. Hence, the effect of predicted changes in future climate are not included in the analyses. For the Rhine delta, it is likely that the design discharges are underestimated considering future scenarios: It is expected that peak discharges will become larger as a result of earlier snow melt in the Alps, coinciding with the period of high rainfall intensities in the Lower Rhine catchment areas (de Wit et al, 2008). If such a clear climate change signal is identified, it is important to include this signal in flood safety assessments to correctly predict future design discharges. This can be done by including climatic variables as covariates of the Generalized Extreme Value (GEV) distribution parameters in the flood frequency analysis (Steirou et al, 2019). In this way, it is assumed that the probability density function of discharges is not constant in time, but it is conditioned on external variables (Steirou et al, 2019). As a result, the flood frequency distribution can be assessed by including the influence of changes in large-scale climate patterns. This type of non-stationary flood frequency analysis has been studied by many researchers in the last decades, and many different covariate types have been examined for their influence on flood extremes. A review of these approaches is given by Khaliq et al (2006), while their limitations are discussed by Koutsoyiannis and Montanari (2015) and Serinaldi et al (2018).

Although non-stationary flood frequency analyses have been applied in literature, there is still a lack of research on assessing the reliability of these analyses to represent low-frequency climate variability over centennial historical periods (Machado et al, 2015). Machado et al (2015) argues that future climate models incorporate too much uncertainty to accurately specify expected patterns of precipitation change or to estimate expected changes in the frequencies and magnitudes of extreme storm and flood events. Therefore, their study concludes that flood frequency predictions can only be improved by incorporating historical long-term 
flood records in flood frequency analyses (Machado et al, 2015). This shows the importance of accurate historic flood reconstructions to extend the data set of measured discharges which was the main purpose of this study. We thus conclude that the data set of measured annual maximum discharges must only be extended with past events since incorporating expected future flood scenarios only increases the uncertainty in flood frequency relations.

\subsection{Co-benefits of the proposed methodologies}

We reconstructed historic flood events of the Rhine river to calculate their maximum discharges at Lobith. Besides providing maximum discharges, the use of hydraulic models for flood reconstructions provides knowledge about the potential inundated areas as well as the system behaviour under extreme conditions in general. This information is also important for historical research. It can be used to explain e.g. human behaviour in terms of settlement locations. In the historical time period, the inhabitants built their houses on higher terraces that did not inundate during extreme flood events. Knowing which areas did not inundate in the past can explain locations of villages, cities and current land use patterns.

Furthermore, the flood events can help to get insight in past river management and how this management has changed over time. Typically, past river management was reactive rather than proactive. This means that a flood event was needed before actions were taken to improve flood safety. Typical and quite recent examples for the Netherlands are the sea flood in 1953 and the flood events of the Rhine river in 1993 and 1995. These flood events stimulated decision makers to reconsider the current flood protection measures.

In addition, the historical system behaviour can be compared with the current system behaviour. In the past, floodplains of rivers were commonly much wider (Klijn et al, 2018) and the rivers had a more meandering pattern. However, the size of river floodplains has been decreased and many meanders were cut off to improve navigation. Using information of historical system behaviour, some river management interventions might not have been taken in the last century. For example, in 1955 and 1969 two great meander bends in the IJssel river were cut off. As a result, the flood wave is now capable of propagating much faster in downstream direction. This has a negative effect on flood safety further downstream. Comparing historical system behaviour with current system behaviour can thus improve decision making on potential future flood measures.

Finally, simulating historic flood events can help in creating awareness of presentday flood risk. Some of the historic flood events, such as the flood in 1374 (Bomers et al, 2019e), were larger than ever occurring in our measured record. IPCC scenarios suggest that, due to climate change, such events occur more frequently 
in the near future (IPCC, 2014). Predicting the consequences of such events helps to understand the potential effects in present times.

\subsection{The applicability of the proposed methodolo- gies to other problems}

In this study, we showed how uncertainty in flood frequency predictions of the Rhine river can be reduced by extending the data set of annual measured discharges with reconstructed historic flood events. The proposed methodologies can also be applied to coastal areas. Bermudez et al (2018) showed that response surface surrogate models are capable of reproducing inundation maps with tide times series as input parameter. A least squares support vector machine was set up to construct a synthetic 500 year time series of daily maximum water levels. Such a surrogate model can also be used to reconstruct historic flood events caused by a combination of spring high tide and storm water level. Since floods from sea commonly resulted in large inundation areas and casualties, sufficient historical information of such events is available such that the proposed methodologies in this study can be applied. As a result, the physical characteristics (e.g. wave setup, storm duration) of the flood event and to hence determine its frequency can be determined.

Furthermore, the proposed methodologies can be applied to low flows. In this study, we extended the flood frequency curve with historic flood events. Such curves can also be set up for low flow conditions. Although the consequences of severe flood events are generally known, also low flows can have large societal impacts. It may hinder navigation, and limit the amount of water available for irrigation and drinking water. However, most probably the amount of historical sources providing information about the severeness of the low flow conditions is much less than for flood events. This is because low flows do not result in large casualties at a specific moment in time, but rather has its consequences on a longer time period. Furthermore, low flows affect economic losses rather than mortality rates, but can cause societal disruption.

\subsection{Computational cost reduction using efficient hydraulic modelling tools}

Up till now, no sophisticated hydraulic modelling methods have been used for historic flood reconstructions. However, the use of these models has the potential to 
decrease uncertainty in future flood predictions. The reduction in this uncertainty is twofold. Firstly, the confidence intervals of reconstructed maximum discharges of a flood event can be decreased compared to existing methods. Secondly, extending the data set of measured annual maximum discharges with these reconstructed historic flood events results in a reduction of the uncertainty in flood frequency relations. We firstly focus on the remaining knowledge gaps related to the first uncertainty in terms of computational cost reduction using hydraulic modelling tools. In the next section, the reduction in the uncertainty in flood frequency relations is elaborated.

The development of efficient hydraulic models in terms of computational time and model accuracy enables the possibility of highly detailed historic flood reconstruction with potentially little uncertainty. With these models, it is possible to include all uncertain input parameters related to the historic flood event as random parameters in a Monte Carlo framework. By doing so, knowledge about the maximum discharge and its uncertainty during historic events can be gained with high accuracy. Furthermore, the most important input parameter influencing the uncertainty of the simulated maximum discharge can be determined. This can be done by performing a sensitivity analysis in which the uncertain input parameters are varied using a Monte Carlo approach. The reconstructed maximum discharges and corresponding uncertainties can be used, after normalization for alterations in the river system, to extend the data set of measured discharges. This leads consequently to a reduction in flood frequency predictions. However, a major disadvantage of the hydraulic models is the large computational cost.

We showed several methods to significantly reduce computational times. A lowerfidelity physically based surrogate model reduces total computational cost since simulation time of a single run is reduced by neglecting several physical processes of the original system. In Chapter 3, a 1D-2D coupled model is set up in which the main channels and their floodplains are schematized with $1 \mathrm{D}$ profiles and the embanked areas are discretized on a $2 \mathrm{D}$ grid. This model computes much faster compared to a fully $2 \mathrm{D}$ model if the water levels are below the dike crest levels and water is thus only flowing in the $1 \mathrm{D}$ profiles. However, as soon as water starts to flow into the embanked areas and thus into the $2 \mathrm{D}$ grid, the computational time of this surrogate model starts to increase. The larger the overland flows, the smaller the reduction in computational times of a $1 \mathrm{D}-2 \mathrm{D}$ coupled model is compared to a fully $2 \mathrm{D}$ model.

The reduction in computational cost in case of response surface surrogate models is even less straightforward since still model runs have to be performed with the high-fidelity model to create the training data used to set up the response surface surrogate model. However, the computational time of such a trained surrogate model is in the order of seconds. Hence, after setting up the surrogate model many simulations can be performed in just a short period of time which is beneficial for Monte Carlo and scenario studies. 
Although the surrogate models reduce computational time, the total cost remains large. This is because the historic flood events, after being reconstructed, also have to be normalized for changes in the river system. Again, many model runs with a high-fidelity or lower-fidelity physically based surrogate hydraulic model have to be executed to perform this translation of historical discharges into presentday discharges. For this reason, it is clear that the proposed methodologies must only be used if a significant reduction of the confidence interval of the predicted maximum discharge can be reached compared to results of earlier reconstructions (Chapter 4). Input data that is required to perform a flood reconstruction with a hydraulic model is at least:

- Information about the potential course of the main channel

- Estimation of the bathymetry of the main channel

- Land use of the hinterland

- At least one (preferably several) maximum water level(s) of the flood event

For the Rhine river, the number of flood reports gradually increased during the $13^{\text {th }}$ century and in the $14^{\text {th }}$ century river floods became a recurrent problem (Tol and Langen, 2000). It is therefore likely that for reconstructing flood events before the $12^{\text {th }}$ century there is too little reliable data to predict a maximum discharge with a reasonable confidence interval.

\subsection{Construction of a continuous data set of annual maximum discharges}

To perform a flood frequency analysis, we created a continuous data set in Chapter 6. We proposed a bootstrap method in which the missing years in the historical time period, i.e. the years of which no data is available, are drawn from resampling the systematic data set. However, the proposed methodology is based on two assumptions which are discussed in more detail below.

Firstly, by resampling the systematic data set, it is assumed that the current flooding regime is applicable for the historical time period. It is thus assumed that the systematic data set consist of independent and identically distributed random variables. This assumption only holds if the flood producing mechanisms did not change which might not be the case in periods of e.g. glacial periods. For an elaborated discussion on the effect of climate change on flood frequency relations see Section 7.2. 
Secondly, it is assumed that for the years of which no data is available, no large flood event occurred and the maximum annual discharge was relatively small, i.e. smaller than the smallest flood event known in the historical time period. This smallest event is referred to as the perception threshold. This assumption is based on the fact that a flood event was only considered as a catastrophe if it had a huge impact on the society. However, if other events, such as a civil war or famine, had a larger impact on society it might be that a flood event was not perceived as a disaster. Hence, no information of this event may be available. Therefore, the assumption about the perception threshold is only valid if no other catastrophes, having a larger societal impact, took place in the time period considered.

The assumptions explained above influence the shape of the fitted flood frequency relation and its uncertainty interval. Therefore, these assumptions must be evaluated before they can be applied to another river basin. Furthermore, although the data set of approximately 120 years of annual maximum discharges has been increased to a length of 700 years in Chapter 6, its size is still relatively small compared to the maximum safety standard of $1 / 100,000$ years considered in the Dutch water policy. However, it is impossible to create a data set of such an extent using historic flood reconstructions. Information about historic flood events only goes back to certain moment in time.

\subsection{A comparison with GRADE results}

In the Netherlands, the flood safety assessment has changed from an exceedance probability approach towards a risk based approach. In this new approach, not only the probability of a flood event is considered but also its consequences (Van der Most et al, 2014). While previously a maximum exceedance level of $1 / 1,250$ years was defined along the Dutch Rhine river branches, the new approach has a maximum safety standard of 1/100,000 years (Van Alphen, 2016). This new safety standard is expressed in the probability of flooding and considers the impact of various dike failure mechanisms. Predicting design discharges corresponding to such extreme safety standards results in large uncertainties if only the data set of 120 years of measured annual maximum discharges is used.

To overcome this problem, a new modelling approach has been developed, which is called GRADE: Generator of Rainfall And Discharge Extremes (Fig. 7.1). Using a stochastic weather generator, GRADE creates annual maximum discharge series with a length up to 50,000 years based on daily precipitation and temperature observations covering the 56-years period 1951-2006 (Hegnauer et al, 2014). The generated weather data is used as input data for a HBV rainfall-runoff model (Fig. 7.1). The annual maximum discharges are selected and routed through the river by a hydrodynamic SOBEK model (Fig. 7.1), resulting in discharges through 
Weather Generator

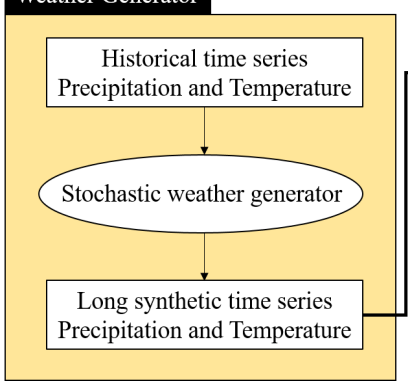

Hydrological model

Figure 7.1

\section{Hydrodynamic model}

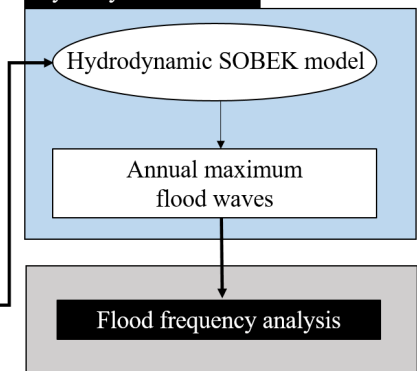

Components of GRADE.

the river system (Hegnauer et al, 2014). The created data set of 50,000 years of annual maximum discharges is then used to set up a flood frequency relation in which the Weismann fit is used to extrapolate to return periods of 100,000 years (Hegnauer et al, 2014). Because of the long time series of annual maximum discharges used, the statistical uncertainty caused by extrapolation is reduced. However, the method of GRADE itself is still subject to several uncertainties. Firstly, uncertainty is introduced by resampling measured weather data since each created time series varies as a result of the resampling method (Van den Boogaard et al, 2014). Therefore, many time series are created such that the variability in current climate uncertainty is included. Secondly, the model parameters of the HBV-model are uncertain as a result of model calibration. Various sets of input parameters are capable of producing correct model results. The calibration of an HBV-model for a particular basin thus consists of a set of "behavioral" parameter combinations rather than a single deterministic estimate for each of the input parameters (Van den Boogaard et al, 2014). Finally, also the hydrodynamic SOBEK model is subject to uncertainties. Relevant sources of uncertainty in the hydrodynamic model are: measurement errors in the dike heights, the storage volume of the embanked areas which are schematized by $1 \mathrm{D}$ retention areas, the surface friction, the locations and heights of the sand bags (emergency measure) and finally whether a dike breach occurs (Prinsen et al, 2015).

To compute the $95 \%$ confidence intervals of the GRADE flood frequency curve, firstly the uncertainties introduced by resampling measured weather data and the uncertainties in the model parameters of the HBV-model are considered. The uncertainty was determined by simulating 11 resampled weather data sets, all having a length of 20,000 years, with five different HBV parameter combinations (Van den Boogaard et al, 2014). The simulated 20,000 years of annual maximum discharges are sorted in ascending order. Next, the annual maximum discharges can be coupled to a return period such that a flood frequency curve is constructed. The 
Difference between GRADE (Prinsen et al., 2015) and the bootstrap method where T represents the return period, and the upper and lower boundaries of the $95 \%$ confidence interval.

\begin{tabular}{l|ccc}
\hline & Lower bound $\left[\mathrm{m}^{3} / \mathrm{s}\right]$ & $\mathrm{T}=100,000$ years $\left[\mathrm{m}^{3} / \mathrm{s}\right]$ & Upper bound $\left[\mathrm{m}^{3} / \mathrm{s}\right]$ \\
\hline Bootstrap & 14,420 & 16,560 & 19,300 \\
GRADE & 15,070 & 17,710 & 20,350 \\
Difference & 650 & 1.150 & 1,050 \\
\hline \hline
\end{tabular}

uncertainty interval is hence determined by including the uncertainty as a result of the 11 sampled weather data sets and the five different HBV parameter combinations (Prinsen et al, 2015). Finally, the uncertainties caused by the hydraulic model are added, since each simulated annual maximum discharge is uncertain caused by uncertainties in the bathymetry and the occurrence of dike breaches (Prinsen et al, 2015). After that, the uncertainty intervals of the GRADE flood frequency curve are recomputed.

Comparing the results of this thesis with those generated by GRADE, we find that GRADE predicts higher design discharges corresponding to return periods of between 50 and 500 years (Fig. 7.2). This is most probably caused by the occurrence of the 1993 and 1995 flood events in the observational data set. These two events had a maximum discharge of approximately 11,000 and $12,000 \mathrm{~m}^{3} / \mathrm{s}$ at Lobith respectively. As GRADE only uses a data set of 56 years of daily weather observations to create a data set of 50,000 years, the 1993 and 1995 flood event have a relatively high probability of occurrence. However, Chapter 6 showed that only the 1926 flood event had a higher maximum discharge at Lobith than the 1995 flood event in the last 250 years.

Furthermore, GRADE predicts higher design discharges corresponding to return periods larger than 1,000 years compared to the results of this study (Fig. 7.2). GRADE includes the potential effects of emergency measures on the maximum discharge at Lobith in the hydrodynamic SOBEK model. During a flood event, sand bags might be placed on the dike crests along the Lower Rhine resulting in higher crest levels. GRADE assumes that the sand bags increase the dike crests with a maximum of $0.5 \mathrm{~m}$ and that they stay in place even during high discharges. As a result, the maximum discharge that can flow in downstream direction increases and subsequently the maximum discharge at Lobith can increase. Consequently, we find that GRADE predicts a design discharge with a return period of 100,000 years of $17,710 \mathrm{~m}^{3} / \mathrm{s}$. This is $1,150 \mathrm{~m}^{3} / \mathrm{s}$ larger than predicted by the proposed bootstrap method (Table 7.1). If no emergency measures are included in the GRADE analysis, the design discharges corresponding to large return periods are close to our findings: both GRADE without emergency measures (Hegnauer et al, 2014) and this study find a design discharge of approximately $16,600 \mathrm{~m}^{3} / \mathrm{s}$ for a 
return period of 100,000 years.

The comparison of the confidence intervals of the two methods is more troublesome since both methods consider different sources of uncertainties in their analysis. The uncertainty of the bootstrap method is mainly determined by statistical uncertainty caused by extrapolation of the relatively short data set of annual max-
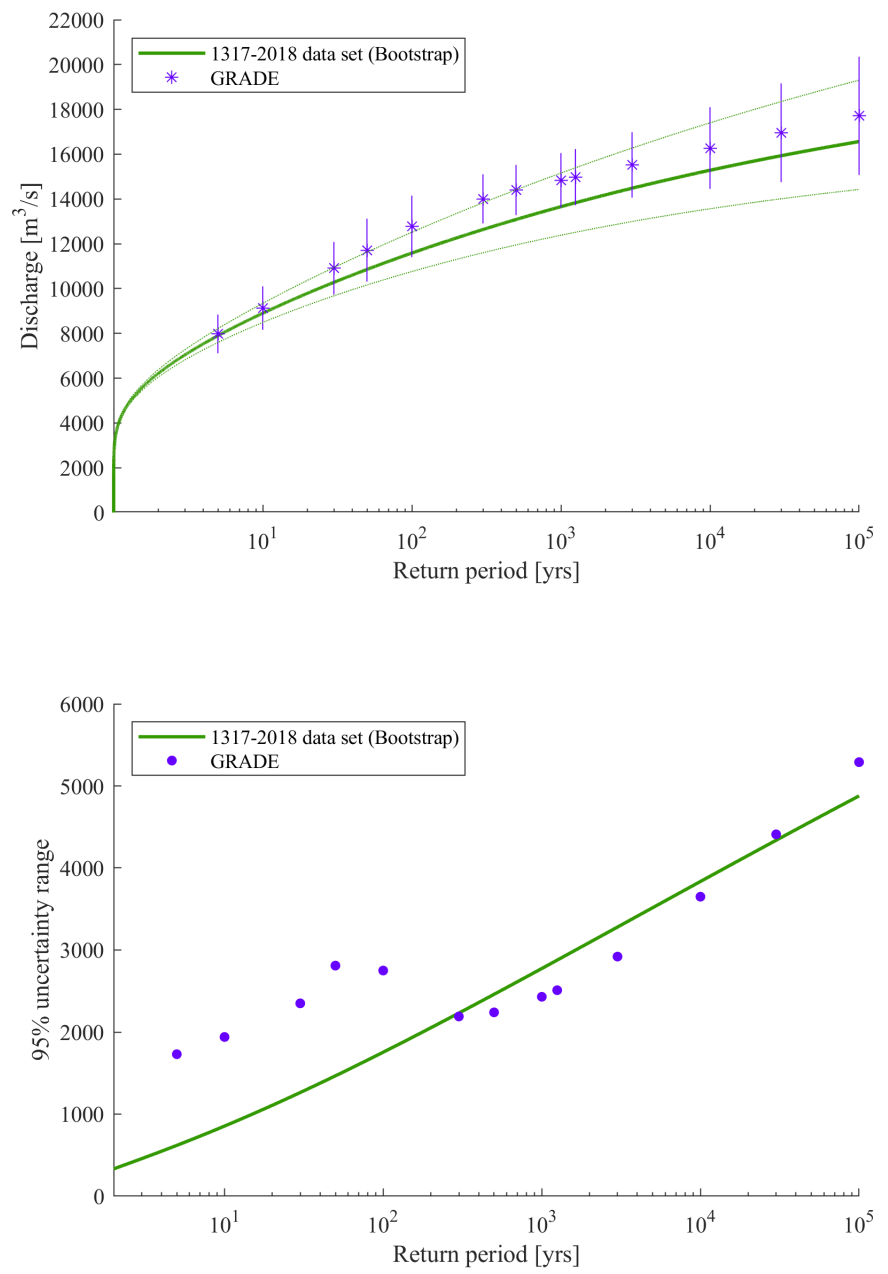

Figure 7.2

FFA results of the 1317-2018 data set and GRADE (Prinsen et al., 2015). In the upper figure, the dashed lines of the 1317-2018 data set represent the $95 \%$ confidence intervals. The $95 \%$ confidence intervals of GRADE are presented by the purple vertical lines. 
imum discharges to large return periods. This uncertainty is still small for small return periods (Fig. 7.2), whereas GRADE has a larger confidence interval caused by the various sources of uncertainty (the weather generator, the HBV-model and the SOBEK model) included in the analysis. Furthermore, we observe that the uncertainty of GRADE decreases for return periods larger than 100 years (Fig. 7.2). This is most probably caused by the system behaviour of the Upper Rhine basin. In this region, overflow starts to occur for discharges corresponding to return periods larger than 100 years. This results in a decrease of the peak flow in downstream direction and consequently into a decrease of the uncertainty in corresponding discharges at Lobith. After a return period of approximately 1,000 years, the uncertainty increases again caused by statistical uncertainty. The uncertainty of the bootstrap method shows a smoother pattern: the uncertainty increases for larger return periods (Fig. 7.2) which is mainly caused by the still limited length of the extended data set of approximately 700 years.

Overall, we can conclude that the 95\% confidence interval of GRADE is larger for small return periods compared to the proposed bootstrap method. For return periods larger than 250 years, the confidence intervals are comparable. However, the synthetically created 50,000 years of weather data is only based on 56 years of daily observations. Hence, the long-term climate variability is neglected. The question arises then whether the 56 years of daily observations are sufficient to cover the variability of 50,000 years of current climate conditions. Although a Jackknife procedure has been used to estimate this uncertainty (Van den Boogaard et al, 2014), it still might be that the variance in the created data sets of annual maximum discharges is underestimated. This results in an underestimation of the confidence intervals of discharges corresponding to large return periods in the GRADE analysis. 
198 Chapter 7 


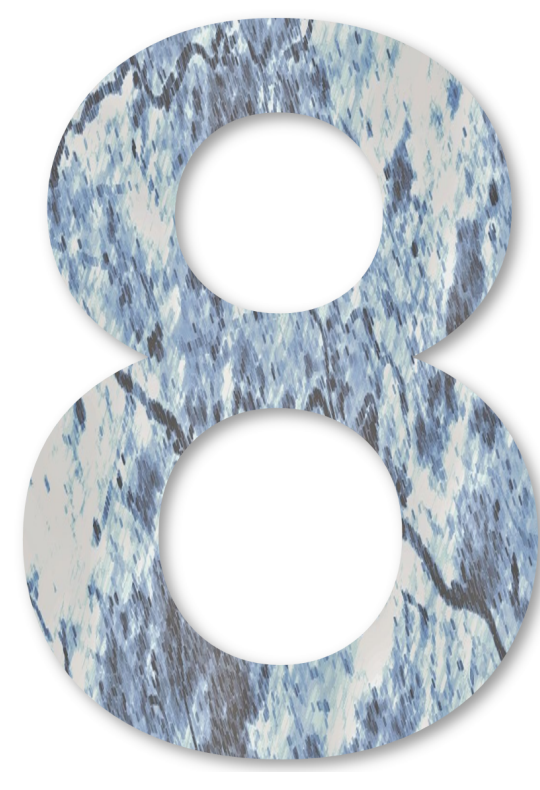

Conclusions and recommendations 


\subsection{Conclusions}

The aim of this thesis (Section 1.5) is to develop novel hydraulic modelling approaches to reconstruct historic flood events such that these events can be used to extend the data set of measured discharges. To reach this aim, we firstly studied which type of $2 \mathrm{D}$ grid is most efficient in terms of computational time and model accuracy. Then, two types of surrogate models were developed, namely: a lower-fidelity physically based model and a response surface model, used for the analysis of the 1926 and 1809 Rhine river floods, respectively. With these models it is possible to reconstruct the maximum discharges of the historic flood events. However, these discharges must be translated into present-day discharges since the river system has significantly altered over the last decades. For this translation, we use a current topography in combination with a hydraulic 1D-2D coupled model. Finally, a bootstrap method was developed that enables the inclusion of the normalized maximum discharges of historic flood events in a flood frequency analysis. We found that uncertainties in flood frequency predictions can be reduced significantly by extending the data set of measured discharges. In this section, we answer the research questions formulated in Section 1.5.

Q1 What kind of computational 2D grid is most efficient for hydraulic modelling of large river systems in terms of flood events?

In Chapter 2, we studied the effect of grid shape and grid size on computational time and model accuracy. Structured, unstructured and hybrid grids with each high and low resolutions were compared. It was found that all grids are capable of predicting accurate water levels with the main channel friction as a calibration parameter. However, the different grid types showed a large range in calibrated main channel friction values and computational time. These differences can be explained by three factors that influence simulated water levels, namely: (1) bathymetry accuracy, and (2) numerical friction which are both caused by grid resolution, and (3) numerical viscosity which is caused by grid shape. Low resolution grids are not capable of correctly representing the cross-sectional area of the rivers main channel. Therefore, the discharge capacity and hence simulated water levels are not correctly predicted for the uncalibrated model results. In addition, the low resolution grids result in high numerical friction and therefore in high simulated water levels. Finally, it was found that grids that are well-aligned with the flow direction have low numerical viscosity and hence perform better compared to less aligned grids.

Based on model performance of the six grid types studied, we recommend to use a hybrid grid with curvilinear grid cells in the main channel and triangles in the floodplains for hydraulic $2 \mathrm{DH}$ modelling since it combines the advantages of both a structured and an unstructured grid. With a hybrid 
grid, it is possible to have a high resolution grid in the main channel, resulting in good representation of the bathymetry. The resolution in the floodplains can be much lower which is beneficial for computational time. A triangular grid in the floodplains is thus more efficient than a curvilinear grid.

Q2 What kind of lower-fidelity physically based surrogate model can be used to reconstruct a historic flood event if the upstream discharge wave is known?

In Chapter 3, we developed a 1D-2D coupled model for historic flood reconstruction purposes. The 1926 flood event of the Rhine river was used as a case study. It was found that this type of lower-fidelity model predicts maximum discharges close to those predicted by the high-fidelity fully $2 \mathrm{D}$ model. Furthermore, the method can be applied to any type of historic flood event since the model is capable of accurately simulating flood wave propagation for both discharges below as above bankfull conditions.

For the 1926 flood event, a maximum discharge at Lobith of 12,402 $\mathrm{m}^{3} / \mathrm{s}$ was found with a standard deviation of only $49 \mathrm{~m}^{3} / \mathrm{s}$. The uncertainty was relatively small since much data (e.g. measured water levels, land use maps) was available. Reconstruction of an older flood event will probably result in larger uncertainties. The sensitivity analysis showed that for this specific flood event the output uncertainty is mostly affected by the roughness of grassland areas which also was the roughness class with the largest share in surface area.

Q3 What kind of response surface surrogate model can be used to reconstruct a historic flood event if the upstream discharge wave is unknown?

In Chapter 4, an Artifical Neural Network (ANN) was set up to reconstruct the maximum discharge of the 1809 flood event at Lobith. The 1D-2D coupled modelling approach, as developed in Chapter 3, was used to create the training data. An ANN with one hidden layer and two neurons was capable of reproducing the input-output relations of the $1 \mathrm{D}-2 \mathrm{D}$ coupled model with high accuracy. Therefore, this ANN was used to perform a Monte Carlo analysis with varying upstream discharge wave and main channel friction of the Dutch Rhine river branches to find the 1809 maximum discharge and its $95 \%$ confidence interval.

We found a maximum discharge of $11,265 \mathrm{~m}^{3} / \mathrm{s}$ with a $95 \%$ confidence interval of between $10,787-11,919 \mathrm{~m}^{3} / \mathrm{s}$ for the predicted 1809 flood. The proposed methodology decreased the $95 \%$ confidence interval of the maximum discharge at Lobith significantly compared to the studies that did not use hydraulic models for historic flood reconstruction purposes. 
Q4 What are the most important elements in normalizing reconstructed historic flood events?

The 1D-2D coupled modelling approach developed in Chapter 3 was extended in Chapter 5 such that flood wave propagation can be simulated in which both overflow and dike breaches are possible to occur. The method is applied to the present-day geometry. Potential dike breach locations along the Lower Rhine and Dutch Rhine river branches were included in the modelling approach.

We found that, as a result of the overflow and dike breaches along the Lower Rhine, the maximum discharge decreases in downstream direction. Consequently, the maximum discharge that can enter the Netherlands at Lobith is restricted to a maximum value. A large amount of water that flows into the embanked areas flows through the Old IJssel Valley towards the embanked areas of the IJssel river. As a result of this overland flow pattern, the flood risk increases in the latter area. Also, the maximum discharge at the IJssel river, downstream of Doesburg, can become much larger than currently expected during extreme flood events.

Q5 How can maximum discharges of historic flood events be included into a flood frequency analysis to reduce the uncertainty interval of the flood frequency relation?

In Chapter 6, we have set up an efficient bootstrap method to extend the data set of measured discharges. The data set of measured discharges at Lobith, dating back to 1901, was extended with the 1772-1900 continuous data set constructed by Toonen et al (2015). Furthermore, the modelling approach as developed in Chapter 5 was used to determine the maximum discharges at Lobith of 12 historic flood events being reconstructed near the city of Cologne by Herget and Meurs (2010). Using the bootstrap method, a continuous data set was created starting around 1300 AD.

It was found that extending the data set of measured discharges results in a significant decrease of the $95 \%$ uncertainty interval. This specifically applies for flood events with an extremely low probability of occurrence, which are the ones policy makers are interested in for designing flood protection measures and determining dike heights. Even though some of the historic flood events were highly uncertain themselves, including these in the data set still results in a large reduction of the uncertainty intervals of the predicted flood frequency relations. The proposed method to include historical discharges into a traditional flood frequency analysis can be easily implemented in flood safety assessments because of its simple nature in terms of mathematical computations as well as of its computational efforts. 


\subsection{Recommendations}

We conclude this chapter with some recommendations for future research on historic flood reconstructions, hydraulic modelling related to historic flood reconstructions and flood frequency analyses. We also discuss some recommendations for policy makers.

\subsubsection{Future work to further decrease uncertainty in historic flood reconstructions}

\section{Reconstruct historic flood events of the Rhine river}

We showed that extending the data set of measured discharges with historic flood events has the potential to significantly reduce uncertainty intervals of flood frequency relations. In this study, only the 1926 and 1809 Rhine river floods were reconstructed by setting up two types of surrogate modelling approaches. For future work, it is recommended to reconstruct more historic flood events that occurred in the Rhine river delta for which sufficient data is available such that a reconstruction is feasible. Herget and Meurs (2010) showed that in total 13 flood events occurred after AD 1350 that were not influenced by ice jams. For these events sufficient information was available to reconstruct the maximum discharges at Cologne, Germany. However, Herget and Meurs (2010) reconstructed these events using a single cross section near the city of Cologne which resulted in quite large confidence intervals of the maximum discharges of the historic events. These maximum discharges and related uncertainties were used as input data in Chapter 5 to predict corresponding discharges at Lobith. Reducing the uncertainty of the input data can be reached by reconstructing the 13 historic flood events along a long stretch of the Rhine river with the use of the hydraulic models presented in this thesis. As a result, the maximum discharges at Cologne can be estimated more precisely. These discharges can subsequently be routed towards Lobith on the present bathymetry to normalize the reconstructed historic flood events. In this way, the uncertainty of the flood frequency relation at Lobith can be reduced even further. Note that the proposed methodologies can be applied to any river system of which sufficient information about historic flood events is available.

\section{Altered river system of the Upper Rhine}

In Chapter 6, the reconstructed flood events at Cologne (Herget and Meurs, 2010) were used to predict corresponding maximum discharges at Lobith in present times. 
By routing the historic discharges over the present bathymetry, the historic flood events have been normalized for anthropegenic interventions and natural changes in the river system of the Middle and Lower Rhine. However, the reconstructed flood events at Cologne were not normalized for land use changes upstream of Cologne. It might be that the reconstructed maximum discharges at Cologne would be larger in present times, because of more direct run-off as a result of deforestation. For future work, we recommend to study the effect of land use changes and changes in the river system (e.g. canalization of the Upper Rhine) on the maximum discharges at Cologne. As a consequence, the reconstructed maximum discharges by Herget and Meurs (2010) can be adapted such that they are normalized for changes upstream of Cologne. Routing these discharges over present bathymetry results in a more reliable result of the maximum discharges of the historic flood events at Lobith in present times.

\section{Main channel friction}

Although many research has been done on the main channel friction during flood events (e.g. Best (2005); Naqshband et al (2014); Paarlberg et al (2010)), the value of this parameter under varying discharge stages is still largely unknown. Therefore, this parameter is commonly used as calibration parameter (Bomers et al, 2019d; Caviedes-Voullième et al, 2012). Generally, with a discharge wave as upstream boundary condition, the main channel friction is altered until the water levels are predicted close to water level measurements. However, for historic flood events this upstream discharge is often unknown. As a consequence, there is in principle an infinite number of potential combinations of maximum upstream discharge and main channel friction values that results in the same simulated water levels. To enable prediction of the maximum discharge of a historic flood event, a range of potential main channel friction values must be defined. In Chapter 4, this range was based on a calibrated hydraulic model using data of the 1995 flood event. However, calibrated friction values are model dependent since they compensate for e.g. grid generated errors in the model. Hence, these values are not directly transferable to another model. Therefore, it is important to gain more knowledge on the main channel friction values that are appropriate for hydraulic river models if calibration is not possible. The difficulty lies within the fact that the calibrated main channel friction values have no physical interpretation anymore. The appropriate calibrated friction values can thus not be explained by the physical behaviour of sand dunes, and resulting bed friction, under varying discharge conditions. 


\subsubsection{Future work to increase hydraulic modelling efficiency}

\section{Advanced 2D grids for hydraulic modelling purposes}

In Chapter 7 we discussed the use of efficient $2 \mathrm{D}$ grids in other fields. It seems that other fields such as fluid mechanics and aerodynamics are already using more efficient schemes compared to the field of hydraulics. We recommend to study the applicability of adaptive grids for hydraulic modelling of large river branches. These grids have as advantage that they can be updated during the simulation such that a smaller resolution can be implemented in areas where locally rapid changes in flow velocity and flow direction occur. This has the potential to reduce the computational times of hydraulic models even further. Consequently, Monte Carlo analyses incorporating uncertainties related to historic flood reconstructions can be performed faster.

\section{Validation hydraulic models}

Generally, hydraulic models are calibrated by adapting the main channel friction until simulated water levels are close to measured water levels (Bomers et al, 2019d; Caviedes-Voullième et al, 2012). However, in Chapter 2 we found that, although maximum water levels are simulated correctly, other physical processes may not be accurately simulated. Maximum flow velocities in a meander bend highly deviated from physical expectations. Therefore, we recommend not only to validate hydraulic models on simulated water levels but also on other physical processes.

\subsubsection{Future work in flood frequency analyses}

\section{Combination of multiple distributions}

In Chapter 6, we fitted the Generalized Extreme Value (GEV) distribution function to the data set of annual maximum discharges since several studies showed the applicability of the GEV distribution on the flooding regime of the Rhine river (Chbab et al, 2006; Te Linde, 2011; Toonen et al, 2015). This distribution has, such as the other most commonly used distributions, three parameters. These parameters describe the location, scale and shape of the distributions, giving the distributions the flexibility to approximate a wide range of potential distribution shapes (Parkes and Demeritt, 2016). The uncertainty related to the chosen distribution function is referred to as model uncertainty in literature. This uncertainty was not considered in Chapter 6. One approach to manage this uncertainty is to 
create a composite distribution of several different distributions (e.g. GEV, Gumbel, Pearson) each allocated a weighting based on how well it fits the available data (Apel et al, 2008). For future work, it is advised to perform this analysis to identify the increase in uncertainty in flood frequency predictions if a composite distribution is considered instead of the use of a single distribution function. Furthermore, the uncertainty related to the use of various goodness-of-fit tests must be included since each test will result in a slightly different fitted distribution function.

\section{Bayesian statistics}

In Chapter 6, a flood frequency analysis was performed based on frequentist statistics. However, the last decade, Bayesian statistics are increasingly used to predict flood frequency relations. Several studies have shown the applicability of Bayesian statistics for a data set of annual maximum discharges extended with several historic flood events. This has various advantages compared to the proposed bootstrap method based on frequentist statistics (Chapter 6). Among others, frequency statistics provide a point estimate of the parameter values of the distribution function considered. These point estimates are computed based on a goodness-of-fit test such as the Maximum Likelihood function. However, solely providing a point estimate is not sufficient since we think that policy makers should also know the related parameter uncertainty. To estimate this uncertainty, it is commonly assumed that the parameters are normally distributed in frequentist statistics. An advantage of Bayesian statistics is that one does not have to use any approximation because the full posterior distribution of the parameters are provided (Reis and Stedinger, 2005). Furthermore, Bayesian statistics can be applied to a noncontinuous data set such that the use of a bootstrap approach provided in Chapter 6 becomes redundant. However, Bayesian statistics also have several drawbacks. The greatest drawback is related to the choice of the priors describing the distributions of the parameters. This prior is generally based on some foreknowledge about the data set and is used to compute the posterior distributions of the parameters. Consequently, the prior influences the results of the parameter estimates and hence related uncertainties. For future work, we recommend to study the effects on uncertainty intervals of flood frequency relations by using the two statistical methods. This will provide knowledge on whether the use of the two methods results in large differences in uncertainty interval estimates of flood frequency relations. If this is the case, it must be evaluated which method is most reliable to use for flood safety assessment purposes. 


\subsubsection{Recommendations for policy makers}

\section{Overland flow patterns}

Up till now, overland flow patterns have not, or only in a very simple way, been included in flood safety assessments. However, in Chapter 5 we found that overland flow patterns caused by overflow and dike breaches can have a large impact on flood risk and maximum discharges of downstream river branches. For the Waal river and Nederrijn river, it was found that flood risk decreases as a result of dike breaches along the Lower Rhine. However, the flood risk along the IJssel river can increase tremendously. As a result of dike breaches near the city of Wesel, Germany, a large amount of water is capable of flowing through the Old IJssel Valley towards the hinterland of the IJssel river. Consequently, flood risk of the embanked areas along the IJssel river becomes larger than if solely flood risk caused by dike breaches and overflow from the IJssel river itself is considered. Therefore, we recommend to include the effects of potential overland flow patterns in future flood safety assessments.

\section{Evaluate uncertainty in GRADE analysis}

Chapter 7.7 discusses the differences between the uncertainty intervals of the proposed bootstrap method (Chapter 6) and GRADE. It was found that the method of GRADE results in smaller $95 \%$ confidence intervals for discharges corresponding to large return periods because of the use of 50,000 years of annual maximum discharges. However, this data set is only based on 56 years of daily weather observations. It is unlikely that the 56 years of observations are sufficient to cover the variability of 50,000 years of current climate conditions. If the variability in the 56 years of measured weather conditions is too low to sufficiently describe 50.000 years of current climate conditions, the $95 \%$ confidence intervals of GRADE are underestimated. Therefore, we recommend to evaluate the computed uncertainty intervals of GRADE by assessing the influence of the length of the resampled data set on the $95 \%$ confidence intervals of the flood frequency curves. 


\section{List of References}

Alkema D, Middelkoop H (2005) The influence of floodplain compartmentalization on flood risk within the Rhine-Meuse delta. Natural Hazards 36:125-145, DOI 10.1007/s11069-004-4545-8

Apel H, Thieken AH, Merz B, Blöschl G (2004) Flood risk assessment and associated uncertainty. Natural Hazards and Earth System Science 4:295-308, DOI 10.5194/nhess-4-295-2004

Apel H, Merz B, Thieken AH (2008) Quantification of uncertainties in flood risk assessments. International Journal of River Basin Management 6(2):149-162, DOI 10.1080/15715124.2008. 9635344

Apel H, Merz B, Thieken AH (2009) Influence of dike breaches on flood frequency estimation. Computers and Geosciences 35(5):907-923, DOI 10.1016/j.cageo.2007.11.003

Atlasproducties WN (1987) Topographical survey, 1950 - 1965, in Grote Topografische Atlas van Nederland, scale 1:50.000. Wolters-Noordhoff, Groningen, The Netherlands

Baker TJ (1996) Discretization of Navier-Stokes equations and mesh-induced errors. In: 5th International Conference Numerical Grid Generation in Computational Fluid Simulation, Mississipi State University, Mississippi, USA

Barriendos M, Coeur D, Lang M, Llasat MC, Naulet R, Lemaitre F, Barrera A (2003) Stationarity analysis of historical flood series in France and Spain. Natural Hazards and Earth System Sciences 3:583-592, DOI 10.5194/nhess-3-583-2003

Bayliss AC, Reed DW (2001) The use of historical data in flood frequency estimation. Tech. rep., Centre for Ecology and Hydrology, Wallingford, UK, URL http://nora.nerc.ac.uk/8060/1/ BaylissRepN008060CR.pdf

Beale M, Demuth H (2004) Neural network toolbox User's Guide. Tech. rep., The MathWorks, Inc, Natick, USA, URL http://www . mathworks.com.au/help/pdf\{_\}doc/nnet/nnet\{_\}ug.pdf

Beck C, Jacobeit J, Jones PD (2007) Frequency and within-type variations of large-scale circulation types and their effects on low-frequency climate variability in Central Europe since 1780. International Journal of Climatology 27:473-491, DOI 10.1002/joc.1410

Benito G, Lang M, Barriendos M, Llasat C, Francés F, Ouarda T, Thorndycraft V, Enzel Y, Bardossy A, Coeur D, Bobée B (2004) Use of Systematic, Palaeoflood and Historical Data for the Improvement of Flood Risk Estimation. Review of Scientific Methods. Natural Hazards 31:623-643, DOI 10.1023/B:NHAZ.0000024895.48463.eb

Berends KD, Straatsma MW, Warmink JJ, Hulscher SJMH (2019) Uncertainty quantification of flood mitigation predictions and implications for interventions. Natural Hazards and Earth System Sciences 19:1737-1753, DOI 10.5194/nhess-19-1737-2019 
Bermudez M, Cea L, Puertas J, Sopelana J, Ruano S (2018) Application of least squares support vector machine regression for historical reconstruction and real-time prediction of flood inundation. In: Armanini A, Nucci E (eds) Proc. of the 5th IAHR Europe Congress, Trento, Italy, pp 737-738, DOI 10.3850/978-981-11-2731-1\{\_\}222-cd

Bernard RS, Berger RC (1999) A parallel coupling scheme for disparate flow solvers. In: 1999 Users Group Conference, Department of Defense, Monterey, Calif

Best J (2005) The fluid dynamics of river dunes: A review and some future research directions. Journal of Geophysical Research 110:1-21, DOI 10.1029/2004JF000218

Bladé E, Gómez-Valentín M, Dolz J, Aragón-Hernández JL, Corestein G, Sánchez-Juny M (2012) Integration of $1 \mathrm{D}$ and $2 \mathrm{D}$ finite volume schemes for computations of water flow in natural channels. Advances in Water Resources 42:17-29, DOI 10.1016/j.advwatres.2012.03.021

Blauw M (2005) 'Eene aanschouwelijke voorstelling van den waterstaat.' De Waterstaatskaart van Nederland, 1865-1992. Caert-Thresoor 24:112-119

Blöschl G, Hall J, Parajka J, Perdigão RAP, Merz B, et al (2017) Changing climate shifts timing of European floods. Science 357(6351):588-590, DOI 10.1126/science.aan2506

Bobée B, Cavadias G, Ashkar F, Bernier J, Rasmussen P (1993) Towards a systematic approach to comparing distributions used in flood frequency analysis. Journal of Hydrology 142(1-4):121136, DOI 10.1016/0022-1694(93)90008-W

Bomers A, Hulscher SJMH, Lammersen R, Schielen RMJ (2018) The effect of dike breaches on downstream discharge partitioning near a river bifurcation. In: Armanini A, Nucci E (eds) New Challenges in Hydraulic Research and Engineering: Proceedings of the 5th IAHR Europe Congress, Trento, Italy, pp 805-806, DOI 10.3850/978-981-11-2731-1\{\_\}070-cd

Bomers A, Schielen RMJ, Hulscher SJMH (2019a) Application of a lower-fidelity surrogate hydraulic model for historic flood reconstruction. Environmental Modelling and Software 117:223-236, DOI 10.1016/j.envsoft.2019.03.019

Bomers A, Schielen RMJ, Hulscher SJMH (2019b) Consequences of dike breaches and dike overflow in a bifurcating river system. Natural Hazards 97(1):309-334, DOI 10.1007/ s11069-019-03643-y

Bomers A, Schielen RMJ, Hulscher SJMH (2019c) Decreasing uncertainty in flood frequency analyses by including historic flood events in an efficient bootstrap approach. Natural Hazards and Earth System Sciences 19:1895-1908, DOI 10.5194/nhess-19-1895-2019

Bomers A, Schielen RMJ, Hulscher SJMH (2019d) The influence of grid shape and grid size on river modelling performance. Environmental Fluid Mechanics 19(5):1273-1294, DOI 10.1007/ s10652-019-09670-4

Bomers A, Schielen RMJ, Hulscher SJMH (2019e) The severe 1374 Rhine river flood event in present times. In: Proceedings of the 38th IAHR World Congress, Water - connecting the World, Panama City, Panama, DOI 10.3850/38WC092019-0501

Boode MF (1979) 150 jaar rivierkaarten van Nederland. Tech. rep., Report of the Meetkundige Dienst, Rijkswaterstaat, Delft, The Netherlands

Brázdil R, Glaser R, Pfister C, Dobrovolny P, Antoine J, Barriendos M, Camuffo D, Deutsch M, Enzi S, Guidoboni E, Kotyza O, Sanchez Rodrigo F (1999) Flood event of selected European rivers in the sixteenth century. Climatic Change 43:239-285, DOI 10.1023/A:1005550401857

Brázdil R, Kundzewicz ZW, Benito G (2006) Historical hydrology for studying flood risk in Europe. Hydrological Sciences Journal 51(5):739-764, DOI 10.1623/hysj.51.5.739 
Bridge JS (2003) Rivers and Floodplains. Forms, Processes and Sedimentary Record. Blackwell Science, DOI 10.1002/jqs.856

Bronstert A, Bardossy A, Bismuth C, Buiteveld H, Disse M, Engel H, Fritsch U, Hundecha Y, Lammersen R, Niehoff D, Ritter N (2007) Multi-scale modelling of land-use change and river training effects on floods in the Rhine basin. River research and applications 23:1102-1125, DOI $10.1002 /$ rra.1036

Brunner GW (2014a) Combined 1D and 2D Modeling with HEC-RAS. Tech. rep., Hydrologic Engineering Centre (HEC) of the US Army Crops of Engineers, URL http://kiw.ur.krakow.pl/\{ $\}$ loczek/konspekty/9-korytarze/

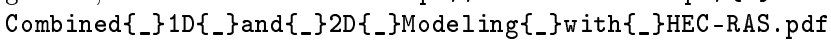

Brunner GW (2014b) Using HEC-RAS for Dam Break Studies, TD-39. Tech. Rep. August, US Army Corps of Engineers, Hydrologic Engineering Center (HEC), Davis, USA, URL https: //www.hec. usace. army . mil/publications/TrainingDocuments/TD-39.pdf

Brunner GW (2016) HEC-RAS, River Analysis System Hydraulic Reference Manual, Version 5.0. Tech. Rep. February, US Army Corp of Engineers, Hydrologic Engineering Center (HEC), Davis, USA, URL https://ww.hec.usace.army.mil/software/hec-ras/ documentation/HEC-RAS5. OReferenceManual.pdf

Campolo M, Andreussi P, Soldati A (1999) River flood forecasting with a neural network model. Water Resources Research 35(4):1191-1197, DOI 10.1029/1998WR900086

Campolo M, Soldati A, Andreussi P (2003) Artificial neural network approach to flood forecasting in the River Arno. Hydrological Sciences Journal 48(3):381-398, DOI 10.1623/hysj.48.3.381. 45286

Caviedes-Voullième D, García-navarro P, Murillo J (2012) Influence of mesh structure on 2D full shallow water equations and SCS Curve Number simulation of rainfall/runoff events. Journal of Hydrology 448(449):39-59, DOI 10.1016/j.jhydrol.2012.04.006

Chau KW, Wu CL, Li YS (2005) Comparison of Several Flood Forecasting Models in Yangtze River. Journal of Hydrologic Engineering 10(6):485-491, DOI 10.1061/(asce)1084-0699(2005) $10: 6(485)$

Chbab EH, Buiteveld H, Diermanse F (2006) Estimating Exceedance Frequencies of Extreme River Discharges Using Statistical Methods and Physically Based Approach. Osterreichse Wasser- und Abfallwirtschaft 58(3-4):35-43, DOI 10.1007/BF03165682

Chow VT (1959) Open-Channel Hydraulics. McGraw-Hill Book Company, Inc, New York

Cobby DM, Mason DC, Horritt MS, Bates PD (2003) Two-dimensional hydraulic flood modelling using a finite-element mesh decomposed according to vegetation and topographic features derived from airborne scanning laser altimetry. Hydrological processes 17:1979-2000, DOI 10.1002/hyp.1201

Coleman JM, Roberts HH, Stone GW (1998) Mississippi River Delta: an Overview. Journal of Coastal Research 14(3):698-716, DOI 10.1017/CBO9781107415324.004

Coulibaly P, Anctil F, Bobée B (2000) Daily reservoir inflow forecasting using artificial neural networks with stopped training approach. Journal of Hydrology 230:244-257, DOI 10.1016/ S0022-1694(00)00214-6

Curran A, De Bruijn KM, Kok M (2018) Influence of water level duration on dike breach triggering, focusing on system behaviour hazard analyses in lowland rivers. Georisk: Assessment and Management of Risk for Engineered Systems and Geohazards pp 1-15, DOI $10.1080 / 17499518.2018 .1542498$ 
Dawson CW, Wilby RL (2001) Hydrological modelling using artificial neural networks. Progress in Physical Geography 25(1):80-108, DOI 10.1177/030913330102500104

Dawson R, Hall J, Sayers P, Bates P, Rosu C (2005) Sampling-based flood risk analysis for fluvial dike systems. Stochastic Environmental Research and Risk Assessment 19(6):388-402, DOI 10.1007/s00477-005-0010-9

De Bruijn KM, Diermanse FLM, Beckers JVL (2014) An advanced method for flood risk analysis in river deltas, applied to societal flood fatality risk in the Netherlands. Natural Hazards and Earth System Sciences 14:2767-2781, DOI 10.5194/nhess-14-2767-2014

Deltares (2016a) D-Flow Flexible Mesh, Technical Reference Manual. Version: 1.1.0. Revision: 48665. Tech. rep., Deltares, Delft, the Netherlands

Deltares (2016b) D-Flow Flexible Mesh, User Manual. Version 1.2.1. Tech. rep., Deltares, Delft

Der Oberdeichinspektor Dusseldorf (1895) Deichbuch der Schau Huisberden. Deichfbaue im Niederrhein No. VII.10, Konigliche Oberdeichinspection Dusseldorf, Book provided by Deichverband Xanten-Kleve

Dibike YB, Solomatine DP (2001) River Flow Forecasting Using Artificial Neural Network. Physics and Chemistry of the Earth 26(1):1-7, DOI 10.1016/S1464-1909(01)85005-X

Diermanse FLM, De Bruijn KM, Beckers JVL, Kramer NL (2015) Importance sampling for efficient modelling of hydraulic loads in the Rhine-Meuse delta. Stochastic Environmental Research and Risk Assessment 29:637-652, DOI 10.1007/s00477-014-0921-4

Disse M, Engel H (2001) Flood events in the Rhine basin: Genesis, influences and mitigation. Natural Hazards 23:271-290, DOI 10.1023/A:1011142402374

Domeneghetti A, Vorogushyn S, Castellarin A, Merz B, Brath A (2013) Probabilistic flood hazard mapping: Effects of uncertain boundary conditions. Hydrology and Earth System Sciences $17(8): 3127-3140$, DOI $10.5194 /$ hess-17-3127-2013

Domhof BCA, Berends KD, Spruyt A, Warmink JJ, Hulscher SJMH (2018) Discharge and location dependency of calibrated main channel roughness: Case study on the River Waal. In: River Flow 2018: 9th International Conference on Fluvial Hydraulics 2018, E3S Web of Conferences, Lyon, France, vol 40, p 8, DOI 10.1051/e3sconf/20184006038

Driessen AMAJ (1994) Watersnood tussen Maas en Waal: overstromingsrampen in het rivierengebied tussen 1780 en 1810. Walburg Pers, Zutphen, The Netherlands. ISBN:9060118642

Dubreuil S, Berveiller M, Petitjean F, Salaün M (2014) Construction of bootstrap confidence intervals on sensitivity indices computed by polynomial chaos expansion. Reliability Engineering and System Safety 121:263-275, DOI 10.1016/j.ress.2013.09.011

Dutch Ministry of Infrastructure and the Environment (1926) Verslag van het voorgevallene tijdens het hooge opperwater op de Nederlandsche rivieren in den winter van 1925 op 1926. Tech. rep., 's-Gravenhage, URL https://repository.tudelft.nl/islandora/object/uuid: 5aee4476-3245-42da-a9aa-5807f2b77b6e

Dutch Ministry of Infrastructure and the Environment (1952) Afvoerkrommen 1948-1951 van de Bovenrijn en zijn Takken. Nota 51.23. Tech. rep., Rijkswaterstaat, Dir. Bovenrivieren, afd. Studiedienst, Anrhem, the Netherlands, URL http://publicaties.minienm.nl/documenten/ af voerkrommen-1948-1951 - van-de-bovenrijn-en-zijn-takken

Dutch Ministry of Infrastructure and the Environment, Ministry of Economic Affairs (2014) Delta Programme 2015 - Working on the delta - The decisions to keep the Netherlands safe and liveable. Tech. rep., URL https ://english.deltacommissaris.nl/delta-programme/documents/ publications /2014/09/16/delta-programme-2015 
EEA (2016) Floodplain management: reducing flood risks and restoring healthy ecosystems. Tech. rep., European Environment Agency, Copenhagen, Denmark, URL http://floodlist. com/europe/report-floods-europe-increase-fivefold-2050

Efendiev Y, Datta-Gupta A, Ginting V, Ma X, Mallick B (2005) An efficient two-stage Markov chain Monte Carlo method for dynamic data integration. Water Resources Research 41:1-6, DOI 10.1029/2004WR003764

Efron B, Tibshirani RJ (1993) An introduction to the Bootstrap, vol 57. Chapman \& Hall/CRC, New York, USA. ISBN:978-0412042317

Elsafi SH (2014) Artificial Neural Networks (ANNs) for flood forecasting at Dongola Station in the River Nile, Sudan. Alexandria Engineering Journal 53(3):655-662, DOI 10.1016/j.aej. 2014.06.010

ESRI (2016) ArcGIS Desktop: Release 10.5

Frances F, Salas JD, Boes DC (1994) Flood frequency analysis with systematic and historical or paleoflood data based on the two-parameter general extreme value models. Water Resources Research 30(6):1653-1664, DOI 10.1029/94WR00154

Gaume E, Gaál L, Viglione A, Szolgay J, Kohnová S, Blöschl G (2010) Bayesian MCMC approach to regional flood frequency analyses involving extraordinary flood events at ungauged sites. Journal of Hydrology 394:101-117, DOI 10.1016/j.jhydrol.2010.01.008

Gayton N, Bourinet J, Lemaire M (2003) CQ2RS: a new statistical approach to the response surface method for reliability analysis. Structural Safety 25:99-121, DOI 10.1016/S0167-4730(02) 00045-0

Gee M (2010) Use of Breach Process Models To Estimate Hec-Ras Dam Breach Parameters. In: Proceedings of the 2nd Joint Federal Interagency Conference, Las Vegas, USA

Haberlandt U, Radtke I (2014) Hydrological model calibration for derived flood frequency analysis using stochastic rainfall and probability distributions of peak flows. Hydrology and Earth System Sciences 18:353-365, DOI 10.5194/hess-18-353-2014

Hagan MT, Menhaj MB (1994) Training Feedforward Networks with the Marquardt Algorithm. IEEE Transactions on Neural Networks 5(6):989-993, DOI 10.1109/72.329697

Hailegeorgis TT, Alfredsen K (2017) Regional flood frequency analysis and prediction in ungauged basins including estimation of major uncertainties for mid-Norway. Journal of Hydrology: Regional Studies 9:104-126, DOI 10.1016/j.ejrh.2016.11.004

Hall J, Solomatine D (2008) A framework for uncertainty analysis in flood risk management decisions. International Journal of River Basin Management 6(2):85-98, DOI 10.1080/15715124. 2008.9635339

Hall JW, Dawson RJ, Sayers PB, Rosu C, Chatterton JB, Deakin R (2003) A methodology for national-scale flood risk assessment. Proceedings of the Institution of Civil Engineers - Water and Maritime Engineering 156(3):235-247, DOI 10.1680/wame.2003.156.3.235

Han D, Chan L, Zhu N (2007) Flood forecasting using support vector machines. Journal of Hydroinformatics 9(4):267-276, DOI 10.2166/hydro.2007.027

Hardy RJ, Bates PD, Anderson MG (1999) The importance of spatial resolution in hydraulic models for floodplain environments. Journal of Hydrology 216:124-136, DOI 10.1016/ S0022-1694(99)00002-5

Harlow FH, Welch JE (1965) Numerical Calculation of Time-Dependent Viscous Incompressible Flow of Fluid with Free Surface. The Physics of Fluids 8(2182), DOI 10.1063/1.1761178View 
Heere E, Storms M (2002) Kartobibliografie van de Waterstaatskaart (1865-1991). Tech. rep., Report of the Meetkundige Dienst, Rijkswaterstaat, Delft, The Netherlands

Hegnauer M (2017) Analysis GRADE results for different locations in the Rhine Basin. Tech. rep., Deltares. Project 11200540-000-ZWS-0002, Delft, the Netherlands

Hegnauer M, Beersma JJ, van den Boogaard HFP, Buishand TA, Passchier RH (2014) Generator of Rainfall and Discharge Extremes (GRADE) for the Rhine and Meuse basins. Final report of GRADE 2.0. Tech. rep., Deltares, Delft, The Netherlands. ISBN:9789036914062

Heniche M, Secretan Y, Boudreau P, Leclerc M (2000) A two-dimensional finite element dryingwetting shallow water model for rivers and estuaries. Advances in Water Resources 23:359-372, DOI 10.1016/S0309-1708(99)00031-7

Herget J, Meurs H (2010) Reconstructing peak discharges for historic flood levels in the city of Cologne, Germany. Global and Planetary Change 70:108-116, DOI 10.1016/j.gloplacha.2009. 11.011

Herget J, Kapala A, Krell M, Rustemeier E, Simmer C, Wyss A (2015) The millennium flood of July 1342 revisited. Catena 130:82-94, DOI 10.1016/j.catena.2014.12.010

Hewitson BC, Crane RG (2006) Consensus between GCM climate change projections with empirical downscaling: Precipitation downscaling over South Africa. International Journal of Climatology 10:1315-1337, DOI 10.1002/joc.1314

Hirsch RM, Stedinger JR (1987) Plotting positions for historical floods and their precision. Water Resources Research 23(4):715-727, DOI 10.1029/WR023i004p00715

Hooijer A, Klijn F, Pedroli GBM, van Os AG (2004) Towards sustainable flood risk management in the Rhine and Meuse river basins: Synopsis of the findings of IRMA-SPONGE. River Research and Applications 20(3):343-357, DOI 10.1002/rra.781

Hornik K, Stinchcombe M, White H (1989) Multilayer Feedforward Networks are Universal Approximators. Neural Networks 2:359-366, DOI 10.1016/0893-6080(89)90020-8

Horritt MS, Bates PD (2002) Evaluation of 1D and 2D numerical models for predicting river flood inundation. Journal of Hydrology 268:87-99, DOI 10.1016/S0022-1694(02)00121-X

Horritt MS, Bates PD, Mattinson MJ (2006) Effects of mesh resolution and topographic representation in 2D finite volume models of shallow water fluvial flow. Journal of Hydrology 329:306-314, DOI 10.1016/j.jhydrol.2006.02.016

ICPR (2001) Rhine-Atlas. Tech. rep., Internationale Kommission zum Schutz des Rhein, Koblenz, Germany, URL http://www.iksr.org/idex.php?=302

Ikeda S, Parker G, Sawai K (1981) Bend theory of river meanders. Part 1. Linear development. Journal Fluid Mechanics 112:363-377, DOI 10.1017/S0022112081000451

IPCC (2014) Climate Change 2014: Synthesis Report. Contribution of Working Groups I, II and III to the Fifth Assessment Report of the Intergovernmental Panel on Climate Change. IPCC, Geneva, Switzerland, DOI 10.1017/CBO9781107415324, arXiv:1011.1669v3

Janon A, Nodet M, Prieur C, Janon A, Nodet M, Prieur C (2011) Confidence intervals for sensitivity indices using reduced-basis metamodels. Tech. rep., INRIA, URL https://hal. inria.fr/inria-00567977v 1

Jones JE (2002) Coastal and Shelf-sea modelling in European context. In: Gibson RN, Atkinson RJA, Gordon JDM (eds) Oceanography and Marine Biology: an annual review, vol 40, CRC Press, pp 37-141, DOI 10.1201/9780203180594.ch2 
Julien PY, ASCE M, Klaassen GJ, Brinke WBMT, Wilbers AWE (2002) Case Study: Bed Resistance of Rhine River during 1998 Flood. Journal of Hydraulic Engineering 128(12), DOI 10.1061/(ASCE)/0733-9429(2002)128:12(1042)

Keating EH, Doherty J, Vrugt JA, Kang Q (2010) Optimization and uncertainty assessment of strongly nonlinear groundwater models with high parameter dimensionality. Water Resources Research 46:1-18, DOI 10.1029/2009WR008584

Kerh T, Lee CS (2006) Neural networks forecasting of flood discharge at an unmeasured station using river upstream information. Advances in Engineering Software 37(8):533-543, DOI 10.1016/j.advengsoft.2005.11.002

Kernkamp HWJ, Van Dam A, Stelling GS, De Goede ED (2011) Efficient scheme for the shallow water equations on unstructured grids with application to the Continental Shelf. Ocean Dynamics 61(8):1175-1188, DOI 10.1007/s10236-011-0423-6

Khaliq MN, Ouarda TB, Ondo JC, Gachon P, Bobée B (2006) Frequency analysis of a sequence of dependent and/or non-stationary hydro-meteorological observations: A review. Journal of Hydrology 329:534-552, DOI 10.1016/j.jhydrol.2006.03.004

Kia MB, Pirasteh S, Pradhan B, Mahmud AR, Sulaiman WNA, Moradi A (2012) An artificial neural network model for flood simulation using GIS: Johor River Basin, Malaysia. Environmental Earth Sciences 67(1):251-264, DOI 10.1007/s12665-011-1504-z

Kiss A (2009) Floods and Weather in 1342 and 1343 in the Carpathian Basin. Journal of Env Geogr 2(3-4):37-47

Klemeš V (1986) Dilettantism in hydrology: Transition or destiny? Water Resources Research 22(9):177-188, DOI 10.1029/WR022i09Sp0177S

Kleptsova O, Pietrzak JD, Stelling GS (2009) On the accurate and stable reconstruction of tangential velocities in C-grid ocean models. Ocean Modelling 28:118-126, DOI 10.1016/j. ocemod.2008.12.007

Klerk WJ, Kok M, De Bruijn KM, Jonkman SN, van Overloop PJATM (2014) Influence of Load Interdependencies of Flood Defences on Probabilities and Risks at the Bovenrijn/IJssel Area, The Netherlands. In: 6th International Conference on Flood Management, Brazilian Water Resources Association and Acquacon Consultoria, São Paulo, Brazil

Klijn F, De Bruijn KM, Knoop J, Kwadijk J (2012) Assessment of the Netherlands' flood risk management policy under global change. AMBIO 41(2):180-192, DOI 10.1007/ s13280-011-0193-x

Klijn F, Asselman N, Wagenaar D (2018) Room for rivers: Risk reduction by enhancing the flood conveyance capacity of The Netherlands' large rivers. Geosciences 8(6), DOI 10.3390/ geosciences 8060224

Knepper TP (2014) The Rhine. Springer-Verlag Berlin Heidelberg, Berlin, Germany, DOI 10. $1007 / \mathrm{b} 11739$

KNMI (2015) Brochure KNMI klimaatscenario's '14, Herziene uitgave 2015. Tech. rep., Koninklijk Nederlands Meteorologisch Insituut, Ministry of Infrastructure and the Environment, URL http: //www.klimaatscenarios.nl/images/Brochure\{_\}KNMI14\{_\}NL.pdf

Knol WC, Kramer H, Gijsbertse H (2004) Historisch Grondgebruik Nederland: een landelijke reconstructie van het grondgebruik rond 1990. Tech. rep., Alterra, Wageningen, The Netherlands, URL https://www.wur.nl/nl/Publicatie-details.htm?publicationId= publication-way-333238323739 
Koutsoyiannis D, Montanari A (2015) Negligent killing of scientific concepts: the stationarity case. Hydrological Sciences Journal 60(7-8):1174-1183, DOI 10.1080/02626667.2014.959959

Lai YG (2010) Two-Dimensional Depth-Averaged Flow Modeling with an Unstructured Hybrid Mesh. Journal of Hydraulic Engineering 136(1):12-23, DOI 10.1061/(ASCE)HY.1943-7900. 0000134

Laio F, Porporato A, Revelli R, Ridolfi L (2003) A comparison of nonlinear flood forecasting methods. Water Resources Research 39(5):1-4, DOI 10.1029/2002WR001551

Lammersen R (2004) Grensoverschrijdende effecten van extreem hoogwater op de Niederrhein. Tech. rep., Dutch Ministry of Infrastructure and Water Management, Arnhem, The Netherlands, URL https://www.commissiemer.nl/docs/mer/p12/p1252/ 1252-120grensoverschrijdend.pdf

Lammersen R, Hegnauer M (2019) Effect of upstream flooding on extreme discharge frequency estimations. In: Stouthamer E, Middelkoop H, Kleinhans M, van der Perk M, Straatsma M (eds) NCR Days 2019: Land of Rivers, Netherlands Centre for River Studies publication 43-2019, Utrecht, The Netherlands, pp 14-15

Lane SN, Hardy RJ, Elliott L, Ingham DB (2004) Numerical modeling of flow processes over gravelly surfaces using structured grids and a numerical porosity treatment. Water Resources Research 40, DOI 10.1029/2002WR001934

Leandro J, Chen AS, Schumann A (2014) A 2D parallel diffusive wave model for floodplain inundation with variable time step (P-DWave). Journal of Hydrology 517:250-259, DOI 10. 1016/j.jhydrol.2014.05.020

Lekkas DF, Onof C, Lee MJ, Baltas EA (2004) Application of Artificial Neural Networks for Flood Forecasting. Global Nest: the Int $J$ 6(3):209-215

Leshno M, Lin VY, Pinkus A, Schocken S (1993) Multilayer feedforward networks with a nonpolynomial activation function can approximate any function. Neural Networks 6:861-867, DOI $10.1016 / \mathrm{S} 0893-6080(05) 80131-5$

Li C, Mahadevan S (2016) An efficient modularized sample-based method to estimate the firstorder Sobol' index. Reliability Engineering and System Safety 153:110-121, DOI 10.1016/j. ress.2016.04.012

Liang Q, Du G, Hall JW, Borthwick AGL (2008) Flood Inundation Modeling with an Adaptive Quadtree Grid Shallow Water Equation Solver. Journal of Hydraulic Engineering 134(11):1603-1610, DOI 10.1061/(asce)0733-9429(2008)134:11(1603)

Liefveld WM, Postma R (2007) Two rivers: Rhine and Meuse. Dutch Ministry of Infrastructure and Water Management, Arnhem, The Netherlands. ISBN:9789036913850

Lintsen HW (1993) Geschiedenis van de techniek in Nederland. De wording van een moderne samenleving 1800-1890. Deel II. Gezondheid en openbare hygiëne. Waterstaat en infrastructuur. Papier, druk en communicatie. Walburg Pers, Zutphen, The Netherlands. ISBN:9060118111

Liong SY, Sivapragasam C (2002) Flood stage forecasting with support vector machines. Journal of the American Water Resources Association 38:173-186, DOI 10.1111/j.1752-1688.2002. tb01544.x

Llasat MC, Barriendos M, Barrera A, Rigo T (2005) Floods in Catalonia (NE Spain) since the 14 th century. Climatological and meteorological aspects from historical documentary sources and old instrumental records. Journal of Hydrology 313:32-47, DOI 10.1016/j.jhydrol.2005. 02.004 
MacDonald N, Kjeldsen TR, Prosdocimi I, Sangster H (2014) Reassessing flood frequency for the Sussex Ouse, Lewes: The inclusion of historical flood information since AD 1650. Natural Hazards and Earth System Sciences 14(10):2817-2828, DOI 10.5194/nhess-14-2817-2014

Machado MJ, Botero BA, López J, Francés F, Díez-Herrero A, Benito G (2015) Flood frequency analysis of historical flood data under stationary and non-stationary modelling. Hydrology and Earth System Sciences 19(6):2561-2576, DOI 10.5194/hess-19-2561-2015

MacKay DJC (1992) Bayesian interpolation. Neural Computation 4(3):415-447

Maschler T, Savic Da (1999) Simplification of Water Supply Network Models Through Linearisation. Tech. rep., Centre of Water Systems, Report No.99/01, School of Engineering, University of Exeter, Exeter, United Kingdom, URL https://emps.exeter.ac.uk/media/ universityofexeter/emps/research/cws/downloads/Machler\{_\}and\{_\}Savic\{_\}1999-01. pdf

Matta E, Duda R, Scheer C, Ma Y, Zhang Q, Hassan A, Hinkelman R, Meissner D, Schellenberg H, Schmid A (2018) Water level predictions using neural networks in critical gauges of the Rhine River, Germany. In: Armanini A, Nucci E (eds) Proc. of the 5th IAHR Europe Congress, Trento, Italy, pp 657-658, DOI 10.3850/978-981-11-2731-1\{\_\}117-cd

McPhee J, Yeh WWG (2008) Groundwater Management Using Model Reduction via Empirical Orthogonal Functions. Journal of Water Resources Planning and Management 134(2):161170, DOI 10.1061/(ASCE)0733-9496(2008) 134:2(161)

Mens MJP, Klijn F, Schielen RMJ (2014) Enhancing flood risk system robustness in practice: Insights from two river valleys. International Journal of River Basin Management 13(3):297304, DOI 10.1080/15715124.2014.936876

Meurs H (2006) Bestimmung der Spitzenabflusse historischer Hochwasser Koln. Diploma thesis, University of Bonn

Milly PCD, Betancourt J, Falkenmark M, Hirsch RM, Kundzewicz ZW, Lettenmaier DP, Stouffer RJ (2008) Stationarity Is Dead: Whither Water Management? Science 319:573-574, DOI $10.1126 /$ science. 1151915

Moussa R, Bocquillon C (2009) On the use of the diffusive wave for modelling extreme flood events with overbank flow in the floodplain. Journal of Hydrology 374:116-135, DOI 10.1016/ j.jhydrol.2009.06.006

Moya Quiroga V, Kure S, Udo K, Mano A (2016) Application of 2D numerical simulation for the analysis of the February 2014 Bolivian Amazonia flood: Application of the new HEC-RAS version 5. RIBAGUA - Revista Iberoamericana del Agua 3:25-33, DOI 10.1016/j.riba.2015. 12.001

Murawski A, Vorogushyn S, Bürger G, Gerlitz L, Merz B (2018) Do Changing Weather Types Explain Observed Climatic Trends in the Rhine Basin? An Analysis of Within- and BetweenType Changes. Journal of Geophysical Research: Atmospheres 123(3):1562-1584, DOI 10. 1002/2017JD026654

Naqshband S, Ribberink JS, Hulscher SJMH (2014) Using Both Free Surface Effect and Sediment Transport Mode Parameters in Defining the Morphology of River Dunes and Their Evolution to Upper Stage Plane Beds. Journal of Hydraulic Engineering 140(6), DOI 10.1061/(ASCE) HY.1943-7900.0000873

Nash JE, Sutcliffe JV (1970) River flow forecasting through conceptual models. Part 1. A discussion of principles. Journal of Hydrology 10:282-290 
Neppel L, Renard B, Lang M, Ayral Pa, Coeur D, Gaume E, Jacob N, Payrastre O, Pobanz K, Vinet F (2010) Flood frequency analysis using historical data: accounting for random and systematic errors. Hydrological Sciences Journal 55(2):192-208, DOI 10.1080/02626660903546092

O'Connell DRH, Ostenaa DA, Levish DR, Klinger RE (2002) Bayesian flood frequency analysis with paleohydrologic bound data. Water Resources Research 38(5):1058-1071, DOI 10.1029/ 200WR000028

Paarlberg AJ, Schielen RMJ (2012) Integration of a dune roughness model with a large-scale flow model. In: River Flow 2012 - Proceedings of the International Conference on Fluvial Hydraulics, Taylor \& Francis Group, San Jose, Costa Rica, 5-7 September 2012, pp 155-161

Paarlberg AJ, Dohmen-Janssen CM, Hulscher SJMH, Termes P, Schielen R (2010) Modelling the effect of time-dependent river dune evolution on bed roughness and stage. Earth surface processes and landforms 35(15):1854-1866, DOI 10.1002/esp.2074

Pappenberger F, Beven K, Horritt M, Blazkova S (2005) Uncertainty in the calibration of effective roughness parameters in HEC-RAS using inundation and downstream level observations. Journal of Hydrology 302:46-69, DOI 10.1016/j.jhydrol.2004.06.036

Parkes B, Demeritt D (2016) Defining the hundred year flood: A Bayesian approach for using historic data to reduce uncertainty in flood frequency estimates. Journal of Hydrology 540:1189-1208, DOI 10.1016/j.jhydrol.2016.07.025

Parmet B, van de Langemheen W, Chbab E, Kwadijk J, Diermanse F, Klopstra D (2001) Analyse van de maatgevende afvoer van de Rijn te Lobith. Tech. rep., RIZA rapport 2002.012, Arnhem, The Netherlands, URL https://edepot.wur.nl/84989

Perot B (2000) Conservation Properties of Unstructured Staggered Mesh Schemes. Journal of Computational Physics 159:58-89, DOI 10.1006/jcph.2000.6424

Peters R, Schmitz G, Cullmann J (2006) Flood routing modelling with Artificial Neural Networks. Advances In Geosciences 9:131-136

Pinter N (2003) One Step Forward, Two Steps Back on U.S. Floodplains. Science 308(5719):207208, DOI $10.1126 /$ science. 1108411

Ploeger B (1992) Bouwen aan de Rijn: Menselijke ingrepen op de Rijn en zijn takken. Tech. rep., Dutch Ministry of Infrastructure and the Environment, URL http://publicaties.minienm. $\mathrm{nl} /$ documenten/bouwen-aan-de-rijn-menselijke-ingrepen-op-de-rijn-en-zijn-takken

Prinsen G, Van den Boogaard H, Hegnauer M (2015) Onzekerheidsanalyse hydraulica in GRADE. Tech. rep., Deltares, Delft, The Netherlands, URL http://publications.deltares . $\mathrm{nl} / 1220082\left\{\_\right\} 010 . \mathrm{pdf}$

Raghavendra S, Deka PC (2014) Support vector machine applications in the field of hydrology: A review. Applied Soft Computing Journal 19:372-386, DOI 10.1016/j.asoc.2014.02.002, URL http://dx.doi.org/10.1016/j.asoc.2014.02.002

Razavi S, Tolson BA, Burn DH (2012a) Numerical assessment of metamodelling strategies in computationally intensive optimization. Environmental Modelling and Software 34:67-86, DOI 10.1016/j.envsoft.2011.09.010

Razavi S, Tolson BA, Burn DH (2012b) Review of surrogate modeling in water resources. Water Resources Research 48(W07401), DOI 10.1029/2011WR011527

Refsgaard JC, van der Sluijs JP, Højberg AL, Vanrolleghem PA (2007) Uncertainty in the environmental modelling process - A framework and guidance. Environmental Modelling and Software 22(11):1543-1556, DOI 10.1016/j.envsoft.2007.02.004 
Reis DS, Stedinger JR (2005) Bayesian MCMC flood frequency analysis with historical information. Journal of Hydrology 313(1-2):97-116, DOI 10.1016/j.jhydrol.2005.02.028

Rezaeianzadeh M, Tabari H, Arabi Yazdi A, Isik S, Kalin L (2014) Flood flow forecasting using ANN, ANFIS and regression models. Neural Computing and Applications 25:25-37, DOI $10.1007 / \mathrm{s} 00521-013-1443-6$

Saltelli A, Chan K, Scott EM (2000) Sensitivity Analysis: Gauging the Worth of Scientific Models. John Wiley \& Sons, Ltd. ISBN:978-0-471-99892-1

Saltelli A, Ratto M, Andres T, Campologno F, Cariboni J, Gatelli D, Saisana M, Tarantola S (2008) Global Sensitivity Analysis: The Primer. John Wiley \& Sons, Ltd. ISBN:978-0-470$05997-5$

Sankarasubramanian A, Lall U (2003) Flood quantiles in a changing climate: Seasonal forecasts and causal relations. Water Resources Research 39(5), DOI 10.1029/2002WR001593

Sartor J, Zimmer KH, Busch N (2010) Historische Hochwasserereignisse der deutschen Mosel. Wasser Abfall 10:46-51, URL https://www.hochschule-trier.de/fileadmin/Hauptcampus/ Fachbereich\{_\}BL/BI/Personen/Sartor/Veroef fentlichungen/Fachzeitschriften/ $35\left\{\_\right.$Hosel-HW-Sartor-W\{_\}A10.pdf

Scheidt C, Li L, Caers J (2018) Quantifying Uncertainty in Subsurface Systems. Volume 236 of Geophysical Monograph Series. John Wiley \& Sons, Ltd. ISBN:9781119325864

Schendel T, Thongwichian R (2017) Considering historical flood events in flood frequency analysis: Is it worth the effort? Advances in Water Resources 105:144-153, DOI 10.1016/j. advwatres.2017.05.002

Schubert JE, Sanders BF, Smith MJ, Wright NG (2008) Unstructured mesh generation and landcover-based resistance for hydrodynamic modeling of urban flooding. Advances in Water Resources 31(12):1603-1621, DOI 10.1016/j.advwatres.2008.07.012

Schweckendiek T, Vrouwenvelder ACWM, van Mierlo MCLM, Calle EOF, Courage WMG (2008) River System Behaviour Effects on Flood Risk. In: Proceedings of the European Safety and Reliability Conference, ESREL 2008, Valencia, Spain, pp 1-8, URL https://repository. tudelft.nl/islandora/object/uuid: fc9dff $2 e-34 a 6-4 a 1 b-a d c 1-e e a 9 c a 39 b 1 b 0$

Serinaldi F, Kilsby CG, Lombardo F (2018) Untenable nonstationarity: An assessment of the fitness for purpose of trend tests in hydrology. Advances in Water Resources 111:132-155, DOI 10.1016/j.advwatres.2017.10.015

Sheffer NA, Enzel Y, Benito G, Grodek T, Poart N, Lang M, Naulet R, Cœur D (2003) Paleofloods and historical floods of the Ardeche River, France. Water Resources Research 39(12), DOI 10.1029/2003WR002468

Shrestha RR, Theobald S, Nestmann F (2005) Simulation of flood flow in a river system using artificial neural networks. Hydrology and Earth System Sciences Discussions 9(4):313-321, DOI $10.5194 /$ hess-9-313-2005

Silva W (2002) Hoeveel (hoog)water kan ons land binnenkomen via de Rijn bij Lobith, nu en in de toekomst. Tech. rep., RIZA report 2003.015. ISBN:9036954940, Arnhem, The Netherlands

Silva W, Klijn F, Dijkman J (2001) Room for the Rhine Branches in The Netherlands. What the research has taught us. Tech. rep., WL | Delft Haydraulics report R3294, Delft, The Netherlands, URL https://repository.tudelft.nl/islandora/object/uuid: 12b2ad06-3469-49ea-a280-78e1dcc2f cb9 
Simpson TW, Peplinski J, Koch PN, Allen JK (2001) Metamodels for computer-based engineering design: Survey and recommendations. Engineering with Computers 17(2):129-150, DOI 10. 1007/PL00007198

Sleigh PA, Gaskell PH, Berzins M, Wright NG (1998) An unstructured finite-volume algorithm for predicting flow in rivers and estuaries. Computers \& Fluids 27(4):479-508, DOI 10.1016/ S0045-7930(97)0071-6

Spruyt A, Asselman N (2017) Afvoerverdeling rijntakken: Eenvoudig regelbaar of niet? Tech. rep., Deltares. Project 11200539-000, Delft, the Netherlands

Steirou E, Gerlitz L, Apel H, Sun X, Merz B (2019) Climate influences on flood probabilities across Europe. Hydrology and Earth System Sciences 23(3):1305-1322, DOI 10.5194/ hess-23-1305-2019

Stelling GS (1983) On the construction of computational methods for shallow water flow problems. PhD thesis, Technical Unversity of Delft, URL http://resolver.tudelft.nl/uuid: $\mathrm{d} 3 \mathrm{~b} 818 \mathrm{cb}-9 \mathrm{f} 91-4369-\mathrm{a} 03 \mathrm{e}-\mathrm{d} 90 \mathrm{c} 8 \mathrm{c} 175 \mathrm{a} 96$

Stendinger JR, Cohn RA (1987) Flood frequency analysis with historical and paleoflood information. Water Resources Research 22(5):785-793, DOI 10.1029/WR022i005p00785

Sukhodolov AN (2012) Structure of turbulent flow in a meander bend of a lowland river. Water Resources Research 48:1-21, DOI 10.1029/2011WR010765

Tayefi V, Lane SN, Hardy RJ, Yu D (2007) A comparison of one- and two-dimensional approaches to modelling flood inundation over complex upland floodplains. Hydrological processes 21:3190-3202, DOI 10.1002/hyp.6523

Te Linde AH (2011) Rhine at risk? Impact of climate change on low-probability floods in the Rhine basin and the effectiveness of flood management measures. PhD thesis, Vrije Universiteit Amsterdam. ISBN:9789085707424

Te Linde AH, Aerts JC, Bakker AM, Kwadijk JC (2010) Simulating low-probability peak discharges for the Rhine basin using resampled climate modeling data. Water Resources Research 46(3):1-19, DOI 10.1029/2009WR007707

Terfehr H (2008) Hochwasser in der Düffel. Reintjes Graphischer Betrieb GmbH, Kleve, Germany, URL https://www.yumpu.com/de/document/view/6099673/ hochwasser-1809-hochwasserplattform

The OpenDA Association (2016) OpenDA User Documentation. Tech. rep., URL info@openda. org

Thokala P, Martins JR (2007) Variable-complexity optimization applied to airfoil design. Engineering Optimization 39(3):271-286, DOI 10.1080/03052150601107976

Tijssen A (2009) Herberekening werklijn Rijn in het kader van WTI2011. Tech. rep., Deltares, Delft, the Netherlands, URL http://publicaties.minienm.nl/documenten/ herberekening-werklijn-rijn-in-het-kader-van-wti2011

Tol RSJ, Langen A (2000) No Title. Climatic Change 46(3):357-369, DOI 10.1023/A: 1005655412478, URL http://link. springer.com/10.1023/A: 1005655412478

Toonen WHJ (2015) Flood frequency analysis and discussion of non-stationarity of the Lower Rhine flooding regime (AD 1350-2011): Using discharge data, water level measurements, and historical records. Journal of Hydrology 528:490-502, DOI 10.1016/j.jhydrol.2015.06.014 
Toonen WHJ, Winkels TG, Cohen KM, Prins MA, Middelkoop H (2015) Lower Rhine historical flood magnitudes of the last 450 years reproduced from grain-size measurements of flood deposits using End Member Modelling. Catena 130:69-81, DOI 10.1016/j.catena.2014.12.004

Triet NVK, Dung NV, Fujii H, Kummu M, Merz B, Apel H (2017) Has dyke development in the Vietnamese Mekong Delta shifted flood hazard downstream? Hydrology and Earth System Sciences 21(8):3991-4010, DOI 10.5194/hess-21-3991-2017

Tysell L (2010) Hybrid grid generation for viscous flow computations around complex geometries. Tech. Rep. January, Royal Institute of Technology. Department of Mechanics, Stockholm, Sweden, URL http://www.diva-portal.org/smash/get/diva2:290618/fulltext01.pdf

Ulanicki B, Zehnpfund A, Martinez F (1996) Simplification of Water Distribution Network Models. In: Proceedings of the 2nd International Conference on Hydroinformatics, Rotterdam, The Netherlands, pp 493-500, DOI 10.13140/RG.2.1.4340.8404

Uusitalo L, Lehikoinen A, Helle I, Myrberg K (2015) An overview of methods to evaluate uncertainty of deterministic models in decision support. Environmental Modelling and Software 63:24-31, DOI 10.1016/j.envsoft.2014.09.017

Van Alphen J (2016) The Delta Programme and updated flood risk management policies in the Netherlands. Journal of Flood Risk Management 9(4):310-319, DOI 10.1111/jfr3.12183

Van den Boogaard H, Hegnauer M, Beersma J (2014) GRADE Uncertainty Analysis. Tech. rep., Deltares. Report 1209424-004-ZWS-0003, Delft, The Netherlands, URL https://www.knmi. $\mathrm{nl} /$ kennis-en-datacentrum/publicatie/grade-uncertainty-analys is

Van den Brink P (2002) Kartobibliografie van de Rivierkaart (1830-1961). Tech. rep., Report of the Meetkundige Dienst, Rijkswaterstaat, Delft, The Netherlands, URL http://publicaties . minienm.nl/documenten/kartobibliografie-van-de-rivierkaart-1830-1961

Van der Meer J, Ter Horst W, Van Velzen E (2008) Calculation of fragility curves for flood defence assets. In: Flood Risk Management: Research and Practice, January, pp 567-573, DOI 10.1201/9780203883020.ch65

Van der Meulen B, Deggeller TS, Bomers A, Cohen KM, Middelkoop H (2018) The historical river: morphology of the Rhine before river normalization. In: Huismans Y, Berends KD, Niesten I, Mosselman E (eds) The future river: NCR Days 2018 proceedings, Utrecht, The Netherlands, pp 44-45

Van der Most H, De Bruijn KM, Wagenaar D (2014) New Risk-Based Standards for Flood Protection in the Netherlands. In: 6th International Conference on Flood Management, pp 1-9, DOI 10.1017/CBO9781107415324.004

Van Hal L (2003) Hydraulische randvoorwaarden Rijn en Maas. Tech. rep., RIZA. Memo RYN2003-12(A), Arnhem, The Netherlands

Van Leeuwe G (2018) Approximating river bed level at river bifurcations if data is scarce. Master thesis, University of Twente, URL https://www.utwente.nl/en/et/wem/education/ msc-thes is $/ 2018 /$ leeuwevan.pdf

Verheij HJ, Van der Knaap FCM (2003) Modification breach growth model in HIS-OM. Tech. rep., Project Q3299. WL | Delft Hydraulics, Delft, The Netherlands

Verwey A, Kernkamp HWJ, Stelling GS, Tse ML, Leung WC (2011) Potential and application of hydrodynamic modelling on unstructured grids. In: Proceedings of the Sixth International Conference on Asian and Pacific Coasts (APAC), Hong Kong, China 
Volp ND, van Prooijen BC, Pietrzak JD, Stelling GS (2016) A subgrid based approach for morphodynamic modelling. Advances in Water Resources 93:105-117, DOI 10.1016/j.advwatres. 2015.07.013, URL http://dx.doi.org/10.1016/j.advwatres .2015.07.013

Vorogushyn S, Merz B (2013) Flood trends along the Rhine: The role of river training. Hydrology and Earth System Sciences 17(10):3871-3884, DOI 10.5194/hess-17-3871-2013

Vorogushyn S, Merz B, Lindenschmidt KE, Apel H (2010) A new methodology for flood hazard assessment considering dike breaches. Water Resources Research 46(8):1-17, DOI 10.1029/ 2009WR008475

Vorogushyn S, Apel H, Merz B (2011) The impact of the uncertainty of dike breach development time on flood hazard. Physics and Chemistry of the Earth $36: 319-323$, DOI 10.1016/j.pce. 2011.01.005, URL http://dx.doi.org/10.1016/j.pce.2011.01.005

van Vuren S, Levelt O, Pol J, van der Meij R, de Grave P, Nugroho D, ter Horst W, Koopmans R, van der Scheer P, Asselman N, de Kruif A (2017) Beleidsstudie Kostenreductie Dijkversterking door Rivierverruiming. Toepassing methodiek op Rijntakken. Tech. rep., Consortium Deltares, HKV lijn in Water, Arcadis, Royal HaskoningDHV, Rijkswaterstaat

Wang QJ (1990) Unbiased estimation of probability weighted moments and partial probability weighted moments from systematic and historical flood information and their application to estimating the GEV distribution. Journal of Hydrology 120:115-124, DOI $10.1016 / 0022-1694(90) 90145-\mathrm{N}$

Warmink JJ (2014) Dune dynamics and roughness under gradually varying flood waves, comparing flume and field observations. Advances in Geosciences 39:115-121, DOI 10.5194/ adgeo-39-115-2014

Warmink JJ, Straatsma MW, Huthoff F, Booij MJ, Hulscher SJMH (2013) Uncertainty of design water levels due to combined bed form and vegetation roughness in the Dutch River Waal. Journal of Flood Risk Management 6(4):302-318, DOI 10.1111/jfr3.12014

Warmink JJ, Brugnach M, Vinke-de Kruijf J, Schielen RMJ, Augustijn DCM (2017) Coping with Uncertainty in River Management: Challenges and Ways Forward. Water Resources Management 31(14):4587-4600, DOI 10.1007/s11269-017-1767-6

Wasimi SA, Kitanidis PK (1983) Real-time forecasting and daily operation of a multireservoir system during floods by linear quadratic Gaussian control. Water Resources Research 19(6):1511-1522, DOI 10.1029/WR019i006p01511

Wierda M, Zweerus L (1994) Omzetting rivierkaarten 1830-1860 naar GIS. Tech. rep., RIZA working document 94.105X, the Netherlands, URL http://publicaties.minienm.nl/documenten/ omzetting-rivierkaarten-1830-1860-naar-gis

de Wit M, Buiteveld H, van Deursen WPA, Keller F, Bessembinder (2008) Klimaatverandering en de afvoer van Rijn en Maas. Memo WRR/2007-006. Stromingen 14(1):13-24

Wolfe BB, Hall RI, Last WM, Edwards TWD, English MC, Karst-Riddoch TL, Paterson A, Palmini R (2006) Reconstruction of multi-century flood histories from oxbow lake sediments, Peace-Athabasca Delta, Canada. Hydrological Processes 20:4131-4153, DOI 10.1002/hyp.6423

Xiang C, Ding SQ, Lee TH (2005) Geometrical interpretation and architecture selection of MLP. IEEE Transactions on Neural Networks 16(1):84-96, DOI 10.1109/TNN.2004.836197

Ye J, McCorquondal JA (1997) Depth-Averaged Hydrodynamic Model in Curvilinear Collocated Grid. Journal of Hydraulic Engineering 123(5):380-388, DOI 10.1061/(ASCE) 0733-9429(1997)123:5(380) 
Yu PS, Chen ST, Chang IF (2006) Support vector regression for real-time flood stage forecasting. Journal of Hydrology 328(3-4):704-716, DOI 10.1016/j.jhydrol.2006.01.021

Zhan W, Yang SY, Liu XL, Li JW, Choi MS (2010) Reconstruction of flood events over the last 150 years in the lower reaches of the Changjiang River. Chinese Science Bulletin 55(21):22682274, DOI 10.1007/s11434-010-3263-8

Zhou Y, Ma Z, Wang L (2002) Chaotic dynamics of the flood series in the Huaihe River Basin for the last 500 years. Journal of Hydraulic Engineering 258:100-110, DOI 10.1016/ S0022-1694(01)00561-3 


\section{List of publications}

\section{Peer-reviewed journal papers}

Bomers, A., Aguilar-Lopez, J.P., Warmink, J.J., Hulscher, S.J.M.H. (2018). Modelling effects of an asphalt road at a dike crest on dike cover erosion onset during wave overtopping. Natural hazards, 93(1), 1-30. DOI:10.1007/s11069-018-3287-y

Aguilar-Lopez, J.P., Warmink, J.J., Bomers, A., Schielen, R.M.J., Hulscher, S.J.M.H. (2018). Failure of grass covered flood defences with roads on top due to wave overtopping: A probabilistic assessment method. Journal of Marine Science and Engineering, 6(3), 74. DOI:10.3390/ jmse6030074

Bomers, A., Schielen, R.M.J., Hulscher, S.J.M.H. (2019). The influence of grid shape and grid size on hydraulic river modelling performance. Environmental Fluid Mechanics, 19(5), 1273-1294. DOI:10.1007/s10652-019-09670-4

Bomers, A., Schielen, R.M.J., Hulscher, S.J.M.H. (2019). Application of a lower-fidelity surrogate hydraulic model for historic flood reconstruction. Environmental Modelling and Software, 117, 223-236. DOI:10.1016/j.envsoft.2019.03.019

Bomers, A., Schielen, R.M.J., Hulscher, S.J.M.H. (2019). Consequences of dike breaches and dike overflow in a bifurcating river system. Natural Hazards, 97(1), 309-334. DOI:10.1007/s11069019-03643-y

Bomers, A., Schielen, R.M.J., Hulscher, S.J.M.H. (2019). Decreasing uncertainty in flood frequency analyses by including historic flood events in an efficient bootstrap approach. Natural Hazards and Earth System Sciences, 19, 1895-1908. DOI:10.5194/nhess-19-1895-2019.

Bomers, A., Van der Meulen, B., Schielen, R.M.J., Hulscher, S.J.M.H. (2019). Historic flood reconstruction with the use of an Artificial Neural Network. Water Resources Research. DOI:10.1029/2019 WR025656 


\section{Conference papers and abstracts}

Schielen, R.M.J., Bomers, A., Kroekenstoel, D. (2014). Unraveling the contributions of wind, sea level and discharge to design water levels in the Dutch delta. Proc. $7^{\text {th }}$ River Flow Congress, Lausanne, Switzerland, pp. 1729-1736.

Cohen, K.M., Schielen, R., van der Meulen, B., Bomers, A., Hulscher, S.J.M.H., Middelkoop, H. (2016). Floods of the Past, Design of Tomorrow - Project Introduction. In: Fontana, A., Rossata, S. (Eds.), Abstract Volume Ex-Aqua 2016 Palaeohydrological Extreme Events: Evidence and Archives. Università degli Studi di Padova, Padova, Italy.

Bomers, A., Aguilar-Lopez, J.P., Warmink, J.J., Hulscher, S.J.M.H. (2016). Erosion development during wave overtopping of an asphalt road covered dike. In M. Lang, F. Klijn \& P. Samuels (Eds.), FLOODrisk 2016: $3^{\text {rd }}$ European Conference on Flood Risk Management 17-21 October 2016, Lyon, France (pp. 1-8; Vol. 7), E3S Web of Conferences. DOI:10.1051/e3sconf/20160703003

Bomers, A., Schielen, R.M.J., Hulscher, S.J.M.H. (2017). Modelling historic floods to validate present and future design discharges: the 1926 case. 68-69. Abstract from NCR Days 2017, Wageningen, The Netherlands.

Bomers, A., Schielen, R.M.J., Hulscher, S.J.M.H. (2017). Benchmark study of numerical model grids to study historic floods of the river Rhine. 1-3. Abstract from $4^{\text {th }}$ International Symposium on Shallow Flows, ISSF 2017, Eindhoven, The Netherlands.

Warmink, J.J., van Bergeijk, V.M., Chen, W., Aguilar-Lopez, J.P., Bomers, A., Hulscher, S.J.M.H. (2018). Modelling wave overtopping for flood defense reliability. $3^{\text {rd }}$ international Conference on Protection against Overtopping, 6-8 June 2018, UK.

Bomers, A., Schielen, R.M.J., Hulscher, S.J.M.H. (2018). Flood patterns in the Old IJssel Valley. 126-127. Abstract from NCR Days 2018, Delft, The Netherlands.

van der Meulen, B., Deggeller, T.S., Bomers, A., Cohen, K.M., Middelkoop, H. (2018). The historical river: morphology of the Rhine before river normalization. 44-45. Abstract from NCR Days 2018, Delft, The Netherlands.

Bomers, A., Hulscher, S.J.M.H., Lammersen, R., Schielen, R.M.J. (2018). The effect of dike breaches on downstream discharge partitioning near a river bifurcation. In A. Armanini, E. Nucci (Eds.), New Challenges in Hydraulic Research and Engineering: Proceedings of the $5^{\text {th }}$ IAHR Europe Congress. 805-806, Trento, Italy. DOI: 10.3850/978-981-11-2731-1_070-cd

Bomers, A., Schielen, R.M.J., Hulscher, S.J.M.H. (2019). The effect of dike breaches on downstream discharge partitioning. 28-28. Abstract from NCR Days 2019: Land of Rivers, Utrecht, The Netherlands.

Bomers, A., Schielen, R.M.J., Hulscher, S.J.M.H. (2019). The severe 1374 Rhine river flood event in present times. Water - connecting the World: Proceedings of the $38^{\text {th }}$ IAHR World Congress, Panama City, Panama. DOI: 10.3850/38WC092019-0501 


\section{Other contributions}

Bomers, A., Aguilar-Lopez, J.P., Warmink, J.J., Hulscher, S.J.M.H. (2017). Invloed van een weg op dijkerosie tijdens golfoverslag. H2O-Online.

Bomers, A. (2016). Historische overstromingen - ontwerp voor de toekomst. ConcepTueel 25(2), 1-4

Bomers, A., Schielen, R.M.J., Hulscher, S.J.M.H. (2019). Decreasing uncertainty in flood frequency analyses by including historic flood events in an efficient bootstrap approach. Natural Hazards and Earth System Sciences Discussion. DOI: 10.5194/nhess-2019-83

Bomers, A., Schielen, R.M.J., Hulscher, S.J.M.H. (2019). The effect of dike breaches on overland flow patterns. Burgers Symposium 2019, Lunteren, The Netherlands

Bomers, A., Schielen, R.M.J., Hulscher, S.J.M.H. (2019). Verkleinen van de onzekerheid in huidig waterbeleid met historische overstromingen. $\mathrm{H} 2 \mathrm{O}-$ online

Bomers, A., Van der Meulen, B. (2019). Reconstructed data on the 1809 historic flood event of the Rhine river. 4TU. Centre for Research Data, DOI: 10.4121/uuid:2068ddc3-1726-4d9d-bbe7$37477767 \mathrm{~b} 220$ 


\section{About the author}

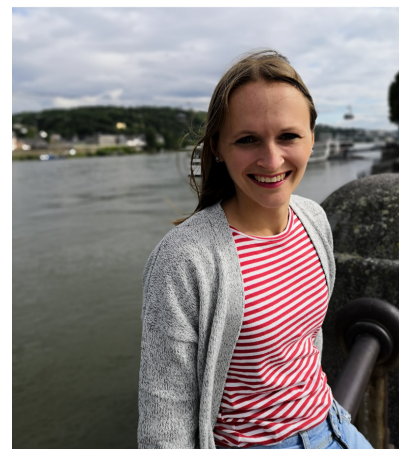

Anouk Bomers was born on the $21^{\text {st }}$ of January in 1992. Born and raised in Enschede, the Netherlands, she attended secondary school in 2004. Six years later she started her BSc Civil Engineering at the University of Twente. With great pleasure, she fulfilled a minor in Physical Geography at the Lund University in Sweden. Anouk successfully completed her Bachelor degree in 2013 and started a MSc Civil Engineering and Management with the main focus on the waterrelated courses. During her graduation thesis, Anouk developed a CFD model that predicts the impact of a road section located on a dike crest on erosion development of the dike during wave overtopping conditions. This thesis was awarded with the 'Waternetwerk Scriptieprijs: Best Msc. Graduation thesis with a water related topic'. Anouk received her MSc degree in June 2015. After travelling through Asia for three months, Anouk started a PhD and became part of the Water Engineering and Management group in November of 2015. In this period, she has supervised BSc and MSc graduation projects and supervised tutorials at MSc level.

During her PhD, Anouk focused on the development of efficient hydraulic modelling approaches in order to reconstruct historic flood events. She presented her research at international conferences in Delft, Trento, Eindhoven and Panama City. Furthermore, she presented her work at the Institute of Hydraulic Engineering and Water Resources Management (Vienna University of Technology), at the GFZ German Research Centre for Geosciences in Potsdam, and at the School of Geographical Sciences (University of Bristol).

Anouk is grateful to be continuing her research in the role of Assistant Professor in Numerical methods and Numerical models for river hydraulics at the University of Twente. 